\title{
Auftreten und Schadwirkung von Rhizoctonia im deutschen Winterweizenanbau
}

\author{
Dissertation \\ zur Erlangung des Doktorgrades \\ der Fakultät für Agrarwissenschaften \\ der Georg-August-Universität Göttingen \\ vorgelegt von \\ Ines Döring geb. Eikenberg \\ geboren am 11.08.1984 in Holzminden
}

Göttingen, .....02-2021.............(Monat, Jahr) 
1. Referent:

2. Korreferent:

Tag der mündlichen Prüfung:
Prof. Dr. Andreas von Tiedemann

Prof. Dr. Mark Varrelmann

12.04.2021 
Für meinen Vater 
Inhalt

Inhaltsverzeichnis

Abkürzungsverzeichnis VII

1 Einleitung 9

1.1 Die Ertragsentwicklung in Winterweizen (Triticum aestivum L.) 9

1.2 Die Bedeutung von Rhizoctonia in Weizen 9

1.2.1 Die Einordnung von Rhizoctonia als Schaderreger 9

1.2.2 Die wirtschaftliche Relevanz von Rhizoctonia 10

1.3 Taxonomie von Rhizoctonia 11

1.4 Rhizoctonia-Befall in Weizen: Entwicklung, Infektion und Symptomatik12

1.5 Bekämpfung von Rhizoctonia in Weizen 14

1.6 Zielsetzung der Arbeit $\quad 16$

2 Material und Methoden 17

2.1 Chemikalien 17

2.2 Pilzisolate 17

2.3 Saatgut 19

2.4 Feldversuchsflächen 19

2.4.1 Feldversuch 19

2.4.2 Göttinger Bodenerwärmungsanlage 19

2.4.3 Versuchsflächen für Rhizoctonia-Monitoring 20

2.5 Softwareprogramme 20

2.6 Herstellung von Nährmedien, Puffer und Agarosetrenngelen 21

2.7 Vermehrung und Lagerung von Pilzmyzel 22

$\begin{array}{ll}2.7 .1 \text { Pilzkultivierung } & 22\end{array}$

2.7.2 Pilzkonservierung 23

2.7.3 Myzelanzucht in Flüssigmedium 23

2.7.4 Inokulumproduktion $\quad 24$

2.8 Anzucht von Versuchspflanzen und Probenaufbereitung 24

2.8.1 Herstellung sterilisierter vorgekeimter Weizensaat im Labor 24

2.8.2 Probenahme und -aufbereitung von Weizenpflanzen aus dem Freiland (Feldversuche) 25

2.8.3 Probenaufbereitung für das Monitoring 25

2.9 Rhizoctonia-Bonitur $\quad 25$

2.10 Untersuchungen unter sterilen Kulturbedingungen (in vitro) 27

2.10.1 Nachweis sezernierter Säure durch Einsatz von Bromphenolblau 27

2.10.2 Ermittlung des Temperaturoptimums 27

2.10.3 Pathogenitätstest an Weizenkeimlingen (Agarplattentest) 28

2.10.4 Infektionsassay zur Untersuchung befallener Weizenwurzeln $\quad 29$

2.11 Herstellung von mikroskopischen Präparaten 30 
2.11.1 Herstellung Agarose-beschichteter Objektträger 30

2.11.2 Mikroskopische Präparate von Rhizoctonia spp. 31

2.11.3 Mikroskopische Präparate von infizierten Weizenwurzeln 31

2.12 Erregerisolierung aus getrockneten Weizenhalmen mit Läsionen:

Monitoring und Feldversuche 32

2.13 Erregernachweis auf PDA 33

2.14 Erregernachweis durch PCR 33

2.14.1 DNA Extraktion aus Pilzmyzel 33

2.14.2 Flachbettgelelektrophorese 35

2.14.3 PCR-Größenstandards $\quad 35$

2.14.4 Prüfung der DNA auf Qualität, Quantität und Funktionalität 36

2.15 Anlage und Auswertung der Feldversuche 40

2.15.1 Künstliche Rhizoctonia-Inokulation im Feld 40

2.15.2 Feldversuch mit künstlicher Rhizoctonia-Inokulation in der Göttinger Bodenerwärmungsanlage (Kleinparzellen) 41

2.15.3 Erfassung und Aufbereitung meteorologischer Daten 43

2.15.4 Erfassung von Bestandes- und Ertragsparametern 43

2.15.5 Ermittlung der Befallshäufigkeit mit Rhizcotonia 45

2.16 Statistische Auswertung $\quad 45$

3 Ergebnisse $\quad 47$

3.1 Monitoring des Vorkommens von Rhizoctonia in Deutschland $\quad 47$

3.1.1 Isolatgewinnung 51

3.1.2 Bestimmung der Anastomosegruppe $\quad 51$

3.2 Differenzierung von Rhizoctonia spp. in vitro 51

3.2.1 Erregernachweis 51

3.2.2 Morphologie $\quad 55$

3.2.3 Säurebildung $\quad 57$

3.2.4 Temperaturansprüche $\quad 59$

3.2.5 Pathogenität an Weizenkeimlingen 66

3.3 Feldversuch 69

3.3.1 Meteorologische Daten $\quad 69$

3.3.2 Erregernachweis und Befallsverlauf $\quad 70$

$\begin{array}{ll}\text { 3.3.3 Bestandesparameter } & 77\end{array}$

3.3.4 Ertragsparameter $\quad 82$

3.4 Versuch in der Göttinger Bodenerwärmungsanlage 86

3.4.1 Meteorologische Daten 86

3.4.2 Befallsverlauf und Erregernachweis $\quad 87$

$\begin{array}{ll}\text { 3.4.3 Bestandesparameter } & 91\end{array}$

$\begin{array}{ll}\text { 3.4.4 Ertragswirkungen } & 94\end{array}$ 
4 Diskussion

4.1 Monitoring 94

4.2 Differenzierung von Rhizoctonia spp. in vitro 95

4.2.1 Erregernachweis $\quad 95$

4.2.2 Morphologie 96

$\begin{array}{ll}4.2 .3 \text { Säurebildung } & 97\end{array}$

4.2.4 Temperaturansprüche $\quad 98$

4.2.5 Pathogenität und Infektionsprozess an Weizenkeimlingen 100

$\begin{array}{ll}4.3 \text { Feldversuch } & 101\end{array}$

4.4 Versuch in der Bodenerwärmungsanlage 104

5 Zusammenfassung 107

6 Summary 109

Literaturverzeichnis $\quad 111$

$\begin{array}{ll}\text { Anhang } & 117\end{array}$

Danksagung $\quad 119$

Eidesstattliche Erklärung $\quad 120$ 


\section{Abkürzungsverzeichnis}
A Abb.
Abbildung
Abk.
Abkürzung
Abschn. Abschnitt
AG Anastomosegruppe
at
atmosphärischer Druck
B $\quad$ BCH
Bsp.
Entwicklungsstadium der Pflanze
bspw.
Beispiel
bp
beispielsweise
BW
Basenpaare
C ca.
Baden-Württemberg

ca. circa
$\mathrm{cm}$
Zentimeter
CTAB Cetyltrimethylammoniumbromid
D D
Deutschland
DNA Desoxyribonukleinsäure
dpi
$\mathrm{dt}$
Tage nach Infektion
Dt.
Dezitonne
Daten
DS
E E
Befallsstärke
EDTA
Spanien
Erw.
Ethylendiamintetraessigsäure
erw.
Erwärmung
et al.
erwärmt
$\mathrm{EtOH}$
lateinisch „und weitere“
F $\quad F$
Ethanol
G $\quad g$
Frankreich
Gramm
GB Großbritannien
gDNA Gesamt-DNA
GLM
Verteilungsanpassung
GÖ
H ha
Göttingen
HG
Hektar
I IC
in vitro
"homogenous group"
"infection cushions“ (Infektionskissen, -einheiten)
IPP
lateinisch „im Glas“"
Institut für Allgemeine Pflanzenpathologie und Pflanzenschutz, GAU Göttingen, Deutschland
ITS
J JB
K k. A.
„internal transcribed spacer", Sequenzabschnitt im Pilzgenom Josef Breun (Saatgutzüchter)
keine Angabe
k. Dt. keine Daten
L L Liter
M m Meter
$\mathrm{m}^{2} \quad$ Quadratmeter
max. maximal
$\mathrm{mm} \quad$ Millimeter
$\min \quad$ Minute
$\mathrm{ml} \quad$ Milliliter
MV Mecklenburg-Vorpommern
MW Mittelwert
N $\quad \mathrm{n}$
Anzahl der Wiederholungen
$\mathrm{N} \quad$ Anzahl der Bonitierten 


\begin{tabular}{|c|c|c|}
\hline & nachf. & nachfolgend \\
\hline & $\mathrm{NaOCl}$ & Natriumhypochlorid \\
\hline & neg. & negativ \\
\hline & $\mathrm{ng}$ & Nanogramm \\
\hline & $\mathrm{NI}$ & Niedersachsen \\
\hline & Nr. & Nummer \\
\hline 0 & od. & oder \\
\hline $\mathbf{P}$ & PCR & Polymerasekettenreaktion \\
\hline & PDA & Potato Dextrose Agar \\
\hline & PDAS & PDA mit Streptomycin \\
\hline & PDB & Kartoffelextrakt Glucose Boullion \\
\hline & $\mathrm{PL}$ & Polen \\
\hline & pos. & positiv \\
\hline $\mathbf{Q}$ & -- & \\
\hline $\mathbf{R}$ & R. & Rhizoctonia \\
\hline & RC, R. C. & R. cerealis \\
\hline & $\mathrm{RHI}$ & Rhizoctonia \\
\hline & RS, R. s. & R. solani \\
\hline $\mathbf{S}$ & s. & siehe \\
\hline & SD & Standardabweichung \\
\hline & $\mathrm{SH}$ & Schleswig-Holstein \\
\hline & SN & Sachsen \\
\hline & s. o. & siehe oben \\
\hline & Sp. & Spalte \\
\hline & sp. & species \\
\hline & spez. & spezifisch \\
\hline & spp. & sub-species \\
\hline & ST & Sachsen-Anhalt \\
\hline & SÜ & Sequenzübereinstimmung \\
\hline $\mathbf{T}$ & $\mathrm{T}$ & Temperatur \\
\hline & Tab. & Tabelle \\
\hline & TAE & Tris-EDTA (für Gelelektrophoresen) \\
\hline & TE & Tris-EDTA-Pufferlösung \\
\hline & Temp. & Temperatur \\
\hline & $\mathrm{TH}$ & Thüringen \\
\hline & $\mathrm{TI}$ & Testerisolat \\
\hline & TKM & Tausendkornmasse \\
\hline $\mathbf{U}$ & $U$ & Unit \\
\hline & u. & und \\
\hline & u. a. & unter anderem \\
\hline & $\begin{array}{l}\text { usw. } \\
\text { UV-Licht }\end{array}$ & $\begin{array}{l}\text { und so weiter } \\
\text { ultraviolettes Licht }\end{array}$ \\
\hline $\mathbf{v}$ & Var. & Variante \\
\hline $\mathbf{W}$ & WA & Wasseragar \\
\hline $\mathbf{X}, \mathbf{Y}$ & -- & \\
\hline $\mathbf{Z}$ & z.B. & zum Beispiel \\
\hline
\end{tabular}

\section{Sonstiges}

$\begin{array}{ll}\Delta & \text { Delta für Differenz } \\ \mu & \text { micro } \\ { }^{\circ} \mathrm{C} & \text { Temperaturangabe in Grad Celsius } \\ \infty & \text { unendlich } \\ <;> & \text { kleiner als; größer als }\end{array}$


Einleitung

\section{Einleitung}

\subsection{Die Ertragsentwicklung in Winterweizen (Triticum aestivum L.)}

Die Kalorienzufuhr in der menschlichen Ernährung wird zu über $50 \%$ aus Getreide gedeckt (FAO, 2013). Dabei ist Weizen nach Mais die wichtigste Getreideart (Matusinsky et al., 2008). Im Jahr 2019 wurden weltweit etwa 761,5 Millionen Tonnen Weizen produziert (FAO, 2020). Daher ist die Sicherung der Weizenproduktion von großer Bedeutung. In Europa kann eine Verringerung des jährlichen Ertragszuwachses im Winterweizen beobachtet werden (Brisson et al., 2010). So konnte bspw. in Dänemark bis in die 1990er Jahre noch eine Ertragssteigerung von $0,8 \mathrm{dt} / \mathrm{ha} / \mathrm{a}$ festgestellt werden, welche sich etwa seit Mitte der 1990er gegen $0 \mathrm{dt} / \mathrm{ha} / \mathrm{a}$ entwickelt hat (Petersen et al., 2010). In Deutschland wird der jährliche Ertragszuwachs der 1960er und 1970er Jahre mit 0,9 dt/ha und bis Mitte der 1980er Jahre mit 1,7 dt/ha angegeben, jedoch ist dieser seit etwa 1985 rückläufig (Ahlemeyer und Friedt, 2010). Diese Plateauphase kann auch in Ländern wie dem Vereinigten Königreich (Knight et al., 2012) und Frankreich (Brison et al., 2010) beobachtet werden.

\subsection{Die Bedeutung von Rhizoctonia in Weizen}

\subsubsection{Die Einordnung von Rhizoctonia als Schaderreger}

Da die Anfälligkeit von Weizen gegenüber Blattkrankheiten wie Mehltau, Braunrost und Septoria abnimmt, können diese Erreger nicht ursächlich für den rückläufigen Ertragszuwachs sein (Ahlemeyer und Friedt, 2010). Möglicherweise sind bodenbürtige Schaderreger wie bspw. Rhizoctonia, der Erreger des Scharfen Augenflecks in Weizen, ausschlaggebend für derartige Ertragsabschwächungen im Winterweizen. In Deutschland hat sich die Gesamtanbaufläche für Winterweizen seit Beginn der 1960er Jahre mit 1,8 Millionen ha in etwa verdoppelt auf 3 Millionen ha (Statistisches Bundesamt Deutschland, 2017). Dabei wird im Anbau die Kulturart Winterweizen den weniger anspruchsvollen Kulturen wie Wintergerste oder Roggen vorgezogen und infolge auch auf weniger geeigneten Flächen angebaut (Ahlemeyer und Friedt, 2010). Ein leichter Boden mit Sandanteil erleichtert es dem bodenbürtigen Erreger (Gill et al., 2000; Bockus et al., 2010), 
Einleitung

ein vitales Inokulum im Boden aufzubauen (Lemańczyk, 2012). Förderlich ist zudem eine frühe Aussaat im Herbst in Kombination mit trockenen warmen Wetterbedingungen (Lemańczyk, 2012). Der Erreger ist zudem unempfindlich gegenüber einem Fruchtwechsel (Lemańczyk, 2012), da er auch ohne Wirtspflanze lange Zeit im Boden auf Ernterückständen (Goll et al., 2013) oder als Sklerotium (Sneh et al., 1991) überdauern kann. Das Vorhandensein von Rhizoctonia in ackerbaulich genutzten Böden europäischer Weizenanbaugebiete ist nachgewiesen (Goll et al., 2013). So ist die generell zunehmende Bedeutung und weltweite Verbreitung des Schaderregers bereits zuvor beschrieben worden (Hamada et al., 2011a). In Deutschland wird der Erreger des Scharfen Augenflecks jedoch als wenig relevant wahrgenommen, obgleich bspw. im Nachbarland Polen jüngst eine Zunahme des Erregers im Winterweizen beobachtet wurde (Kurowski u. Adamiak, 2007; Lemańczyk, 2010a, 2010b). Den Schaderreger nicht zu kennen, erschwert jedoch im Bedarfsfall dessen effektive Kontrolle (Duveiller et al., 2007).

\subsubsection{Die wirtschaftliche Relevanz von Rhizoctonia}

Als bodenbürtiger Schaderreger verursachen Vertreter der Gattung Rhizoctonia in einer Vielzahl von Kulturarten Wurzel- und Auflaufschäden (Hamada et al., 2011a). Als Erreger der Wurzelfäule im Getreide wurde Rhizoctonia solani AG 8 in Nordamerika erstmals 1984 beschrieben (Weller et al., 1986). In Australien ist der Erreger schon seit den 1930er Jahren bekannt (Samuel u. Garrett, 1932). Die jährlich auftretenden Verluste durch den Befall werden für den südlichen Teil Australiens auf 59 Millionen Dollar geschätzt (Murray u. Brennan, 2009). Auch auf anderen Kontinenten ist der Erreger u. a. im Weizen bekannt. Berechnungen zufolge hat Rhizoctonia in China ab 2005 innerhalb von drei Jahren einen Gesamtschaden von 15 Millionen U.S. Dollar verursacht (Chen et al., 2008). In Europa ist der durch Rhizoctonia bedingte Ertragsausfall im Weizen noch gering (Bateman et al., 2000). Ertragsverluste durch Rhizoctonia cerealis werden als stark abhängig von den lokalen Gegebenheiten beschrieben (Goll et al., 2013) und sind gering bei Befallsstärken von unter 10\% (Cromey et al., 2002). Kommt es jedoch zu hohen Befallsstärken, konnten in England bereits Ertragsverluste von 26\% ermittelt werden (Cromey et al., 2002; Clarkson u. Cook, 1983). 
Einleitung

\subsection{Taxonomie von Rhizoctonia}

Der Genus Rhizoctonia gehört zur Klasse der Basidiomyceten. Rhizoctonia beschreibt einen heterogenen Spezieskomplex bestehend aus filamentösen Pilzen, die keine asexuellen Sporen bilden und Wurzel-assoziiert als bodenbürtige Pflanzenpathogene oder saphrophytisch im Boden auf Pflanzenresten vorkommen (García et al, 2006). Ihre weltweite Verbreitung in ackerbaulich sowie auch in forstwirtschaftlich genutzten Böden ist bekannt (García et al., 2006; Hamada, 2011a) und weist sie als ökonomisch relevante Schaderreger an Pflanzen aus (García et al., 2006).

Das Genuskonzept Rhizoctonia wurde erstmals im Jahr 1815 von De Candolle etabliert und nachfolgend wiederholt überarbeitet z.B. von Parmeter und Whitney im Jahr 1970 oder von Moore im Jahr 1987, sodass unterschiedliche Konzepte nebeneinander existieren. Einzelne Isolate der Gattung, die u.a. auf Grundlage ihrer DNA-Sequenz und Hyphenanastomosetests von anderen Isolaten unterschieden werden können, teilt man traditionell in Anastomosegruppen/ AG ein (Anderson, 1982; Sneh et al., 1991; Carling, 1996). Derzeit sind diese für Rhizoctonia solani von AG 1 bis $A G 14$ beschrieben. $R$. solani ist die am intensivsten untersuchte Spezies in der Gattung und zeichnet sich durch sein weltweites Vorkommen in den Böden und ein hohes Schaderregerpotenzial an einem breiten Pflanzenspektrum wie bspw. AG 3-PT an Kartoffeln, AG 2-2IIIB an Zuckerrübe, AG 1-IB an Salat, AG 12 an Orchideen, AG 13 an Baumwolle oder AG 8, AG 4, und AG 11 an Getreide aus (Carling et al., 1999; Carling et al., 2002; García et al., 2006; Lemańczyk, 2012) und AG 5 an Weizen in Großbritannien (Woodhall et al., 2012). Das Anamorph R. solani besteht aus mehrzellkernigen Hyphen und lässt sich daher taxonomisch zu zweizellkernigen Formen aus dem Genus Ceratobasidium, die binuklearen Rhizoctonia-Arten abgrenzen. Diese sind ebenfalls in Anastomosegruppen eingeteilt und werden als AG A bis AG $U$ beschrieben. Im Vergleich zu R. solani Arten enthält Ceratobasidium nur wenige AG, die als pflanzenpathogen beschriebenen werden (García et al., 2006). Weniger bekannt sind bspw. AGT und AGU, welche Schäden an Wurzeln von Zierpflanzen verursachen (Hyakumachi et al., 2005). Einen hohen Bekanntheitsgrad genießt Rhizoctonia cerealis AG D aufgrund der beschriebenen Schadwirkung im Weizen (Furgal-Wegrzycka et al., 1997; Hamada et al., 2011a). 
Tabelle 1: Taxonomie von Rhizoctonia mit Angabe der Anastomosegruppe (Abk. AG), der Wirtspflanze, Anzahl der Zellkerne der anamorphen Form sowie der wissenschaftlichen Bezeichnung des Ana- und Teleomorphs (aus García et al., 2006; Woodhall et al., 2012).

\begin{tabular}{|c|c|c|c|c|}
\hline \multirow[t]{2}{*}{ AG } & \multirow{2}{*}{$\begin{array}{l}\text { Wirts- } \\
\text { pflanze }\end{array}$} & \multirow{2}{*}{$\begin{array}{l}\text { Anzahl Zellkerne } \\
\text { des Anamorph }\end{array}$} & \multicolumn{2}{|c|}{ Gattungs- und Artname } \\
\hline & & & Anamorph & Teleomorph \\
\hline AG D & Getreide & binuklear & $\begin{array}{l}\text { Rhizoctonia } \\
\text { cerealis }\end{array}$ & $\begin{array}{l}\text { Ceratobasidium } \\
\text { cereale }\end{array}$ \\
\hline AG 1-IB & Salat & \multirow{6}{*}{ multinuklear } & \multirow{6}{*}{ R. solani } & $\begin{array}{l}\text { Thanathephorus } \\
\text { cucumeris, } \\
\text { T. microsclerotium }\end{array}$ \\
\hline AG 3-PT & Kartoffel & & & Thanathephorus? \\
\hline AG 4 & \multirow{4}{*}{$\begin{array}{l}\text { Getreide } \\
\text { bzW. } \\
\text { AG 5: } \\
\text { Weizen }\end{array}$} & & & $\begin{array}{l}\text { T. cucumeris } \\
\text { (= Pellicularia } \\
\text { praticola) } \\
\text { T. praticola? }\end{array}$ \\
\hline AG 8 & & & & T. cucumeris \\
\hline AG 5 & & & & \\
\hline AG 11 & & & & \\
\hline
\end{tabular}

\subsection{Rhizoctonia-Befall in Weizen: Entwicklung, Infektion und Symptomatik}

Rhizoctonia bildet keine asexuellen Sporen und ist ein bodenbürtiger Schaderreger. Im Zusammenhang mit Rhizoctonia wird häufig ein nesterweises Auftreten im Bestand beschrieben (Anees et al., 2010). Der Pilz überdauert saprophytisch als Dauermyzel auf Pflanzenresten oder als Sklerotium im Boden (Lemańczyk, 2010a). Bei guten Bedingungen oder bei Vorhandensein einer geeigneten Wirtspflanze keimt das Sklerotium aus und infiziert die Wurzeln oder den Halm (Nyvall, 1989). Dabei erreicht das Myzel zunächst die Wurzeloberfläche und besiedelt diese großflächig. Nach einiger Zeit bilden sich T-förmige Hyphen aus und schließlich Infektionskissen. Beim Infektionskissen handelt es sich um eine komplexe Struktur bestehend aus kuppelförmigen Zellen, die eine gute Anhaftung an das Pflanzengewebe ermöglichen sollen. Durch die Ausbildung eines Infektionskeils kann der Pilz durch Aufbau eines mechanischen Drucks die Zellwand durchdringen (Keijer in Sneh et al., 1996). Im Zusammenhang mit Rhizoctonia in Weizen existieren zwei Symptombeschreibungen, die auf unterschiedliche Gattungsvertreter zurückgehen. So existiert zum einen das sogenannte bare patch Symptom, was im Zusammenhang mit $R$. solani AG 8 beschrieben wird (Gupta et al., 2010; Paulitz et al., 2003). Die auf AG 8 zurückzuführenden 


\section{Einleitung}

bare patches sind klar abgegrenzte Bereiche im Bestand mit stark verringertem Pflanzenwachstum, deren genaue Entstehung noch ungeklärt ist, da inner- und außerhalb gleichsam befallene Wurzeln gefunden werden (Rovira, 1986). Die Form des bare patch variiert, jedoch ist meist ein Verlauf in Drillrichtung zu beobachten, was auf eine Verschleppung des Erregers durch die Bodenbearbeitung hindeutet (McNish u. Neate, 1996).

Des Weiteren wird im Zusammenhang mit Rhizoctonia in Weizen der Scharfe Augenfleck am Weizenhalm beschrieben, der dem Erreger $R$. cerealis AG D zugeschrieben wird (Cromey et al., 2002; Hamada et al., 2011a). Dabei handelt es sich um eine ovale Läsion am unteren Halm, begrenzt von einem scharfen braunen Rand und einem hellen cremefarbenen Inneren (Abb. 1).
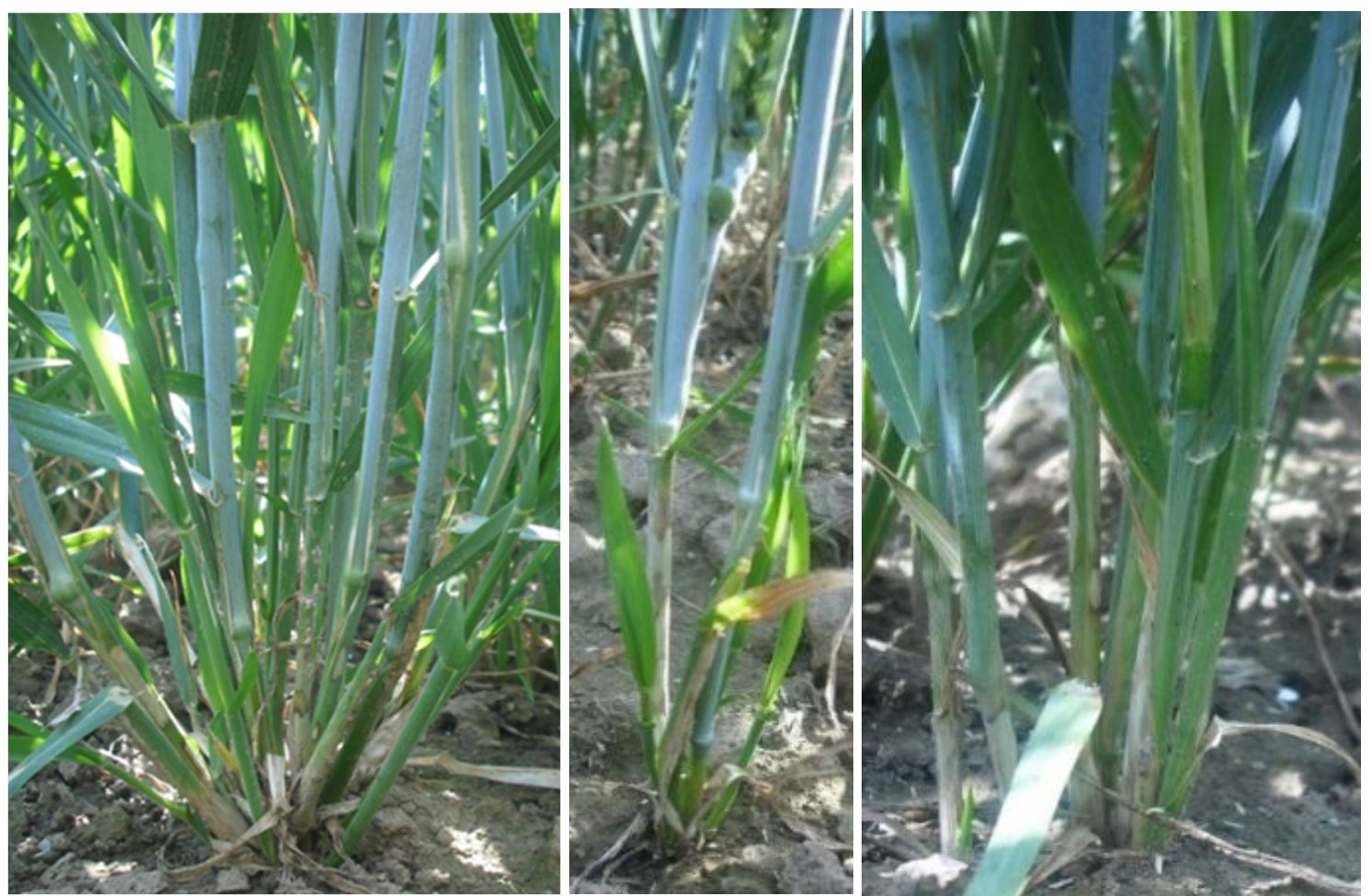

Abbildung 1: Symptome des Scharfen Augenflecks zu BBCH 55 am unteren Halmabschnitt von Winterweizenpflanzen, zu erkennen als ovale Läsion mit einem hellen oder creme-farbenen Inneren und begrenzt von einem scharfen braunen Rand (Feldversuch am Standort Weende im Jahr 2011/12)

Generell können R. cerealis AG D und R. solani Winterweizen befallen und das Symptom des Scharfen Augenflecks erzeugen, Analysen zeigen allerdings, dass die Symptomausprägungen mehrheitlich auf $R$. cerealis AG D zurückzuführen sind (Lemańczyk, 2012). 
Einleitung

Im Falle des Scharfen Augenflecks wird auch von WSED, Wheat Sharp Eyespot Disease, gesprochen (Hamada et al., 2011a) oder im deutschen Sprachraum vom „Spitzen Augenfleck“. Die Bonitur dieser Krankheit erfolgt normalerweise im frühen Stadium der Milchreife, sie kann aber auch schon in der Streckungsphase der Pflanze bonitiert werden (Lemańczyk, 2012). Meist entstehen im Augeninneren Sklerotien anhand deren Größe die symptomauslösende Art von Rhizoctonia erkennbar ist (Schlüter, mündlich 2011). So deuten kleine Sklerotien (Größe eines Stecknadelkopfes) auf $R$. cerealis AG D und große Sklerotien (ca. 3 Stecknadelkopfe aneinander gereiht) auf $R$. solani hin. Des Weiteren wird Weißährigkeit an Pflanzen im späten Stadium der Krankheit beschrieben, die auf eine Schädigung der Wasserleitgefäße durch den Pilz zurückführen ist (Bockus et al., 2010; Hamada et al., 2011a). An Weizenhalmen konnten Läsionen in einer Höhe von bis zu 35 $\mathrm{cm}$ beobachtet werden (Lovell et al., 2003). Es bestehen gute Infektionsbedingungen im Winterweizen, wenn mehrere Faktoren zusammentreffen. Zum einen wird dem Pilz durch eine frühe Aussaat im Herbst ausreichend Zeit vor der Winterruhe eingeräumt (Clarkson $u$. Cook, 1983; Colbach et al., 1997). In dieser Phase sollten günstige klimatische Bedingungen herrschen (Hamada et al., 2011a). Dazu gehört u. a. niederschlagsarmes und trockenes Wetter (Schlüter, mündlich, 2011), sowie eine Temperatur im Bereich zwischen 16 und $20^{\circ} \mathrm{C}$ (Abdel-Shife u. Jones, 1981). Des Weiteren begünstigt bei solchen Wetterbedingungen ein vom Erreger bevorzugter leichter Boden mit Sandanteil die Infektion (Diao et al., 1998), da der Pilz die Pflanze ersatzhalber als Feuchtigkeitsquelle nutzen kann (Schlüter, mündlich, 2011).

\subsection{Bekämpfung von Rhizoctonia in Weizen}

Hinsichtlich einer geeigneten Bekämpfung von Rhizoctonia im Weizen sei zunächst erwähnt, dass - wie bei vielen bodenbürtigen Erregern - keine vollends zufriedenstellenden Maßnahmen zur Verfügung stehen (MacNish u. Neate, 1996). Im Bereich der chemischen Bekämpfungsmöglichkeiten wird Rhizoctonia nicht als vorrangig behandlungswürdig betrachtet. Die empfohlenen Fungizidmaßnahmen belaufen sich auf ein bis zwei, maximal drei Behandlungen während der Vegetationsperiode, in denen hauptsächlich Blattkrankheiten abgedeckt werden. Dazu zählen in erster Linie Septoria tritici, DTR-Blattdürre, Mehltau und Braunrost, neuerdings auch Gelbrost. Des Weiteren wird die Behandlung von u. a. Ährenfusariosen betont (LfL Bayern, 2012). Zum Einsatz kommen zumeist breit wirksame azolhaltige Wirkstoffe, Strobilurine und die neueren Succinat-Dehydrogenase- 
Inhibitoren (SDHI), die fundamentale Biosynthesen der Mitochondrien und somit der pilzlichen Erreger hemmen (Cecchini, 2003). Als relevanter Schaderreger im Bereich der Halmbasis wird - abgesehen von Fusarium - lediglich der Erreger des Halmbruchs angeführt. Dieser kann beim Erreichen einer behandlungswürdigen Schadschwelle im Rahmen der Erstbehandlung bspw. durch Einsatz von Epoxiconazol, Morpholin und Metrafenone mitbehandelt werden. Rhizoctonia profitiert von einer ungünstigen Prädisposition der Pflanze (Rodemann in Christen, 2006), daher sollte stets die Ausgangssituation der Pflanze durch anbautechnisch günstig gestaltete Maßnahmen gestärkt werden.

Um bspw. geeignetes Weizenausgangsmaterial für die Züchtung resistenter Sorten zu erhalten, wurden schnelle Substrat-basierte Testverfahren etabliert (Okubara et al., 2016). Dazu wird die Pflanze in einem mit Pilz beimpften Sandgemisch herangezogen und anschließend hinsichtlich der Schädigung im Bereich der Wurzel bonitiert. Dennoch fehlen der Praxis bislang resistente Weizensorten (Hamada et al., 2011a). Zwar konnte in Feldversuchen bei verschiedenen Weizensorten eine Graduierung in der Anfälligkeit gegenüber Rhizoctonia von hoch bis moderat ermittelt werden, jedoch war diese Resistenz stark korreliert mit den saisonalen Standortbedingungen und nicht mit der Weizensorte (Shamim et al., 2014). Dies erklärt sich damit, dass Rhizoctonia stark von der Präsdisposition der Wirtspflanze abhängig ist und solange latent agiert, bis äußere Faktoren die Pflanze stressen und den Erreger parasitär werden lassen (Oros et al., 2013).

Für einen bodenbürtigen Schaderreger wie Rhizoctonia (Sneh et al., 1996), der im Boden ein vegetatives Hyphengeflecht ausbildet, nimmt die optimale Saatbettbereitung eine besondere Rolle ein. So wird eine tiefe Bodenbearbeitung unter Einsatz von Scharpflügen kurz vor der Aussaat als gute Präventivmaßnahme gegen Rhizoctonia beschrieben (Smith u. Wehner, 1988), da sie die Infektionsstärke des Erregers vorübergehend herabsetzt (Rovira, 1986). Durch das Aufbrechen der Bodenkrume und des darin verlaufenden Hyphengeflechts des Pilzes wird dessen Energiehaushalt erheblich gestört und die Infektionsfähigkeit sinkt (Boswell et al., 2002). Obgleich intensive Boden-bearbeitung Rhizoctonia reduzieren kann, ist der Erreger dadurch nicht vollkommen kontrollierbar (MacNish, 1985) und es bleiben infektiöse Sklerotien im Boden zurück. Durch eine späte Winterweizenaussaat verkürzt sich die Expositionszeit vor der Winterruhe und setzt damit die Infektionswahrscheinlichkeit herab (Cromey et al., 2006; Lemańczyk, 2012). Im Fall von $R$. solani AG 8 in Weizen ist auch die Fruchtfolge keine hinreichend präventive Maßnahme, 
Einleitung

um den Erreger zu bekämpfen, da dieser ein breites Wirtsspektrum hat (Schillinger $u$. Paulitz, 2006) und lange Zeit im Boden überdauern kann (Sneh et al., 1991). Dennoch gibt es erfolgreiche Ansätze. So können bspw. Leguminosen als Vorfrucht die Krankheit reduzieren (King, 1984), während reine Weizenmonokulturen den Erreger fördern (Rovira, 1986). Des Weiteren konnten Langzeitstudien über sieben Jahre zeigen, dass eine WeizenGerste Fruchtfolge einen reduzierenden Effekt hat, obgleich Gerste eine Wirtspflanze der AG 8 darstellt (Schillinger u. Paulitz, 2006). Dies kann damit erklärt werden, dass Gerstenwurzeln im Boden schneller abgebaut werden und daher kein optimales Substrat für den Pilz darstellen (Schillinger u. Paulitz, 2006). Im Falle von R. cerealis wird das Auftreten eng verknüpft mit dem häufigen Anbau von Weizen, Roggen oder Triticale (Lemańczyk, 2012). Ein Wirtswechsel des Pilzes zur Zuckerrübe oder zur Erbse ist nur gelegentlich und unter besonderen Umständen beim Anbau zu beobachten (FurgałWęgrzycka et al., 1996). Aufgrund des weniger weiten Wirtsspektrums von $R$. cerealis ist daher eine aufgelockerte Fruchtfolge sinnvoll.

\subsection{Zielsetzung der Arbeit}

In der vorliegenden Arbeit sollte das Auftreten und die Bedeutung von Rhizoctonia im deutschen Winterweizenanbau untersucht werden. Eine zentrale Frage war die nach der symptomauslösenden Anastomosegruppe (AG) und der Einschätzung des jeweiligen Schadpotentials. In diesem Zusammenhang wurde die Arbeitshypothese verfolgt, dass $R$. solani AG 5 in Europa möglicherweise eine neue im Weizen relevante AG sein könnte. Zur Beantwortung dieser Frage, sowie zur Beurteilung der generellen Befallssituation in Deutschland wurden ein Monitoring von Flächen mit natürlichem Befall sowie Inokulationsversuche im Feld durchgeführt. Dabei sollten die ertragsrelevanten Faktoren der Krankheit im Feld und die relevanten Arten und Anastomosegruppen von Rhizoctonia ermittelt werden. Begleitet wurden diese Untersuchungen von in vitro Studien, in denen die Temperaturansprüche, die Morphologie und der Infektionsprozess untersucht werden sollten. Grundlage dieser Untersuchungen war eine Sammlung verschiedener RhizoctoniaStämme, die zu Projektbeginn aus Ackerbodenproben verschiedener europäischer Länder isoliert wurden. 


\section{Material und Methoden}

\subsection{Chemikalien}

Tabelle 2: Verwendete Chemikalien

\begin{tabular}{|l|l|}
\hline Bezeichnung & Bezugsquelle \\
\hline Agar-Agar, Kobe 1, Nr. 5210.2 & Carl Roth, Karlsruhe, D \\
\hline Agarose & Carl Roth, Karlsruhe, D \\
\hline Ammoniumacetat & Merck, Darmstadt, D \\
\hline ß-Mercaptoethanol & Sigma-Aldrich, Seelze, D \\
\hline Bromphenolblau (BPB) & VWR, Darmstadt, D \\
\hline Cetyltrimethylammoniumbromid (CTAB) & Carl Roth, Karlsruhe, D \\
\hline Ethanol 99,8\% (unvergällt) & Carl Roth, Karlsruhe, D \\
\hline Ethidiumbromid 1\% & AppliChem, Darmstadt, D \\
\hline Ethylendiamintetraessigsäure (EDTA), Fertiglösung & AppliChem, Darmstadt, D \\
0,5 M & \\
\hline Isoamylalkohol & AppliChem, Darmstadt, D \\
\hline Kartoffelextrakt Glucose Boullion (PDB), Nr. CP74.1 & Carl Roth, Karlsruhe, D \\
\hline Magnesiumsulfat-Heptahydrat & Merck, Darmstadt, D \\
\hline Natriumchlorid & AppliChem, Darmstadt, D \\
\hline Natriumhypochlorid & Carl Roth, Karlsruhe, D \\
\hline Natriumnitrit & AppliChem, Darmstadt, D \\
\hline RNAse A & Fermentas, St. Leon-Rot, D \\
\hline Potato Dextrose Agar (PDA), Fertigmedium, Nr. & Fluka Analytical, Buchs/ \\
70139 & Schweiz \\
\hline Polyvinylpyrrolidin (PVP), 40 kD & Sigma-Alderich, Seelze, D \\
\hline TBE-Lösung [10x], Fertiglösung & AppliChem, Darmstadt, D \\
\hline TAE-Lösung [50x], Fertiglösung & AppliChem, Darmstadt, D \\
\hline Trishydroxyaminomethan (Tris-HCl), Fertiglösung, & Carl Roth, Karlsruhe, D \\
Ultra Qualität, Nr. 5429.3 & \\
\hline Trishydroxiaminomethan (TRIS), Fertiglösung 1 M & AppliChem, Darmstadt, D \\
\hline Tween 20 & \\
\hline Paraffinöl, dickflüssig, Dichte 0.87, Nr. 8904.1 & Carl Roth, Karlsruhe, D \\
\hline
\end{tabular}

\subsection{Pilzisolate}

Tabelle 3: Verwendete Pilzisolate von Rhizoctonia spp. für die Labor-, Gewächshaus- und Feldversuche mit Angabe der Referenznummer in der Stammdatenbank der Abteilung Pflanzenpathologie und Pflanzenschutz, GAU-Göttingen (IPP-Nr.) sowie der Referenz, welche bei der Syngenta Agro Deutschland bzw. beim Institut für Zuckerrübenforschung, GAU-Göttingen (Abk. i. d. Tab.: IfZ) geführt wird. Zusätzlich die Angabe der Anastomosegruppe (Abk. AG), der Isolatherkunft sowie der wissenschaftlichen Bezeichnung des Anaund Teleomorphs (aus García et al., 2006). Die zuletzt angeführten Islate Nr. 1 bis Nr. 11 entstammen aus dem Monitoring dieser Arbeit. Abk. Herkunft: $D=$ Deutschland; SH = Schleswig-Holstein; $M V=$ 
Material und Methoden

Mecklenburg-Vorpommern; SN = Sachsen-Anhalt; TH = Thüringen; $\mathbf{N I}=$ Niedersachsen; BW = BadenWürttemberg; Neugatterslb. = Neugattersleben

\begin{tabular}{|c|c|c|c|c|c|}
\hline \multirow{2}{*}{$\begin{array}{l}\text { IPP. } \\
\text { Nr. }\end{array}$} & \multirow[t]{2}{*}{ Referenz } & \multirow[t]{2}{*}{ AG } & \multirow[t]{2}{*}{ Herkunft } & \multicolumn{2}{|c|}{ Gattungs- und Artname } \\
\hline & & & & Anamorph & Teleomorph \\
\hline 0931 & RHI-196 & AG D & Schweiz & $\begin{array}{l}\text { Rhizoctonia } \\
\text { cerealis }\end{array}$ & $\begin{array}{l}\text { Ceratobasidium } \\
\text { cereale }\end{array}$ \\
\hline 1042 & RHI09-018 & \multirow[t]{6}{*}{ AG 5} & $\mathrm{D}$ & \multirow{9}{*}{ R. solani } & \multirow{6}{*}{$\begin{array}{l}\text { Thanathephorus } \\
\text { cucumeris }\end{array}$} \\
\hline 1043 & RHI09-029 & & Polen & & \\
\hline 1044 & RHI09-036 & & $\mathrm{D}$ & & \\
\hline 1045 & RHI09-049 & & Polen & & \\
\hline 1046 & RHI09-072 & & Polen & & \\
\hline 1047 & RHI09-081 & & Polen & & \\
\hline 1050 & RHI09-18/3 & $\begin{array}{l}\text { AG 4- } \\
\text { HGII }\end{array}$ & $\mathrm{D}$ & & $\begin{array}{l}\text { T. cucumeris } \\
\text { (= Pellicularia } \\
\text { praticola) } \\
\text { T. praticola? }\end{array}$ \\
\hline 1056 & RHI09-75/11 & AG 1-IB & Polen & & $\begin{array}{l}\text { T. cucumeris, } \\
\text { T. microsclerotium }\end{array}$ \\
\hline 1064 & RHI09-346 & AG 8 & Spanien & & T. cucumeris \\
\hline 1079 & RHI196-47 & AG D & -- & R. cerealis & C. cereale \\
\hline 1080 & IfZ 0232 r7 & AG 1-IB & -- & \multirow{5}{*}{ R. solani } & $\begin{array}{l}\text { T. cucumeris, } \\
\text { T. microsclerotium }\end{array}$ \\
\hline 1083 & IfZ 0246 r6 & $\begin{array}{l}\text { AG 4- } \\
\text { HGII }\end{array}$ & -- & & $\begin{array}{l}\text { T. cucumeris } \\
\text { (= Pellicularia } \\
\text { praticola) } \\
\text { T. praticola? }\end{array}$ \\
\hline 1084 & IfZ 0247 r5 & AG 5 & -- & & T. cucumeris \\
\hline 1085 & IfZ 0251 r6 & AG 8 & -- & & \multirow[t]{2}{*}{ T. cucumeris } \\
\hline 1087 & IfZ 0260 r4 & AG 11 & -- & & \\
\hline-- & SN-18 & \multirow[t]{4}{*}{ AG D } & $\mathrm{PL}$ & \multirow[b]{4}{*}{ R. cerealis } & \multirow[b]{4}{*}{ Cerealis cereale } \\
\hline-- & 1.Futterkamp & & $\mathrm{D}(\mathrm{SH})$ & & \\
\hline- & 2.Birkenkamp & & $\mathrm{D}(\mathrm{SH})$ & & \\
\hline-- & 3.Ostenfeld & & $\mathrm{D}(\mathrm{SH})$ & & \\
\hline-- & $\begin{array}{l}\text { 5.Blanken- } \\
\text { hagen (b) }\end{array}$ & & $\mathrm{D}(\mathrm{MV})$ & & \\
\hline-- & $\begin{array}{l}\text { 4.Blanken- } \\
\text { hagen (a) }\end{array}$ & & $\mathrm{D}(\mathrm{MV})$ & & \\
\hline- & 6.Neugatterslb. & & $\mathrm{D}(\mathrm{ST})$ & R. cerealis & Cerealis cereale \\
\hline- & 7.Methau & & $\mathrm{D}(\mathrm{SN})$ & & \\
\hline-- & 8.Sora & & $\mathrm{D}(\mathrm{SN})$ & & \\
\hline-- & 9.Thiemendorf & & $\mathrm{D}(\mathrm{TH})$ & & \\
\hline- & 10.Borwede & & $\mathrm{D}(\mathrm{NI})$ & & \\
\hline-- & 11.Tigerfeld & & $\mathrm{D}(\mathrm{BW})$ & & \\
\hline
\end{tabular}


Material und Methoden

\subsection{Saatgut}

Für den Feldversuch Weende 2011/12 wurden die Winterweizensorten Hermann, Inspiration, Mulan und Toras ausgewählt. Die Sortenwahl geschah auf Grundlage von Vorversuchen im Gewächshaus. Hierbei wurden Inokulationsversuche am Weizen unter Anwendung des EPPO Protokolls „Preliminary guidelines for greenhouse trials to test the efficacy of seed treatment against Rhizoctonia spec. in wheat according to EPPOguidelines PP 1 / 28 (3), PP 1 / 125 (3), PP 1 / 262 (1)“ (modifiziert) durchgeführt. Die vier verwendeten Sorten zeigten im Vergleich mit weiteren Sorten schon frühzeitig (BBCH 55) Symptome (Daten nicht gezeigt).

Tabelle 4: Verwendetes Weizensaatgut für Labor-, Gewächshaus- und Feldversuche mit Angabe des Sortennamens, der Züchternummer und des Jahres der Zulassung in Deutschland.

\begin{tabular}{|l|l|l|}
\hline Kultur & Sortenname & Zulassung in Deutschland \\
\hline \multirow{5}{*}{ Winterweizen } & Hermann & 2004 \\
\cline { 2 - 3 } & Inspiration & 2007 \\
\cline { 2 - 3 } & Mulan & 2006 \\
\cline { 2 - 3 } & Toras & 2004 \\
\hline Sommerweizen & Thasos & 1994 \\
\hline
\end{tabular}

\subsection{Feldversuchsflächen}

\subsubsection{Feldversuch}

Für den Feldversuch im Jahr 2011/12 wurde eine insgesamt 2 ha große ackerbaulich genutzte Fläche im Raum Göttingen (Südniedersachsen) verwendet. Die Größe der Versuchsparzellen betrug $3 \times 8 \mathrm{~m}$; der gesamte Versuch bestand aus 64 Parzellen. Die verwendete Fläche befindet sich westlich des Stadtteils Weende im Östlichen Göttinger Leinegraben. Die Koordinaten lauten $51.565^{\circ}$ (Längengrad) zu $9.918^{\circ}$ (Breitengrad). Der Boden im Leinegraben ist ein von Löss bedeckter Auenlehm mit 75 Bodenpunkten.

\subsubsection{Göttinger Bodenerwärmungsanlage}

Die Göttinger Bodenerwärmungsanlage stellt eine künstlich angelegte Feldversuchsfläche mit zwölf Parzellen einheitlicher Größe dar. Das Maß einer einzelnen Parzelle beträgt $2 \mathrm{x}$ 2,5 m. Die Parzellen abstandslos zueinander in zwei Sechserreihen angeordnet (s. beispielhaft Abb. 4). Die Koordinaten des Standortes lauten $51.557^{\circ}$ (Längengrad) zu $9.951^{\circ}$ (Breitengrad). Beim Bau der Anlage wurden in 10 bis $15 \mathrm{~cm}$ Tiefe 
Material und Methoden

witterungsbeständige Heizkabel im Boden verlegt, was eine künstliche und regelbare Erwärmung des Bodens ermöglicht. Die Bodentemperatur wurde entsprechend der Variantenzuteilung um $\Delta+1,6^{\circ} \mathrm{C}$ (leicht erwärmt) bzw. um $\Delta+3,2^{\circ} \mathrm{C}$ (stark erwärmt) erhöht. Zur Imitation realer Feldbedingungen wurden die Parzellen mit Mutterboden angefüllt. Nähere Informationen zu der Anlage sind bei Siebold und von Tiedemann (2012) zu entnehmen.

\subsubsection{Versuchsflächen für Rhizoctonia-Monitoring}

Im Jahr 2012 wurden 15 Feldversuchsflächen in Deutschland beprobt. Das Probenmaterial wurde dieser Arbeit von Syngenta Agro Deutschland zur Verfügung gestellt. Die beprobten Winterweizenschläge befanden sich jeweils in der Nähe der folgenden Ortschaften: Birkenmoor, Blankenhagen, Borwede, Düpow, Futterkamp, Gerdshagen, Neugattersleben, Rottmersleben, Roßleben, Thiemendorf, Methau, Sora, Ostenfeld, Obbornhofen und Tigerfeld. Im Jahr 2013 wurden insgesamt 22 Winterweizenschläge beprobt. Die beprobten deutschen Flächen befanden sich jeweils in der Nähe der folgenden Ortschaften: Auetal, Blankenhagen, Bückwitz, Gerichshain/ Schölen, Glasin/ Zurow, Grabau, Hiddestorf, Jena, Letschin, Merzen, Nienburg, Rothenburg, Schwarzach, Tützpatz, Vreden, Wittighausen und Ziesendorf.

\subsection{Softwareprogramme}

Tabelle 5: Verwendete Softwareprogramme mit Angabe der genauen Bezeichnung und der Version.

\begin{tabular}{|l|l|}
\hline Bezeichnung & Version \\
\hline Word & $\begin{array}{l}\text { Microsoft } ® \text { Word 2013 (15.0.4745.1001) 32-Bit; Bestandteil von } \\
\text { Microsoft Office 365, Produkt-ID: 00201-10069-07207-AA708 }\end{array}$ \\
\hline Excel & $\begin{array}{l}\text { Microsoft @ Excel ® 2013 (15.0.4745.1000) MSO (15.0.4745.1000) 32- } \\
\text { Bit; Bestandteil von Microsoft Office 365, Produkt-ID: 00201-10069- } \\
\text { 07207-AA708 365; Version 15.0.4745.1002). }\end{array}$ \\
\hline $\begin{array}{l}\text { Geldoku- } \\
\text { mentations- } \\
\text { software } \\
\text { Multi-Analyst }\end{array}$ & Gel Doc System BioRad, München \\
\hline Statistica & $\begin{array}{l}\text { STATISTICA (Version 10.0.1011.0 und Version 12.5.192.7); Firma } \\
\text { StatSoft. Inc. }\end{array}$ \\
\hline
\end{tabular}


Material und Methoden

\subsection{Herstellung von Nährmedien, Puffer und Agarosetrenngelen}

Die unten aufgelisteten Nährmedien wurden bei $121^{\circ} \mathrm{C}$ für 20 min autoklaviert und anschließend unter Rühren auf eine Temperatur von etwa $50^{\circ} \mathrm{C}$ heruntergekühlt. Aufgrund der Verwendung einer standarisierten Fertiglösung war eine $\mathrm{pH}-$ Werteinstellung nicht nötig. Für die Kultivierung von Rhizoctonia spp. wurden die folgenden Medien verwendet:

\section{Potato Dextrose Agar (PDA)}

39 g PDA-Fertigmedium

Auf $1000 \mathrm{ml}$ bidest. $\mathrm{H}_{2} \mathrm{O}$

Ausgegossen in Petrischalen (Durchmesser $9 \mathrm{~cm}$ ) zu ca. $25 \mathrm{ml}$ oder ca. $10 \mathrm{ml}$

Die nachfolgenden Nährmedien wurden in Petrischalen (Durchmesser $9 \mathrm{~cm}$ ) zu etwa $25 \mathrm{ml}$ augegegossen:

\section{Potato Dextrose Agar mit Streptomycin (PDAS)}

39 g PDA-Fertigmedium

$1000 \mathrm{ppm}$ Streptomycin (steril filtriert, Zugabe bei $50^{\circ} \mathrm{C}$ nach dem Autoklavieren)

Auf $1000 \mathrm{ml}$ bidest. $\mathrm{H}_{2} \mathrm{O}$

Potato Dextrose Agar mit Bromphenolblau (PDA+BPB)

39 g PDA-Fertigmedium

1\% Bromphenolblau (Zugabe vor dem Autoklavieren)

Auf $1000 \mathrm{ml}$ bidest. $\mathrm{H}_{2} \mathrm{O}$

\section{Wasseragar 2\% (WA 2\%)}

20 g Agar-Agar

Auf $1000 \mathrm{ml}$ bidest. $\mathrm{H}_{2} \mathrm{O}$

Für die Kultivierung von Rhizoctonia in Flüssigmedium wurde die folgende flüssige Nährlösung angesetzt: 
Material und Methoden

Potato-Dextrose-Broth (PDB-flüssig)

36 g PDB-Fertigmedium

Auf $500 \mathrm{ml}$ bidest. $\mathrm{H}_{2} \mathrm{O}$

Abfüllen zu $20 \mathrm{ml}$ in 50ml-Reaktionsgefäße (Schraubverschluss)

Für die molekularen Untersuchungen wurde der nachfolgende Puffer angesetzt:

CTAB-Puffer $(\mathrm{pH} \mathrm{8,0)}$

7,4 g Na-EDTA (Ethylendiamintetraessigsäure)

$23 \mathrm{~g}$ Sorbitol

$10 \mathrm{~g} \mathrm{~N}$-Lauroylsarcosin-Natriumsalz

$8 \mathrm{~g}$ CTAB (Cetyltrimethylammoniumbromid)

$47 \mathrm{~g} \mathrm{NaCl}$

10 g Polyvinylpyrrolidon

$10 \mathrm{ml}$ Tris (1 M)

Auf $1000 \mathrm{ml}$ bidest. $\mathrm{H}_{2} \mathrm{O}$

Zur Auftrennung von DNA-Gemischen wurde das folgende Agarosetrenngel angesetzt:

Agarosetrenngel $1 \%$

$50 \mathrm{ml}$ TAE-Puffer (1-fach)

$0,5 \mathrm{~g}$ Agarose

In der Mikrowelle aufkochen, unter Schwenken abkühlen auf circa $45^{\circ} \mathrm{C}$, dann Zugabe von 1,3 $\mu$ l Ethidiumbromidlösung (1\% Lösung)

Homogenat ausgießen in eine Gelkammer mit Probentaschenkamm, vollständig aushärten lassen und dann den Kamm entnehmen

\subsection{Vermehrung und Lagerung von Pilzmyzel}

\subsubsection{Pilzkultivierung}

Zur Pilzkultivierung diente Festplattenmedium mit Potato-Dextrose-Agar (PDA). Zum Beimpfen einer frischen PDA-Platte wurde Pilzmyzel von einer älteren überwachsenen PDA-Platte entnommen und auf frisches Plattenmedium überführt. Dazu wurde aus dem frischen Myzelrand eine geringe Menge Myzel entnommen und auf das frische Medium 
Material und Methoden

mittig transferiert. Ein ausgestochenes Agarstück wurde mit der Myzel-bewachsenen Seite nach unten zentral auf die neue Platte aufgelegt. Verwendung fand hierfür eine abgeflammte Impfnadel, mit der ein kleines Agarstück ausgeschnitten wurde. Die beimpften Platten konnten für einen Zeitraum von etwa 3 Wochen bei $4^{\circ} \mathrm{C}$ in Kultur gehalten werden.

\subsubsection{Pilzkonservierung}

Zur dauerhaften (mehrere Jahre, genaue Obergrenze ist derzeit noch unbekannt) Pilzkonservierung wurden sogenannte PDA-Schrägröhrchen hergestellt. Dazu wurden 25 ml Reaktionsgefäße (rund, mit Schraubdeckel) mit flachem Boden mit $18 \mathrm{ml}$ PDA befüllt. Nach dem Autoklavieren wurde das Gefäß verschlossen und bis zum Aushärten des Mediums mit einem Neigungswinkel von $40^{\circ}$ ausgelegt, um eine große Oberfläche zu erhalten. Die entstandene Fläche wurde mittig mit einem Pilzmyzelplättchen beimpft. Nachdem der Pilz die Fläche vollständig überwachsen hatte, wurde das Röhrchen mit sterilem Paraffinöl vollständig gefüllt. Es erfolgte eine Lagerung bei $4^{\circ} \mathrm{C}$ im Dunkeln. Bei Bedarf konnte ein wenig Myzel mit einer sterilen Impfnadel dem Röhrchen entnommen und auf eine PDA-Platte ausgestrichen werden. Nach mehrmaligem Überimpfen erhielt man eine Stammplatte mit sauberem Myzel, das als Ausgangsmaterial für weitere Einsätze verwendet werden konnte.

\subsubsection{Myzelanzucht in Flüssigmedium}

Zur Myzelvermehrung wurde von einer Mutterplatte ein Pilzmyzelplättchen entnommen und in ein 50ml-Reaktionsgefäß (Schraubverschluss), befüllt mit $20 \mathrm{ml} \mathrm{PDB}$, überführt. Die beimpfte Flüssigkultur wurde bewegungslos in $30^{\circ}$ Schräglage (zur Oberflächenvergrößerung) im Dunkeln bei $20^{\circ} \mathrm{C}$ kultiviert. Ausgehend vom Pilzmyzelplättchen wuchs das Pilzmyzel bis zur Oberfläche und begann dort einen Myzelrasen zu bilden. Dieser schwamm wie ein Seerosenblatt auf der Flüssigkeit und konnte nach Verstreichen der Inkubationszeit mit einer langen Pinzette abgenommen werde. Der Pilzmyzelplättchen wurde entfernt und verworfen. In Abhängigkeit von der Wuchsgeschwindigkeit des Isolats betrug die Kulturzeit 7 (für $R$. solani Arten) oder 14 Tage (für $R$. cerealis AG D). Das geerntete Myzel wurde durch mehrmaliges Tupfen auf Handtrocknungspapiertücher getrocknet und anschließend in einem frischen $50 \mathrm{ml}$-Reaktionsgefäß in flüssigem Stickstoff eingefroren. Die Lagerung bis zur weiteren Verwendung erfolgte bei $-20^{\circ} \mathrm{C}$. 


\subsubsection{Inokulumproduktion}

Für die Herstellung von Rhizoctonia-Inokulum wurden sterile Weizenkörner verwendet. Dazu wurden unbehandelte Weizenkörner mehrmals in Leitungswasser gewaschen, bei $30^{\circ} \mathrm{C}$ getrocknet und ein zweites Mal in Leitungswasser gewaschen. Der anschließende Trocknungsprozess bei $30^{\circ} \mathrm{C}$ erfolgte für 4 Stunden, sodass noch eine geringe Restfeuchte im Korn erhalten war. Anschließend wurden 11-Glaskolben zur Hälfte mit den gereinigten Körnern befüllt und 2-mal im Abstand von 24 Stunden autoklaviert $\left(121^{\circ} \mathrm{C}, 20 \mathrm{~min}, 1 \mathrm{at}\right)$. Dies sterilen Weizenkörner wurden dann zur Inokulumproduktion eingesetzt. Im 1LGlaskolben wurden präparierte Weizenkörner bis zum Füllstand von $350 \mathrm{ml}$ mit acht ( $R$. solani) oder zehn ( $R$. cerealis AG D) Myzelplättchen aus frischen Mutterkulturen beimpft. Der Kolben wurde bei $20^{\circ} \mathrm{C}$ im Dunkeln bis zu drei Wochen kultiviert (ohne schütteln) bis die Weizenkörner vollständig vom Pilz überwachsen waren. Zur Inokulumproduktion auf Platte hingegen wurden 10ml-PDA-Platten mit zwei Pilzmyzelplättchen beimpft und für zwei bis drei Tage bei $20^{\circ} \mathrm{C}$ (dunkel) kultiviert. Anschließend wurde auf jede Platte $35 \mathrm{~g}$ autoklavierter Weizen ausgestreut. Die Platten wurden mit Parafilm verschlossen und bis zur vollständigen Besiedelung des Weizens durch den Pilz kultiviert $\left(20^{\circ} \mathrm{C}\right.$, dunkel). Unabhängig von der Herstellungsweise (im Kolben oder auf Platte) wurde das Inokulum immer frisch ohne Trocknungsprozess verwendet. Die Produktion erfolgte bedarfsgerecht. Inokuli verschiedener Anastomosegruppen wurde separat erzeugt und erst kurz vor dem Ausbringen miteinander vermischt. Zur Überprüfung der Vitalität des Inokulums wurden acht überwachsene Körner auf eine PDA-Platte ausgelegt. Innerhalb von etwa 5 Stunden sollten Pilzhyphen ausgewachsen sein und die Platte großflächig besiedelt haben. Der Einsatz des Inokulums für die Feldinokulation wird im Abschnitt 2.15.1 beschrieben.

\subsection{Anzucht von Versuchspflanzen und Probenaufbereitung}

\subsubsection{Herstellung sterilisierter vorgekeimter Weizensaat im Labor}

Zur Herstellung von sterilem und vorgekeimtem Weizensaatgut $(\mathrm{BBCH} 4)$ wurde Weizen mehrmals mit Leitungswasser gewaschen und anschließend mit destilliertem Wasser gespült. Das gewaschene Saatgut wurde unter der Sterilarbeitsbank mittels $5 \%$ Natriumhypochlorid für 2-mal 2,5 Minuten desinfiziert und anschließend mit sterilem Leitungswasser gespült. Die Saat wurde auf Festplattenmedium (Wasseragar WA 2\%) 
Material und Methoden

ausgelegt und leicht angedrückt. Die Kultivierung erfolgte bei $20^{\circ} \mathrm{C}$ im Klimaschrank für 5 Tage (Tag 1 und 2 im Dunkeln, dann im Licht).

\subsubsection{Probenahme und -aufbereitung von Weizenpflanzen aus dem Freiland (Feldversuche)}

Die Entnahme der Weizenpflanzen aus den Feldversuchen erfolgte entwicklungsabhängig zu BBCH 25, 35, 55 und 75 per Hand, indem die Pflanze bodennah umgriffen und samt Wurzeln herausgezogen wurde. Die anhaftende Erde wurde weitestgehend durch mehrmaliges Abklopfen entfernt. Pflanzen der frühen Entwicklungsstadien (BBCH 25) wurden samt Erde unter Zuhilfenahme eines Spatens von der Feldversuchsfläche entnommen. Anschließend wurden die Pflanzen in Leitungswasser von anhaftender Erde befreit und auf Rhizoctonia bonitiert. Für die nachfolgende Erregerisolation wurden Halmabschnitte mit Läsionen (Boniturnote 2 oder $>2$, Rhizoctonia-Boniturschema s. Abschn. 2.9) zurückbehalten. Die Halmabschnitte wurden unter fließendem Leitungswasser gespült und bei Raumtemperatur getrocknet.

\subsubsection{Probenaufbereitung für das Monitoring}

Es wurden pro Standort und Parzelle etwa 25 Pflanzen stichprobenartig per Hand durch Herausziehen entnommen. Die Pflanzen waren auf eine Länge von circa $25 \mathrm{~cm}$ gekürzt und durch Abklopfen weitgehend von Erde befreit. Es folgte ein Trocknungsschritt bei Raumtemperatur vor dem Versand, sodass vollkommen trockene Halme versandt werden konnten. Nach dem Probeneingang erfolge eine Rhizoctonia-Bonitur (Abschn. 2.9). Es wurden Halmabschnitte mit der Boniturnote 2 oder höher herauspräpariert und für die nachfolgende Erregerisolation (Abschn. 2.12) aufbereitet.

\subsection{Rhizoctonia-Bonitur}

Zur visuellen Bonitur von symptomatischen Weizenpflanzen (Abb. 1) wurde in modifizierter Weise das von Clarkson \& Cook (1983) beschriebene Boniturschema herangezogen (Tab. 6). 
Material und Methoden

Tabelle 6: Rhizoctonia Bonitur an Weizen nach Clarkson und Cook (1983; modifiziert)

\begin{tabular}{|c|l|}
\hline Boniturnote & Beschreibung \\
\hline 0 & symptomfreie Pflanze \\
\hline 1 & eine oder mehrere Läsionen auf dem äußeren Blatt \\
\hline 2 & $\begin{array}{l}\text { eine oder mehrere Läsionen auf dem Halm, die Hälfte oder weniger als } \\
\text { die Hälfte den Halm umfassend }\end{array}$ \\
\hline 3 & $\begin{array}{l}\text { eine oder mehrere Läsionen auf dem Halm, die Hälfte oder mehr als die } \\
\text { Hälfte den Halm umfassend }\end{array}$ \\
\hline 4 & $\begin{array}{l}\text { eine oder mehrere Läsionen auf dem Halm; penetriert; der Halm ist } \\
\text { morsch und knickt um }\end{array}$ \\
\hline
\end{tabular}

Für den in vitro durchgeführten Pathogenitätstest an Weizenkeimlingen (Agarplattentest; Abschn. 2.10.3) wurde das Boniturschema von Clarkson und Cook transformiert, indem zunächst die Verbräunung der Koleoptile prozentual erfasst und diese anschließend in Boniturnoten überführt wurde (Tab. 7).

Tabelle 7: Rhizoctonia Boniturschema für den in vitro Pathogenitätstest (Agarplattentest) für Rhizoctonia an Weizen zur visuellen Erfassung der Verbräunung der Koleoptile als prozentualer Anteil und deren Übertragung in Boniturnoten

\begin{tabular}{|c|c|l|}
\hline Verbräunung der Koleoptile in \% & Boniturnote & Beschreibung \\
\hline 0 & 0 & Symptomfreie Pflanze \\
\hline $1-25$ & 1 & Leichte Verbräunung \\
\hline $26-50$ & 2 & Mittelstarke Verbräunung \\
\hline $51-75$ & 3 & Starke Verbräunung \\
\hline $76-100$ & 4 & $\begin{array}{l}\text { Sehr starke Verbräunung; } \\
\text { Pflanze abgestorben }\end{array}$ \\
\hline
\end{tabular}

Nach Abschluss der Bonitur wurde unter Verwendung einer Formel der Befalls-Index (DS) berechnet (Tab. 8).

Tabelle 8: Formel für die Berechnung eines Befallsindix DS, aufgestellt für vier Befallsgrade bzw. -noten (0 und 1 bis 4), indem die jeweilige Anzahl an Individuuen eines Befallsgrads/einer Boniturnote multipliziert wird mit deren Gewichtung, wobei folgende Faktoren gelten: $\mathbf{0}=$ symptomfreie Individuuen, $1=$ leicht Befallene, 2 = mäßig Befallene, 3 = mäßig bis stark Befallene und 4 = sehr stark Befallene, was wiederum nach Aufaddierung geteilt wird durch die Gesamtanzahl aller bonitierten Individuen - multipliziert mit der Gesamtanzahl an Befallsgraden

\begin{tabular}{|l|}
\hline Berechnung des Befallsstärke DS \\
$\qquad \underline{\left(N_{0} \times 0\right)+\left(N_{1} \times 1\right)+\left(N_{2} \times 2\right)+\left(N_{3} \times 3\right)+\left(N_{4} \times 4\right)}$ \\
$(\mathbf{N} \times 5)$
\end{tabular}


Material und Methoden

Im Feldversuch wurde die Befallshäufigkeit (DS) ermittelt. Dabei wurde lediglich entschieden, ob die Einzelpflanze gesund (Note 0) oder symptomatisch ist (Note 1 bis 4). Der Anteil der symptomatischen Pflanzen wurde als prozentualer Anteil angegeben.

\subsection{Untersuchungen unter sterilen Kulturbedingungen (in vitro)}

\subsubsection{Nachweis sezernierter Säure durch Einsatz von Bromphenolblau}

Durch die Zugabe von Bromphenolblau (BPB) zum Festplattenmedium PDA entsteht blau gefärbtes Nährmedium (blau $=\mathrm{pH} 7,5$ ), welches sich in Anwesenheit von Säure gelb verfärbt (gelb $=\mathrm{pH}$ 1,08). Im Rahmen der Untersuchungen wurden insgesamt 19 Isolate der Gattung Rhizoctonia getestet (Tab. 3). Das verwendete Spektrum setzte sich folgendermaßen zusammen:

a) sechs Pilzisolate der AG 5 (IPP-Nr. 1042, 1044 bis 1047 und 1084)

b) zwei Isolate der AG 8 (IPP-Nr. 1064 und 1085)

c) ein Isolat der AG 1-IB (IPP-Nr. 1056)

d) zwei Isolate der AG 4 HGII (IPP-Nr. 1050 und 1083)

e) zwei Isolate der AG 11 (IPP-Nr. 1060 und 1087)

f) fünf Isolate des R. cerealis AG D (IPP-Nr. 0931 und 1079), Isolat SN-18 und die Isolate R. cerealis AG D (Tab. 3) aus „Futterkamp“ (Nr. 1) und aus „Tigerfeld“ (Nr. 11)

Ausgehend von einer frischen Stammplatte wurden frische PDA + BPB-Platten mittig beimpft. Die Platten wurden mit Parafilm verschlossen und bei $20^{\circ} \mathrm{C}$ im Dunkeln für zwölf Tage kultiviert. Von jeder Variante wurden drei Wiederholungen angesetzt. Die Auswertung der Färbereaktion erfolgte durch visuelle Betrachtung des Nährmediums nach 6, 8 und 10 Tagen. Um die Farbe sicher einem pH-Wert zuordnen zu können, wurde zuvor BPB in Wasser angesetzt und mit $\mathrm{HCl} 2 \%$ angesäuert. Dabei wurde solange angesäuert bis der pH-Wert 1.08 (gelb), 2.63 (orange), 4.45 (hellviolett), 6.5 (violett), 7.5 (blau) und 10.58 (dunkelblau) eingestellt und als Farbe notiert war.

\subsubsection{Ermittlung des Temperaturoptimums}

Um Temperaturoptima verschiedener Anastomosegruppen zu ermitteln, wurde PDA-Festplattenmedium mittig mit einem Myzelplättchen definierter Größe (Durchmesser 6 mm, 2/3 
Material und Methoden

bewachsen) beimpft. Den Platten wurde zuvor unterseitig mittels Marker (schwarz, $0.5 \mathrm{~mm}$ ) ein Kreuz aufgezeichnet, um einerseits die Ablageposition zu definieren und andererseits die Zuwachsraten anzeichnen und ausmessen zu können. Die Myzelplättchen wurden aus dem Rand frischer Mutterkulturen mittels abgeflammter umgedrehter Pasteurpipette ausgestanzt und mit einer Abflammnadel entnommen. Die beimpften Platten wurden für sieben Tage bei konstanter Temperatur kultiviert. Die tägliche Zuwachsrate des radial wachsenen Pilzes wurde täglich zur gleichen Uhrzeit umseitig auf dem Plattenkreuz markiert und ausgemessen. Der Wachstumsverlauf wurde als Graphik dargestellt. Durch Interpolation mittels einer eingefügten Trendlinie wurde die Steigung des Graphen ermittelt. So wurde aus den Messwiederholungen jeweils die mittlere Zuwachsrate in $(\mathrm{cm} / \mathrm{Tag})$ bei gegebener Temperatur abgelesen.

Im ersten Durchlauf wurde ein Set aus verschiedenen AG's geprüft. Das Set bestand aus AG 1-IB (IPP-Nr. 1056), AG 5 (IPP-Nr. 1047), AG 8 (IPP-Nr. 1064) und AG D (IPP-Nr. 0931) (Tab. 3). Die Isolate stammten aus Bodenproben ackerbaulich genutzter Flächen. Der untersuchte Temperaturbereich lag zwischen 8 und $32^{\circ} \mathrm{C}$ Celsius (aufsteigend in $4^{\circ} \mathrm{C}$ - Schritten). Pro Variante wurden vier Wiederholungen angesetzt.

Im zweiten Durchlauf wurden elf Isolate der AG D untersucht. Die Isolate stammten aus Pflanzenproben (Winterweizen), die im Rahmen des Monitorings in Rahmen dieser Arbeit aufgereinigt wurden. Der untersuchte Temperaturbereich lag zwischen 4 und $28^{\circ} \mathrm{C}$ Celsius (aufsteigend in $4^{\circ} \mathrm{C}$ - Schritten). Pro Variante wurden drei Wiederholungen angesetzt. Da für diese Isolate keine IPP-Nr. vergeben worden ist, wurde die Herkunft als Isolatbezeichnung verwendet: Futterkamp (Isolat Nr. 1, SH), Birkenkamp (Nr. 2, SH), Ostenfeld (Nr. 3, SH), Blankenhagen [a] (Nr. 4, MV), Blankenhagen [b] (Nr. 5, MV), Neugattersleben (Nr. 6, ST), Methau (Nr. 7, SN), Sora (Nr. 8, SN), Thiemendorf (Nr. 9, TH), Borwede (Nr. 10, NI) und Tigerfeld (Nr. 11, BW) (s. auch Tab. 2).

\subsubsection{Pathogenitätstest an Weizenkeimlingen (Agarplattentest)}

Beim in vitro Testsystem wurden Weizenkeimlinge zu BBCH 05 mit dem Pilz auf Wasseragar (2\%, s. Abschn. 2.6) cokultiviert. Alle Arbeitsschritte erfolgten unter sterilen Bedingungen. Das Testset bestand aus sieben Isolaten der AG 5 (IPP-Nr. 1042 bis 1047 u. 1085), zwei Isolaten der AGD (IPP-Nr. 0931 u. 1079), zwei Isolaten der AG 8 (IPP-Nr. 1064 u. 1085) und einem Isolat der AG 1-IB (IPP-Nr. 1056). Die im Test geprüften Weizensorten waren Hermann, Inspiration, Mulan, Thasos und Toras (Tab. 4). Pro 
Material und Methoden

Wasseragarplatte wurden vier sterile Weizenkeimlinge kreisförmig um eine Inokulumquelle (Myzelplättchen mit Durchmesser 6 mm, zu 2/3 Pilzmyzel bewachsen) abgelegt. Die Anzahl der eingesetzten Myzelplättchen zur Inokulation stieg mit abnehmender Fähigkeit des Isolats, auf dem nährstoffarmen Wasseragar zu wachsen (von R. cerealis AG D drei Pilzmyzelplättchen; von $R$. solani-Isolaten ein Pilzmyzelplättchen). Zur Herstellung der Plättchen wurde eine abgeflammte Pasteurpipette - analog zu einem Korkbohrer verwendet. Die Myzelplättchen wurden aus dem Rand einer frischen PDA-Pilzkulturplatte entnommen; dabei waren die Plättchen zu 2/3 mit Myzel bewachsen (Durchmesser $6 \mathrm{~mm}$ ). Pro Variante wurden drei Wiederholungen angesetzt. Als Gesundkontrolle dienten Platten, die mit PDA-Agar ohne Pilz inokuliert wurden. Die mit Parafilm verschlossenen Platten wurden bei $20^{\circ} \mathrm{C}$ für vier Tage im Dunkeln kultiviert und anschließend in einen vierzehnstündigen Lichtrhythmus überführt. Die finale Bonitur erfolgte unter Öffnen der Platte nach zehn Tagen (bei $R$. solani Arten) bzw. nach 14 Tagen (bei $R$. cerealis). Da bei diesem Test keine eindeutig voneinander abgegrenzten Läsionen erkennbar waren (Abb. 1), wurde die Verbräunung der Koleoptile prozentual geschätzt und in Boniturnoten überführt (Tab. 7). Es erfolgte abschließend wurde die Befallsstärke (DS) nach der in Tabelle 8 eingeführten Formel berechnet.

\subsubsection{Infektionsassay zur Untersuchung befallener Weizenwurzeln}

Zur Untersuchung des Infektionsprozesses von Rhizoctonia spp an der Weizenwurzel. wurde der im Folgenden beschriebene in vitro Assay verwendet (Abb. 2). Alle Arbeitsschritte erfolgten unter sterilen Bedingungen. Zunächst wurde $2 \%$ Wasseragar in Petrischalen (Durchmesser $9 \mathrm{~cm}$ ) ausgegossen (Abschn. 2.6). Mittels eines sterilisierten Skalpells wurde das obere Drittel des Wasseragars abgetrennt, aus der Schale entnommen und verworfen. Die freigelegte Schnittkante wurde nun nachträglich angeschrägt. Mittels einer umgedrehten Pasteurpipette - analog verwendet wie ein Korkbohrer - wurden im gleichmäßigen Abstand 3 Löcher in die Kante gestochen, um eine spätere Ablagestelle für den Weizenkeimling zu schaffen. Als Saatgut diente Sommerweizen der Sorte Thasos (Tab. 4), da hier ein Vernalisationsreiz und ein damit verbundenes Kontaminationsrisiko vermieden werden konnte. Der Weizen wurde in $5 \% \mathrm{NaOCl}$ oberflächensterilisiert und nach Waschen in Wasser vorgekeimt bis BBCH 5 (Abschn. 2.8.1). Die Platten wurden im unteren Drittel mit drei (bei $R$. cerealis AG D IPP-Nr. 0931) oder mit einem (bei $R$. solani AG 5 IPP-Nr. 1047 und AG 1-IB IPP-Nr. 1056) Pilzmyzelplättchen inokuliert. Dazu wurden aus 
Material und Methoden

dem Rand einer frischen Mutterkultur mittels einer umgedrehten Pasteurpipette - analog verwendet wie ein Korkbohrer - Pilzmyzelplättchen entnommen. Pro Isolat wurden drei Wiederholungen angesetzt. Die Platten wurden mittels Parafilm verschlossen und in aufrechter Position im Klimaschrank bei $20^{\circ} \mathrm{C}$ (dunkel) für 6 Tage kultiviert (Abb. 2). Die auf diese Weise hergestellten pilzassoziierten Wurzeln dienten als Ausgangsmaterial für die Herstellung von Mikroskopiepräparaten.

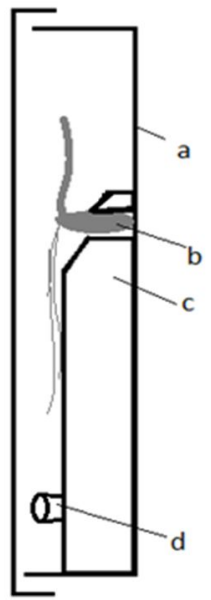

Abbildung 2: Versuchsaufbau des in vitro-Assays (Wasseragarplatte $2 \%$ mit ca. $25 \mathrm{ml}$, hochkant aufgestellt) für Infektionsstudien von Rhizoctonia sp. an der Weizenwurzel als schematische Darstellung im Profil: $a=$ Petrischale, $b=$ Weizenkeimling, $c=2 \%$-Wasseragar, $d=$ Pilzinokulum/Pilzmyzelplättchen. Durch die definierte Ablage des Weizenkorns (b) in der vorgestanzten Vertiefung am abgeschrägten oberen Rand des Wasseragars (c) und die Ausrichtung des Weizenembryos (b) mit der Wurzel nach unten war sichergestellt, dass die Wurzeln für die Pilzhyphen leicht zugänglich sind.

Die Herstellung der Präparate und deren Auswertung im Lichtmikroskop wird im nachfolgenden Abschnitt 2.11.3 beschrieben.

\subsection{Herstellung von mikroskopischen Präparaten}

\subsubsection{Herstellung Agarose-beschichteter Objektträger}

Zur Herstellung von Agarose-beschichteten Objektträgern (nach Pfennig u. Wagener, 1986; modifiziert) wurde zunächst eine $2 \%$ Agaroselösung mit demineralisiertem Wasser im 150ml-Glaskolben angesetzt, mit einem Magnetrührstab versehen und im Autoklav (20 min, $121^{\circ} \mathrm{C}, 1$ at) sterilisiert (Abschn. 2.6). Alle weiteren Arbeitsschritte erfolgten unter einer Sterilarbeitsbank.

Nach dem Autoklaviervorgang wurde die Agaroselösung im Wasserbad unter Rühren bei $50^{\circ} \mathrm{C}$ flüssig gehalten. Währenddessen wurden die Objektträger mit $70 \%$ Ethanol gereinigt, 
Material und Methoden

um eine staubfreie Oberfläche zu erhalten. Die Objektträger wurden horizontal im Schein einer Rotlichtlampe ausgelegt, um die Oberfläche zu erwärmen und die gleichmäßige Verteilung der Agaroselösung sicherzustellen. Nun wurden mittels einer Pipette bis zu $2 \mathrm{ml}$ der flüssigen Agarose in einer Zickzacklinie auf den Objektträger aufgetragen, welche zu einer gleichmäßigen Oberfläche ineinanderfloss. Nach dem vollständigen Aushärten der Agarose konnten die Objektträger staubfrei in sterilen Petrischalen verpackt und bei $4^{\circ} \mathrm{C}$ gelagert werden.

Im Laufe der Zeit bildete sich eine materialärmere Variante des Verfahrens heraus, die im Folgenden beschrieben werden soll. Fortan erfolgten alle weiteren Arbeitsschritte unter einer Sterilarbeitsbank. Nach dem Autoklaviervorgang $\left(20 \mathrm{~min}, 121^{\circ} \mathrm{C}, 1\right.$ at) wurde die $2 \%$ Agaroselösung unter Rühren bei Raumtemperatur heruntergekühlt. Währenddessen wurden Objektträger mit 70\% Ethanol gereinigt und in halb geöffneten Petrischalen schräg platziert, sodass das Ethanol vollständig verdampfen konnte. Anschließend wurden die Objektträger in der Schale in Horizontallage gebracht. Die inzwischen auf $45^{\circ} \mathrm{C}$ heruntergekühlte Agarose wurde zu etwa $15 \mathrm{ml}$ in die Petrischalen ausgegossen. Dabei wurde darauf geachtet, dass der darin liegende Objektträger vollständig mit Agraose überschichtet wurde. Nachdem die Agaroselösung ausgehärtet war, wurde die Petrischale verschlossen. Die anschließende Lagerung erfolgte bei $4^{\circ} \mathrm{C}$. Bei Bedarf konnten mittels eines Skalpells die Objektträger samt Agarose aus der Petrischale herausgetrennt und verwendet werden (s. nachf. Abschnitte).

\subsubsection{Mikroskopische Präparate von Rhizoctonia spp.}

Zur Herstellung von Mikroskopiepräparaten mit Pilzmyzel wurden mit Agarose beschichtete Objektträger mit einem Pilzmyzelplättchen, entnommen von einer Reinkultur, beimpft und ein bis zwei Tage bei $20^{\circ} \mathrm{C}$ (dunkel) kultiviert. Alle Arbeitsschritte erfolgten unter sterilen Bedingungen. Die ausgewachsenen Hyphen konnten im Lichtmikroskop bei 40 -facher Vergrößerung betrachtet werden. Die Dokumentation erfolgte fotografisch.

\subsubsection{Mikroskopische Präparate von infizierten Weizenwurzeln}

Die zu untersuchenden Weizenwurzeln, welche mit Pilzhyphen assoziiert waren, wurden dem in vitro Infektionsassay (Abschnitt 2.10.4) entnommen. Die Aufbereitung der Wurzeln und die Färbung der Pilzhyphen erfolgte wie nachfolgend beschrieben: 
Material und Methoden

1. Wurzelentnahme vom in vitro Infektionsassay mittels gereinigtem Skalpell und Pinzette

2. Färbung des Pilzmyzels durch vollständiges Eintauchen der Wurzeln in autoklaviertes Wasser mit 10\% Lactophenolblau für 2 Minuten

3. Spülen von Wurzeln und Hyphen in autoklaviertem Leitungswasser für 25 bis 30 Sekunden

4. Auslage der Wurzeln auf einem Objektträger, vollständige Überschichtung mit destilliertem Wasser und Abdeckung mit einem Deckglas

5. Betrachtung der Wurzeln im Lichtmikroskop (Vergrößerung 100-fach oder 200-fach) Die Auswertung erfolgte durch Auszählen der Infektionskissen im Bereich der pilzassoziierten Wurzelabschnitte. Die Infektionskissen erscheinen als verdickte Myzelpakete. Die Angabe erfolgte als Anzahl an Infektionskissen pro cm pilzassoziierter Wurzel.

\subsection{Erregerisolierung aus getrockneten Weizenhalmen mit Läsionen:}

\section{Monitoring und Feldversuche}

Zur Isolation von Rhizoctonia aus getrockneten Weizenhalmen mit Läsionen (vgl. Abb. 1) wurden aufbereitete Proben (Abschn. 2.8) unter sterilen Arbeitsbedingungen wie folgt behandelt. Die Weizenhalme wurden zunächst oberflächensterilisiert:

1. 30 Sekunden $70 \%$ Ethanol

2. 2 Minuten $2 \%$-Natriumhypochlorid (optional mit 0,02\% Tween 20 versetzt)

3. Spülen mit autoklaviertem Leitungswasser

Die Halme wurden auf frisches PDA-Festplattenmedium mit Streptomycin (= PDAS) ausgelegt und leicht angedrückt. Dabei sollte die Läsion halbseitig Kontakt zum Medium haben. Die PDAS-Platte verblieb halb geöffnet unter der Sterilarbeitsbank, bis überschüssiges Wasser verdunstet war. Die Platte wurde anschließend mit Parafilm verschlossen und bei $20^{\circ} \mathrm{C}$ für zwei bis zweieinhalb Tage im Dunkeln kultiviert. Die ausgewachsenen Pilzhyphen wurden mittels umgedrehter Pasteurpipette - verwendet wie ein Korkbohrer - und Impfnadel von der Platte entnommen. Die entnommenen Pilzmyzelplättchen wurden mit der Myzel-bewachsenen Seite nach unten auf eine frische PDAS-Platte überführt. Es folgte ein weiterer Kultivierungsschritt bei $20^{\circ} \mathrm{C}$ für zwei bis zweieinhalb Tage im Dunkeln. Frisch ausgewachsene Hyphenspitzen wurden wiederholt auf PDAS-Medium überführt. Diese Maßnahme wurde so häufig wiederholt bis eine reine 
Material und Methoden

Kultur etabliert war. Eine kurzzeitige Lagerung der Isolate erfolgte auf verschlossenen PDAS- oder PDA-Platten bei $4^{\circ} \mathrm{C}$ (dunkel).

\subsection{Erregernachweis auf PDA}

In den künstlich inokulierten Feldversuchen wurde ein Erregernachweis auf PDA angewendet. Dazu wurde PDA-Festplattenmedium mit isolierten Reinkulturen beimpft, verschlossen und 6 Wochen bei $20^{\circ} \mathrm{C}$ im Dunkeln kultiviert. Eine Kontrollplatte mit dem Ausgangsisolat diente als Referenz. Das Erscheinungsbild des Pilzes konnte während der anfänglichen Wachstumsphase (null bis zehn Tage) sowie nach dem vollständigen Verstreichen der Zeit mit der Referenzplatte visuell abgeglichen werden. Geachtet wurde dabei auf die Ausbildung konzentrischer Ringe im Wachstumsverlauf, die Myzelfarbe sowie die Sklerotienerscheinung und deren Entstehungort auf der Platte.

\subsection{Erregernachweis durch PCR}

Als Ausgangsmaterial für die PCR dienten erfolgreich etablierte Rhizoctonia-Reinkulturen, welche von symptomatischem Pflanzenmaterial isoliert worden waren (Abschn. 2.12). An die Myzelvermehrung in Flüssigkultur (Abschn. 2.7.3) schloss sich eine Gesamt-DNAExtraktion aus Pilzmyzel an, sowie deren Qualitätsprüfung. Anschließend wurde mittels spezifischer PCR zwischen $R$. solani (AG 1 bis AG 14) und $R$. cerealis AG D differenziert.

\subsubsection{DNA Extraktion aus Pilzmyzel}

Die Extraktion der Gesamt-DNA (gDNA) erfolgte nach dem Protokoll von Doyle (1991; modifiziert), welches ursprünglich zur raschen Aufreinigung von pflanzlicher DNA entwickelt wurde. Das Ausgangsmaterial für die Extraktion war eine große Menge an Myzel, welches aus einer Flüssigkultur geerntet wurde.

Der CTAB-Puffer (Abschn. 2.6) wurde auf $65^{\circ} \mathrm{C}$ im Wasserbad vorgewärmt. Das $\beta$ Mercaptoethanol wurde direkt vor dem Gebrauch zur benötigten Menge Puffer (1 ml CTABPuffer $+2 \mu \mathrm{l}$ beta-Mercaptoethanol) hinzugegeben. Das Pilzmyzel wurde direkt im $2 \mathrm{ml}$ Reaktionsgefäß mittels einer gereinigten Pinzette gemörsert, indem diese geschlossen durch schnelles Rotieren das Probenmaterial am Gefäßrand fein zerstoßen hat. War dies nicht möglich, wurde das Myzel im gekühlten Mörser mit Pistill in flüssigem Stickstoff gemörsert. Pro Probe wurde ein $2 \mathrm{ml}$ Reaktionsgefäß zu einem Drittel mit pulverisiertem 
Material und Methoden

Material gefüllt (Füllstand des Gefäßes wurde visuell abgeschätzt). Das Material wurde mit $800 \mu$ l gebrauchsfertigem CTAB-Puffer (s. o.) homogenisiert und für 45 bis 60 Minuten bei $65^{\circ} \mathrm{C}$ inkubiert. Nach der Inkubation wurde dem Ansatz $800 \mu \mathrm{l}$ frisch angesetzte Chloroform/Isoamylalkohol-Lösung (Mischungsverhältnis 24:1, v/v) hinzugegeben. Der Ansatz wurde optional per Hand für zehn bis 15 Minuten über Kopf geschüttelt und anschließend für zehn Minuten ruhen gelassen. Es folgte ein Zentrifugationsschritt für 25 Minuten bei $12.000 \mathrm{~g}$ (Raumtemperatur). Danach befanden sich zwei Phasen im Gefäß. Von den zwei Phasen wurde die obere wässrige Phase vorsichtig abgenommen und in ein frisches $2 \mathrm{ml}$ Reaktionsgefäß überführt. Die untere organische Phase und die darüberliegende Zwischenphase wurden nicht weiterverwendet. Durch Zugabe von 2/3 Volumen Isopropanol $\left(-20^{\circ} \mathrm{C}\right)$ und invertieren des Ansatzes fiel die DNA aus. Der Fällungsschritt wurde verstärkt, indem der Ansatz für 10 bis 30 Minuten bei -20 inkubiert wurde. Optional konnte der Ansatz auch über Nacht bei $-20^{\circ} \mathrm{C}$ verbleiben, um am Tag darauf damit weiter zu arbeiten. Schließlich folgte ein weiterer Zentrifugationsschritt von 15 Minuten bei $12.000 \mathrm{~g}$ (Raumtemperatur), um die DNA zu vollständig zu pelletieren. Der Überstand wurde abgenommen und das Gefäß kurz zum Trocknen offenstehen gelassen. Es folgte ein Reinigungsschritt durch Zugabe von $300 \mu$ l Waschpuffer (70\% Ethanol). Das Gefäß wurde dreimal geschwenkt, um die gesamte Oberfläche mit dem Puffer zu spülen. Anschließend wurde der Puffer mittels Pipette abgenommen und das Gefäß kurz offen stehengelassen. Um mögliche mitisolierte Ribonukleinsäure zu entfernen, folgte ein RNAVerdau. Dazu wurde das Pellet in $200 \mu \mathrm{l}$ TE-Puffer mit $0,75 \mu \mathrm{l}$ RNAse A $(10 \mu \mathrm{g} / \mathrm{ml})$ resuspendiert und für 20 bis 30 Minuten bei $37^{\circ} \mathrm{C}$ inkubiert (Wasserbad). Anschließend folgte der zweite Präzipitationsschritt, indem $100 \mu$ Ammoniumacetat $(7,5 \mathrm{M})$ und $750 \mu \mathrm{l}$ $\mathrm{EtOH}$ (absolut, $-20^{\circ} \mathrm{C}$ ) zum Ansatz gegeben wurden. Durch behutsames Invertieren fiel die DNA aus. Es folgte ein Zentrifugationsschritt für 10 Minuten bei $12.000 \mathrm{~g}$ (Raumtemperatur). Der Überstand wurde vollständig abgenommen und das Gefäß für 4 Stunden zum Trocknen offenstehen gelassen. Danach wurde das DNA-Pellet im demineralisierten Wasser (autoklaviert) aufgenommen und rückgelöst. Um den Lösungsprozess zu beschleunigen, wurde der Ansatz auf einen Kreisschüttler gestellt (120 Umdrehungen pro Minute). Das gewählte Volumen zum Rücklösen der DNA wurde bestimmt durch die Pelletgröße und bewegte sich zwischen mindestens 20 bis zu $45 \mu$. Die rückgelöste DNA wurde anschließend bei $4^{\circ} \mathrm{C}$ oder $-20^{\circ} \mathrm{C}$ gelagert. 
Material und Methoden

\subsubsection{Flachbettgelelektrophorese}

Zur Herstellung von 1\% Agarosetrenngelen wurde 1-fach angesetzte TAE-Puffer-Lösung verwendet:

Agarosetrenngel

$50 \mathrm{ml}$ Tris-Acetat-EDTA (TAE)-Pufferlösung (1-fach)

$0,5 \mathrm{~g}$ Agarose

1,3 $\mu \mathrm{l} \mathrm{EtBr-Lsg.} \mathrm{(Ethidiumbromidlösung)} \mathrm{(1 \%} \mathrm{w/v)}$

Die präparierte Lösung wurde im Mikrowellengerät kurz aufgekocht, um die Agarose zu lösen. Anschließend wurde die Lösung unter leichtem Schwenken auf $40^{\circ} \mathrm{C}$ heruntergekühlt und das hitzelabile Ethidiumbromid nachträglich hinzugegeben. Das Gel wurde in eine Flachbettgelelektrophorese überführt und mit 1-fach TAE-Laufpuffer überschichtet. Die aufzutrennende Probe wurde in die Tasche eingefüllt und mittels elektrischer Spannung durch das Agarosegel geführt. Dabei lief die negativ geladene DNA in Richtung Pluspol (Anode). Die Elektrophorese wurde für 30 min unter einer Spannung von 5 Volt pro $\mathrm{cm}$ Elektrodenabstand betrieben. Die Fragmente wurden entsprechend ihrer Länge aufgetrennt. Zur Verifizierung wurde ein DNA-Größenstandard (s. nachf. Abschn.) parallel zur Probe mit aufgetrennt. Die Visualisierung erfolgte nach beendetem Lauf im UV-Licht (360 nm).

\subsubsection{PCR-Größenstandards}

In der Flachbettgelelektrophorese wurde standardmäßig ein DNA-Marker verwendet. Je nach Anwendung wurde ein 100 bp- bzw. ein 50 bp-Marker eingesetzt. Das eingesetzte Gesamtvolumen des Markers belief sich auf $3 \mu \mathrm{l}(\mathrm{c}=0,5 \mu \mathrm{g} / \mu \mathrm{l})$ und wurde in die erste Taschenvertiefung des Agarosegels aufgetragen (Abk. mit M).

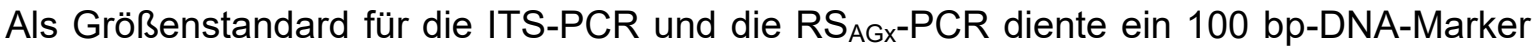
(Gene Ruler $100 \mathrm{bp}$ Plus DNA Ladder, c $=0,5 \mu \mathrm{g} / \mu \mathrm{l}$; Fermentas). Dieser trennte sich auf in 14 Fragmente, die eine Messgröße zwischen 100 bp und 3000 bp abdeckten. Die Auftrennung der Fragmente (in bp) lautet absteigend: 3000, 2000, 1500, 1200, 1000, 900 , $800,700,600,500,400,300,200,100$. Im Fragmentgemisch sind die Banden der Größen 1000 bp und 500 bp anteilsmäßig mit 16\% vertreten, während die übrigen Banden mit 5,6\% (Banden > 1000 bp), 5,4\% (Banden zwischen 1000 bp und 500 bp) bzw. 6\% (Banden $<500$ 
Material und Methoden

bp) vertreten sind (It. Herstellerangaben). Diese ungleiche Verteilung bedingt im Agarosegel eine optische Aufhellung der 1000 bp-Bande und der 500 bp-Bande des Markers.

Als Größenstandard für die RC-PCR wurde ein 50 bp-Marker (Gene Ruler 50 bp DNA Ladder, $c=0,5 \mu \mathrm{g} / \mu \mathrm{l}$; Fermentas). verwendet. Dabei handelt es sich um ein Gemisch, welches sich in 13 Fragmente aufteilt. Die Messbreite reicht dabei zwischen von 50 bp bis 1000 bp. Die Auftrennung der Fragmente (in bp) lautet absteigend wie folgt: 1000, 900, 800, 700, 600, 500, 400, 300, 250, 200, 150, 100, 50. Im Fragmentgemisch sind die Banden der Größen 500 bp und 250 bp anteilsmäßig mit 15\% vertreten, während die übrigen Banden mit 6\% (Banden > 500 bp) bzw. 7\% (Banden < 250 bp) vertreten sind (It. Herstellerangaben). Diese ungleiche Verteilung erzeugt im Agarosegel eine optische Aufhellung der 500 bp- und der 250 bp-Bande des Markers. Für die PCR-Ansätze wurde das Kit von Fermentas in Anleitung des Herstellers verwendet.

\subsubsection{Prüfung der DNA auf Qualität, Quantität und Funktionalität}

Zur Überprüfung der Qualität und Quantität der DNA-Extraktion wurde die DNA in einer Flachbettgelelektrophorese eingesetzt. Dazu wurden zunächst $5 \mu \mathrm{l}$ der aufgereinigten DNA mit 10-fachem Ladepuffer beschwert und in einem 1\% Agarosegel aufgetragen. Die DNA wanderte entsprechend des elektrischen Spannungsfeldes bis zur Kompressionszone in das Gel ein. Als mitaufgetragener Größenstandard wurde Lambda-DNA in den drei Verdünnungsstufen 300 ng, 600 ng und 900 ng verwendet. Dabei handelte es sich um unverdaute genomische Gesamt-DNA des Bakteriophagen Lambda $\lambda$ (Bezugsfirma Fermentas, Lot-Nr. 00036855). Diese lag als Stocklösung mit einer Konzentration von $c=0,3 \mu \mathrm{g} / \mu \mathrm{l}$ vor. Nach anschließender Dokumentation im UV-Licht wurde von jeder DNA geeigneter Qualität eine Arbeitslösung in einer Konzentration von 300 ng/ $\mu$ l hergestellt.

Zur Überprüfung der DNA-Aufreinigung auf ihre Funktionalität wurde die DNA in einer Standard-PCR eingesetzt (Dream Taq-Polymerase PCR-System; Firma Bioline).

Tabelle 9: PCR-Reaktionsmix mit Aufführung der Einzelbestandteile sowie deren Endkonzentration

\begin{tabular}{|l|l|}
\hline Bestandteil & Endkonzentration \\
\hline PCR-Puffer (10-fach konzentriert) & $1,2 \mu \mathrm{l} \mathrm{bzw.} 2,5 \mu \mathrm{l}$ \\
\hline Primer (sense und anti-sense) & $1 \mu \mathrm{M}$ \\
\hline $\mathrm{MgCl}_{2}$ & $2 \mathrm{mM}$ \\
\hline dNTP's (Mix) & $2 \mathrm{mM}$ \\
\hline Dream Taq DNA-Polymerase & $0,5 \mathrm{U} / 12 \mu \mathrm{lbzw} .1 \mathrm{U} / 25 \mu \mathrm{l}$ \\
\hline \multicolumn{2}{|l|}{ Die Fortsetzung der Tabelle erfolgt auf der nächsten Seite. } \\
\hline
\end{tabular}


Material und Methoden

\begin{tabular}{|l|l|}
\hline DNA (Arbeitslösung c $=\sim 300 \mathrm{ng} / \mu \mathrm{l})$ & $\begin{array}{l}\text { ca. } 30 \mathrm{ng} \text { für } 12 \mu \mathrm{l} \text { PCR-Ansatz bzw. } 60 \mathrm{ng} \\
\text { für einen } 25 \mu \mathrm{l} \text { PCR-Ansatz }\end{array}$ \\
\hline demineralisiertes Wasser (autoklaviert) & $\begin{array}{l}\text { zum Auffüllen, Gesamtvolumen für den } \\
\text { PCR-Ansatz mit } 12 \text { oder } 25 \mu \mathrm{l}\end{array}$ \\
\hline
\end{tabular}

Das Ergebnis dieses PCR-Assays ist die sogenannte ribosomale Internal Transcribed Spacer Sequenz (ITS). Das erhaltene Fragment variierte je nach Isolat zwischen 690 und 810 bp. Die Sequenz ist hoch spezifisch und kann im Fall von Rhizoctonia ssp. zur molekularen Identifikation der Anastomosegruppe dienen (Tab. 10).

Tabelle 10: ITS-Primer mit Angabe der Verwendung, Sequenz, Literaturquelle, Anlagerungstemperatur und der zu erwartenden Fragmentgröße nach erfolgter Amplifikation der ITS-Sequenz (Internal Transcribed Spacer) im Pilzgenom

\begin{tabular}{|l|l|l|l|l|l|}
\hline Verwendung & $\begin{array}{l}\text { Bezeich- } \\
\text { nung }\end{array}$ & $\begin{array}{l}\text { Sequenz in } \\
\mathbf{5}^{\prime}-3^{\prime} \text { Orientierung }\end{array}$ & $\begin{array}{l}\text { Literatur- } \\
\text { quelle } \\
\text { Test der DNA }\end{array}$ & $\begin{array}{l}\text { Anlagerungs- } \\
\text { temperatur }\end{array}$ & $\begin{array}{l}\text { Fragment } \\
\text {-größe }\end{array}$ \\
\hline $\begin{array}{l}\text { Tem } \\
\text { auf PCR- } \\
\text { Tauglichkeit }\end{array}$ & $\begin{array}{l}\text { TCC TCC GCT } \\
\text { TAT TGA TAT GC }\end{array}$ & $\begin{array}{l}\text { White et } \\
\text { al., 1990 }\end{array}$ & $57^{\circ} \mathrm{C}$ & $690-810$ \\
ITS & $\begin{array}{l}\text { GGA AGT AAA } \\
\text { AGT CGT AAC } \\
\text { AAG G }\end{array}$ & & & \\
& & bp & & \\
\end{tabular}

PCR-Reaktionen wurden stets auf Eis angesetzt. Dazu wurde zunächst das PCR-Wasser in einem $1,5 \mathrm{ml}$ Reaktionsgefäß vorgelegt. Anschließend wurden nacheinander PCRPuffer, Magnesiumchlorid, Primer, dNTP's und die DNA-Polymerase hinzugegeben. Der so entstandene Mastermix wurde gut gemischt und anschließend auf 0,2 ml PCR-Reaktionsgefäße aufgeteilt. Bei Anwendung der ITS-PCR wurden in jedes Gefäß 11,5 $\mu$ l Reaktionsmix appliziert. Letztlich wurden zu jedem Reaktionsgefäß $0,5 \mu \mathrm{l}$ der DNA (vorliegend in Arbeitsverdünnung, c = $300 \mathrm{ng} / \mu \mathrm{l}$ ) hinzugegeben. Generell wurden zur Qualitätssicherung bei jeder PCR eine Positiv-, eine Negativ- und eine Wasserkontrolle mit eingesetzt. Bei der ITS-PCR diente eine wiederholt eingesetzte, funktionale DNA als Positivkontrolle, eine Negativkontrolle gab es bei dieser PCR aufgrund fehlender Spezifität nicht. In der Wasserkontrolle wurde die Template-DNA durch ein entsprechendes Volumen an Wasser ersetzt. Auf diese Weise konnten das verwendete Wasser und die verwendeten Bestandteile auf mögliche Verunreinigungen geprüft werden. Die fertig präparierten Ansätze wurden sogleich in die PCR-Maschine überführt. Die nachfolgende Tabelle zeigt das verwendete PCR-Programm. 
Material und Methoden

Tabelle 11: PCR-Programm für die ITS-PCR (Internal Transcribed Spacer- Polymerasekettenreaktion) mit Angabe der Syntheseschritte 1 bis 6, deren Temperatur und Laufzeit

\begin{tabular}{|l|l|c|l|}
\hline ITS-PCR & Syntheseschritte & Temperatur & Laufzeit \\
\hline & 1. Denaturierung der DNA & $96^{\circ} \mathrm{C}$ & $30 \mathrm{~min}$ \\
\hline Durchlaufen der & 2. Denaturierung der DNA & $96^{\circ} \mathrm{C}$ & $30 \mathrm{~s}$ \\
Schritte 2.-4. zu & 3. Anlagerungstemperatur & $57^{\circ} \mathrm{C}$ & $30 \mathrm{~s}$ \\
30 Zyklen & 4. Synthese & $72^{\circ} \mathrm{C}$ & $30 \mathrm{~s}$ \\
\hline & 5. Abschlusssynthese & $72^{\circ} \mathrm{C}$ & $10 \mathrm{~min}$ \\
\hline & 6. Kurzzeitige Lagerung & $12^{\circ} \mathrm{C}$ & $\infty$ \\
\hline
\end{tabular}

Nachdem der PCR-Lauf abgeschlossen war, wurden die Proben unter Verwendung einer Flachbettgelelektrophorese aufgetrennt und ausgewertet. Zunächst wurde die gesamte Probe mit DNA-Ladepuffer vermengt, um diese einerseits zu beschweren und um zweitens mögliche nachfolgende enzymatische Reaktionen durch eine Verschiebung des pH-Werts zu unterbinden. Schließlich wurden die Proben in die Taschen eines 1\% Agarosegels eingefüllt und im elektrischen Spannungsfeld der Elektrophoresekammer der Größe nach aufgetrennt. Als Größenstandard dienten $3 \mu$ eines 100 bp-DNA-Markers (Gene Ruler 100 bp Plus DNA Ladder, c = 0,5 $\mu \mathrm{g} / \mu \mathrm{l}$; Lot-Nr. 00050227; Fermentas). Dieser trennte sich auf in 14 Fragmente, welche eine Messgröße von 100 bp bis 3000 bp abdeckten.

\subsubsection{Differenzierung zwischen $R$. cerealis $A G D$ und $R$. solani}

Zur Unterscheidung von $R$. solani und $R$. cerealis AGD mittels PCR-Assay wurden spezifische Primer verwendet. Die nachfolgende Tabelle gibt die verwendeten Primersequenzen wieder (Tab. 12). In der RS $_{A G x}-P C R$ wird eine Teilsequenz des ITSSequenzabschnittes amplifiziert. Durch die Wahl der spezifischen Primer ist der Assay in der Lage, zwischen $R$. cerealis AG D und $R$. solani zu unterscheiden. Zur Bestimmung der genauen Anastomosegruppe von $R$. solani ist der PCR-Assay nicht geeignet. Für diesen Informationsgewinn wäre die Sequenzierung des ITS-Abschnittes nötig. Die für $R$. cerealis $A G D$ spezifische PCR wurde ursprünglich für einen qualitativen Realtime-PCR-Assay entwickelt (Guo et al., 2012), wurde aber in der vorliegenden Arbeit als spezifische Nachweismethode für $R$. cerealis AG D verwendet. Die zu erwartende Fragmentgröße beläuft sich auf $138 \mathrm{bp}$. Für die Auftrennung im Agarosegel wurde ein 50 bp-Marker als 
Material und Methoden

Größenstandard verwendet. Dabei handelt es sich um ein Gemisch, welches sich in 13 Fragmente aufteilt. Die Messbreite reicht dabei von 50 bp bis $1000 \mathrm{bp}$.

Im Folgenden wird die für $R$. cerealis AG D spezifische PCR als RC-PCR bezeichnet. Die für $R$. solani $A G \times$ spezifische $P C R$ wird im Folgenden als $R_{A G x}-P C R$ bezeichnet. Der Zusatz „X“ meint, dass die Anastomosegruppe nicht bestimmt werden kann. Für das PCRReaktionsgemisch wurde ein Gesamtvolumen von $25 \mu$ verwendet.

Tabelle 12: Verwendete Primerpaare für den PCR Nachweis für $R$. cerealis AG D (RC-PCR) und $R$. solani ( $\left.R S_{A G x}-P C R\right)$ mit Angabe von Sequenz, Literaturquelle, Anlagerungstemperatur und der zu erwartenden Fragmentgröße nach erfolgter Amplifikation

\begin{tabular}{|c|c|c|c|c|c|c|}
\hline Assay & $\begin{array}{l}\text { Pilznach- } \\
\text { weis }\end{array}$ & $\begin{array}{l}\text { Primer- } \\
\text { paar }\end{array}$ & $\begin{array}{l}\text { Sequenzdaten } \\
5^{\prime}-3^{\prime} \\
\text { Orientierung }\end{array}$ & $\begin{array}{l}\text { Literatur- } \\
\text { quelle }\end{array}$ & $\begin{array}{c}\text { Anlage- } \\
\text { rungs- } \\
\text { tempe- } \\
\text { ratur }\end{array}$ & $\begin{array}{l}\text { Fragment- } \\
\text { größe bp }\end{array}$ \\
\hline \multirow[t]{2}{*}{$\begin{array}{l}\text { RC- } \\
\text { PCR }\end{array}$} & \multirow[t]{2}{*}{$\begin{array}{l}\text { R. cerealis } \\
\text { (RC) AG D }\end{array}$} & RtubF4 & $\begin{array}{l}\text { CCT AAA TGA } \\
\text { GTC TGG AGT } \\
\text { AAG TC }\end{array}$ & \multirow[t]{2}{*}{$\begin{array}{l}\text { Guo et al., } \\
2012\end{array}$} & \multirow[t]{2}{*}{$65^{\circ} \mathrm{C}$} & \multirow[t]{2}{*}{$138 \mathrm{bp}$} \\
\hline & & RtubR4 & $\begin{array}{l}\text { GCT AGT GCG } \\
\text { GTC AAT GTA } \\
\text { TAG }\end{array}$ & & & \\
\hline \multirow[t]{2}{*}{$\begin{array}{l}\mathrm{RS}_{\mathrm{AGx}}{ }^{-} \\
\mathrm{PCR}\end{array}$} & \multirow[t]{2}{*}{$\begin{array}{l}\text { R. solani } \\
\text { (RS) } \\
\text { AG 1-14 }\end{array}$} & $\mathrm{ITS}_{1}$ & $\begin{array}{l}\text { TCC GTA GGT } \\
\text { GAA CCT GCG } \\
\text { G }\end{array}$ & $\begin{array}{l}\text { White et al., } \\
1990\end{array}$ & \multirow[t]{2}{*}{$60^{\circ} \mathrm{C}$} & \multirow[t]{2}{*}{$550 \mathrm{bp}$} \\
\hline & & GMRS3 & $\begin{array}{l}\text { AGT GGA ACC } \\
\text { AAG CATA ACA } \\
\text { CT }\end{array}$ & $\begin{array}{l}\text { Johanson et } \\
\text { al., } 1998\end{array}$ & & \\
\hline
\end{tabular}

Nachfolgend werden die einzelnen Syntheseschritte für die jeweilige PCR aufgeführt (Tab. 13).

Tabelle 13: PCR-Programm für die RC-PCR und die RS $_{A G x}-P C R$ mit Angabe der Temperatur und Zeit des jeweiligen Syntheseschrittes

\begin{tabular}{|c|c|c|c|c|c|}
\hline \multirow{2}{*}{$\begin{array}{c}\text { RS }_{\text {AGx }}-\mathrm{PCR} / \\
\mathrm{RC}-\mathrm{PCR}\end{array}$} & \multirow[t]{2}{*}{ Syntheseschritte } & \multicolumn{2}{|c|}{ Temperatur } & \multicolumn{2}{|c|}{ Zeit } \\
\hline & & $\begin{array}{l}\text { RC- } \\
\text { PCR }\end{array}$ & $\begin{array}{l}\mathrm{RS}_{\mathrm{AG} \mathrm{x}^{-}} \\
\mathrm{PCR}\end{array}$ & $\begin{array}{l}\text { RC- } \\
\text { PCR }\end{array}$ & $\begin{array}{l}\text { RS } \text { AGx- }^{-} \\
\text {PCR }\end{array}$ \\
\hline & 1. Denaturierung der DNA & \multicolumn{2}{|c|}{$96^{\circ} \mathrm{C}$} & \multicolumn{2}{|c|}{$30 \mathrm{~min}$} \\
\hline \multirow{3}{*}{$\begin{array}{l}\text { Durchlaufen der } \\
\text { Schritte 2.-4. zu } \\
\text { RC-PCR: } 35 \\
\text { RS }_{\text {AGx }} \text {-PCR: } 30 \\
\text { Zyklen }\end{array}$} & \multirow{3}{*}{$\begin{array}{l}\text { 2. Denaturierung der DNA } \\
\text { 3. Anlagerungstemperatur } \\
\text { 4. Synthese }\end{array}$} & \multicolumn{2}{|c|}{$96^{\circ} \mathrm{C}$} & \multicolumn{2}{|c|}{$30 \mathrm{~s}$} \\
\hline & & \multicolumn{2}{|c|}{\begin{tabular}{l|l}
$60^{\circ} \mathrm{C}$ & $57^{\circ} \mathrm{C}$ \\
\end{tabular}} & \multicolumn{2}{|c|}{$30 \mathrm{~s}$} \\
\hline & & \multicolumn{2}{|c|}{$72^{\circ} \mathrm{C}$} & $25 \mathrm{~s}$ & $30 \mathrm{~s}$ \\
\hline & 5. Abschlusssynthese & \multicolumn{2}{|c|}{$72^{\circ} \mathrm{C}$} & \multicolumn{2}{|c|}{$10 \mathrm{~min}$} \\
\hline & 6. Lagerung & \multicolumn{2}{|c|}{$12^{\circ} \mathrm{C}$} & \multicolumn{2}{|c|}{$\infty$} \\
\hline
\end{tabular}


Material und Methoden

\subsection{Anlage und Auswertung der Feldversuche}

Im Rahmen der Arbeit wurden zwei Feldversuche angelegt und bearbeitet. Im anschließenden Absatz wird der Versuch auf der Großfeldanlage in Weende beschrieben. Das anschließende Kapitel erläutert den Feldversuch auf der „Göttinger Bodenerwärmungsanlage“. Auf dieser speziellen Feldversuchsfläche wird mittels Kleinparzellen gearbeitet, welche über im Boden verlegte Heizkabel künstlich erwärmt werden können. Dadurch ist es möglich, die Bodentemperatur präzise zu erhöhen und so wärmere klimatische Bedingungen zu simulieren.

\subsubsection{Künstliche Rhizoctonia-Inokulation im Feld}

Im Jahr 2011 wurde nahe der Ortslage Weende ein Feldversuch angelegt und künstlich mit Rhizoctonia sp. inokuliert. Im Feldversuch Weende 2011/12 wurden die Prüfglieder Winterweizensorte, Aussaatzeitpunkt und Inokulationsvariante untersucht. Das verwendete Saatgut war mit Arena C gebeizt. In einer teilrandomisierten Split-Blockanlage wurde zu einem frühen (28.09.2011) und zu einem späteren Termin (21.10.2011) ausgesät. Von jeder Variante wurden insgesamt vier Wiederholungen angesetzt. Die Parzellengröße betrug 3 mal $8 \mathrm{~m}$ (Abb. 3).

\begin{tabular}{|c|c|c|c|c|c|c|}
\hline $\mathrm{d}$ & 4 & 1 & 2 & 3 & 6 & 5 \\
\hline $\mathrm{c}$ & 6 & 3 & 5 & 1 & 4 & 2 \\
\hline $\mathrm{b}$ & 5 & 4 & 6 & 2 & 3 & 1 \\
\hline $\mathrm{a}$ & 1 & 2 & 3 & 4 & 5 & 6 \\
\hline
\end{tabular}

Abbildung 3: Lateinisches Rechteck nach Lochow et al. (1961) zur Anlage des Feldversuchs mit sechs Varianten (1 bis 6) zu je vier Wiederholungen, indem jede Variante an wechselnder Position der Reihen a bis d aufgerführt wurde und dies insgesamt 4-mal

Nach erfolgter Bodenbearbeitung (Pflug, Kreiselegge) wurden 300 keimfähige Körner pro Quadratmeter mit einer Saattiefe von $3 \mathrm{~cm}$ ausgedrillt. Die Aussaat erfolgte unter Einsatz einer Parzellendrillmaschine. Das Inokulum bestehend aus $R$. cerealis AG D (IPP-Nr. 0931) und R. solani AG 5 (IPP-Nr. 1047) wurde direkt nach der Aussaat auf der zu inokulierenden Parzelle ausgebracht. Die Inokuli beider Isolate wurde direkt vor dem Ausbringen zu gleichen Teilen gemischt. Zur Parzelleninokulation wurden insgesamt $400 \mathrm{~g}$ Inokulum pro Parzelle $\left(16,6 \mathrm{~g} / \mathrm{m}^{2}\right)$ per Hand gleichmäßig ausgestreut und durch leichtes Einharken in Drillrichtung mit einer Fächerharke in die obere Bodenschicht eingearbeitet. Im Feldversuch wurde auf eine explizite Fungizidmaßnahme gegen Halmbasiserreger verzichtet. 
Material und Methoden

Ansonsten erfolgte eine praxisübliche Anwendung von Pflanzenschutzmaßnahmen, Wachstumsreglern und Düngern. Die Schlagdatei mit detaillierten Angaben befindet sich im Anhang. Die Inokulumproduktion wird im Abschnitt 2.7.4 beschrieben.

\subsubsection{Feldversuch mit künstlicher Rhizoctonia-Inokulation in der Göttinger Boden-erwärmungsanlage (Kleinparzellen)}

Auf der Feldversuchsanlage "Göttinger Bodenerwärmungsanlage" ist es möglich, die Bodentemperatur durch im Erdreich verlegte Heizkabel - extern gesteuert - zu erhöhen. Dafür ist eine unbeheizte Referenzparzelle nötig, die eine gegebene Ist-Temperatur vorgibt (im Versuch bezeichnet als: Temperaturvariante „ohne Erwärmung“). Anhand der IstTemperaturmessung kann die Bodentemperatur in den übrigen Parzellen eine konstante simultane Temperaturerhöhung erfahren. Temperaturdaten in 5 und $15 \mathrm{~cm}$ Bodentiefe sowie in der Luft und weitere metereologische Wetterdaten wie Luftfeuchte und Niederschlag wurden von einer Wetterstation erfasst. Zur Einhaltung einer Wiederholungsanzahl von 4 wurden die insgesamt zwölf Parzellen den Temperaturvarianten wie nachfolgend aufgeführt zugeteilt:

- Parzellen Nr. 1, 6, 8, 10: Temperaturvariante „ohne Erwärmung“ = unbeheizte Kontrollparzellen/ Ist- Temperatur als Referenz

- Parzellen Nr. 2, 5, 9, 12: Temperaturvariante „leicht erwärmt" $=\Delta+1,6^{\circ} \mathrm{C}$

- Parzellen Nr. 3, 4, 7,11: Temperaturvariante „stark erwärmt“ $=\Delta+3,2^{\circ} \mathrm{C}$

Auf der Bodenerwärmungsanlage erfolgte die Aussaat per Hand. Zunächst wurde die oberste Bodenschicht mittels Gartenhacke gelockert. Durch den Einsatz einer Fächerharke wurde eine zur Aussaat geeignete Krümelstruktur erzeugt. Daraufhin wurden die Parzellen in Viertel unterteilt, indem mit einem Gartenband aus Plastik Trennwände eingezogen wurden. Auf jedem Viertel wurden mittels Drillreihenziehers 7 Reihen gezogen. In jede Reihe wurden per Hand 2,84 g Saatgut der Sorte Toras (Tab. 4; Beize: Arena C; 300 keimfähige Körner/ $\mathrm{m}^{2}$ ) eingesät. Die Inokulation erfolgte mit $11,4 \mathrm{~g}$ Inokulum/ $\mathrm{m}^{2} \mathrm{der}$ jeweiligen AG (s.u.) direkt in die Drillreihen. Neben einer nicht inokulierten Gesundkontrolle wurde mit drei Erregerformen (Tab. 3) gearbeitet, die wie folgt gehandelt werden:

- A: AG 5 (IPP-Nr. 1047)

- B: AG 1-IB (IPP-Nr. 1056)

- C: Gesundkontrolle (ohne Inokulation) 
Material und Methoden

- D: AG D (IPP-Nr. 0931)

Nachdem Saatgut und Inokulum ausgebracht waren, konnten die Drillreihen mit Erde bedeckt werden, indem die Bodenoberfläche mit einer umgedrehten Fächerharke glattgezogen wurde. Die Abbildung 4 verdeutlicht den Versuchsaufbau. Auf der Bodenerwärmungsanlage wurde auf eine explizite Fungizidmaßnahme gegen Halmbasiserreger, wie sie zu Schossbeginn überlicherweise durchgeführt wird, verzichtet. Ansonsten erfolgte eine praxisübliche Anwendung von Pflanzenschutzmaßnahmen, Wachstumsreglern und Düngern. Zur Schneckenbekämpfung wurde bedarfsgerecht „Schneckenkorn“ (Wirkstoff: Metaldehyd, Bezug: Neudorff) per Hand nach Herstellerangabe ausgebracht. Die Schlagdatei mit detaillierten Angaben befindet sich im Anhang.
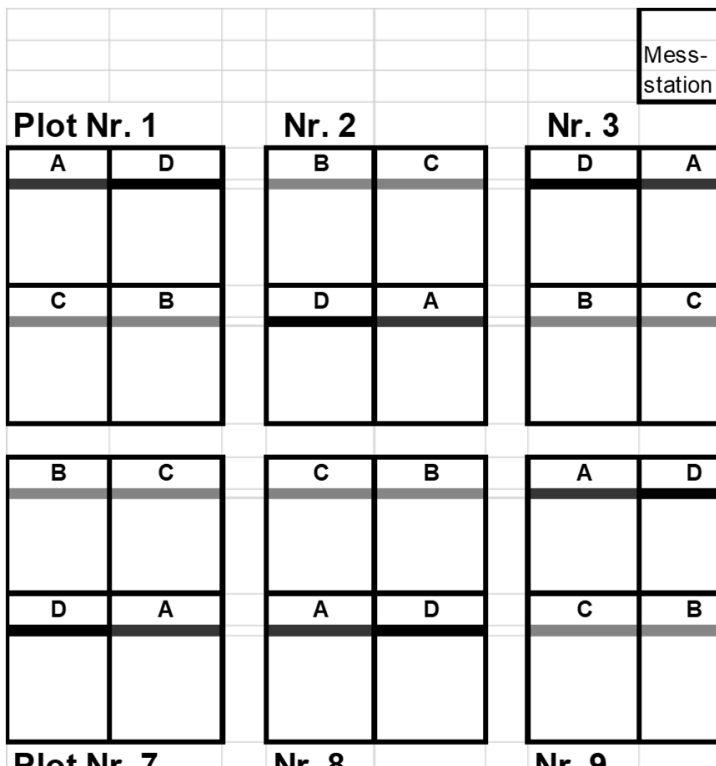

Nr. 3
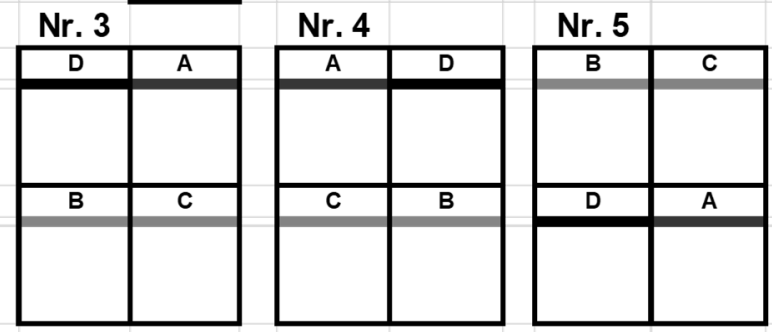

Nr. 6
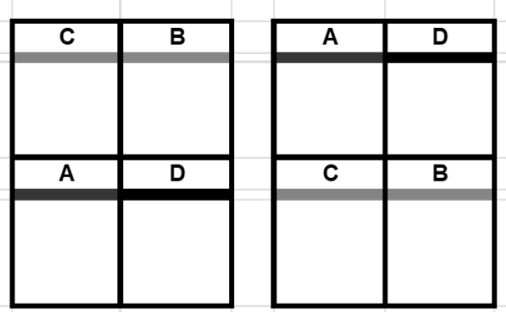

Nr. 9

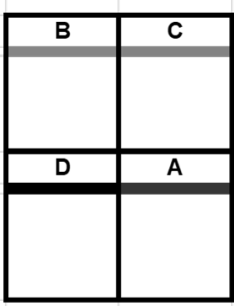

Nr. 10

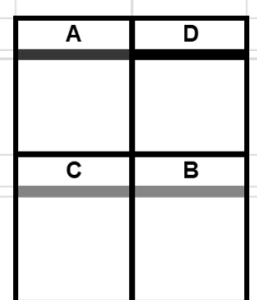

Nr. 11
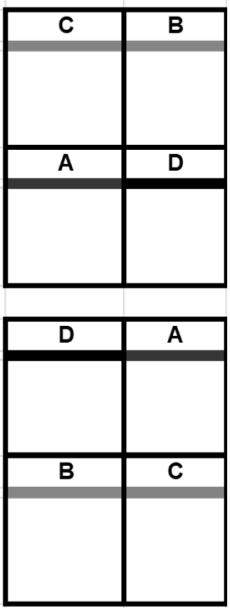

Nr. 12

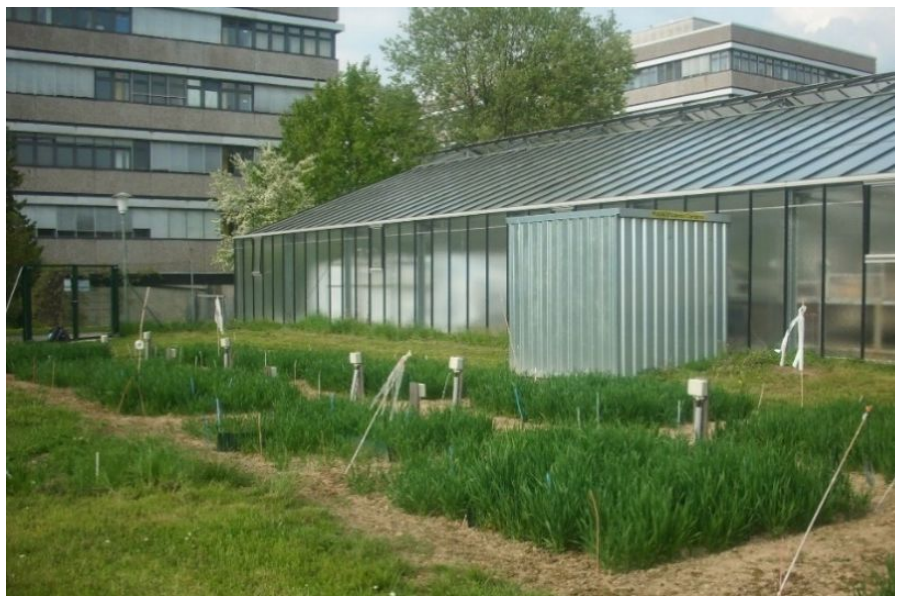


Material und Methoden

Abbildung 4: Versuchsaufbau (schematisch und als Foto) auf der Göttinger Bodenerwärmungsanlage im Temperatur- und Inokulationsversuch mit Winterweizen der Sorte Toras (Arena C gebeizt, Aussaat 10.10.2012, 300 keimfähige Körner pro $\mathrm{m2}$ ) gefahren wurde mit den drei Temperaturvarianten $(n=4)$ „ohne Erwärmung“ (Parzelle Nr. 1, 6, 8, 10), „leicht erwärmt/ $\Delta+1,6^{\circ} \mathrm{C}$ “ (Parzelle Nr. 2, 5, 9, 12) und „stark erwärmt/ $\Delta+3,2^{\circ} C^{\prime \prime}$ (Parzelle Nr. 3, 4, 7, 11) sowie den Inokulationsvarianten $\left(n=4 ; 11,4 \mathrm{~g} / \mathrm{m}^{2}\right)$ auf je einer Viertelparzelle mit $R$. solani AG 5 (A), R. solani AG-1BI (B), R. cerealis AG D (D) und der Gesundkontrolle (C); Orientierungshilfe: auf dem Foto ist im Vordergrund vollständig die Parzelle Nr. 10 „ohne Erwärmung“ zu sehen, die Messstation ist direkt dahinter gelegen.

\subsubsection{Erfassung und Aufbereitung meteorologischer Daten}

Meteorologische Wetterdaten Punkt 1, 3 und 4 für den Feldversuch am Standort WeendeGöttingen in der Vegetationsperiode 2011/ 2012 (Abk.: „Weende 2011/ 12“) wurden von der Wetterstation Göttingen bezogen. Punkt 2 wurde direkt am Standort gemessen.

1. Mittlere Tagestemperatur in Grad Celsius

2. Mittlere Tagestemperatur des Bodens in $5 \mathrm{~cm}$ und $15 \mathrm{~cm}$ Tiefe in Grad Celsius

3. Relative Luftfeuchte in \% (Tagesmittelwert)

4. Niederschlag in $\mathrm{mm} / \mathrm{Tag}$

Des Weiteren wurden die monatlich herausgegebenen Schriften zum regionalen Wetter des Deutschen Wetterdienstes herangezogen und zusammenfassend dargestellt.

Im Falle der Göttinger Bodenerwärmungsanlage wurden Wetterdaten von einer im Versuch integrierten Wetterstation bezogen (Vegetationsperiode 2012/ 2013). Neben den oben bereits aufgeführten Parametern wurde des Weiteren die Bodenfeuchte erfasst. Sämtliche Parameter wurden im 5-minütigen Zeitabstand gemessen (288 Messungen pro Tag). Zwecks Überprüfung der zu erzielenden konstanten Temperaturdifferenzen von $\Delta+1,6^{\circ} \mathrm{C}$ (Temperaturvariante „leicht erwärmt“) bzw. $\Delta+3,2^{\circ} \mathrm{C}$ (Variante „stark erwärmt“) wurden von der tatsächlich gemessenen Temperatur der jeweiligen Temperaturvariante der Messwert der Referenz-Variante „ohne Erwärmung“ subtrahiert. Dabei wurden zwecks Vereinfachung der Mittelwert pro Tag aller der Variante jeweils zugehörigen Parzellen verwendet. Es sollten dabei erwartungsgemäß alle Datenpunkte bei $+1,6^{\circ} \mathrm{C}$ bzw. $+3,2^{\circ} \mathrm{C}$ liegen. Die Überprüfung wurde getrennt für $5 \mathrm{~cm}$ und $15 \mathrm{~cm}$ Bodentiefe vorgenommen. Die Darstellung erfolgte als Graph.

\subsubsection{Erfassung von Bestandes- und Ertragsparametern}

Zur Charakterisierung des Pflanzenbestands wurden innerhalb der Vegetationsperiode beschreibende Parameter erfasst. Im Feldversuch wurde zur Markierung der 
Material und Methoden

auszuzählenden Fläche ein quadratischer Zählrahmen benutzt. Dieser Rahmen erfasste eine Fläche von 0,25 $\mathrm{m}^{2}$. Der Zählrahmen wurde so in der Parzelle platziert, dass insgesamt 4 Drillreihen eingerahmt wurden. Insgesamt wurde 3-mal pro Parzelle gezählt, sodass drei Werte zur Errechnung eines repräsentativen Mittelwertes pro Parzelle zur Verfügung standen. Eine einzelne Parzelle stellte dabei eine von insgesamt vier Wiederholungen dar. Auf der Göttinger Bodenerwärmungsanlage wurden von den gesamt sieben Drillreihen jeweils die zweite, vierte und sechste Reihe ausgezählt. Zur Erfassung des Pflanzenbestandes wurden der Auflauf vor Winter sowie der Winterausfall nach Winter als [grüne Triebe/ $\mathrm{m}^{2}$ ] erfasst. Im späten Reifestadium der Pflanzen wurde des Weiteren der Parameter [Ähren tragende Halme/ $\mathrm{m}^{2}$ ] erhoben.

Zur Ertragsermittlung wurden folgende Parameter erfasst:

- Kornzahl/ Ähre

- Tausenkornmasse TKM

- Kornertrag in $\mathrm{dt} / \mathrm{ha}$

Nach abgeschlossener Reife wurden die Parzellen mittels Parzellenmähdrescher abgeerntet. Dabei wurde der gesamte Ertrag einer jeden Parzelle gedroschen und ausgewogen. Noch am Erntetag wurde eine Stichprobe von $250 \mathrm{~g}$ entnommen. Anhand der Stichprobe wurden der Fremdbesatz und die Kornfeuchte ermittelt. Zur Bestimmung der Feuchte wurde die Probe für 24 Stunden bei $105^{\circ} \mathrm{C}$ Celsius getrocknet und sogleich rückgewogen. Auf Grundlage dieser zwei Werte (gegebene Feuchte und 0\% Feuchte) wurde der Ertrag bei optimaler Feuchte (bei Weizen 14,5\%) errechnet. Zur Bestimmung des Besatzes wurde die Probe am Tag der Messdurchführung erneut gewogen. Anschließend wurde die Probe in der Getreidereinigung von Spelzen und anderen Verunreinigungen befreit und erneut gewogen. Der prozentuale Fremdbesatz konnte nun von jeder Probe subtrahiert werden. Letztlich erfolgte eine bereinigte Ertragsangabe in $\mathrm{dt} /$ ha mit einer Feuchte von 14,5\%. Von der gereinigten Probe wurde nachfolgend eine kleine Probe abgenommen, ausgezählt und gewogen. Schließlich wurde die Masse auf 1000 Körner umgerechnet, um die TKM zu erhalten. Auf der Bodenerwärmungsanlage war eine Ertragserfassung in der oben beschriebenen Form nicht möglich. Es wurden lediglich die Parameter [Körner/ Ähre] und die TKM bestimmt. Die TKM wurde ebenfalls durch Rücktrocknung bei $105^{\circ} \mathrm{C}$ die Feuchte ermittelt, sodass eine TKM bei $14,5 \%$ angegeben werden konnte. Zur Bestimmung der [Kornzahl/ Ähre] wurden gegen Ende der Vegetationsperiode 50 Ähren aus den Feldversuchsparzellen und 20 Ähren aus den 
Material und Methoden

Kleinparellen entnommen, gedroschen und von Spelzen gereinigt. Schließlich wurde die Anzahl der Körner unter Zuhilfenahme eines Zählgeräts bestimmt und ein Mittelwert Anzahl Körner pro Ähre errechnet.

\subsubsection{Ermittlung der Befallshäufigkeit mit Rhizcotonia}

Innerhalb der Vegetationsperiode wurden mehrere Bonituren auf Rhizoctonia zu verschiedenen Wachstumsstadien der Pflanzen durchgeführt. Neben dem in der Literatur beschriebenen klassischen Boniturtermin in der Milchreife wurden weitere frühere Bonituren angesetzt. Der Feldversuch in Weende 2011/12 wurde insgesamt 4-mal beprobt und bonitiert: $\mathrm{BBCH}$ 25, 35, 55 und 75. Der Feldversuch auf der Göttinger Bodenerwärmungsanlage 2012/13 wurde in geringem Stichprobenumfang in BBCH 30 und abschließend in $\mathrm{BBCH} 75$ beprobt. Die Termine zur Probenahme wurden in Abhängigkeit vom Entwicklungsstadium der Pflanzen angesetzt. Zum frühesten Boniturtermin (BBCH 25 - 35) wurden die Pflanzen mit einem Spaten samt Boden ausgegraben. An den späteren Bonituren (ab BBCH 39) wurden die Pflanzen per Hand aus dem Boden herausgezogen. Durchschnittlich wurden 65 Pflanzen pro Boniturtermin und Parzelle bonitiert. Zur Bonitur in der Milchreife wurden 85 Pflanzen pro Parzelle bonitiert. Die Pflanzen wurden zufallsverteilt per Hand aus der Parzelle entnommen und zu Bündeln verschnürt. Eine kurzzeitige Lagerung erfolgte locker verpackt in Plastikfolie bei $10^{\circ} \mathrm{C}$ Celsius im Dunkeln. Zur Erfassung des Befalls wurden die Pflanzen in Wasser gereinigt und der Befall pro Pflanze ermittelt. Die nachfolgende Aufbereitung der Pflanzen wird in Abschnitt 2.8.2 beschrieben. Der Erregernachweis erfolgte mittels PDA-Abgleichtest (Abschnitt 2.13) und durch das PCR-Assay (Abschnitt 2.14).

\subsection{Statistische Auswertung}

Die statistische Auswertung erfolgte mit der Software STATISTICA (Tab. 5).

Prüfung auf Normalverteilung und Datentransformation bei nicht normalverteilten Daten

Zu Beginn der Analyse wurden die Daten durch zwei Verfahren auf Normalverteilung geprüft. Um zunächst einen visuellen Eindruck über die Datenverteilung zu erhalten, wurde ein Quantil-Quantil-Plot erstellt. Dabei werden die Daten als Punkte dargestellt, die bei gegebener Normalverteilung einem bestimmten Verlauf folgen. Bei intervallskalierten Daten befinden sich die Datenpunkte auf einer Geraden mit linearem Verlauf ins Positive. Bei ordinalskalierte Daten zeigt sich bei Normalverteilung eine Datenverteilung im Rechteck. 
Material und Methoden

Anschließend wurde im zweiten Verfahren ein Chi-Quadrat-Test durchgeführt. Konnte die Nullhypothese mit einem p-Wert größer 0,05 abgelehnt werden, waren die Daten normal verteilt. Schließlich folgte für normalverteilten intervallskalierten Daten für eine statistische Analyse mittels nicht-transformierender ANOVA. Waren die Daten hingegen nicht normalverteilt wurde im GLM unter Verteilungsanpassung weitergearbeitet, welche von Statistica automatisch vorgenommen wird. Unter Anwendung der Transformation lässt sich dann eine ANOVA Analyse vornehmen. Für ordinalskalierte Daten wurde ein nicht parametrisches Testverfahren, der Kruskal-Wallis-Test, verwendet.

Betrachtung der Effektgröße und der Teststärke

Generell erfolgte zu Beginn der Datenauswertung eine Betrachtung hinsichtlich der Effektgrößen der Prüffaktoren. Wenn Faktoren als nicht-gültiger Effektgröße ( $p$-Wert ist $>0,05)$ ausgeschlossen werden konnten, wurde eine erneute Betrachtung ohne diesen Faktor durchgeführt, falls dies möglich war. Als Maß für die Zulässigkeit des verwendeten Tests zur Abbildung des biologischen Systems wurde die Teststärke betrachtet. Diese musste für die korrekte Abbildung einen Wert von 0,9 oder $>0,9$ haben. Letztlich wurde ein Fisher LSD Test mit alpha = 0,05 durchgeführt. Das Ergebnis der Signifikanzanalyse wurde in Form von Minuskeln wiedergegeben. Falls innerhalb einer Tabelle zwei statistische Auswertungen dargestellt wurden, wurde zur Unterscheidung mit Minuskeln und Manuskeln gearbeitet.

Art der Darstellung

Die Ergebnisse wurden als Tabelle oder als Säulendiagrammn mit positiver Standardabweichung SD dargestellt. 
Ergebnisse

\section{Ergebnisse}

\subsection{Monitoring des Vorkommens von Rhizoctonia in Deutschland}

Tabelle 14 zeigt den natürlichen Befall mit Rhizoctonia, wie er in Winterweizenschlägen an verschiedenen Standorten in Deutschland 2012 erhoben werden konnte. Insgesamt wurden 15 Standorte beprobt. Das Befallsniveau mit Rhizoctonia war allgemein sehr niedrig. So wurde an 8 Standorten eine Befallshäufigkeit von unter 1,6\% beobachtet. Darunter fielen die Standorte Blankenhagen (4.1 und 4.2), Gerdshagen (5), Düpow (6), Rottmersleben (8), Roßleben (9), Thiemendorf (10), Sora (12) und Borwede (13.1). An 3 Standorten lag die Befallshäufigkeit unter 3\%: Ostenfeld (1), Borwerde (13.2) und Obbornhofen (14). Zwischen 3 und 6\% Befall traten auf in Birkemoor (2), Futterkamp (3) und Neugattersleben (7) auf. An lediglich zwei Standorten lag die Befallshäufigkeit mit Rhizoctonia über 10\%: Methau (11) und Tigerfeld (15).

Tabelle 14: Rhizoctonia-Monitoring 2012 an 15 Standorten in Deutschland dargestellt als Befallshäufigkeit; pro Standort wurden etwa 25 Pflanzen untersucht; an allen Standorten war das Saatgut mit Vibrance gebeizt; k. A. = keine Angabe

\begin{tabular}{|c|c|c|c|}
\hline Nr. & Versuchsstandort & $\begin{array}{c}\text { Winter- } \\
\text { weizensorte }\end{array}$ & $\begin{array}{c}\text { Befallshäufigkeit } \\
\text { Rhizoctonia in \% }\end{array}$ \\
\hline 1 & Ostenfeld & Dekan & 2,1 \\
\hline 2 & Birkenmoor & k. A. & 5,2 \\
\hline 3 & Futterkamp & Tiflis & 4,2 \\
\hline 4.1 & Blankenhagen & k. A. & 0,9 \\
\hline 4.2 & Blankenhagen & k. A. & 0,4 \\
\hline 5 & Gerdshagen & k. A. & 0,3 \\
\hline 6 & Düpow & Sailor & 0,0 \\
\hline 7 & Neugattersleben & k. A. & 6,0 \\
\hline 8 & Rottmersleben & k. A. & 1,2 \\
\hline 9 & Roßleben & Dekan & 1,3 \\
\hline 10 & Thiemendorf & Akteur & 1,4 \\
\hline 11 & Methau & Sailor & 11,3 \\
\hline 12 & Sora & k. A. & 0,4 \\
\hline 13.1 & Borwede & Tiflis & 1,6 \\
\hline 13.2 & Borwede & JB Asano & 2,7 \\
\hline 14 & Obbornhofen & k. A. & 2,2 \\
\hline 15 & Tigerfeld & & 13,1 \\
\hline
\end{tabular}


Ergebnisse

Die Auswertung von Pflanzenproben verschiedener Standorte Deutschlands des Jahres 2013 ergaben eine natürliche Befallshäufigkeit mit Rhizoctonia im Bereich von 0\% bis zu 36,4\% (Tab. 15). Insgesamt wurden 20 Standorte untersucht. An jedem Standort wurde pro Feld eine Mischprobe á 25 Pflanzen gezogen. An einigen Standorten wurden mehrere Versuche beprobt. In 17 Proben konnte keine Rhizoctonia Symptome gefunden werden. Die Befallshäufigkeit wurde mit $0,00 \%$ angegeben. An zwei Probeentnahmeorten konnte eine sehr geringe $\mathrm{BH}$ von unter $1 \%$ ermittelt werden. Zwischen 1 und $3 \% \mathrm{BH}$ war an den Standorten mit den Nummern 18, 29 und 30.2 feststellbar. Ein leichter Befall (3 bis 6\%) konnte an den Standorten 16.1, 34.2 und 35 festgestellt werden. Ein moderater Befall (6 bis $11,7 \%$ ) konnte an den Standorten 30.3, 30.4 und 19.2 ermittelt werden. An den Standort 25 lag die $\mathrm{BH}$ bei $24,4 \%$. Ein hoher Befall zwischen mit $36,4 \%$ lag bei Standort 19.4 Tützpatz vor. Unter einbeziehender Betrachtung weiterer Angaben zur Schlaghistorie und zur Bestandesführung, lassen sich nur wenige Muster erkennen. Bei der Mehrheit der Standorte wurde eine Bodenbearbeitung durch den Einsatz von Pflug, Grubber oder Kreiselegge vorgenommen (Spalte 8). Die Befallshäufigkeit mit Rhizoctonia scheint von dieser Maßnahme unbeeinflusst zu sein. So gibt es gepflügte Standorte mit sehr starkem Befall $(\mathrm{Nr} .20,25)$ neben pfluglos bestellten Flächen mit 0\% Befall (Nr. 17.1, 17.2, 22, 28). Die phytopathologische Erwartungshaltung, dass der Befall durch einen bodenbürtiger Erreger wie Rhizoctonia sp. durch intensive Bodenbearbeitung reduziert würde, kann verneint werden. Bei der Mehrheit der Standorte wurde gebeiztes Saatgut verwendet (Spalte 5). Die Befallshäufigkeit lag zwischen 0 bis zu 36,4\%. Es gab 1 Standorte, an dem ungebeiztes Saatgut verwendet wurde (Nr. 30.5). Bei diesen Standorten lag die Befallshäufigkeit jedoch bei $0 \%$. Betrachtet man die Beize als qualitatives Merkmal, kann man anhand der vorliegenden Daten aussagen, dass die Beizung per se einen RhizoctoniaBefall nicht verhindern kann und dass ungebeiztes Saatgut nicht unmittelbar den Befall begünstigt. Aufgrund der Vorfrucht (Spalte 7) lassen sich keine Aussagen ableiten. Die Auswinterung (Spalte 10) wurde als Faktor mit erhoben. Da die Bestände nicht auswinterten, können diesbezüglich auf den Befall keine Rückschlüsse gezogen werden. Die Bodenart (Spalte 9) beeinflusst das Auftreten von Rhizoctonia in Weizen. So kann häufig ein Befall $(2,1-36,4 \%)$ auf Standorten mit sandigem Lehm (sL) beobachtet werden. 
Tabelle 15: Rhizoctonia-Monitoring 2013 an 21 verschiedenen Standorten in Deutschland zur Ermittlung des natürlichen Rhizoctonia-Befalls an Winterweizen, dargestellt als Befallshäufigkeit (BH), mit Angabe der Schlagdaten (Sorte, Aussaattermin, Ausaatstärke, Beize, Vorfrüchte, Bodenbearbeitung, Winterausfall). An jedem Standort

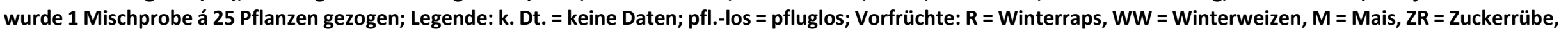
SG = Sommergerste, $\mathbf{G}=$ Gerste, $\mathbf{W G}=$ Wintergerste

\begin{tabular}{|c|c|c|c|c|c|c|c|c|c|c|}
\hline $\mathrm{Nr}$. & $\begin{array}{l}\text { Versuchs- } \\
\text { standort }\end{array}$ & Sorte & $\begin{array}{l}\text { Aussaat } \\
2012\end{array}$ & $\begin{array}{l}\text { Saatgut- } \\
\text { beize }\end{array}$ & $\begin{array}{l}\text { Aussaat- } \\
\text { stärke } \\
\text { kg/ ha }\end{array}$ & $\begin{array}{l}\text { Vorfrucht, } \\
\text { Vorvorfrucht }\end{array}$ & $\begin{array}{l}\text { Boden - } \\
\text { bearb. }\end{array}$ & Bodenart & $\begin{array}{l}\text { Auswin- } \\
\text { terung }\end{array}$ & $\mathrm{BH} \%$ \\
\hline 16.1 & Rothenburg & Schamane & 14.10. & k. Dt. & 360 & SG & Pflug & $\mathrm{L}$ & nein & 5,9 \\
\hline 16.2 & Rothenburg & Linus & 11.10. & $\begin{array}{l}\text { Landor } \\
\text { CT }\end{array}$ & 380 & $R$ & Grubber & LÖß-L & nein & 0,0 \\
\hline 17.1 & Auetal & Asano & \multirow{2}{*}{$\begin{array}{l}\text { Ca. } \\
01.10 .\end{array}$} & \multirow[t]{2}{*}{ Rubin } & \multirow[t]{2}{*}{150} & \multirow[t]{2}{*}{ WW, R } & \multirow[t]{2}{*}{ nein } & \multirow[t]{2}{*}{ k. D. } & \multirow[t]{2}{*}{ nein } & 4,3 \\
\hline 17.2 & Auetal & Julius & & & & & & & & 0,0 \\
\hline 18 & Grabau & Inspiration & 03.10 & $\begin{array}{l}\text { Efa+ } \\
\text { Latitude }\end{array}$ & 185 & WW, R & k. D. & IS & nein & 2,5 \\
\hline 19.1 & \multirow[t]{4}{*}{ Tützpatz } & \multirow[t]{4}{*}{ Bussard } & \multirow{5}{*}{30.09.} & \multirow{5}{*}{$\begin{array}{l}\text { Landor } \\
\text { CT }\end{array}$} & & \multirow{5}{*}{$\begin{array}{l}\text { Hafer, } \\
\text { Erbsen }\end{array}$} & \multirow{5}{*}{ Pflug } & \multirow{5}{*}{$\mathrm{sL}$} & \multirow{5}{*}{ nein } & 0,0 \\
\hline 19.2 & & & & & & & & & & 11,7 \\
\hline 19.3 & & & & & & & & & & 0,0 \\
\hline 19.4 & & & & & & & & & & 0,0 \\
\hline 20 & Merzen & Hermann & & & & & & & & 36,4 \\
\hline 21 & Letschin & Hermann & 25.09. & k. Dt. & k. Dt. & $\mathrm{R}$ & ja & --- & --- & 0,5 \\
\hline 22 & Blankenhagen & Ritmo & 10.09 & k. Dt. & 200 & $\mathrm{R}, \mathrm{WW}$ & pfl.-los & IS & nein & 0,0 \\
\hline 23.1 & Vreden & Smaragd & \multirow[t]{3}{*}{19.10.} & Celest & \multirow[t]{3}{*}{350} & \multirow[t]{3}{*}{ M, Triticale } & \multirow[t]{3}{*}{ Pflug } & \multirow[t]{3}{*}{$\mathrm{S}$} & nein & 0,0 \\
\hline 23.2 & Vreden & Winnetou & & k. Dt. & & & & & etwas & 0,0 \\
\hline 23.3 & Vreden & Inspiration & & Celest & & & & & Nein & 0,0 \\
\hline
\end{tabular}


Ergebnisse

\begin{tabular}{|c|c|c|c|c|c|c|c|c|c|c|}
\hline Nr. & $\begin{array}{l}\text { Versuchs- } \\
\text { standort }\end{array}$ & Sorte & $\begin{array}{l}\text { Aussaat } \\
2012\end{array}$ & $\begin{array}{l}\text { Saatgut- } \\
\text { beize }\end{array}$ & $\begin{array}{l}\text { Aussaat- } \\
\text { stärke } \\
\text { kg/ ha }\end{array}$ & $\begin{array}{l}\text { Vorfrucht, } \\
\text { Vorvorfrucht }\end{array}$ & $\begin{array}{l}\text { Boden - } \\
\text { bearb. }\end{array}$ & Bodenart & $\begin{array}{l}\text { Auswin- } \\
\text { terung }\end{array}$ & $\mathrm{BH} \%$ \\
\hline 24 & Bückwitz & Akteur & 11.10. & EfA & 320 & $\mathrm{R}, \mathrm{G}$ & pfl.-los & Gley D3 & --- & 0,0 \\
\hline 25 & $\begin{array}{l}\text { Gerichshain/ } \\
\text { Schkölen }\end{array}$ & Kerubino & 18.09. & k. Dt. & 270 &,-- G & ja & $\mathrm{sL}$ & nein & 24,7 \\
\hline 26 & Wittighausen & Tommi & 17.10. & k. Dt. & 180 & ZR, M & Pflug & $\mathrm{L}$ & nein & 0,8 \\
\hline 27 & Schwarzach & Cubus & 29.09. & Celist & 220 & $\mathrm{R}, \mathrm{WG}$ & ja & IS (pH 6,6) & nein & 0,0 \\
\hline 28 & Nienburg & Akteur & 25.09. & $\begin{array}{l}\text { Landor } \\
\mathrm{CT}\end{array}$ & 300 & $\mathrm{R}, \mathrm{WW}$ & pfl.-los & $s L$ & k. Dt. & 0,0 \\
\hline 29 & Hiddendorf & Ritmo & 12.09. & Latitude & 128 & WW & ja & SL & nein & 1,3 \\
\hline 30.1 & Jena & JB Asano & 21.10. & EfA & 350 & \multirow[t]{2}{*}{$R, W G$} & pfl.-los & IS & ja & 4,0 \\
\hline 30.2 & Jena & Akteur & 04.10. & Arena C & 350 & & Pflug & $s L$ & ja & 1,4 \\
\hline 30.3 & Jena & Akteur & 10.10. & $\begin{array}{l}\text { Landor } \\
\mathrm{CT}\end{array}$ & $280-300$ & WG, M & ja & $\mathrm{uL}$ & nein & 8,4 \\
\hline 30.4 & Jena & Bussard & 11.09. & k. Dt. & & k. D., R & ja & $\mathrm{tL}$ & k. Dt. & 7,6 \\
\hline 30.5 & Jena & Cubus & 28.09. & $\begin{array}{l}\text { Ungebei } \\
\text { zt }\end{array}$ & 300 & WG, M & ja & $\mathrm{uL}$ & nein & 0,0 \\
\hline 31 & Bodenkamp & Julius & 30.09. & \multirow{2}{*}{$\begin{array}{l}\text { Landor } \\
\text { CT }\end{array}$} & 140 & $\mathrm{R}$ & Grubber & SL & \multirow[t]{2}{*}{ k. Dt. } & 0,0 \\
\hline 32 & Wittbüschen & Julius & 02.10. & & k. D. & WW & Pflug & $L$ & & 0,0 \\
\hline 33 & Holtler & JB Asano & 18.10. & k. Dt. & 180 & ZR & & $\mathrm{tL}$ & k. Dt. & 0,0 \\
\hline 34.1 & Glasin/Zurow & Akteur & 20.09. & k. Dt. & 260 & $\mathrm{R}, \mathrm{G}$ & ja & $s L$ & nein & 2,1 \\
\hline 34.2 & Glasin/Zurow & Brilliant & 19.09. & k. Dt. & 285 & $R, G$ & Pflug & sL & nein & 4,5 \\
\hline 35 & Ziesendorf & Brilliant & & & & & & & & 4,3 \\
\hline
\end{tabular}


Ergebnisse

\subsubsection{Isolatgewinnung}

Ein weiterer Teilaspekt des Monitorings in 2012 und 2013 war die Frage nach den symptomauslösenden Anastomosegruppen. Hierzu wurde von jedem Standort stichprobenartig 25 Pflanzen per Hand und zufällig verteilt entnommen. Die 25 Pflanzen wurden anschließend getrocknet und auf Läsionen bonitiert. Aus Weizenhalmen mit Läsionen wurde der Pilz isoliert und in eine Reinkultur gebracht, von der DNA aufgereinigt wurde. Von einem Halm konnten 1 bis zu 3 Pilzisolate isoliert werden.

\subsubsection{Bestimmung der Anastomosegruppe}

In 2012 wurden von jedem verfügbaren Standort Isolate aus Pflanzenmaterial aufgereinigt. Nur der Standort Düpow (Nr. 6) mit einer Befallshäufigkeit von $0 \%$ lieferte kein auswertbares Material. Pro Standort wurden etwa 2 bis 3 Isolate in Reinkultur gewonnen und anschließend die AG mittels PCR bestimmt. In allen untersuchten Proben konnte ausschließlich $R$. cerealis AG D nachgewiesen werden.

In 2013 wurde Pflanzenmaterial von jedem verfügbaren Standort aufgereinigt. Falls von einem Standort mehrere Proben erhalten worden waren, wurden mehrere Halme analysiert. Von einigen Standorten mit sehr geringen Befallshäufigkeiten standen nur wenige Halme zur Verfügung. So kam es vor, dass die Aufreinigung misslang und das Material für eine mögliche Wiederholung aufgebraucht war. Von jedem erfolgreich aufgereinigten Isolat wurde DNA extrahiert und geprüft. In allen Proben konnte ausschließlich $R$. cerealis AG D nachgewiesen werden.

\subsection{Differenzierung von Rhizoctonia spp. in vitro}

\subsubsection{Erregernachweis}

Zur einfachen Identifikation von Rhizoctonia spp. wurde das phänotypische Erscheinungsbild auf PDA-Plattenmedium im Zeitraum von drei bis zehn Tagen sowie abschließend nach sechs Wochen beurteilt und mit der Referenz verglichen. Insgesamt war das Myzel von Rhizoctonia flach und netz- oder textilartig aufgebaut. Häufig konnten auf dem halben Plattendurchmesser konzentrische Ringe beobachtet werden. Der Pilz drang nicht in das feste Nährmedium ein, sodass dieses stabil blieb. Das Myzel des Pilzes ist zu Wachstumsbeginn von gelblich-brauner Farbe. Nach einer Kultivierungszeit von acht Tagen war stets ein Farbumschlag ins Braune zu beobachten. Nach dem vollständigen 
Ergebnisse

Überwachsen der Platte bildeten sich tief dunkelbraune bis schwarze Sklerotien von unregelmässiger oder ovaler Form aus. Diese waren im Bereich des konzentrischen Rings und am Plattenrand zu sehen. Nach sechs Wochen war auf dem hell-gelben Plattengrund nur noch das typische Verteilungsmuster der Sklerotien zu erkennen, während das Myzel kennzeichnende Merkmale wie die konzentrischen Ringe oder die braune Färbung verschwunden waren.

Für den Nachweis mittels PCR wurde zunächst die Gesamt-DNA (gDNA) im Agarosetrenngel hinsichtlich ihrer Quantität und Qualität betrachtet. Die Verdünnungsstufe für die Arbeitslösung der DNA wurde nun anhand der Bandenstärke im Gel festgelegt (Abb. 5).

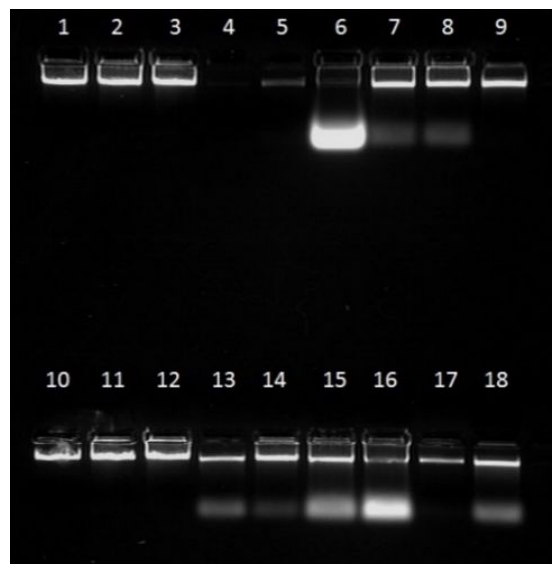

Abbildung 5: Genomische Gesamt-DNA (Proben-Tasche Nr. 4 bis 9, 13 bis 18) visualisiert im UV-Licht (360 $\mathrm{nm}$ ) und Einwanderung ins 1\%ige Agarosegel im Vergleich mit Lambda-DNA-Standard zu $300 \mathrm{ng}, 600 \mathrm{ng}$ und $900 \mathrm{ng}$ (Proben-Tasche Nr. 1 bis 3, 10 bis 12) als Voarb-Test auf Qualität und Quantität und zur Ermittlung der Verdünnungsstufe der Arbeitslösung für weiterführende PCR-Assays.

Proben mit starken Banden (Proben-Tasche 7 - 9, 13 - 15, 18: Abb. 5) wurden 1:10 verdünnt, Proben mit schwächeren Banden (Tasche 16, 17: Abb. 5) wurden 1:5 verdünnt und Proben mit einer nur geringen Bandenstärke (Tasche 5: Abb. 5) wurden 1:2 verdünnt. Proben, in denen keine DNA vorhanden war (Tasche 4: Abb. 5) oder in denen potenziell PCR-hemmende Substanzen ausfindig gemacht werden konnten (Tasche 6, 16: Abb. 5), wurden verworfen und es wurde aus frischem Myzel neu extrahiert.

Gebräuchliche gDNAs wurden auf ihre PCR-Tauglichkeit in einer ITS-PCR geprüft. Abbildung 6 zeigt das Ergebnis einer ITS-PCR nach elektrophoretischer Auftrennung und Visualisierung. 
Ergebnisse
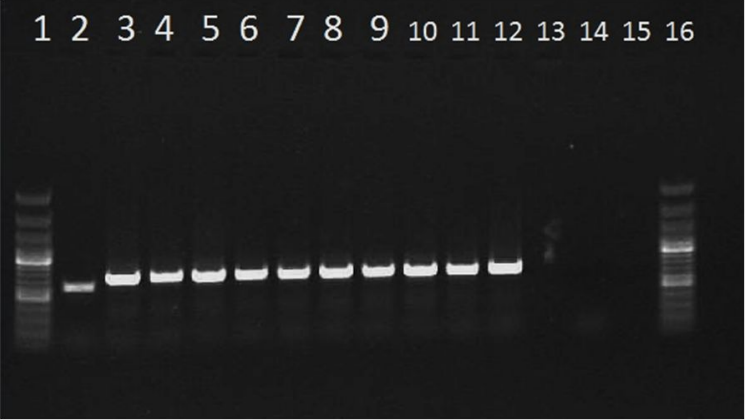

Abbildung 6: ITS-PCR-Assay der gDNA von R. cerealis AG D (Proben-Tasche Nr. 2 bis 11) im Abgleich mit einem 100 bp-Marker $(1,16)$, einer Positivkontrolle (12) und einer Wasserkontrolle (14) nach Auftrennung im 1\%igen Agarosegel und visualisiert im UV-Licht $(360 \mathrm{~nm})$, als Vorab-Test auf die generelle PCRTauglichkeit.

Die hier getesteten gDNAs (Tasche 2 bis 11: Abb. 6) erwiesen sich alle als PCR-tauglich. PCR-taugliche gDNAs wurden anschließend in speziesdifferenzierenden PCRs eingesetzt. Die nachfolgende Abbildung zeigt beispielhaft das Ergebnis einer $R$. cerealis AG D spezifischen RC-PCR nach erfolgter elektrophoretischer Auftrennung und Visualisierung (Abb. 7).

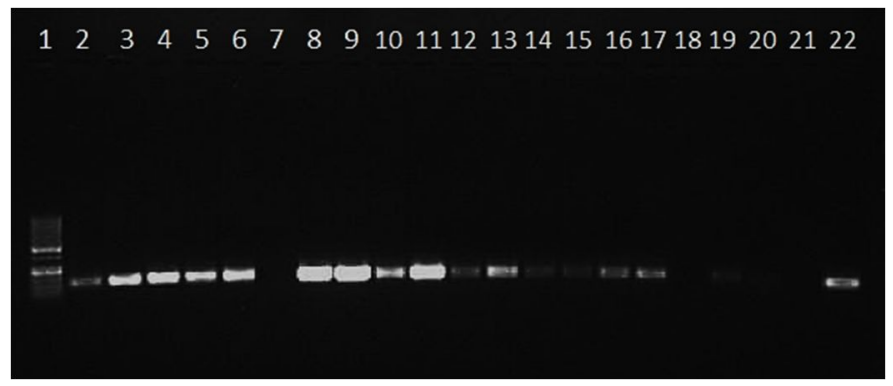

Abbildung 7: PCR-Assay spezifisch für Rhizoctonia cerealis AG D (Proben-Tasche 2 bis 17) im Abgleich mit einem 50bp-Marker (1), einer Negativkontrolle (19), einer Wasserkontrolle (20) und einer Positivkontrolle (22) nach Auftrennung im 1\%igen Agarosegel visualisiert im UV-Licht (360 nm) als Erregernachweis.

Im Set der getesteten Proben wurden 9 als $R$. cerealis AG D positiv detektiert (Taschen 3 bis 6, 8 bis 11 und 13: Abb. 7). Erwartungsgemäß konnte ein positives Signal bei 138 bp beobachtet werden. Als nicht eindeutig $R$. cerealis positiv bewertet wurden Proben der Taschen 1, 12, 14, 15 bis 17. Erwartungsgemäß zeigte die Negativkontrolle (Tasche 19: Abb. 7) und die Wasserkontrolle (Tasche 20: Abb. 7) kein eindeutiges bzw. kein Signal. In Tasche 7 ist ein Beispiel für eine eindeutig $R$. cerealis AG D negative Probe zu sehen. Da die Proben zuvor einer PCR-Tauglichkeitsprüfung unterzogen wurden, war diese Aussage abgesichert. Die unklaren Proben der Taschen 3 bis 6 und 8 bis 11 und 13 (Abb. 7) wurden nachfolgend zur Absicherung des Ergebnisses in der $R$. solani spezifischen PCR eigesetzt 
Ergebnisse

(Abb. 8). Erwartungsgemäß zeigte die Positivkontrolle ein Signal bei 550 bp, während kein Signal bei der Wasser- und der Negativkontrolle zu sehen war (Taschen 9 und 10: Abb. 8). Die getesteten gDNAs waren alle $R$. solani negativ, da kein Signal zu sehen ist.

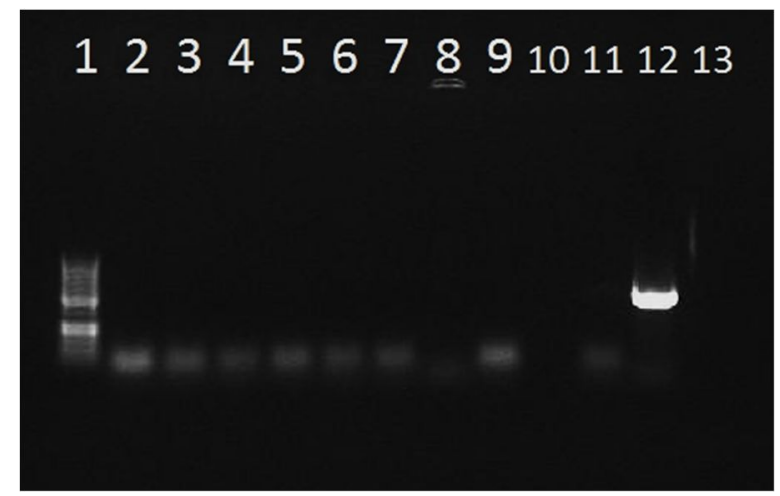

Abbildung 8: Rhizoctonia solani spezifischer PCR-Assay (Proben-Taschen Nr. 2 bis 8 ) im Abgleich mit einem 50bp-Marker (1), einer Wasserkontrolle (9), einer Negativ- (11) und einer Positivkontrolle (12) nach Auftrennung im 1\%igen Agarosegel und Visualisierung im UV-Licht (360 nm) als Nachweis des Erregers.

Im Feldversuch Weende 2011/12 wurde der Erregernachweis parallel mittels PCR und mittels PDA-Test bei 128 Isolaten durchgeführt. Es erfolgte eine Bewertung des PDA-Tests hinsichtlich seiner Testsicherheit. Von den 128 erfolgreich aufgereinigten Isolaten konnten 105 mittels PCR-Assay eindeutig als $R$. cerealis AG D identifiziert werden. Des Weiteren konnte eine Zugehörigkeit zu R. solani mittels PCR ausgeschlossen werden. Von diesen 105 Isolaten konnten mittels PDA-Test 96 Isolate in korrekter Weise als Rhizoctonia spp. identifiziert werden, während die verbleibenden 9 Isolate mittels PDA-Test nicht als Rhizoctonia erkannt wurden. Damit belief sich der Anteil der richtig-positiven Fallentscheidungen auf $91,42 \%$. Der Anteil der falsch-positiven lag bei 8,58\%. Mittels PCR konnten 23 Isolate weder $R$. cerealis AG D noch $R$. solani zugeordnet werden. Mittels PDATest konnte dies bei 17 der 23 Isolate korrekt abgebildet werden, was einem Anteil an richtig-negativen Fällen von 73,91\% entspricht. In den übrigen 6 Fällen konnte der PDATest das PCR-Ergebnis nicht korrekt abbilden, was dem Anteil an falsch-negativen Fällen von $26,08 \%$ entspricht. Die nachfolgende Tabelle stellt die Anzahl an richtig-positiven/ negativen und falsch-positiven/negativen Fälle gegenüber. 
Ergebnisse

Tabelle 16: PDA-Testsicherheit zur Bestimmung von Pilzisolaten der Gattung Rhizoctonia spp. aus künstlich inokulierten Feldversuchen. Es konnten von 128 aufgereinigten Isolaten insgesamt $105(96+9)$ mittels PCR eindeutig als $R$. cerealis AG D identifiziert und gleichkzeitig eine Zugehörigkeit zu $R$. solani AG-1 bis 14 ausgeschlossen werden. Dies konnte mithilfe des PDA-Tests bei 96 Isolaten korrekt abgebildet werden (richtig-positiv Rate von 91,42\%), während 9 Isolate nicht als solche erkannt werden konnten, obgleich es sich laut PCR um $R$. cerealis AG D handelte (falsch-positiv Rate von 8,58\%). Laut PDA-Test wurden 6 Isolate als Rhizoctonia spp. bestimmt, obwohl es sich laut PCR weder um $R$. cerealis AG D, noch um $R$. solani AG-1 bis 14 handelte (falsch-negativ Rate von 26,08\%). Damit führt der PDA-Test insgesamt in 88,28\% der Fälle zur korrekten Identifikation des Erregers auf Gattungsebene.

\begin{tabular}{|c|c|c|c|c|c|}
\hline \multicolumn{2}{|c|}{ Nachweismethode: PCR-Assay } & \multicolumn{4}{|c|}{ Nachweismethode: PDA-Test } \\
\hline \multicolumn{2}{|l|}{ Ergebnis } & \multicolumn{4}{|l|}{ Ergebnis } \\
\hline Aussage & $\begin{array}{l}\text { Anzahl } \\
\text { Isolate }\end{array}$ & Frage & $\begin{array}{l}\text { Ant- } \\
\text { wort }\end{array}$ & $\begin{array}{l}\text { Anzahl } \\
\text { Isolate }\end{array}$ & in $\%$ \\
\hline $\begin{array}{l}\text { Ja: } R \text {. cerealis AG D, nein: } \\
R . \text { solani AG-1 bis } 14\end{array}$ & 96 & \multirow{4}{*}{\begin{tabular}{|l} 
Gattungs- \\
vertreter \\
aus Rhizoc- \\
tonia spp.?
\end{tabular}} & $\mathrm{Ja}$ & $\begin{array}{l}96 \text { (richtig } \\
\text { positiv) }\end{array}$ & 91,4 \\
\hline $\begin{array}{l}\text { Nein: } R \text {. cerealis AG D/ } \\
R \text {. solani AG-1 bis } 14\end{array}$ & 17 & & Nein & $\begin{array}{l}17 \text { (richtig } \\
\text { negativ) }\end{array}$ & 73,9 \\
\hline $\begin{array}{l}\text { Ja: Rhizoctonia cerealis, } \\
\text { nein: } R \text {. solani AG-1 bis } 14\end{array}$ & 9 & & Nein & $\begin{array}{l}9 \text { (falsch } \\
\text { positiv) }\end{array}$ & 8,5 \\
\hline $\begin{array}{l}\text { Nein: } R \text {. cerealis AG D/ } \\
R \text {. solani AG-1 bis } 14\end{array}$ & 6 & & Ja & $\begin{array}{l}6 \text { (falsch } \\
\text { negativ) }\end{array}$ & 26 \\
\hline
\end{tabular}

\subsubsection{Morphologie}

Zur morphologischen Beschreibung wurden lichtmikroskopische Aufnahmen gemacht. Bei $R$. solani AG 5 fallen Verzweigungen in kurzen Abständen ( 25 bis $50 \mu \mathrm{m}$; Abb. 9) auf. Die frischen Hyphenansätze stehen meist in Winkeln von $90^{\circ}$ oder $45^{\circ}$ (Abb. $9 \mathrm{~B}$ und C) zur Ursprungshyphe. Die Hyphenspitzen sind abgerundet. R. solani AG 1-IB bildet Myzelverzweigungen mit langen Abständen von ca. 100 bis $200 \mu \mathrm{m}$ zueinander aus. Häufig steht die Verzweigung im $90^{\circ}$ Winkel zur Ursprungshyphe (Abb. $10 \mathrm{~A}$ u. B). Es können Querverbindungen zwischen einzelnen Hyphen beobachtet werden (Abb. $10 \mathrm{~A}$ ). Die Querverbindungen bilden sich zwischen dicht zusammenliegenden Hyphen aus (ca. $75 \mu \mathrm{m}$; Abb. 10 A), aber auch bei Hyphen mit größeren Distanzen (ca. $600 \mu \mathrm{m}$; Abb. 10 C). Die Hyphenspitzen sind abgerundet. Bei der Betrachtung des Myzels von R. cerealis AG D fallen häufig lang gestreckte und nicht verzweigte Hyphen auf (Abb. $11 \mathrm{~B}$ ). Kommt es doch zu Verzweigungen, bilden sich diese im kurzen Abstand von ca. 25 bis $50 \mu \mathrm{m}$ und im flachen Winkel von $<45^{\circ}$ zur Ursprungshyphe aus (Abb. 11 A). Insgesamt wirkt das Myzel im Vergleich zu R. solani (AG 5, AG 1-IB) filigran und dünn. Die Hyphenspitzen unterstreichen diesen Eindruck durch ihr rundes bis spitzes Erscheinungsbild. 

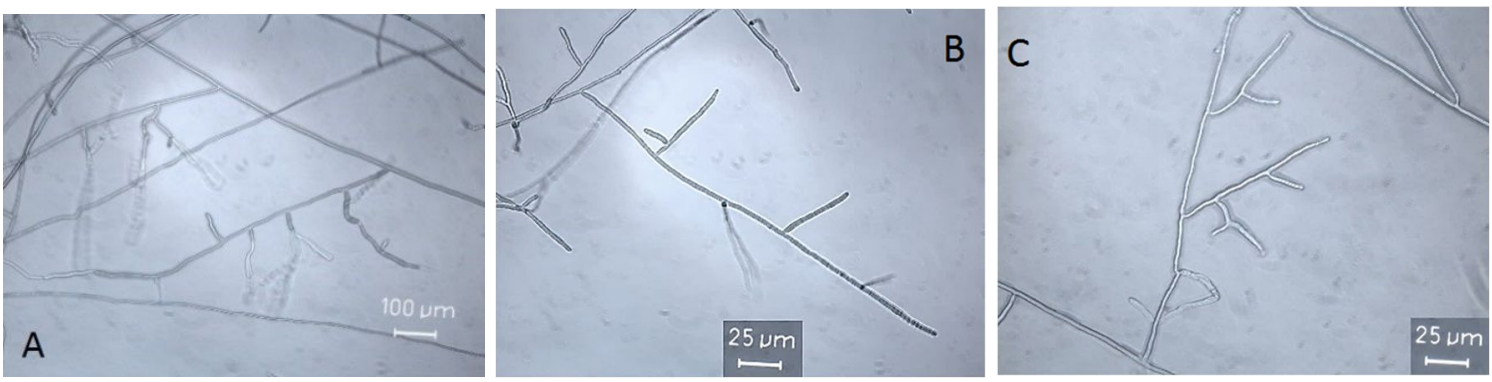

Abbildung 9: Lichtmikroskopische Aufnahmen des Myzels von R. solani AG 5 (IPP-Nr. 1084; Tab. 2) in 10facher (A) bzw. in 40-facher Vergrößerung (B, C) zeigen kurzabständige ( $25-50 \mu \mathrm{m}$ ) Verzweigungen im $90^{\circ}$ oder $45^{\circ}$ Winkel zur Ursprungshyphe mit abgerundeten Hyphenspitzen.
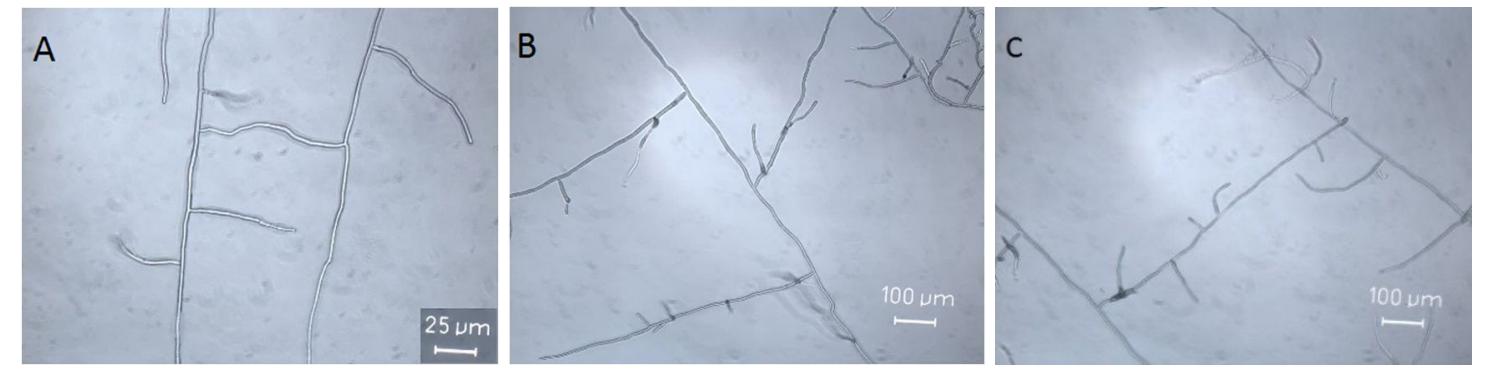

Abbildung 10: Lichtmikroskopische Aufnahmen des Myzels von R. solani AG 1-IB (IPP-Nr. 1056; Tab. 2) in 40-facher (A) bzw. in 10-facher Vergrößerung (B, C) zeigen Myzelverzweigungen mit langen Abständen (100 bis $200 \mu \mathrm{m})$, die häufig im $90^{\circ}$ Winkel zur Ursprungshyphe stehen und Querverbindungen zu dicht angrenzenden Hyphen (ca. $75 \mu \mathrm{m}$; A) sowie auch zu weiter entfernten Hyphen (ca. $600 \mu \mathrm{m}$; C) ausbilden. Die Hyphenspitzen sind abgerundet.
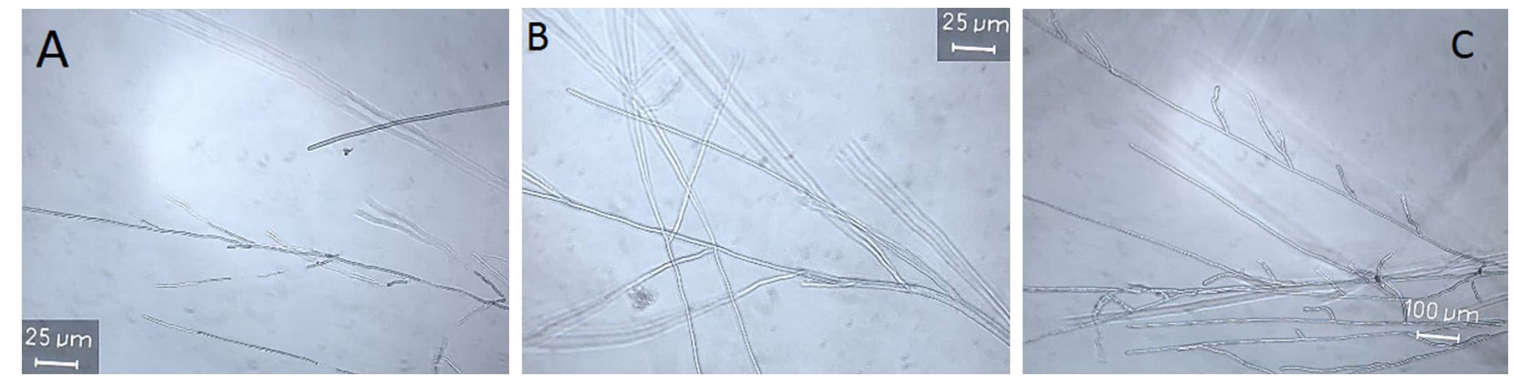

Abbildung 11: Lichtmikroskopische Aufnahmen des Myzels von R. cerealis AG D (IPP-Nr. 0931 (A) und Isolate Laufnr. 50 (B) u. 54 (C) in Tab. 2) in 40-facher (A, B) bzw. in 10-facher Vergrößerung (C) zeigen ein lang gestrecktes, nicht verweigtes und filigranes Myzel mit runden bis spitzen Hyphen (A, B). Kommt es zu Verzweigungen, so stehen diese im $45^{\circ}$ Winkel zur Ursprungshyphe (C).

Die Aufnahmen des Myzels von R. solani AG 8 (Abb. 12) zeigen im Vergleich zu anderen Isolaten nur eine schwache Tendenz zu einer netzartigen Wuchsform. Die neuen Verzweigungen stehen meist im $45^{\circ}$ Winkel zur Ursprungshyphe. Des Weiteren sind viele nicht verzweigte Hyphen zu sehen, die bogenförmig ausgerichtet sind (Abb. $12 \mathrm{C}$ ). Es fallen knäulartig zusammengelagerte Hyphen auf (Abb. 12 D u. E). Zuweilen konnten 
Ergebnisse

Hyphenauswüchse beobachtet werden, die geweihartig verästelt sind und dicke runde Spitzen aufweisen (Abb. 12 B).
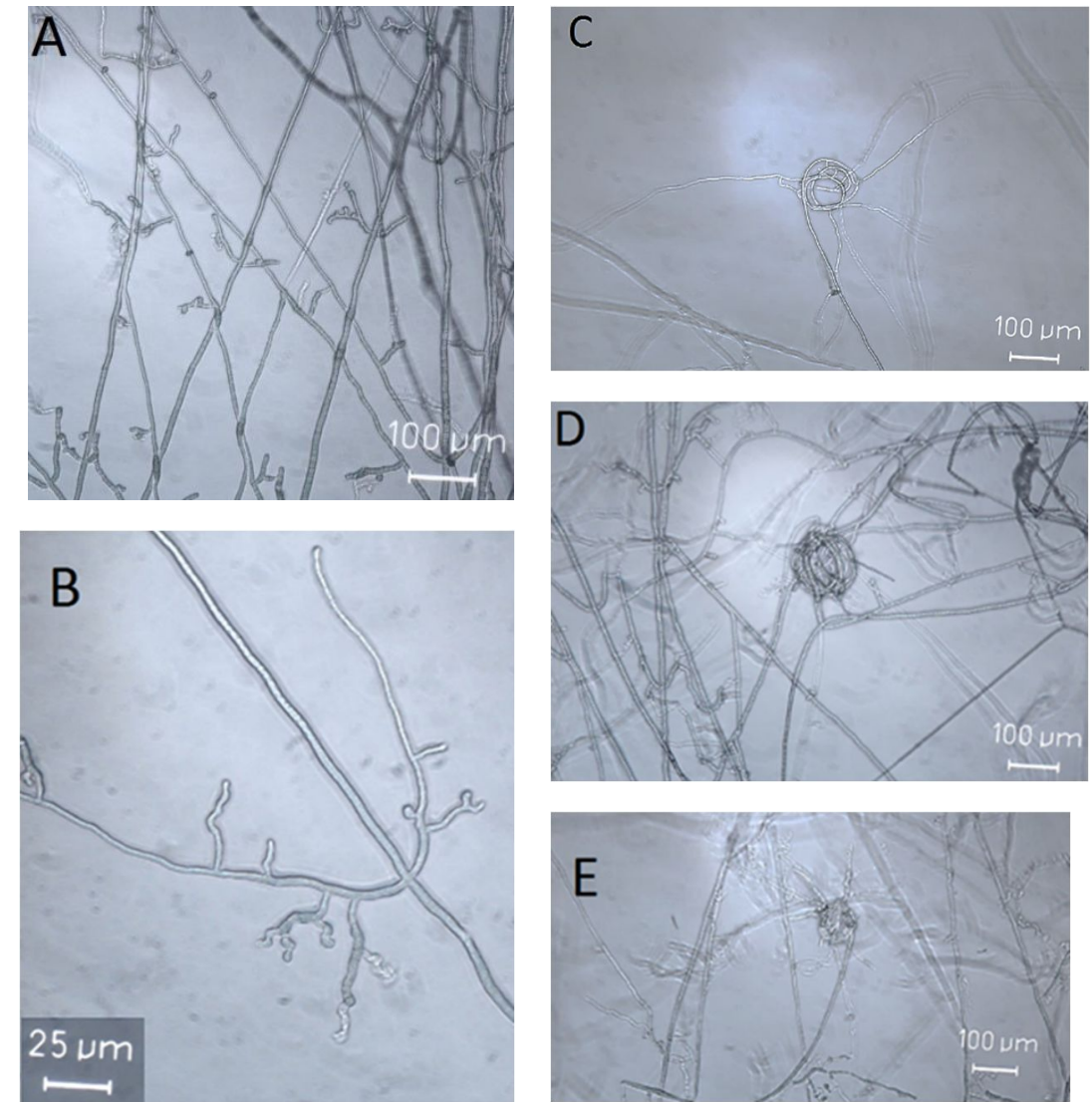

Abbildung 12: Lichtmikroskopische Aufnahmen des Myzels von R. solani AG 8 (IPP-Nr. 1064; Tab. 4) in 40facher (B) und 10-facher Vergrößerung (A, C, D, E). Die Aufnahmen zeigen ein im $45^{\circ}$ Winkel zur Ursprungshyphe verzweigtes Myzel. Es gibt viele nicht verzweigte Hyphen, die bogenförmig ausgerichtet oder als Knäul zusammen gelagert sind (C, D, E). Zudem können geweihartig verästelte Hyphenauswüchse mit dicken runden Spitzen (B) beobachtet werden.

Allen betrachteten Anastomosegruppen gemeinsam ist die Tendenz zu einer netz- oder textilartigen Wachstumstruktur. Diese Tendenz ist bei $R$. solani AG 8 und bei $R$. cerealis AG D nur sehr gering ausgeprägt. Bei AG 8 konnte in vitro in anderen Versuchen stets eine rasche Ausbildung kleiner gelb bis orange farbene Sklerotien beobachtet werden, was sich derart bei anderen Isolaten nicht zeigte.

\subsubsection{Säurebildung}

Durch den Einsatz von Bromphenolblau als Zusatz im Festplattenmedium war es möglich, Anastomosegruppen der Gattung Rhizoctonia zu identifizieren, die durch sezernierte 
Ergebnisse

Substanzen das umgebene Milieu ansäuern. Die Betrachtung der Platten erfolgte zu drei Zeitpunkten (6, 8, $10 \mathrm{dpi})$. Es zeigte sich, dass die getesteten Vertreter von $R$. cerealis AG D (IPP-Nr. 0931, 1079; Isolate SN18, Futterkamp u. Tigerfeld; Tab. 2) keine das Milieu ansäuernden Substanzen sezernieren. Dies änderte sich auch nicht, wenn noch Weizenkeimlinge (Thasos; Tab. 3) mit cokultiviert wurden (Daten nicht gezeigt). Bei Vertretern von R. solani AG 5 (IPP-Nr. 1042 bis 1047) und AG 11 (IPP-Nr. 1060) konnte ein Säureausschlag beobachtet werden. Die als Kontrolle eingesetzten Testerisolate der AG 5 (IPP-Nr. 1084) und AG 11 (IPP-Nr. 1087) konnten dies verifizieren, indem in gleicher Weise ein Umschlag ins Gelbe zu beobachten war. Im Falle von AG 4 HGII (IPP-Nr. 1050) konnte eine stark dunkelviolette Färbung des Mediums beobachtet werden. Dies bestätigte sich auch bei dem eingesetzten Testerisolat (IPP-Nr. 1083). Im Falle von AG 8 (IPP-NR. 1064) konnte lediglich eine Gelbfärbung in Form eines Hofes um den Pilzmyzelplättchen beobachtet werden; dieses Ergebnis konnte jedoch das Testerisolat (IPP-Nr. 1085) nicht bestätigen, denn hier war keinerlei Farbumschlag zu beobachten.

Tabelle 17: Säurebildung bei $R$. cerealis AG D und $R$. solani AG-1 IB, AG 5, AG 4 HGII, AG 8 und AG 11 wie sie durch Zusatz von Bromphenolblau im PDA-Plattenmedium nach 6, 8 und 10 Tagen beobachtet werden konnte $(n=3)$. So kennzeichnet 7,5 die blaue unveränderte Farbe, während 1,08 einen Gelbumschlag und somit Säure anzeigt. Die pH-Werte 10,58 (tiefdunkel violett) und 2,63 (hellorange) sowie die pH-Bereiche 2,63 - 4,45 bzw. 4,45 - 6,5 kennzeichnen Zwischenwerte. Falls möglich, wurde der Farbumschlag lokalisiert (Myzelrand, MR; Hof des Pilzmyzelplättchens, PH). Legende: D = Deutschland; GB = Großbritannien

\begin{tabular}{|c|c|c|c|c|c|c|}
\hline \multirow{2}{*}{$\begin{array}{l}\text { Art- u. } \\
\text { Gattung }\end{array}$} & \multirow[t]{2}{*}{ AG } & \multirow{2}{*}{$\begin{array}{l}\text { IPP-Nr. I } \\
\text { Bez. }\end{array}$} & \multirow[t]{2}{*}{ Herkunft } & \multicolumn{3}{|c|}{ pH-Wert } \\
\hline & & & & $6 \mathrm{dpi}$ & $8 \mathrm{dpi}$ & 10 dpi \\
\hline \multirow{5}{*}{$\begin{array}{l}R . \\
\text { cerealis }\end{array}$} & \multirow[t]{5}{*}{ AG D } & SN-18 & Polen & 7,5 & 7,5 & 7,5 \\
\hline & & Futterkamp & D (Nord) & 7,5 & 7,5 & 7,5 \\
\hline & & Tigerfeld & D (Süd) & 7,5 & 7,5 & 7,5 \\
\hline & & 0931 & Schweiz & 7,5 & 7,5 & 7,5 \\
\hline & & 1079 & Europa & 7,5 & 7,5 & 7,5 \\
\hline \multirow{5}{*}{ R. solani } & \multirow{4}{*}{ AG 5} & 1012 & \multirow{2}{*}{$\mathrm{D}$} & 10 & 2611 & 75 \\
\hline & & 1044 & & 1,0 & 2,6 & 2,6 \\
\hline & & 1045 & \multirow[t]{3}{*}{ Polen } & 1,0 & 2,6 & $4,4-6,5$ \\
\hline & & 1046 & & 1,0 & 2,6 & $4,4-6,5$ \\
\hline & & 1047 & & 1,0 & 2,6 & $\begin{array}{c}2,6 ; \\
\mathrm{PH}: 1,0\end{array}$ \\
\hline R. solani & $\begin{array}{l}\text { AG 1- } \\
\text { IB }\end{array}$ & 1056 & Polen & $\begin{array}{c}7,5 ; \\
\text { MR: } 4,4-6,5\end{array}$ & $\begin{array}{c}\text { 7,5; } \\
\text { MR: } 4,4- \\
6,5\end{array}$ & 7,5 \\
\hline
\end{tabular}


Ergebnisse

\begin{tabular}{|c|c|c|c|c|c|c|}
\hline \multirow{5}{*}{$\begin{array}{l}\text { Art- u. } \\
\text { Gattung }\end{array}$} & \multirow[t]{2}{*}{ AG } & \multirow{2}{*}{$\begin{array}{l}\text { IPP-Nr. I } \\
\text { Bez. }\end{array}$} & \multirow[t]{2}{*}{ Herkunft } & \multicolumn{3}{|c|}{ pH-Wert } \\
\hline & & & & $6 \mathrm{dpi}$ & $8 \mathrm{dpi}$ & $10 \mathrm{dpi}$ \\
\hline & $\begin{array}{l}\text { AG } 4 \\
\text { HGII }\end{array}$ & 1050 & GB & $\begin{array}{c}\text { 7,5; MR: } \\
4,4-6,5\end{array}$ & 10,5 & 10,5 \\
\hline & AG 11 & 1060 & $\mathrm{D}$ & 1,0 & 1,0 & $\begin{array}{c}1,08 \\
\text { MR: } 2,6\end{array}$ \\
\hline & AG 8 & 1064 & Spanien & 7,5; $\mathrm{PH}: 1,0$ & $\begin{array}{c}7,5 ; \mathrm{PH}: \\
1.0\end{array}$ & $\begin{array}{c}\text { 10,8; } \\
\mathrm{PH}: 1,0\end{array}$ \\
\hline \multicolumn{7}{|c|}{ Testerisolate für Hyphenanastomose } \\
\hline \multirow[t]{4}{*}{ R. solani } & AG 5 & 1084 & \multirow[t]{4}{*}{--} & 1,0 & 2,6 & $\begin{array}{c}2,6 ; \\
\mathrm{PH}: 10\end{array}$ \\
\hline & $\begin{array}{l}\text { AG } 4 \\
\text { HGII }\end{array}$ & 1083 & & $\begin{array}{c}7,5 \\
\text { MR: } 4,4-6,5\end{array}$ & 10,5 & 10,5 \\
\hline & AG 11 & 1087 & & 1,0 & 1,0 & 1,0 \\
\hline & AG 8 & 1085 & & 7,5 & 7,5 & 7,5 \\
\hline
\end{tabular}

\subsubsection{Temperaturansprüche}

Im Folgenden werden die bei verschiedenen Kultivierungstemperaturen ermittelten Wachstumsgeschwindigkeiten in $\mathrm{cm}$ pro Tag von Rhizoctonia spp., wie sie auf PDAFestplattenmedium unter sterilen in vitro-Bedingungen ermittelt wurden, dargestellt (Abb. 13). In der Untersuchungsreihe wurde ein gemischtes Set von $R$. solani verschiedener Anastomosegruppen (je 2 Isolate von AG 8 und AG 1-IB, 4 Isolate von AG 5) und 2 Isolate von $R$. cerealis $A G D$ untersucht. Falls vorhanden, wurde ein sogenanntes Testerisolat $(\mathrm{TI})$, wie es für Hyphenanastomosetests Verwendung findet, als interne Referenz mit einbezogen (Tab.3). Die Temperaturstufen lagen aufsteigend in $4^{\circ} \mathrm{C}$ Schritten im Bereich von 8 bis $32^{\circ} \mathrm{C}$.

Die Vertreter der AG 1-IB zeigten in nahezu allen getesteten Temperaturstufen Wachstum. Der Unterschied zwischen den beiden Isolaten lag darin, dass AG 1-IB (IPP-Nr. 1056) von 8 bis $28^{\circ} \mathrm{C}$ Wachstum zeigte, während AG 1-IB (IPP-Nr. 1080) im Bereich von 8 bis $32^{\circ} \mathrm{C}$ wuchs. Die optimale Wachstumstemperatur beider AG 1-IB Isolate lag bei $20^{\circ} \mathrm{C}$ (IPP-Nr. 1056 mit 4,3 und IPP-Nr. 1080 mit 3,8 cm/ Tag). Die zwei jeweils davor und danach liegenden Temperaturbereiche, 12 und $16^{\circ} \mathrm{C}$ bzw. 24 und $28^{\circ} \mathrm{C}$, erzeugten bei $A G$ 1-IB (IPP-Nr. 1056) ebenfalls gute Wachstumsraten. Hier war ein relativ schnelles Wachstum von $2,1 \mathrm{~cm} /$ Tag messbar. Hingegen reduzierte sich das Wachstum bei $8^{\circ} \mathrm{C}$ in um die Hälfte $(0,9 \mathrm{~cm} / \mathrm{Tag})$ und bei $32^{\circ} \mathrm{C}$ stagnierte es vollkommen. Bei AG 1-IB (IPP-Nr. 1080) war das Wachstum im Vergleich zu AG 1-IB IPP-Nr. 1056 bei fünf $\left(8-20^{\circ} \mathrm{C}\right.$ und $\left.28^{\circ} \mathrm{C}\right)$ von insgesamt sieben Temperaturstufen langsamer, was auch statistisch bestätigt wurde. 
Ergebnisse

AG 1-IB IPP-Nr. 1080 wuchs besonders stark in 3 Temperaturbereichen. So lag die optimale Wachstumstemperatur bei $20^{\circ} \mathrm{C}(3,8 \mathrm{~cm} / \mathrm{Tag})$. Bei 16 und $24^{\circ} \mathrm{C}$ zeigte das Isolat mit 2,0 bzw. 2,8 cm/ Tag ein schnelles Wachstum. Bei 12 und $28^{\circ} \mathrm{C}$ zeigte das Isolat mit 1,0 bzw. 0,9 cm/ Tag ein moderates Wachstum. Ein geringes Wachstum zeigte das Isolat mit nur 0,1 bzw. 0,3 cm/ Tag in den extremen Temperaturbereichen von 8 und $32^{\circ} \mathrm{C}$.

Die Vertreter der AG 5 (IPP-Nr. 1044, 1046, 1047 und 1084) zeigten überwiegend moderates bis schnelles Wachstum in den Temperaturbereichen von 12 bis $16^{\circ} \mathrm{C}$. So lag das durchschnittliche Wachstum bei $12^{\circ} \mathrm{C}$ über alle Isolate bei $1,3 \mathrm{~cm} / \mathrm{Tag}$ und bei $16^{\circ} \mathrm{C}$ bei $2,1 \mathrm{~cm} / \mathrm{Tag}$. Die optimale Wachstumstemperatur für AG 5 lag bei 20 und $24^{\circ} \mathrm{C}$ mit im Mittel über alle Isolate 2,2 bzw. 2,1 cm Wachstum pro Tag. Bei 8 und $28^{\circ} \mathrm{C}$ erfolgte eine starke Reduktion des Wachstums auf durchschnittliche $0,5 \mathrm{bzw} \cdot 0,7 \mathrm{~cm} / \mathrm{Tag}$. Bei $32^{\circ} \mathrm{C}$ stagnierte das Wachstum bei einem Isolat vollkommen (IPP-Nr. 1044), während es sich bei den übrigen 3 getesteten Isolaten sehr stark reduzierte auf $0,1 \mathrm{~cm} / \mathrm{Tag}$. Insgesamt fiel das sogenannte Testerisolat, AG 5 IPP-Nr. 1080, mit etwas höheren Wachstumsgeschwindigkeiten gegenüber den übrigen 3 AG 5 Isolaten auf, dies konnte statistisch nur bei $28^{\circ} \mathrm{C}(1,5 \mathrm{~cm} / \mathrm{Tag})$ bestätigt werden.

Die Vertreter von AG D (IPP-Nr. 0931, 1079) und AG 8 (IPP-Nr. 1064, 1085) bevorzugten kühlere Wachstumstemperaturen von 12 und $16^{\circ} \mathrm{C}$. So konnte bei AG D IPP Nr. 0931 bzw. IPP-Nr. 1079 ein moderates Wachstum bei $12^{\circ} \mathrm{C}(0,9 \mathrm{~cm} / \mathrm{Tag})$ und ein Wachstumspeak bei $16^{\circ} \mathrm{C}(1,0 \mathrm{bzw} .1,1 \mathrm{~cm} / \mathrm{Tag})$ ermittelt werden. Bei $20^{\circ} \mathrm{C}$ reduzierten beide Isolate $\mathrm{ihr}$ Wachstum in etwa um die Hälfte auf 0,4 (IPP-Nr. 0931) bzw. 0,4 (IPP-Nr. 1079) cm/ Tag. Bei $24^{\circ}$ war eine sehr starke (IPP-Nr. 0931) bzw. eine starke (IPP-Nr. 1079) Wachstumsreduktion zu beobachten. Analog wie bei AG 8 stagnierte auch bei AG D das Wachstum bei 28 und $32^{\circ} \mathrm{C}$ vollkommen $(0,0 \mathrm{~cm} / \mathrm{Tag})$. AG 8 (IPP-Nr. 1064) wuchs insgesamt schneller als AG 8 (IPP-Nr. 1085). Des Weiteren wuchs AG 8 IPP-Nr. 1064 neben 12 und $16^{\circ} \mathrm{C}$ noch bei $20^{\circ} \mathrm{C}$-Stufe optimal. So war bei 16 und $20^{\circ} \mathrm{C}$ ein ähnlich schnelles Wachstum zu verzeichnen (1,8 bzw. 1,7 cm/ Tag). Bei AG 8 IPP-Nr. 1085 lag der Wachstumspeak bei $16^{\circ} \mathrm{C}(1,1 \mathrm{~cm} / \mathrm{Tag})$, während bei 12 und $20^{\circ} \mathrm{C}$ mit 0,9 bzw. 0,9 cm/ Tag ein ähnlich gutes Wachstum erfolgte. Bei $24^{\circ} \mathrm{C}$ zeigten beide Isolate von $A G 8$ ein stark vermindertes Wachstumsniveau mit lediglich 0,1 (IPP-Nr. 1064) und 0,2 (IPP-Nr. 1085) cm pro Tag.

Der nachfolgende Fließtext erläutert die Ergebnisse der einzelnen Temperaturvarianten im Detail und stellt diese vergleichend gegenüber. 
Ergebnisse

Bei einer Temperatur von $8^{\circ} \mathrm{C}$ lag das Wachstum der Isolate in einem engen Bereich zwischen minimal $0,1 \mathrm{~cm} /$ Tag und maximal $0,9 \mathrm{~cm} / \mathrm{Tag}$, im Mittel lag die $8^{\circ} \mathrm{C}$ Wachstumsrate bei $0,5 \mathrm{~cm} /$ Tag. Die beiden Vertreter der AG 1-IB flankierten den genannten Minimal- und Maximalwert. Die Vertreter der AG 5 zeigten nahe beieinanderliegende Zuwachsraten im Bereich zwischen 0,4 und 0,5 cm/Tag ohne signifikante Unterschiede. Das Isolat AG D IPP-Nr. 1079 mit 0,4 cm/ Tag war signifikant verschieden von AG D IPP-Nr. 0931 mit nur 0,1 cm/Tag. Die Vertreter der AG 8 lagen mit ihren Zuwachsraten von 0,6 (IPP-Nr. 1085) und 0,7 cm/ Tag (IPP-Nr. 1064) im oberen Drittel aller beobachteten Werte.

Bei einer Temperatur von $12^{\circ} \mathrm{C}$ lag das Wachstum der Isolate in einem Bereich zwischen $0,9 \mathrm{~cm} / \mathrm{Tag}$ und $2,0 \mathrm{~cm} / \mathrm{Tag}$. Im Mittel lag die $12^{\circ} \mathrm{C}$-Wachstumsrate aller Isolate bei 1,2 $\mathrm{cm} / \mathrm{Tag}$, was im Vergleich zur $8^{\circ} \mathrm{C}$-Variante in etwa eine Verdopplung darstellte. Die geringste Wachstumsrate nahmen die Vertreter der AG D ein mit einer Zuwachsrate von 0,9 (IPP-Nr. 0931 u. IPP-Nr. 1079). Ebenso AG 8 (IPP-Nr. 1085) präsentierte sich mit 0,9 $\mathrm{cm} /$ Tag im Vergleich zu den übrigen Isolaten als nur schwach wüchsig und war signifikant verschieden zu Isolat AG 8 IPP-Nr. 1064 mit 1,4 cm/ Tag. Die Vertreter der AG 5 lagen im moderaten Wachstumsbereich von 1,2 (IPP-Nr. 1047), 1,4 (IPP-Nr. 1044) und 1,5 cm/ Tag (IPP-Nr. 1084). Einzig statistisch davon abweichend und sich bei den schwach wüchsigen Isolaten positionierend tat sich AG 5 (IPP-Nr. 1046) mit lediglich 0,9 cm/ Tag. Die die AG 1-IB vertretenden Isolate zeigten Inkonsistenz zueinander. So steigerte AG 1-IB (IPP-Nr. 1056) im Vergleich von 8 auf $12^{\circ} \mathrm{C}$ sein Wachstum um das 2 -fache auf $2,0 \mathrm{~cm} / \mathrm{Tag}$ und IPP-Nr. 1080 sogar um das 7-fache auf 1,0 cm/ Tag, jedoch gruppierte sich IPP-Nr. 1080 damit statistisch zu den Isolaten AG 5/ AGD, während AG 1-IB (IPP-Nr. 1056) mit 2,0 cm/ Tag statistisch vor allen anderen Isolaten das am schnellsten wachsende Isolat dieser Temperaturvariante repräsentierte.

Bei einer Temperatur von $16^{\circ} \mathrm{C}$ lag das Wachstum der Isolate in einem Bereich zwischen 1,0 cm/ Tag (AG D, IPP-Nr. 0931) und 2,2 cm/ Tag (AG 1-IB, IPP-Nr. 1056). Im Mittel lag die $16^{\circ} \mathrm{C}$-Wachstumsrate aller Isolate bei $1,6 \mathrm{~cm} /$ Tag. Die $R$. cerealis AG D-Isolate mit 1,0 $\mathrm{cm} / \mathrm{Tag}$ (IPP-Nr., 0931) bzw. $1,1 \mathrm{~cm} / \mathrm{Tag}$ (IPP-Nr. 1079) sowie R. solani AG 8 (IPP-Nr. 1085) mit 1,1 cm/ Tag waren nur gering wüchsig. Das zu prüfende Isolat der AG 8 IPP-Nr. 1064 hatte eine Zuwachsrate von 1,8 cm/Tag und unterschied sich damit statistisch signifikant vom Testerisolat (IPP-Nr. 1085; 1,1 cm/ Tag). Das AG 8 Testerisolat IPP-Nr. 1085 gruppierte sich damit - statistisch betrachtet - aufgrund seiner Wachstums- 
Ergebnisse

geschwindigkeit in die Gruppe der AG 5 Isolate, welche Raten zwischen 1,6 cm/ Tag (IPP-Nr. 1047), $1,7 \mathrm{~cm} /$ Tag (IPP-Nr. 1084) und 1,8 cm/ Tag (IPP-Nr. 1044) aufzeigten. Einzig das AG 5 Isolat mit der IPP-Nr. 1046 war mit einer Wachstumsrate von 1,47 cm/ Tag lediglich mit dem Isolat IPP-Nr. 1047 (1,7 cm/ Tag) vergleichbar. Die höchsten Wachstumsraten nahmen mit 2,0 cm/ Tag (IPP-Nr. 1080) und 2,2 cm/ Tag (IPP-Nr. 1056) die Vertreter der AG-1IB ein.

Bei einer Temperatur von $20^{\circ} \mathrm{C}$ lag das Wachstum der Isolate in einem Bereich zwischen 0,4 cm/ Tag (AG D, IPP-Nr. 0931) und 4,3 cm/ Tag (AG 1-IB, IPP-Nr. 1056). Im Mittel lag die $20^{\circ} \mathrm{C}$-Wachstumsrate aller Isolate bei $2,0 \mathrm{~cm} / \mathrm{Tag}$, was im Vergleich zur $16^{\circ} \mathrm{C}$-Variante eine Zunahme von etwa $20 \%$ bedeutete. Die AG D Isolate nahmen als schwach Wüchsige wiederum den untersten Rang ein. Äquivalent zur vorherigen Variante differenzierten sich wiederum die AG 8 Isolate mit einer Wachstumsrate von 0,9 cm/ Tag (IPP-Nr. 1085) und $1,7 \mathrm{~cm} / \mathrm{Tag}$ (IPP-Nr. 1064) voneinander. Die Isolate verhielten sich nur dahingehend gleich, dass die Wachstumsrate im Vergleich zur $16^{\circ} \mathrm{C}$-Variante bei beiden abnahm. Die Isolate der AG 5 Isolate teilte sich - statistisch betrachtet - in zwei Teilgruppen. So war die Wachstumsrate von AG 5 (IPP-Nr. 1044) mit 2,0 cm/ Tag statistisch gleich wie AG 5 (IPP-Nr. 1046) mit 2,1 cm/Tag. Die zweite Gruppe von AG 5 bestand aus AG 5 IPP-Nr. 1047 mit 2,4 cm/ Tag sowie dem Testerisolat AG 5 (IPP-Nr. 1084) mit 2,5 cm/ Tag. Die am schnellsten wachsenden Isolate waren wiederum die Vertreter der AG1IB, obgleich sich IPP-Nr. 1080 mit 3,8 cm/ Tag statistisch signifikant von AG 1-IB IPP-Nr. 1056 mit 4,3 $\mathrm{cm} /$ Tag unterschied. Im Vergleich zur $16^{\circ} \mathrm{C}$-Variante verdoppelten die genannten Isolate ihre Wachstumsgeschwindigkeit.

Bei einer Temperatur von $24^{\circ} \mathrm{C}$ lag das Wachstum der Isolate in einem weiten Bereich zwischen 0,0 (AG D IPP-Nr. 0931) und 2,8 cm/ Tag (AG 1-IB IPP-Nr. 1056). Die mittlere Wachstumsrate aller Isolate lag bei $1,4 \mathrm{~cm} /$ Tag. Mit Ausnahme des Isolats AG 5 (IPP-Nr. 1046) kann ausgesagt werden, dass sich die Wachstumsgeschwindigkeit bei allen Isolaten im Vergleich mit der $20^{\circ} \mathrm{C}$-Variante verringerte. Schwach wüchsig waren die Isolate AG D mit 0,0 (IPP-Nr. 0931) bzw. 0,2 cm/ Tag (IPP-Nr. 1079) sowie AG 8 mit 0,1 (IPP-Nr. 1064) und 0,2 cm/ Tag (IPP-Nr. 1085). Die Isolate der AG 5 hatten ein durchschnittliches Wachstum von etwa $2,1 \mathrm{~cm} /$ Tag zu beobachten. Die einzelnen Isolate zeigten dabei Wachstumsraten von 1,9 (IPP-Nr. 1044), 2,1 (IPP-Nr. 1047), 2,2 (IPP-Nr. 1046) und 2,2 (IPP-Nr. 1084) cm/ Tag. Die beiden Isolate des AG 1-IB nahmen in der $24^{\circ} \mathrm{C}$-Variante wiederum den Rang der am schnell wüchsigsten AG ein. So zeigten die 
Ergebnisse

AG 1-IB-Isolate Wachstumsraten von $2,4 \mathrm{~cm} / \mathrm{Tag}$ (IPP-Nr. 1056) und $2,8 \mathrm{~cm} / \mathrm{Tag}$ (IPP-Nr. 1080). Damit demonstrierte AG 1-IB IPP-Nr. 1080 gegenüber IPP-Nr. 1056 erstmals eine statistisch signifikant höhere Wachstumsrate und war das am schnellst wachsende Isolat in der $24^{\circ} \mathrm{C}$-Variante.

Bei einer Temperatur von $28^{\circ} \mathrm{C}$ lag das Wachstum der Isolate in einem Bereich zwischen 0,2 und 1,8 cm/ Tag. Die mittlere Wachstumsrate alle Isolate lag bei 0,5 cm/ Tag, was in etwa der Durchschnittsrate bei $8^{\circ} \mathrm{C}(0,50 \mathrm{~cm} / \mathrm{Tag})$ entspricht. Im Vergleich zur vorherigen Temperaturvariante mit $24^{\circ} \mathrm{C}$ reduzierten alle Isolate bei $28^{\circ} \mathrm{C}$ ihr Wachstum bzw. stagnierten vollkommen (AG D IPP-Nr. 0931, 1079 und AG 8 IPP-Nr. 1064, 1085: 0,0 $\mathrm{cm} / \mathrm{Tag}$ ). Die Isolate der AG 5 zeigten Wachstumsraten im Bereich von 0,26 (IPP-Nr. 1047, ST: de) bis zu 1,58 cm/ Tag (IPP-Nr. 1084). Damit teilten sich die Isolate in wenigstens zwei Gruppen: AG 5 IPP-Nr. 1047 kann mit einer Rate von 0,2 cm/ Tag - statistisch betrachtet noch den stagnierenden Isolaten der AG 8 und AG D zugeordnet werden, liegt zugleich aber auch mit der AG 5 IPP-Nr. 1046 mit 0,5 cm/ Tag im selben Rang. Sich von dieser „Mischgruppe“ ausschließen tat sich AG 5 IPP-Nr. 1044, welches mit einer Wachstumsrate von 0,6 cm/ Tag lediglich der AG 5 IPP-Nr. 1046 (0,5 cm/ Tag) zuzuordnen ist. Die AG 5 IPP-Nr. 1084 hat mit 1,5 cm/ Tag den größten Zuwachs und sticht somit - statistisch betrachtet - als schnell wachsendes Isolat aus der Gruppe hervor. Mit einer Wachstumsrate von $1,5 \mathrm{~cm} /$ Tag lag AG 5 IPP-Nr. 1084 statistisch betrachtet gleich wie AG 1-IB IPP-Nr. 1056 mit 1,8 cm/ Tag. Das Testerisolat AG 1-IB IPP-Nr. 1080 hatte eine Wachstumsrate von $0,9 \mathrm{~cm} /$ Tag und nahm damit - statistisch betrachtet - den vorletzten Rang hinter dem am besten wüchsigen Isolat AG 1-IB IPP-Nr. 1056 ein. Damit zeigten die 2 Isolate der AG1IB auch in der $28^{\circ} \mathrm{C}$-Variante wieder das schon in der 8 bis $20^{\circ} \mathrm{C}$-Stufe demonstrierte Verhalten, nämlich dass AG1IB IPP-Nr. 1056 wüchsiger war als AG 1-IB IPP-Nr. 1080.

Bei einer Temperatur von $32^{\circ} \mathrm{C}$ lag das Wachstum der Isolate in einem engen Bereich zwischen 0,0 und 0,4 cm/ Tag. Die mittlere Wachstumsrate alle Isolate lag bei $0,0 \mathrm{~cm} / \mathrm{Tag}$. Im Vergleich zur vorherigen Temperaturvariante mit $28^{\circ} \mathrm{C}$ reduzierten alle Isolate bei $32^{\circ} \mathrm{C}$ inr Wachstum bzw. es vergrößerte sich die Anzahl der Isolate, bei denen das Wachstum vollkommen stagnierte. $\mathrm{Zu}$ den schon bei $28^{\circ} \mathrm{C}$ nicht wachsenden Isolaten der $\mathrm{AG} D$ (IPP-Nr. 0931, 1079: 0,0 cm/ Tag) und AG 8 (IPP-Nr. 1064, 1085: 0,00 cm/ Tag) gesellten sich noch AG 5 IPP-Nr. 1044 (0,0 cm/ Tag) sowie AG 1-IB IPP-Nr. 1056 (0,0 cm/ Tag). Die 
Ergebnisse

wüchsigsten Isolate innerhalb der $32^{\circ} \mathrm{C}$-Variante wurden durch AG 1-IB IPP-Nr. 1080 mit 0,3 cm/ Tag und AG 5 IPP-Nr. 1046 mit 0,4 cm/ Tag repräsentiert.

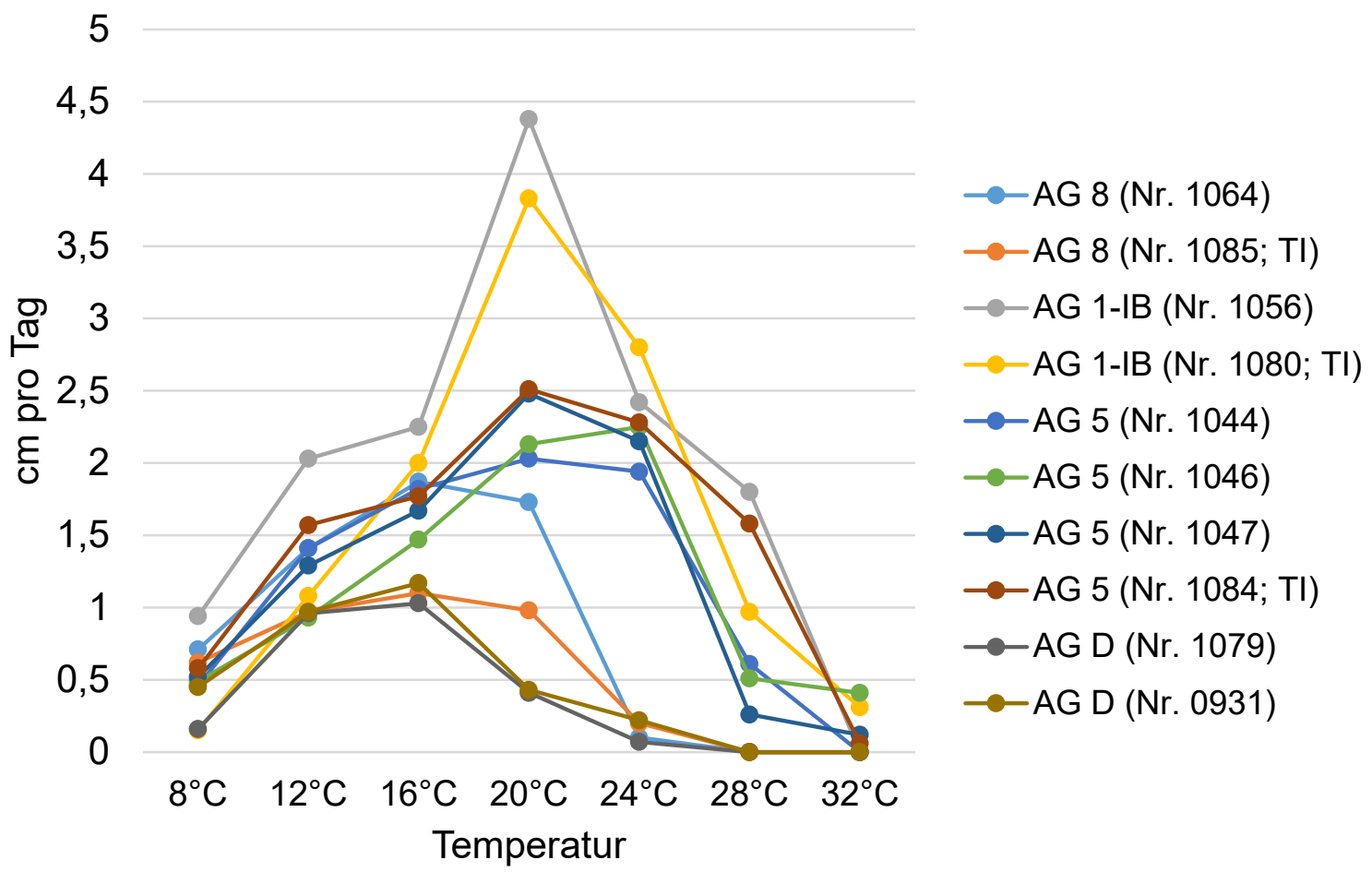

Abbildung 13: Wachstumsraten verschiedener Anastomosegruppen der Gattung Rhizoctonia und Testerisolate ( $\mathrm{TI}$ in vitro auf PDA-Nährstoffplatten bei Temperaturen von $8^{\circ} \mathrm{C}$ bis $32^{\circ} \mathrm{C}$ (in $4^{\circ} \mathrm{C}$-Schritten; $\mathbf{n}=3)$. Gemessen wurde der tägliche radiale Koloniezuwachs, in cm/ Tag.

Im Folgenden werden die bei verschiedenen Kultivierungstemperaturen ( 4 bis $28^{\circ} \mathrm{C}$ in $4^{\circ} \mathrm{C}$ Schritten) ermittelten Wachstumsgeschwindigkeiten in $\mathrm{cm}$ pro Tag von mehreren Isolaten von $R$. cerealis AG D vergleichend dargestellt (Abb. 14). Die radialen Myzelwachstumraten wurden im sterilen in vitro-Assay auf PDA-Festplattenmedium erhoben (Abschn. 2.6). Die Isolate wurden aus symptomatischen Pflanzenproben aufgereinigt. Die Proben stammten aus verschiedenen Winterweizenschlägen in Deutschland und wurden auf natürlichem Rhizoctonia-Befall bonitiert. Die Auswahl der Isolate epräsentiert ein $R$. cerealis AG D Spektrum für Deutschland. Dabei können die Isolate in Nord- (Isolat-Nr. 1 bis 5), Mittel- (Nr. 6 bis 10) und Süddeutschland (Nr. 11) eingeteilt werden. Zur Unterscheidung der AG im Text wird neben der Standortbezeichnung und die interne Isolat-Nr. 1 bis 11 verwendet. Die Isolate $R$. cerealis AG D vom Standort Futterkamp (Nr. 1 in SH) und Ostenfeld (Nr. 3 in $\mathrm{SH}$ ) hatten einen linearen Kurvenverlauf im Temperaturbereich von 4 bis $20^{\circ} \mathrm{C}$. Dabei verdoppelten sie ihre Wachstumsgeschwindigkeit von 4 auf $8^{\circ} \mathrm{C}$ und steigerten diese dann 
Ergebnisse

um 0,2 cm pro Tag in jeder weiteren Temperaturstufe. Die optimale Wachstumstemperatur beider Isolate mit 1,2 (Nr. 1 Futterkamp) und 1,2 cm pro Tag (Nr. 3 Ostenfeld) lag bei $20^{\circ} \mathrm{C}$. Beim Isolat Futterkamp (Nr. 3) lag bei $24^{\circ} \mathrm{C}$ die Geschwindigkeit von $1 \mathrm{~cm}$ pro Tag gleich mit der Rate bei $16^{\circ} \mathrm{C}$. Bei $24^{\circ} \mathrm{C}$ fiel bei beiden Isolaten die Wachstumsrate ab auf $1 \mathrm{~cm}$ pro Tag. Bei $28^{\circ} \mathrm{C}$ stagnierte das Wachstum beider Isolate völlig. Das Isolat Nr. 2 (Birkenmoor in $\mathrm{SH}$ ) hatte einen ähnlichen Kurvenverlauf wie die Isolate $\mathrm{Nr}$. 1 (Futterkamp in $\mathrm{SH}$ ) und Nr. 3 (Ostenfeld in $\mathrm{SH}$ ), jedoch mit geringeren Wachstumsraten. So war ein linarer Kurvenverlauf zu sehen, der bei $24^{\circ} \mathrm{C}$ mit $1,1 \mathrm{~cm}$ pro Tag gipfelte. Das Wachstumsoptimum bei $24^{\circ} \mathrm{C}$ unterschied das Isolat von allen übrigen, welche ihr Optium bei $20^{\circ} \mathrm{C}$ hatten. Die Isolate Nr. 4 bis Nr. 9 hatten einen leicht stufigen Kurvenverlauf. Bei $4^{\circ} \mathrm{C}$ lag die Wachstumsgeschwindkeit im Mittel bei $0,2 \mathrm{~cm}$ pro Tag. Diese Rate verdopelte sich bei $8^{\circ} \mathrm{C}$ und lag bei im Mittel bei $0,5 \mathrm{~cm}$ pro Tag, während bei $12^{\circ} \mathrm{C}$ eine nochmalige Zunahme von $0,2 \mathrm{~cm}$ pro Tag zu sehen war. Bei $16^{\circ} \mathrm{C}$ war die Zunahme der Rate von $0,4 \mathrm{~cm}$ pro Tag zu sehen auf $1,1 \mathrm{~cm}$ pro Tag. Bei $20^{\circ} \mathrm{C}$ lag die optimale Wachstumstemperatur mit im Mittel $1,2 \mathrm{~cm}$ pro Tag. Bei $24^{\circ} \mathrm{C}$ war beim Isolat Nr. 7 und Nr. 8 ein Plateau zu sehen, die Wachstumsraten waren in etwa gleich. Bei den übrigen war ein leichter Abfall auf gemittelte $1,2 \mathrm{~cm}$ pro Tag zu sehen. Bei $28^{\circ} \mathrm{C}$ stagnierte das Wachstum der Isolate $\mathrm{Nr} 4$ bis Nr. 11. Zusammenfassend kann herausgestellt werden, dass sich die im Versuch ermittelten guten Wachstumstemperaturen für $R$. cerealis $A G D$ in einem breiten Bereich zwischen 16 und $24{ }^{\circ} \mathrm{C}$ befinden mit im Mittel über alle Isolate 1,1 bzw. 1,1 cm pro Tag eine ähnlich hohe Wachstumsrate ermittelt werden. Bei $20^{\circ} \mathrm{C}$ war im Mittel nochmals eine leicht höhere Wachstumsrate von 1,2 cm pro Tag feststellbar.

Das Ergebnis des vorrangegangenen Temperaturexperiments zeigte eine Präferenz von R. cerealis AG D für 12 und $16^{\circ} \mathrm{C}$ sowie eine deutliche Wachstumsreduktion bei 20 und $24^{\circ} \mathrm{C}$. In diesem Experiment wurden zwei $R$. cerealis AG D Isolate aus Ackerbodenproben eingesetzt; dabei entstammte IPP-Nr. 0931 der Schweiz, für IPP-Nr. 1079 ist kein Isolatursprung verfügbar. Diese Ergebnisse konnten mit den Isolaten aus Deutschland aus Pflanzenproben nicht in gleicher Weise abgebildet werden. 


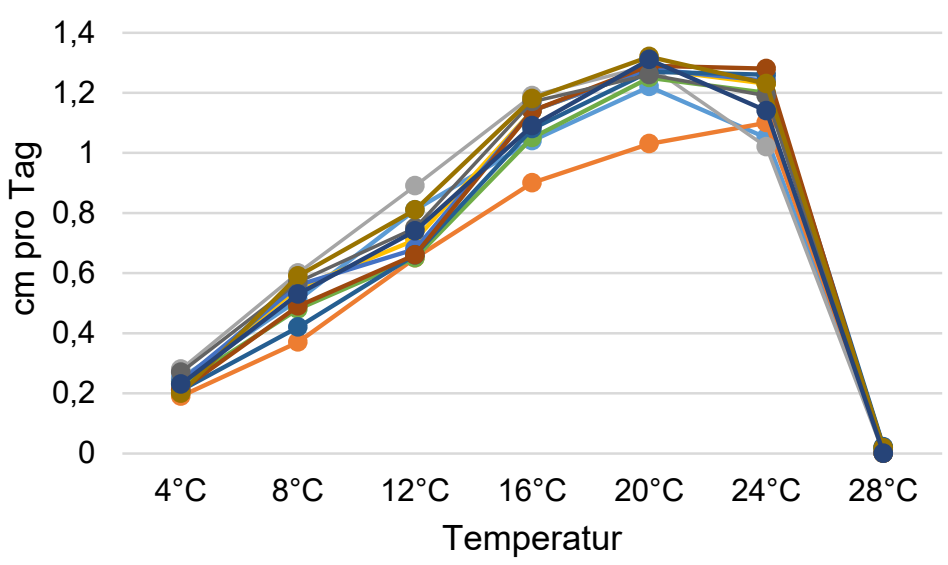

$\longrightarrow$-Nr. 1 Futterkamp SH

$\longrightarrow$-Nr. 2 Birkenmoor SH

- Nr. 3 Ostenfeld SH

- Nr. 4 Blankenhagen (a) MV

$\longrightarrow$ Nr. 5 Blankenhagen (b) MV

- Nr. 6 Neugattersleben ST

$\rightarrow-N r .7$ Methau SN

$\longrightarrow$ Nr. 8 Sora SN

$\longrightarrow$ Nr. 9 Thiemendorf TH

-10 Borwede NI

$\longrightarrow 11$ Tigerfeld BW

Abbildung 14: Wachstumsraten verschiedener $R$. cerealis AG D Isolate aus Pflanzen (Isolatursprung: Deutschland) wie sie im sterilen in vitro Experiment auf PDA-Nährstoffplatten bei Temperaturen von $4^{\circ} \mathrm{C}$ bis $28^{\circ} \mathrm{C}$ (in $4^{\circ} \mathrm{C}$-Schritten) ermittelt wurden $(n=3)$, gemessen wurde der tägliche Zuwachsradius, die Angabe erfolgte als $\mathrm{cm} / \mathrm{Tag}$; Legende: $\mathrm{SH}=$ Schleswig-Holsein, $\mathrm{MV}=$ Mecklenburg-Vorpommern, $\mathbf{S N}=$ Sachsen, $\mathbf{S T}=$ Sachsen-Anhalt, $\mathrm{TH}=$ Thüringen, $\mathbf{N I}=$ Niedersachsen, $\mathrm{BW}=$ Badenwürtemberg.

\subsubsection{Pathogenität an Weizenkeimlingen}

Ein Set von $R$. cerealis und $R$. solani Isolaten (Tab. 3) wurde an 5 Weizensorten (Tab. 4) im in vitro Assay auf sein Schadpotenzial getestet. Generell kann ausgesagt werden, dass alle getesteten Vertreter von AG D und von $R$. solani an Weizen visuell deutlich erkennbare Schäden in Form einer Verbräunung des Halmes verursachen. Die Streuung der Befallsstärke (DS) liegt dabei zwischen minimal 0,07 (AG 5 IPP-Nr. 1043) und maximal 0,61 (AG 1-IB IPP-Nr. 1056). Der Test diente als erste Vorselektion für Zielisolate für weiterführende Versuche bspw. Feldversuche. Aus jeder Anastomosegruppe sollte ein Isolat auf Grundlage der Befallsstärke ausgewählt werden.

Im Mittel war für R. cerealis AG D ein DS von 0,35 (IPP-Nr. 0931) und 0,37 (IPP-Nr. 1079) zu beobachten (Tab. 18). Für Folgeversuche wurde das Isolat $R$. cerealis AG D mit der IPP-Nr. 0931 ausgewählt. R. solani AG 5 Isolate hatten im Mittel Befallsindices von 0,23 (IPP-Nr. 1043), 0,34 (IPP-Nr. 1044 u. 1045), 0,35 (IPP-Nr. 1046) und 0,42 (IPP-Nr. 1047). Das Testerisolat von AG 5 (IPP-Nr. 1084) bestätigte diese Daten mit einer Befallsstärke von 0,49. Für nachfolgende Versuche wurde das AG 5 Isolat mit der IPP-Nr. 1047 ausgewählt. Bei den AG 1-IB Isolaten wurde nur das Isolat IPP-Nr. 1056 getestet. Dieses lieferte mit einem gemittelten DS über alle Varianten von 0,49 vergleichbar hohe Werte wie die AG 5 Isolate und wurde daher für weitere Folgeversuche eingesetzt. 
Ergebnisse

Tabelle 18: Pathogenitätstest (in vitro) mit Rhizoctonia sp. an verschiedenen Winter- (Hermann, Inspiration, Mulan, Toras) und Sommer- (Thasos) Weizensorten. Darstellung der Befallsstärke $D S(n=3)$ nach Sichtbonitur, wobei die Verbräunung der Koleoptile prozentual abgeschätzt und in Boniturnoten übertragen wurde, um diese zu berechnen, aufgestellt für fünf Befallsnoten ( 0 und 1 bis 4 ) indem die jeweilige Anzahl an Individuuen eines Befallsgrads/ einer Boniturnote multipliziert wird mit deren Gewichtung. Boniturestufen: $\mathbf{0}=$ keine Symptome, $\mathbf{1}=$ leicht befallen, $\mathbf{2}=$ mäßig befallen, $\mathbf{3}=$ mäßig bis stark befallen und $4=$ sehr stark befallen (Berechnung des DS siehe Tab. 7).; Legende: $k$. Dt. = keine Daten

\begin{tabular}{|l|c|c|c|c|c|c|}
\hline Befallsstärke DS \\
\hline AG / Sorte & IPP-Nr. & Thasos & Hermann & Inspiration & Mulan & Toras \\
\hline AG D & 0931 & 0,30 & 0,64 & 0,24 & 0,16 & 0,50 \\
\cline { 2 - 7 } & 1079 & k. Dt. & 0,41 & 0,26 & 0,14 & 0,60 \\
\hline \multirow{4}{*}{ AG 5 } & 1042 & 0,43 & 0,41 & 0,32 & 0,32 & 0,63 \\
\cline { 2 - 7 } & 1044 & 0,31 & 0,34 & 0,56 & 0,30 & 0,21 \\
\cline { 2 - 7 } & 1045 & 0,43 & 0,35 & 0,33 & 0,24 & 0,33 \\
\cline { 2 - 7 } & 1046 & 0,26 & 0,57 & 0,50 & 0,26 & 0,14 \\
\cline { 2 - 7 } & 1047 & 0,35 & 0,45 & 0,60 & 0,26 & 0,45 \\
\hline AG 5 Testerisolat & 1084 & 0,45 & 0,55 & 0,32 & 0,47 & 0,64 \\
\hline AG 1-IB & 1056 & 0,44 & 0,59 & 0,35 & 0,45 & 0,61 \\
\hline Kontrolle & --- & 0,00 & 0,00 & 0,00 & 0,00 & 0,00 \\
\hline
\end{tabular}

In den nachfolgenden Untersuchungen wurden die Isolate AG D (IPP-Nr. 0931), AG 5 (Nr. 1047) und AG 1-IB (Nr. 1056) verwendet und stellvertretend als die an Winterweizen potenziell relevanten AGs betrachtet.

Für die Untersuchung des Infektionsprozesses der Weizenwurzel durch Rhizoctonia sp. wurde ein optimiertes in vitro Protokoll verwendet. Dazu wurde ein Weizenkeimling in einer definierten Position (vorgestanzte Vertiefung) sowie in definierter Ausrichtung zur Unterstützung des natürlichen Pflanzenwachstums mit Pilzmyzel in Wurzelnähe inokuliert wie in Abb. 15 dargestellt.

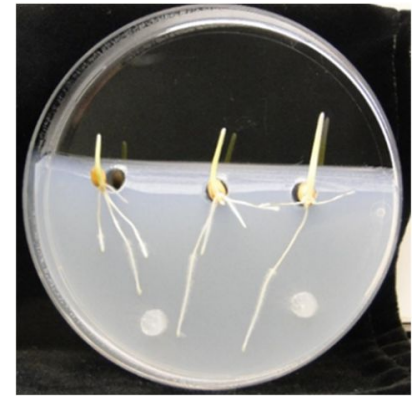

Abbildung 15: Versuchsaufbau des in vitro-Assays (Wasseragarplatte $2 \%$ mit ca. 25 ml, hochkant aufgestellt) für Infektionsstudien von Rhizoctonia sp. an der Weizenwurzel (frontale fotografische Darstellung). Durch die definierte Ablage des Weizenkorns (Sorte Thasos) in der vorgestanzten Vertiefung am abgeschrägten oberen Wasseragarrand und die Ausrichtung des Weizenembryos mit der Wurzel nach unten war sichergestellt, dass die Wurzeln für die Pilzhyphen - ausgehend vom Pilzmyzelplättchen - leicht zugänglich sind. 
Ergebnisse

Zur Dokumentation des Infektionsprozesses wurden Wurzeln zu zwei Zeitpunkten (4 und $6 \mathrm{dpi}$ ) betrachtet. Am früheren Termin ( $4 \mathrm{dpi}$ ) konnte bei $R$. cerealis und $R$. solani eine großflächige Besiedlung der Wurzeloberfläche durch den Pilz beobachtet werden (Abb. $16 \mathrm{~A}$ ). Bei R. cerealis konnten zu diesem Zeitpunkt zusätzlich T-förmige Verzweigungen beobachtet werden (Abb. 16 B). Zum späteren Zeitpunkt (6 dpi) wurden bei allen drei Isolaten Infektionskissen (infections cushions) auf der Wurzeloberfläche beobachtet (Abb. $16 \mathrm{C}$ ). Zur Veranschaulichung wurden die Infektionskissen in Abbildung $16 \mathrm{C}$ im Bild durch Pfeile markiert.
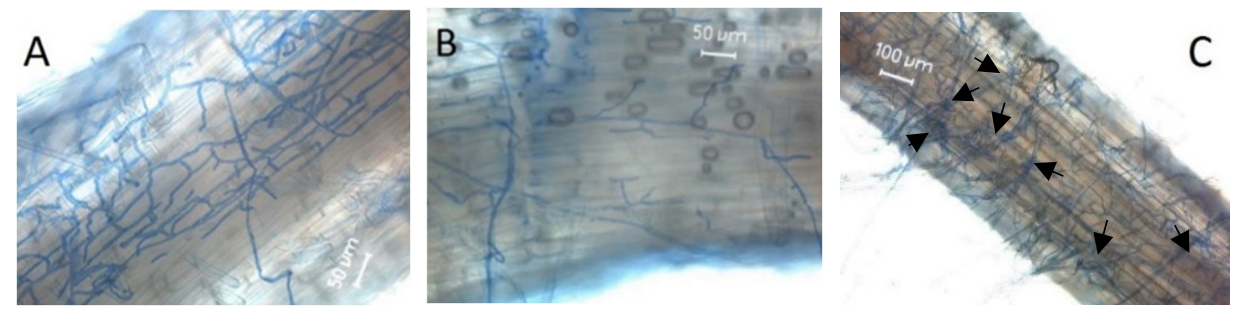

Abbildung 16: Infektionshyphen von R. cerealis AGD (Infektionsassay in vitro Färbung mit Laktophenolblau) an einer Weizenwurzel zu verschiedenen Zeitpunkten: $4 \mathrm{dpi} \mathrm{mit} \mathrm{großflächiger} \mathrm{Besiedlung}$ der Wurzeloberfläche (A) und Ausbildung einer T-förmigen Hyphe (B, Bildmitte); 6 dpi mit Ausbildung von Infektionskissen (C).

Um die Kolonisierungsaktivität des Pilzes zu beurteilen, wurden die Rhizoctonia-typischen Infektionskissen (infection cushions, IC) auf der Wurzel zum Zeitpunkt 6 dpi ausgezählt.

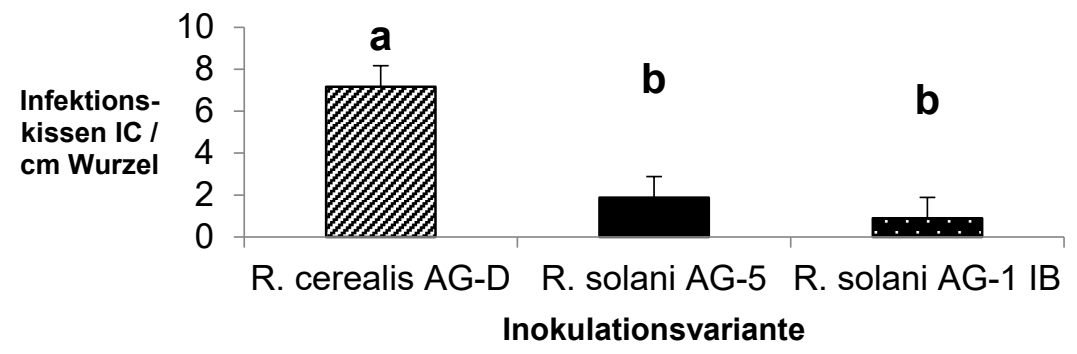

Abbildung 17: Ausbildung von Infektionskissen (IC) auf der Weizenwurzel (Sorte Thasos) durch verschiedene Rhizoctonia sp. (6 dpi) im in vitro Pathogenitätstest $(n=3)$. Die statistische Auswertung erfolgte mittels Fisher LSD Test (alpha 0,05) unter Normalverteilung (gegeben oder angespasst). Signifikanzen werden anhand von unterschiedlichen Buchstaben angezeigt, Vertikale Balken stellen die positive Standardabweichung dar.

Es zeigte sich, dass $R$. cerealis AG D die Wurzel mit durchschnittlich 7 IC pro cm Wurzel kolonisierte. Im Vergleich dazu konnte bei $R$. solani AG 5 und $R$. solani AG 1 IB mit nur 2 bzw. $1 \mathrm{IC} / \mathrm{cm}$ Wurzel signifikant weniger IC beobachtet werden. 
Ergebnisse

\subsection{Feldversuch}

\subsubsection{Meteorologische Daten}

In Abbildung 18 sind die Wetterdaten des Standortes Göttingen in dem Zeitraum von September 2011 bis August 2012 dargestellt.

Rel. Luftfeuchte \%

Temp. ${ }^{\circ} \mathrm{C}$

Niederschlag mm

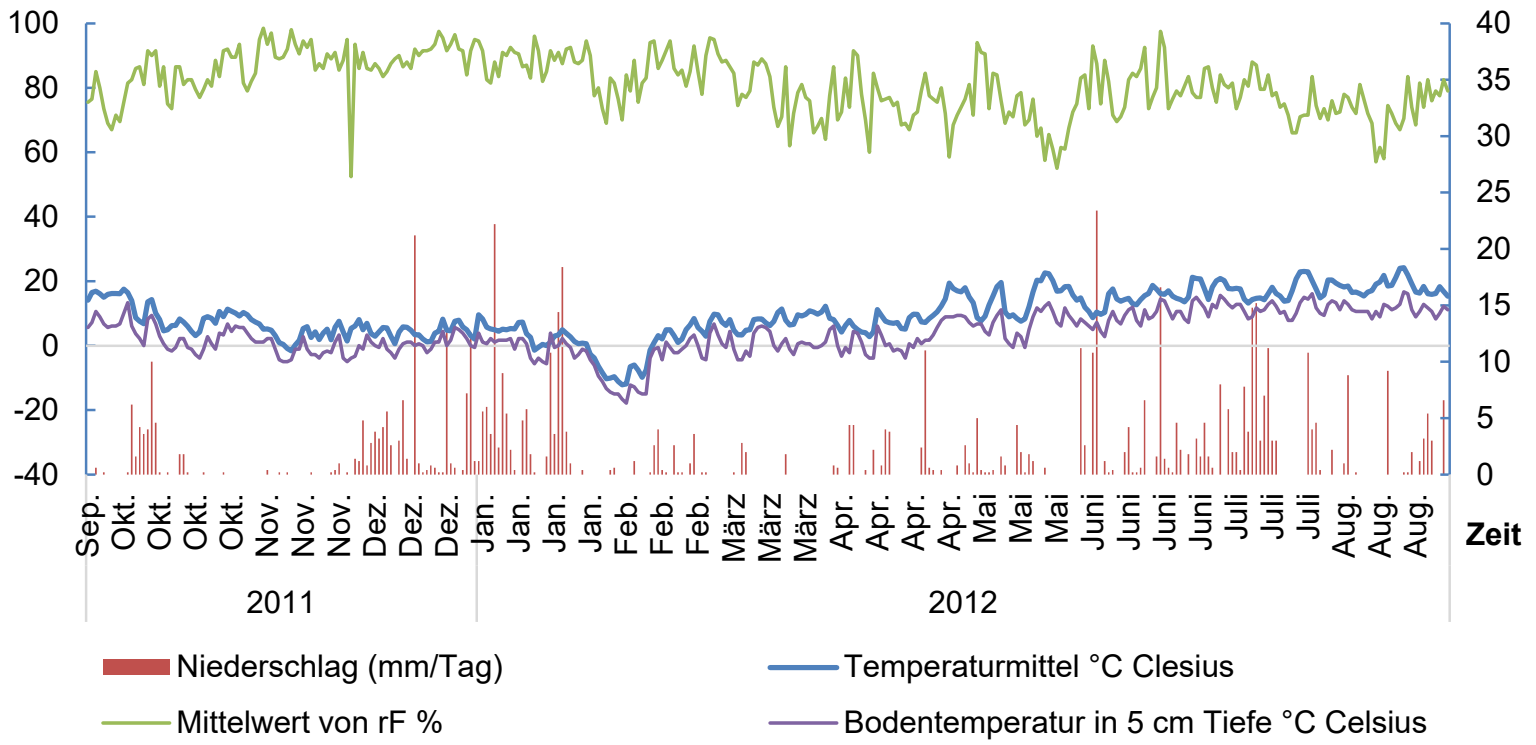

Abbildung 18: Tagesmittelwerte des Niederschlags ( $\mathrm{mm} /$ Tag; rote Säule), der relativen Luftfeuchte (\%; grüne Linie), Lufttemperatur $\left({ }^{\circ} \mathrm{C}\right.$; blaue Linie) und Bodentemperatur $\left({ }^{\circ} \mathrm{C}\right.$; violette Linie) von Ende September 2011 bis Mitte August 2012 am Standort Göttingen.

Die nachfolgende zusammenfassende Beschreibung der Vegetationsperiode bezieht sich inhaltlich auf die monatlich herausgegebenen Mittelwerte der Witterungsreporte des Deutschen Wetterdienstes gemessen von 1961 bis 1990.

Der September 2011 fiel deutschlandweit überdurchschnittlich warm $\left(+1,7^{\circ} \mathrm{C}\right)$ und trocken (Niederschlagsmenge - 41\%) aus. Im Oktober war zu Monatsanfang eine leicht erhöhte Niederschlagsmenge zu verzeichnen $(+13 \%)$ und Temperatur war mit $+0,2^{\circ} \mathrm{C}$ Celsius leicht über dem Durchschnitt. Der November 2011 fiel in ganz Deutschland extrem trocken aus (Niederschlagsmenge - 97\%). Die Temperatur war um $0,3^{\circ} \mathrm{C}$ Celsius höher als erwartet. Die Wintermonate fielen insgesamt sehr mild aus mit einer Durchschnittstemperatur im Dezember und Januar, die um $2,5^{\circ} \mathrm{C}$ Celsius deutlich über dem Normalwert lag. Um den 15./ 16. Januar fielen die Temperaturen kurzzeitig unter die $0^{\circ} \mathrm{C}$ CelsiusGrenze. Der darauffolgende Temperaturanstieg in den Plusbereich begünstigte, dass die 
Ergebnisse

nachfolgenden Niederschläge zum Monatsende keine Schneedecke bildeten. Anfang Februar war ein Temperatursturz zu verzeichnen. Die Temperaturen fielen ab von einem leichten Plus $\left(+0,6^{\circ} \mathrm{C}\right)$ innerhalb von 5 Tagen auf $-10^{\circ} \mathrm{C}$. Diese Frostperiode dauerte vom 29. Januar bis einschließlich dem 13. Februar an. Am 6. und 7. Februar lag die Temperatur bei $-12^{\circ} \mathrm{C}$. Während dieser Zeitspanne kam es nur zu geringfügigen Niederschlägen von insgesamt 2,4 mm. Die Frühjahrsmonate März bis Mai 2012 waren insgesamt zu warm und zu trocken, während die Sommermonate Juni bis August mit zu erwartenden Temperaturen und Niederschlagsmengen verliefen.

\subsubsection{Erregernachweis und Befallsverlauf}

In der Frühsaat (28.09.2011) und Spätsaat (21.10.2011) wurden jeweils insgesamt vier Bonituren durchgeführt. Diese erfolgten im Wachstumsstadium $\mathrm{BBCH} 25, \mathrm{BBCH} 35$, $\mathrm{BBCH} 55$ und $\mathrm{BBCH} 75$. Dabei wurden die Befallshäufigkeit $(\mathrm{BH})$ in \% für Rhizoctonia an Winterweizen erfasst.

\section{Befallshäufigkeit: Frühsaat}

In der Frühsaat wurden insgesamt 4 Bonituren (B1 bis B4) durchgeführt (Tab. 19). In der ersten Bonitur (B1) zu BBCH 25 hatte nur die Inokulation einen signifikanten Effekt ( $p=$ $0,000)$. Die Winterweizensorte $(p=0,276)$, sowie die Interaktion Sorte ${ }^{*}$ Variante $(p=0,261)$ hatten keinen Effekt. In der zweiten Bonitur (B2) zu BBCH 35 zeichnete sich ein ähnliches Bild ab. So waren wiederum die Sorte $(p=0,062)$ und die Interaktionskomponente aus Sorte*Variante $(p=0,062)$ keine gültige Effektgröße. Lediglich die Variante ( $p$-Wert $=0,000)$ ist als gültige Effektgröße zu nennen. In der dritten Bonitur (B3) zu BBCH 55 hatten alle drei Prüfglieder einen Effekt. In der vierten Bonitur (B4) zu BBCH 75 hatte weder die Sorte $(p=0,201)$, noch die Interaktionskomponente aus Sorte ${ }^{*}$ Variante $(p=0,191)$ einen Effekt. Es war lediglich die Variante effektauslösend mit einem $p$-Wert von $p=0,000$. Der statistische Vergleich erfolgte innerhalb einer jeden Bonitur (horizontal, Zeile).

In der ersten Bonitur zu BBCH 25 (B1) hatten die inokulierten Varianten der Sorten Mulan mit $60 \%$ Befallshäufigkeit, Toras mit $55,5 \%$ und Herrmann mit $45,3 \%$ den signifikant höchsten Befall. Der Befallswert von Toras und Hermann war aber statistisch noch gleich mit dem Befall von Inspiration mit 41\%. Die Gesundkontrollen hatten erwartungsgemäß einen Befall von 0\%. In der zweiten Bonitur zu BBCH 25 (B2) gab es mit Ausnahme der 
Ergebnisse

Sorte Mulan (inokluliert) keine sehr großen Veränderungen in den Befallshäufigkeiten. Lediglich Mulan büßte 2/3 an Befall ein von $60 \%$ auf $19 \%$ und war damit statistisch betrachtet gleich mit den Kontrollen, welche nach wie vor einen Befall von 0\% hatten. In der dritten Bonitur zu BBCH 55 (B3) war bei den drei Sorten Hermann und Inspiration in den inokulierten Varianten ein auffällig hoher Rückgang der Befallshäufigkeit um etwa die Hälfte zu sehen. Bei Mulan (inokuliert) ging die $\mathrm{BH}$ um lediglich $>10 \%$ zurück. Einzig die Sorte Toras hatte mit 55\% ein ähnlich hohes Befallsniveau wie schon in B2 und B1, was statistisch signifikant hoch war gegenüber den anderen inokulierten Sorten. In der vierten Bonitur (B4) zur Milchreife hatten die Sorten Hermann und Inspiration in den inokulierten Varianten ihre Befallswerte aus der B2 - mit leichten Schwankungen - wieder erreicht mit 47,4\% und $28,4 \%$. Die Sorte Mulan hatte mit $28 \%$ ein statistisch gleich hohes Befallsniveau erreicht. Mit leichter Steigerung von 4\% hatte die inokulierte Sorte Toras mit 59,7\% den statistisch signifikant höchsten Befallswert. Erstmals in der B4 zeigten die Gesundkontrollen der Sorten Hermann und Mulan einen Befall von unter $1 \%$.

Tabelle 19: Mittlere Befallshäufigkeit BH (\%) mit Rhizoctonia an Winterweizen (Hermann, Inspiration, Mulan, Toras) in der Frühsaat zu vier Boniturterminen B1 (= BBCH 25), B2 (= BBCH 35), B3 (= BBCH 55) und B4 (= BBCH 75) im Vergleich der inokulierten Varianten (inokul. = Mischinokulum bestehend aus $R$. solani AG 5 und $R$. cerealis AG D) im Vergleich zur Gesundkontrolle (Kontr.) am Standort Weende (Feldversuch 2011/12). Pro Parzelle ( $n=4)$ wurden stichprobenartig ca. 65 Pflanzen (B1, B2, B3) bzw. ca. 85 Pflanzen (B4) entnommen. Abweichende Buchstaben kennzeichnen signifikante Unterschiede nach statistischer Analyse (ST) mit Fisher LSD (alpha $=0,05$ ) unter Normalverteilung (gegeben oder angepasst) innerhalb eines Boniturtermins (Tabellenreihe); SD = Standardabweichung

\begin{tabular}{|c|c|c|c|c|c|c|c|c|c|}
\hline \multicolumn{10}{|c|}{ Frühsaat: Befallshäufigkeit in [ \%] } \\
\hline \multicolumn{2}{|c|}{$\begin{array}{l}\text { Winterweizen } \\
\text {-sorte }\end{array}$} & \multicolumn{2}{|c|}{ Hermann } & \multicolumn{2}{|c|}{ Inspiration } & \multicolumn{2}{|c|}{ Mulan } & \multicolumn{2}{|c|}{ Toras } \\
\hline $\begin{array}{l}\text { Boni } \\
\text { - tur }\end{array}$ & & Kontr. & Inokul. & Kontr. & Inokul. & Kontr. & Inokul. & Kontr & Inokul. \\
\hline \multirow[t]{2}{*}{ B1 } & $\mathrm{BH}$ & $\begin{array}{l}0 \\
\text { C }\end{array}$ & $\begin{array}{c}45,3 \\
\text { ab }\end{array}$ & $\begin{array}{l}0 \\
\text { c }\end{array}$ & $\begin{array}{c}41,0 \\
\text { b }\end{array}$ & $\begin{array}{l}0 \\
\text { C }\end{array}$ & $\begin{array}{c}60,0 \\
\mathbf{a}\end{array}$ & $\begin{array}{l}0 \\
\text { c }\end{array}$ & $\begin{array}{c}55,5 \\
\text { ab }\end{array}$ \\
\hline & SD & 0 & 15,7 & 0 & 9,3 & 0 & 9,2 & 0 & 20,9 \\
\hline \multirow[t]{2}{*}{ B2 } & $\mathrm{BH}$ & $\begin{array}{l}0 \\
\text { d }\end{array}$ & $\begin{array}{c}50,5 \\
a b\end{array}$ & $\begin{array}{l}0 \\
\text { d }\end{array}$ & $\begin{array}{c}32,7 \\
\text { bc }\end{array}$ & $\begin{array}{l}0 \\
\text { d }\end{array}$ & $\begin{array}{c}19,0 \\
\text { cd }\end{array}$ & $\begin{array}{l}0 \\
\text { d }\end{array}$ & $\begin{array}{c}53,3 \\
a\end{array}$ \\
\hline & SD & 0 & 33,0 & 0 & 9,3 & 0 & 16,1 & 0 & 6,8 \\
\hline \multirow[t]{2}{*}{ B3 } & $\mathrm{BH}$ & $\begin{array}{l}0 \\
d\end{array}$ & $\begin{array}{c}28,6 \\
\text { B }\end{array}$ & $\begin{array}{l}0 \\
d\end{array}$ & $\begin{array}{c}14,3 \\
\mathbf{c}\end{array}$ & $\begin{array}{l}0 \\
d\end{array}$ & $\begin{array}{c}12,1 \\
\text { cd }\end{array}$ & $\begin{array}{l}0 \\
d\end{array}$ & $\begin{array}{c}55,6 \\
a\end{array}$ \\
\hline & SD & 0 & 19,9 & 0 & 6,5 & 0 & 4,5 & 0 & 15,6 \\
\hline \multirow[t]{2}{*}{ B4 } & $\mathrm{BH}$ & $\begin{array}{c}0,45 \\
\text { c }\end{array}$ & $\begin{array}{c}47,4 \\
\text { ab }\end{array}$ & $\begin{array}{l}0 \\
\text { C }\end{array}$ & $\begin{array}{c}38,4 \\
\text { ab }\end{array}$ & $\begin{array}{c}0,6 \\
\text { c }\end{array}$ & $\begin{array}{c}28,0 \\
\text { b }\end{array}$ & $\begin{array}{c}0,2 \\
\text { c }\end{array}$ & $\begin{array}{c}59,7 \\
\text { a }\end{array}$ \\
\hline & SD & 0,9 & 8,4 & 0 & 38,3 & 0,7 & 13,5 & 0,5 & 1,7 \\
\hline
\end{tabular}


Ergebnisse

\section{Befallshäufigkeit: Spätsaat}

In der Spätsaat wurden insgesamt vier Bonituren (B1 bis B4) durchgeführt und auf ihre gültigen Effekte analysiert (Tab. 20). In der ersten Bonitur hatte die Sorte $(p=0,559)$ sowie die Interaktion aus Sorte ${ }^{*}$ Variante $(p=0,559)$ keinen Effekt. Lediglich die Variante $(p=$ $0,017)$ war als gültige Effektgröße auszumachen. In der zweiten Bonitur hatten Sorte $(p=$ $0,009)$, Variante $(p=0,000)$ und Interaktion aus Sorte ${ }^{*}$ Variante $(p=0,009)$ einen Effekt. In der dritten Bonitur waren - ähnlich der ersten Bonitur - wieder nur die Variante mit $p=$ 0,000 als gültige Effektgröße auszumachen. Die Sorte $(p=0,281)$ und die Interaktionskomponente aus Sorte*Variante $(p=0,320)$ waren keine gültigen Effektgrößen. In der vierten Bonitur waren - ähnlich der zweiten Bonitur - alle drei Prüfglieder gültige Effektgrößen. So hatte die Sorten einen p-Wert von 0,006 und die Variante einen p-Wert von 0,000 und die Interaktionskomponente Sorte*Variante einen $p$-Wert von 0,004.

In der ersten Bonitur (B1) zu BBCH 25 lagen die Befallshäufigkeiten der inokulierten Varianten bei 7,3\% (Hermann), 10,7\% (Inspiration), 14\% (Toras) und 30,5\% (Mulan). Dennoch gab es statistisch wenige Auffälligkeiten. So war lediglich die Sorte Mulan mit $30,5 \%$ BH signifikant verschieden von den Gesundkontrollen mit 0\% Befall, während die übrigen drei Sorten damit statistisch gleich waren. In der zweiten Bonitur (B2) zu BBCH 35 kam es zu leichten Verschiebungen in der $\mathrm{BH}$ der inokulierten Varianten. Bei Hermann und Toras stieg die $\mathrm{BH}$ leicht an um 1,6\% bzw. um 5,4\%. Bei Inspiration kam es zu einem leichten Rückgang von $-4 \%$. Den stärksten Rückgang hatte Mulan mit $-23,2 \%$. Statistisch betrachtet sind in der B2 die Kontrollen mit 0\% Befall signifikant verschieden von den inokulierten Varianten. Den signifikant höchsten Befall hat die Sorte Toras mit 19,4\%. In der dritten Bonitur (B3) zu BBCH 55 war im Falle von Hermann (inokuliert) und Mulan (inokukiert) nochmal eine sehr geringe Zunahme des Befalls von B2 zu B3 von >2\% zu sehen. Bei Inspiration (inokuliert) blieb der Befall konstant. Die inokulierte Toras Variante hatte mit 13,2\% den höchsten Befall; dies war statistisch aber nicht signifikant verschieden von Hermann mit 10,1\%, aber verschieden zu Inspiration und Mulan. Alle inokulierten Sorten waren signifikant verschieden von den Gesundkontrollen mit 0\% Befall und Hermann $<1 \%$ Befall.

In der vierten Bonitur (B4) zu BBCH 75 stieg im Vergleich zur B3 der Befall der inokulierten Varianten bei drei Sorten und lag nun bei 23,4\% (Toras), 17,8\% (Inspiration) und 9,6\% (Mulan). Hermann (inokuliert) mit 9,8\% blieb nahezu konstant im Verlgeich zur B3 und signifikant gleich mit Mulan (inokuliert), ebenso wie Inspiration und Toras zueinander nicht 
Ergebnisse

signifikant verschieden waren. Die Gesundkontrolle Toras hatte nach wie vor (B1 bis B4) einen Befall von 0\%. Bei den übrigen Sorten lag der Befall der Kontrollen in der B4 bei <1\%.

Tabelle 20: Mittlere Befallshäufigkeit (\%) mit Rhizoctonia an Winterweizen (Hermann, Inspiration, Mulan, Toras) in der Spätsaat zu vier Boniturterminen B1 (= BCCH 25), B2 (= BBCH 35), B3 (= BBCH 55) und B4 (= BBCH 75) im Vergleich der inokulierten Varianten (inokul. = Mischinokulum bestehend aus $R$. solani AG 5 und $R$. cerealis AG D) im Vergleich zur Gesundkontrolle (Kontr.) am Standort Weende (Feldversuch 2011/ 12). Pro Parzelle $(n=4)$ wurden stichprobenartig ca. 65 Pflanzen entnommen $(B 1, B 2, B 3)$ bzw. ca. 85 Pflanzen (B4). Abweichende Buchstaben kennzeichnen signifikante Unterschiede nach statistischer Analyse (ST) mit Fisher LSD (alpha $=0,05$ ) unter Normalverteilung (gegeben od. angepasst); SD = Standardabweichung innerhalb eines Boniturtermins (Tabellenreihe).

\begin{tabular}{|c|c|c|c|c|c|c|c|c|c|}
\hline \multicolumn{10}{|c|}{ Spätsaat: Befallshäufigkeit in [\%] } \\
\hline \multicolumn{2}{|c|}{$\begin{array}{l}\text { Winterweizen- } \\
\text { sorte }\end{array}$} & \multicolumn{2}{|c|}{ Hermann } & \multicolumn{2}{|c|}{ Inspiration } & \multicolumn{2}{|c|}{ Mulan } & \multicolumn{2}{|c|}{ Toras } \\
\hline $\begin{array}{l}\text { Boni- } \\
\text { tur }\end{array}$ & Var. & Kontr. & Inokul. & Kontr. & Inokul. & Kontr. & Inokul. & Kontr. & Inokul. \\
\hline \multirow[t]{2}{*}{ B1 } & $\mathrm{BH}$ & $\begin{array}{l}0 \\
b\end{array}$ & $\begin{array}{l}7,3 \\
a b\end{array}$ & $\begin{array}{l}0 \\
b\end{array}$ & $\begin{array}{c}10,7 \\
\mathbf{a b}\end{array}$ & $\begin{array}{l}0 \\
b\end{array}$ & $\begin{array}{c}30,5 \\
a\end{array}$ & $\begin{array}{l}0 \\
b\end{array}$ & $\begin{array}{c}14,0 \\
\text { ab }\end{array}$ \\
\hline & SD & 0 & 7,3 & 0 & 3,4 & 0 & 47,3 & 0 & 10,1 \\
\hline \multirow[t]{2}{*}{ B2 } & $\mathrm{BH}$ & $\begin{array}{l}0 \\
\text { c }\end{array}$ & $\begin{array}{c}8,9 \\
\text { b }\end{array}$ & $\begin{array}{l}0 \\
c\end{array}$ & $\begin{array}{c}6,1 \\
\mathbf{b}\end{array}$ & $\begin{array}{l}0 \\
\text { c }\end{array}$ & $\begin{array}{c}7,3 \\
\mathbf{b}\end{array}$ & $\begin{array}{l}0 \\
c\end{array}$ & $\begin{array}{c}19,4 \\
\mathbf{a}\end{array}$ \\
\hline & $\mathrm{SD}$ & 0 & 3,9 & 0 & 2,6 & 0 & 4,8 & 0 & 8,9 \\
\hline \multirow[t]{2}{*}{ B3 } & $\mathrm{BH}$ & $\begin{array}{c}0,3 \\
\text { c }\end{array}$ & $\begin{array}{c}10,1 \\
\mathbf{a b}\end{array}$ & $\begin{array}{l}0 \\
\text { c }\end{array}$ & $\begin{array}{l}6,0 \\
\text { bc }\end{array}$ & $\begin{array}{l}0 \\
\text { C }\end{array}$ & $\begin{array}{c}6,6 \\
\text { b }\end{array}$ & $\begin{array}{l}0 \\
\text { c }\end{array}$ & $\begin{array}{c}13,2 \\
\mathbf{a}\end{array}$ \\
\hline & SD & 0,7 & 4,5 & 0 & 4,8 & 0 & 4,6 & 0 & 8,4 \\
\hline \multirow[t]{2}{*}{ B4 } & $\mathrm{BH}$ & $\begin{array}{c}0,2 \\
\text { C }\end{array}$ & $\begin{array}{c}9,8 \\
\text { b }\end{array}$ & $\begin{array}{c}0,5 \\
\text { C }\end{array}$ & $\begin{array}{c}17,8 \\
\mathbf{a}\end{array}$ & $\begin{array}{c}0,2 \\
\text { c }\end{array}$ & $\begin{array}{c}9,6 \\
\text { b }\end{array}$ & $\begin{array}{l}0 \\
\text { C }\end{array}$ & $\begin{array}{c}23,4 \\
\text { a }\end{array}$ \\
\hline & SD & 0,5 & 2,9 & 1,1 & 4,6 & 0,5 & 4,7 & 0 & 8,8 \\
\hline
\end{tabular}

Befallshäufigkeit: Vergleich Früh- und Spätsaat innerhalb der Sorte

Innerhalb der Sorte Hermann (Tab. 21) sind lediglich der Saattermin $(p=0,000)$, die Variante $(p=0,000)$ sowie die Interaktionskomponente aus Saattermin*Variante $(p=0,000)$ als Effektgröße gültig. Die inokulierten Frühsaatvarianten mit Werten im Bereich von 28 bis $50 \%$ sind statistisch signifikant höher befallen als die inokulierten Varianten der Spätsaat mit Werten von 7 bis $10 \%$. Innerhalb der Spätsaat gibt es keinen signifikanten Unterschied zwischen den Gesundkontrollen mit $0 \%$ bzw. $<1 \%$ und den inokulierten Varianten. Innerhalb der Frühsaat sind die inokulierten Varianten signifikant höher befallen als die Gesundkontrollen. 
Tabelle 21: Mittlere Befallshäufigkeit (\%) mit Rhizoctonia an Winterweizen der Sorte Hermann der Frühund Spätsaat zu vier Boniturterminen B1 (= BBCH 25), B2 (= BBCH 35), B3 (= BBCH 55) und B4 (= BBCH 75) im Vergleich der inokulierten Varianten (inokul. = Mischinokulum aus $R$. solani AG 5 und $R$. cerealis AG D) im Vergleich zur Gesundkontrolle (Kontr.) am Standort Weende (Feldversuch in 2011/ 12). Pro Parzelle ( $n=4)$ wurden stichprobenartig ca. 65 Pflanzen (B1, B2, B3) entnommen bzw. ca. 85 Pflanzen (B4). Abweichende Buchstaben kennzeichnen signifikante Unterschiede nach statistischer Analyse (ST) mit Fisher LSD (alpha $=0,05$ ) unter Normalverteilung (gegeben od. angepasst) über alle Varianten (Reihen und Säulen); SD = Standardabweichung.

\begin{tabular}{|c|c|c|c|c|c|}
\hline \multicolumn{2}{|c|}{ Sorte Hermann: Befallshäufigkeit in [\%] } \\
\hline \multicolumn{2}{|c|}{ Aussaat } & \multicolumn{2}{c|}{ Frühsaat } & \multicolumn{2}{c|}{ Spätsaat } \\
\hline Bonitur & Var. & Kontr. & Inokul. & Kontr. & Inokul. \\
\hline \multirow{3}{*}{ B1 } & BH & 0 & 45,3 & 0 & 7,3 \\
& ST & C & a & C & C \\
\cline { 2 - 6 } & SD & 0 & 15,7 & 0 & 7,3 \\
\hline \multirow{3}{*}{ B2 } & BH & 0 & 50,5 & 0 & 8,9 \\
& ST & C & a & c & c \\
\cline { 2 - 6 } & SD & 0 & 33 & 0 & 3,8 \\
\hline \multirow{3}{*}{ B3 } & BH & 0 & 28,6 & 0,35 & 10,1 \\
& ST & C & b & C & C \\
\cline { 2 - 6 } & SD & 0 & 19,8 & 0,7 & 4,5 \\
\hline \multirow{3}{*}{ B4 } & BH & 0,4 & 47,4 & 0,25 & 9,8 \\
& ST & c & a & c & c \\
\cline { 2 - 6 } & SD & 0,9 & 8,4 & 0,5 & 2,9 \\
\hline
\end{tabular}

Innerhalb der Sorte Inspiration (Tab. 22) sind als gültige Effektgröße mit einem p-Wert von jeweils 0,000 die Variante, der Saattermin sowie die Interaktionskomponente aus Variante*Saattermin identifizierbar. Innerhalb der Sorte Inspiration war die Frühsaat signifikant höher befallen mit Werten im Bereich von 14 bis $41 \%$ als die Spätsaat mit 6 bis maximal 17\%. Einzig in der B3 gab es keinen statistisch signifikanten Unterschied zwischen Früh- und Spätsaat. Die Gesundkontrollen mit 0\% Befall waren statistisch nicht signifikant verschieden von der inokulierten Variante der Spätsaat in B1 bis B3. Gleiches gillt für die Frühsaatvariante in B3, so gab es auch hier keinen signifikanten Unterschied zur Kontrolle. 
Ergebnisse

Tabelle 22: Mittlere Befallshäufigkeit (\%) mit Rhizoctonia an Winterweizen der Sorte Inspiration der Frühund Spätsaat zu vier Boniturterminen B1 (= BBCH 25), B2 (= BBCH 35), B3 (= BBCH 55) und B4 (= BBCH 75) im Vergleich der inokulierten Varianten (inokul. = Mischinokulum aus $R$. solani AG 5 und $R$. cerealis AG D) im Vergleich zur Gesundkontrolle (Kontr.) am Standort Weende (Feldversuch in 2011/ 12). Pro Parzelle $(n=4)$ wurden stichprobenartig ca. 65 Pflanzen (B1, B2, B3) entnommen bzw. ca. 85 Pflanzen (B4). Abweichende Buchstaben kennzeichnen signifikante Unterschiede nach statistischer Analyse (ST) mit Fisher LSD (alpha $=0,05$ ) unter Normalverteilung (gegeben od. angepasst) über alle Varianten (Reihen und Säulen); SD = Standardabweichung.

\begin{tabular}{|c|c|c|c|c|c|}
\hline \multicolumn{2}{|c|}{ Sorte Inspiration: Befallshäufigkeit in [\%] } \\
\multicolumn{2}{|c|}{ Aussaat } & \multicolumn{2}{c|}{ Frühsaat } & \multicolumn{2}{c|}{ Spätsaat } \\
\hline Bonitur & Var. & Kontr. & Inokul. & Kontr. & Inokul. \\
\hline \multirow{3}{*}{ B1 } & BH & 0 & 41,0 & 0 & 10,7 \\
& ST & c & a & c & bc \\
\cline { 2 - 6 } & SD & 0 & 9,3 & 0 & 3,4 \\
\hline \multirow{4}{*}{ B2 } & BH & 0 & 32,7 & 0 & 6,1 \\
& ST & C & a & C & bc \\
\cline { 2 - 6 } & SD & 0 & 9,4 & 0 & 2,6 \\
\hline \multirow{4}{*}{ B3 } & BH & 0 & 14,3 & 0 & 6,0 \\
& ST & c & bc & c & bc \\
\cline { 2 - 6 } & SD & 0 & 6,5 & 0 & 4,8 \\
\hline \multirow{3}{*}{ B4 } & BH & 0 & 38,4 & 0 & 17,8 \\
& ST & c & a & c & b \\
\cline { 2 - 6 } & SD & 0 & 38,3 & 0 & 4,6 \\
\hline
\end{tabular}

Innerhalb der Sorte Mulan (Tab. 23) sind als gültige Effektgröße die Parameter Saattermin $(p=0,017)$, Variante $(p=0,000)$, Bonitur $(p=0,001)$ sowie die zwei Interaktionskomponenten Saattermin ${ }^{*}$ Variante $(p=0,018)$ und Variante*Bonitur $(p=0,001)$ identifiziert. Die Gesundkontrollen der Früh- und Spätsaatvarianten waren mit $0 \%$ und $<1 \%$ (B4) signifikant geringer befallen als die inokulierten Varianten beider Saattermine. Insgesamt war die Frühsaat mit Befallswerten zwischen 12 bis $60 \%$ zwar höher infiziert als die Spätsaat mit Werten zwischen 6 bis 17\%, dies war aber lediglich in der ersten Bonitur zu $\mathrm{BBCH} 25$ (B1) statistisch signifikant höher.

Innerhalb der Sorte Toras (Tab. 24) war die Variante, der Saattermin und die Interaktion aus Variante*Saattermin gültige Effektgröße $(p=0,000)$. Die Gesundkontrollen hatten in B1 bis B3 und in B4 (Spätsaat) eine Befallshäufigkeit von 0\% bzw. > 1\% (B4 Frühsaat). Damit waren die inokulierten Früh- und Spätsaatvarianten siginifikant höher infiziert als die Kontrolle. In der Frühsaat lag die Befallshäufigkeit in etwa bei $55 \%$ und war damit signifikant höher als in der Spätsaat mit Werten im Bereich von 13 bis $23 \%$. 


\section{Ergebnisse}

Tabelle 23: Mittlere Befallshäufigkeit (\%) mit Rhizoctonia an Winterweizen der Sorte Mulan der Früh- und Spätsaat zu vier Boniturterminen B1 (= BBCH 25), B2 (= BBCH 35), B3 (= BBCH 55) und B4 (= BBCH 75) im Vergleich der inokulierten Varianten (inokul. = Mischinokulum aus $R$. solani AG 5 und $R$. cerealis AG D) im Vergleich zur Gesundkontrolle (Kontr.) am Standort Weende (Feldversuch in 2011/ 12). Pro Parzelle $(n=4)$ wurden stichprobenartig ca. 65 Pflanzen (B1, B2, B3) entnommen bzw. ca. 85 Pflanzen (B4). Abweichende Buchstaben kennzeichnen signifikante Unterschiede nach statistischer Analyse (ST) mit Fisher LSD (alpha = 0,05 ) unter Normalverteilung (gegeben od. angepasst) über alle Varianten (Reihen und Säulen); SD = Standardabweichung.

\begin{tabular}{|c|c|c|c|c|c|}
\hline \multicolumn{2}{|c|}{ Sorte Mulan: Befallshäufigkeit in [\%] } & \multicolumn{2}{c|}{ Spätsaat } \\
\hline \multicolumn{2}{|c|}{ Aussaat } & \multicolumn{2}{c|}{ Frühsaat } & \multicolumn{2}{c|}{} \\
\hline Bonitur & Var. & Kontr. & Inokul. & Kontr. & Inokul. \\
\hline \multirow{3}{*}{ B1 } & BH & 0 & 60,0 & 0 & 30,5 \\
& ST & e & a & e & b \\
\cline { 2 - 6 } & SD & 0 & 9,2 & 0 & 47,3 \\
\hline \multirow{4}{*}{ B2 } & BH & 0 & 19,0 & 0 & 7,3 \\
& ST & e & bcd & e & de \\
\cline { 2 - 6 } & SD & 0 & 16,1 & 0 & 4,8 \\
\hline \multirow{4}{*}{ B3 } & BH & 0 & 12,1 & 0 & 6,6 \\
& ST & e & bcde & e & de \\
\cline { 2 - 6 } & SD & 0 & 4,5 & 0 & 4,6 \\
\hline \multirow{3}{*}{ B4 } & BH & 0,6 & 28,0 & 0,2 & 9,6 \\
& ST & de & bc & de & cde \\
\cline { 2 - 6 } & SD & 0,7 & 13,5 & 0,5 & 4,7 \\
\hline
\end{tabular}

Tabelle 24: Mittlere Befallshäufigkeit (\%) mit Rhizoctonia an Winterweizen der Sorte Toras der Früh- und Spätsaat zu vier Boniturterminen B1 (= BBCH 25), B2 (= BBCH 35), B3 (= BBCH 55) und B4 (= BBCH 75) im Vergleich der inokulierten Varianten (inokul. = Mischinokulum aus $R$. solani AG 5 und $R$. cerealis AG D) im Vergleich zur Gesundkontrolle (Kontr.) am Standort Weende (Feldversuch in 2011/ 12). Pro Parzelle $(n=4)$ wurden stichprobenartig ca. 65 Pflanzen (B1, B2, B3) entnommen bzw. ca. 85 Pflanzen (B4). Abweichende Buchstaben kennzeichnen signifikante Unterschiede nach statistischer Analyse (ST) mit Fisher LSD (alpha = 0,05) unter Normalverteilung (gegeben od. angepasst) über alle Varianten (Reihen und Säulen); SD = Standardabweichung.

\begin{tabular}{|c|c|c|c|c|c|}
\hline \multicolumn{6}{|c|}{ Sorte Toras: Befallshäufigkeit in [\%] } \\
\hline \multicolumn{2}{|c|}{ Aussaat } & \multicolumn{2}{|c|}{ Frühsaat } & \multicolumn{2}{|c|}{ Spätsaat } \\
\hline Bonitur & Var. & Kontr. & Inokul. & Kontr. & Inokul. \\
\hline \multirow{3}{*}{ B1 } & $\mathrm{BH}$ & 0 & 55,5 & 0 & 14,0 \\
\hline & ST & c & a & c & b \\
\hline & SD & 0 & 20,9 & 0 & 10,1 \\
\hline \multirow{3}{*}{ B2 } & $\mathrm{BH}$ & 0 & 53,3 & 0 & 19,4 \\
\hline & ST & c & a & C & b \\
\hline & SD & 0 & 6,8 & 0 & 8,9 \\
\hline \multirow{3}{*}{ B3 } & $\mathrm{BH}$ & 0 & 55,6 & 0 & 13,2 \\
\hline & ST & c & a & c & b \\
\hline & SD & 0 & 15,6 & 0 & 8,4 \\
\hline \multirow{3}{*}{ B4 } & $\mathrm{BH}$ & 0,2 & 59,7 & 0 & 23,4 \\
\hline & ST & c & a & C & b \\
\hline & SD & 0,5 & 1,7 & 0 & 8,8 \\
\hline
\end{tabular}


Ergebnisse

\section{Erregernachweis}

Zum Nachweis des Erregers in Pflanzenmaterial wurde während der Bonitur zu BBCH 75 symptomatisches Stängelmaterial aus den künstlich inokulierten Parzellen gesammelt. Die Erregeridentifikation erfolgte mittels PCR-Nachweis. Des Weiteren wurde ein Nachweis auf PDA-Abgleichstest durchgeführt. Insgesamt wurden 63 Halme analysiert. Von der Winterweizensorte Hermann wurden insgesamt 15 Halme untersucht. Diese stammten aus den Parzellen Nr. 1 (Frühsaat, 6 Halme) und den Spätsaatparzellen Nr. 31 (4 Halme) und Nr. 51 (5 Halme). Von der Sorte Inspiration wurden insgesamt Nr. 14 Halme analysiert, welche aus den Parzellen Nr. 21 (Frühsaat; 5 Halme) und Nr. 53 (Spätsaat; 9 Halme) entnommen wurden. Von der Sorte Mulan wurden 17 Halme aufgereinigt. Diese stammten aus der frühgesäten Parzelle Nr. 13 (6 Halme) und den spätgesäten Parzellen Nr. 35 (6 Halme) und Nr. 55 (5 Halme). Von der Sorte Toras wurden insgesamt 17 Halme analysiert. Dabei entfielen jeweils 6 Halme auf die Frühsaatparzellen Nr. 4 und $\mathrm{Nr}$. 17 und des Weiteren 5 Halme auf die Spätsaatparzelle Nr. 61. Pro Halm konnten zwischen ein und bis zu vier Isolate gewonnen werden, sodass insgesamt 139 Isolate untersucht wurden. Davon wurden 128 Isolate mittels beider Testmethoden analysiert. In allen erfolgreich analysierten Proben konnte ausschließlich $R$. cerealis AG D nachgewiesen werden.

\subsubsection{Bestandesparameter}

\section{$\underline{\text { Auflauf }}$}

Im Herbst 2011 konnte visuell ein homogener Feldaufgang beobachtet werden. Daher wurde von einer Erhebung entsprechender Parameter abgesehen.

\section{$\underline{\text { Auswinterung }}$}

Die Kahlfrostperiode im Februar 2012 führte zu einem messbaren Winterschaden (Abb. 19). Dieser wurde in Form des Parameters [Anzahl an grünen Trieben pro $\mathrm{m}^{2}$ ] erfasst. Die Erhebung der Daten erfolgte am 17.03.2012 (Frühsaat) und 01.04.2012 (Spätsaat). 
Ergebnisse

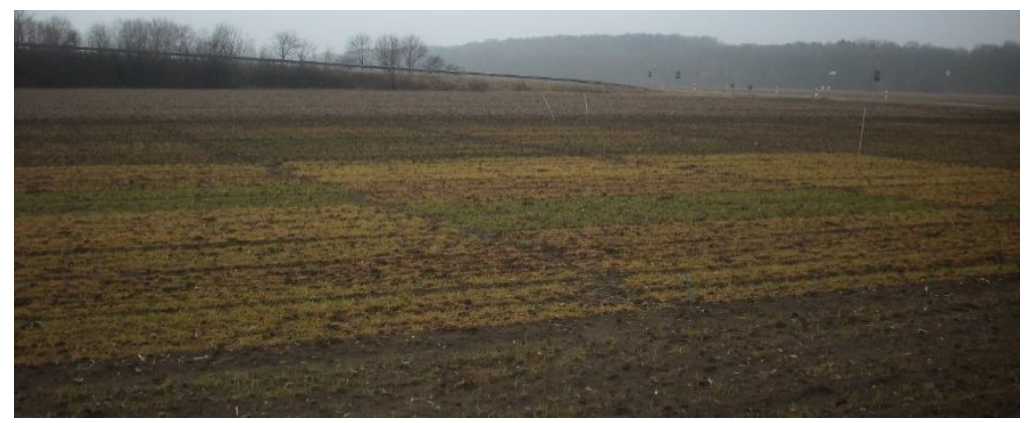

Abbildung 19: Winterweizenfeldversuch in Weende in der Vegetationsperiode 2011/12 (gezeigt: Frühsaat, Parzellengröße $8 \mathrm{~m} \times \mathbf{3} \mathrm{m}$ ) mit den Sorten Hermann, Inspiration, Mulan und Toras nach der Kahlfrostperiode Ende Februar 2012 mit erkennbar frostgeschädigten verbraunten Parzellen bei den drei erstgenannten Sorten. Erkennbar grün sind die Parzellen mit der Sorte Toras.

Zunächst wurden Früh- und Spätsaat ohne den Sortenaspekt betrachtet (Tab. 25). Die Analyse der Daten hinsichtlich möglicher Effektgrößen ergab, dass alle drei Faktoren (Aussaat, Inokulationsvariante, Aussaat*Inokulation) signifikant waren. Den geringsten Bedeckungsgrad mit 272,6 Trieben hatte die inokulierte Spätsaatvariante. Diese unterschied sich aber nicht signifikant von der spät gesäten Gesundkontrolle mit 307 Trieben. Insgesamt zeigte die Spätsaat einen signifikant geringeren Bedeckungsgrad als die Frühsaat. So hatte die inokulierte Frühsaatvariante mit 474,4 signifikant mehr grüne Triebe. Den signifikant höchsten Bedeckungsgrad hatte die nicht-inokulierte Frühsaatkontrolle mit 629,5 grünen Trieben pro $\mathrm{m}^{2}$.

Tabelle 25: Auswinterung [Anzahl grüne Triebe/ $\mathrm{m}^{2}$ ] im Winterweizenversuch Weende 2011/12 (Mitttel von vier Sorten), differenziert nach Aussaatterminvariante (früh/ spät) und Inokulationsvariante (Kontrolle/ inokuliert mit Mischinokulum aus R. solani AG 5 und R. cerealis AG D). Auswertung am 17.03.2012 für die Frühsaat und am 01.04.2012 für die Spätsaat $(n=4)$. Abweichende Buchstaben kennzeichnen signifikante Unterschiede nach statistischer Analyse mit Fisher LSD (alpha $=0,05)$ unter Normalverteilung (gegeben oder angepasst) über alle Varianten, SD = Standardabweichung.

\begin{tabular}{|l|c|c|c|}
\hline Aussaatterminvariante & Inokulationsvariante & Anzahl grüne Triebe/m & SD \\
\hline \multirow{2}{*}{ Früh (28.09.2011) } & Kontrolle & $629,5 \mathrm{a}$ & 185,7 \\
\cline { 2 - 4 } & inokuliert & $474,4 \mathrm{~b}$ & 200,6 \\
\hline \multirow{2}{*}{ Spät (21.10.2011) } & Kontrolle & $307,0 \mathrm{c}$ & 059,1 \\
\cline { 2 - 4 } & inokuliert & $272,6 \mathrm{c}$ & 076,4 \\
\hline
\end{tabular}

Im Folgenden wird eine Betrachtung der Auswinterungsdaten unter Einbeziehung der Sorten durchgeführt.

Die Varianzanalyse ergab, dass Sorte, Aussaat, Inokulationsvariante und die Kombinationen aus Sorte*Aussaat sowie Aussaat*Inokulation mit einem jeweiligen $p$-Wert von 0,000 einen signifikanten Effekt hatten. Während die Kombination aus 
Ergebnisse

Aussaat ${ }^{*}$ Variante mit $p=0,001$ signifikant war, traf dies für die die Kombination aus Sorte*Aussaat*Inokulation nicht zu. Daher wurde eine separate statistische Auswertung mittels Fisher LSD Test vorgenommen (Abb. 20) und Früh- und Spätsaat getrennt voneinander betrachtet.

In den Frühsaatparzellen war in den Sorten Hermann, Inspiration und Mulan in der jeweils inokulierten Variante eine im Vergleich zur Kontrolle signifikante Reduktion der grünen Triebe messbar. So lag der Bedeckungsgrad in den inokulierten Varianten der Sorten Hermann und Inspiration bei 468,3 bzw. bei 468 grünen Trieben, was statistisch gleich ist. In den jeweiligen Kontrollen lag die Anzahl grüner Triebe statisch signifikant höher bei 611,6 (Kontrolle Hermann) und bei 715,3 (Kontrolle Inspiration). Im Falle von Inspiration belief sich - ausgehend von 715,3 grüne Triebe/ $\mathrm{m}^{2}$ bei der Kontrolle - die Reduktion auf 247. Die Sorte Mulan zeigte damit im Vergleich zu Hermann und Inspiration die drastischste Auswinterung mit einer Reduktion der grünen Triebe um etwa 50\%. Einzig die Sorte Toras zeigte in der inokulierten Variante keinen signifikanten Ausfall an grünen Trieben im Vergleich mit der Kontrolle. Die Spätsaat hatte im Vergleich mit der Frühsaat einen viel geringeren Bedeckungsgrad. Signifikante Unterschiede zwischen der inokulierten Variante und der Gesundkontrolle gab bei den Sorten Hermann und Mulan, während Inspiration und Toras keine Auswinterung zeigten.

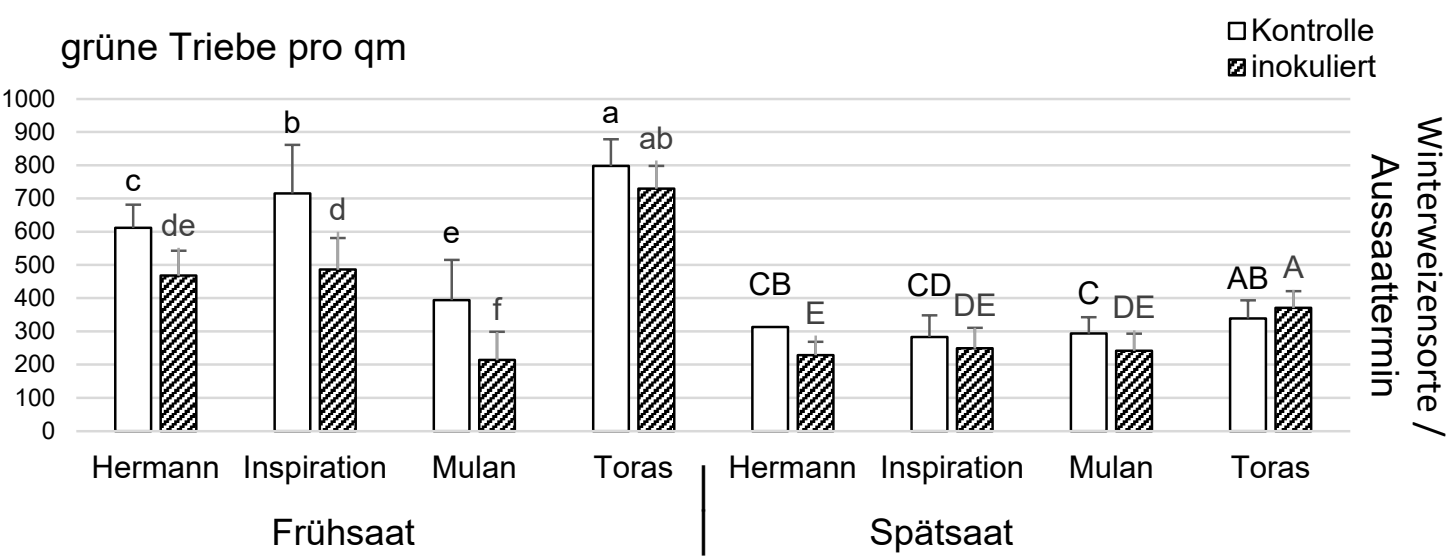

Abbildung 20: Auswinterung im Feldversuch Weende 2011/ 12., ermittelt über den Parameter [grüne Triebe/ $\mathrm{m}^{2}$ ] $(n=4)$ für vier verschiedene Sorten in der Früh- und in der Spätsaat. Vertikale Balken geben die positive Standardabweichung an. Inokulierte Variante (Mischinokulum, gleiche Anteile von $R$. solani AG 5 u. $R$. cerealis AG D = schraffierte Säule). Die statistische Auswertung erfolgte mittels Fisher LSD Test (alpha 0,05 ) bei Normalverteilung (gegeben oder angespasst). Signifikanzen werden anhand von unterschiedlichen Buchstaben angezeigt. Die Auswinterungsdaten wurden getrennt nach Saattermin (Frühsaat: Kleinbuchstaben; Spätsaat: Großbuchstaben) statistisch ausgewertet. 
Ergebnisse

\section{Bestandesdichte}

Bei der Betrachtung der Bestandesdichte wurde zum Zeitpunkt der frühen Milchreife der Parameter [Ähren tragende Halme/ $\mathrm{m}^{2}$ ] erfasst (Tab. 26). Es wurde zunächst die Frühsaat mit der Spätsaat verglichen. Signifikante Effekte ergaben sich hierbei für den Aussaattermin $(p=0,019)$ und die Inokulationsvariante $(p=0,025)$. Die Kombination aus Aussaat*Inokulation war nicht signifikant $(p=0,066)$. Die weitere statistische Analyse mittels Fisher LSD Test zeigte, dass die Spätsaat Kontrolle mit 473,4 Ähren tragenden Halmen/ $\mathrm{m}^{2}$ sowie die inokulierte Spätsaat Variante mit 467,1 statistisch betrachtet gleich waren mit der Frühsaat Kontrolle mit 465,7 Ähren pro $\mathrm{m}^{2}$. Signifikant verschieden von den drei erstgenannten Varianten mit der geringsten Bestandesdichte war die inokulierte Frühsaatvariante mit nur 403,7 Ähren pro Flächeneinheit.

Tabelle 26: Bestandesdichte [Ähren tragende Halme/ $\mathrm{m}^{2}$ ] in der Früh- und Spätsaat im Feldversuch Weende 2011/12, ermittelt am 19.07.2012 in der Früh- und Spätsaat. Inokulation mit einem Mischinokulum aus $R$. solani AG 5 und $R$. cerealis AG D. Gezeigt sind die Mittelwerte $(M W)(n=4)$, die Standardabweichung (SD) und der statistische Vergleich mittels Fisher LSD Test (alpha $=0,05$ ) unter Normalverteilung (gegeben oder angepasst) über alle Varianten. Abweichende Buchstaben kennzeichnen signifikante Unterschiede.

\begin{tabular}{|l|c|c|c|}
\hline $\begin{array}{l}\text { Aussaattermin- } \\
\text { variante }\end{array}$ & $\begin{array}{c}\text { Inokulations- } \\
\text { variante }\end{array}$ & $\begin{array}{c}\text { Mittelwert MW } \\
\text { [Ähren tragende Halme } / \mathbf{m}^{2} \text { ] }\end{array}$ & SD \\
\hline \multirow{2}{*}{ Spät (28.09.2011) } & Kontrolle & $473,4 \mathrm{a}$ & 084,1 \\
\cline { 2 - 4 } & inokuliert & $467,1 \mathrm{a}$ & 095,1 \\
\hline Früh (21.10.2011) & Kontrolle & $465,7 \mathrm{a}$ & 108,6 \\
\cline { 2 - 4 } & inokuliert & $403,7 \mathrm{~b}$ & 126,0 \\
\hline
\end{tabular}

Aufgrund der sortenspezifischen Ertragsbildung und Pflanzenarchitektur ergab sich bei der Betrachtung der Bestandesdichte ein sehr inhomogenes Bild mit signifikanten Unterschieden zwischen den Sorten. Zur besseren Übersicht wurde jede Sorte einzeln betrachtet. Dabei wurden der Aussaattermin und die Inokulationsvariante berücksichtigt und statistisch verglichen.

Bei den Sorten Hermann und Toras konnte kein signifikanter Effekt von Aussaattermin oder Inokulation auf die Bestandesdichte ermittelt werden (Tab. 27). Der erhobene Parameter, Ähren tragende Halme pro $\mathrm{m}^{2}$, lag bei beiden Sorten in einem engen Bereich von minimal 422,3 bis 476,3 (Hermann) bzw. zwischen 514,6 und 577 (Toras). Es gab keine signifikanten Unterschiede in der Bestandesdichte. 
Ergebnisse

Tabelle 27: Bestandesdichten [Ähren tragende Halme $/ \mathrm{m}^{2}$ ] der Sorten Hermann und Toras im Feldversuch 2011/ 12 am Standort Weende differenziert nach Aussaatterminvariante (früh/ spät) und Inokulationsvariante (Gesundkontrolle/ Mischinokulum bestehend aus $R$. solani AG 5 und $R$. cerealis AG D zu gleichen Teilen) Gezeigt sind die Mittelwerte (MW), Angabe der Standardabweichung (SD) und der statistische Vergleich mittels Fisher LSD Test (alpha $=0,05$ ) unter Normalverteilung (gegeben oder angepasst) innerhalb aller Varianten einer Sorte, wobei Signifikanzen durch abweichende Buchstaben gekennzeichnet werden.

\begin{tabular}{|l|c|c|c|c|c|}
\hline \multirow{2}{*}{$\begin{array}{l}\text { Aussaat- } \\
\text { termin- } \\
\text { variante }\end{array}$} & \multirow{2}{*}{$\begin{array}{l}\text { Inokulations- } \\
\text { variante }\end{array}$} & \multicolumn{4}{|c|}{ Ähren tragende Halme $/ \mathbf{m}^{\mathbf{2}}$} \\
\cline { 3 - 6 } & & \multicolumn{2}{|c|}{ Hermann } & \multicolumn{2}{|c|}{ Toras } \\
\cline { 3 - 6 } & & $\mathrm{MW}$ & $\mathrm{SD}$ & $\mathrm{MW}$ & $\mathrm{SD}$ \\
\hline Früh & Kontrolle & $465,3 \mathrm{a}$ & 101,9 & $577,0 \mathrm{a}$ & 082,9 \\
\cline { 3 - 6 }$(28.09 .11)$ & Inokuliert & $422,3 \mathrm{a}$ & 084,8 & $546,0 \mathrm{a}$ & 104,8 \\
\hline Spät & Kontrolle & $476,3 \mathrm{a}$ & 066,8 & $514,6 \mathrm{a}$ & 091,8 \\
\cline { 2 - 6 }$(21.10 .11)$ & Inokuliert & $466,3 \mathrm{a}$ & 078,6 & $526,3 \mathrm{a}$ & 104,8 \\
\hline
\end{tabular}

Bei der Sorte Inspiration variierte die Bestandesdichte zwischen 327,6 (Frühsaat, inokuliert) und 420,0 (Spätsaat, inokuliert) Ähren tragenden Halmen pro $\mathrm{m}^{2}$ (Tab. 28). Einzig die Inokulationsvariante hatte einen Effekt $(p=0,048)$. Die inokulierte Frühsaatvariante hatte signifikant weniger Ähren tragende Halme pro $\mathrm{m}^{2}$. Bei der Sorte Mulan lag die Spannbreite in der Bestandesdichte von 319,0 (Frühsaat, inokuliert) und 485,0 (Spätsaat, Kontrolle) Ähren tragenden Halmen pro $\mathrm{m}^{2}$. Als gültige Effektgrößen konnten die Inokulationsvariante $(p=0,000)$ und der Aussaattermin $(p=0,022)$ ermittelt werden. Die Sorte Inspiration hatte signifikant weniger Ähren tragende Halme in der inokulierten Frühsaatvariante. Hier konnten lediglich 327,6 Ähren tragende Halme pro $\mathrm{m}^{2}$ gezählt werden, was im Vergleich zur Frühsaatkontrolle mit 435,3 und zur Spätsaat mit 417 (Kontrolle) bzw. 420 (inokuliert) signifikant weniger waren. Die Sorte Mulan zeigte in der Spätsaat keine Signifikanzen. Jedoch war dazu im Vergleich die Frühsaat signifikant geringer bedeckt mit Ähren tragenden Halmen pro Quadratmeter. Des Weiteren war die inokulierte Frühsaatvariante gegenüber der Frühsaatkontrolle nochmals signifikant reduziert mit nur 319 Ährenhalmen. 
Ergebnisse

Tabelle 28: Bestandesdichten [Ähren tragende Halme $/ \mathrm{m}^{2}$ ] der Sorten Inspiration und Mulan im Feldversuch 2011/ 12 am Standort Weende differenziert nach Aussaattermin (früh/ spät) und Inokulationsvariante (Gesundkontrolle/ Mischinokulum bestehend aus R. solani AG 5 und R. cerealis AG D zu gleichen Teilen). Gezeigt sind die Mittelwerte (MW), Angabe der Standardabweichung (SD) und der statistische Vergleich mittels Fisher LSD Test (alpha $=0,05$ ) unter Normalverteilung (gegeben oder angepasst) innerhalb aller Varianten einer Sorte, wobei Signifikanzen durch abweichende Buchstaben gekennzeichnet werden.

\begin{tabular}{|c|c|c|c|c|c|}
\hline \multirow{3}{*}{$\begin{array}{l}\text { Aussaat- } \\
\text { termin- } \\
\text { variante }\end{array}$} & \multirow{3}{*}{$\begin{array}{l}\text { Inokulations- } \\
\text { variante }\end{array}$} & \multicolumn{4}{|c|}{ Ähren tragende Halme $/ \mathrm{m}^{2}$} \\
\hline & & \multicolumn{2}{|c|}{ Inspiration } & \multicolumn{2}{|c|}{ Mulan } \\
\hline & & MW & SD & MW & SD \\
\hline \multirow{2}{*}{$\begin{array}{l}\text { Spät } \\
(21.10 .11)\end{array}$} & Kontrolle & $417,6 \mathrm{a}$ & 86,5 & $485,0 \mathrm{a}$ & 64,2 \\
\hline & Inokuliert & $420,0 \mathrm{a}$ & 94,4 & $456,0 \mathrm{a}$ & 64,9 \\
\hline \multirow{2}{*}{$\begin{array}{l}\text { Früh } \\
(28.09 .11)\end{array}$} & Kontrolle & $435,3 \mathrm{a}$ & 90,8 & $385,3 b$ & 60,9 \\
\hline & Inokuliert & $327.6 \mathrm{~b}$ & 87.7 & $319.0 \mathrm{c}$ & 86.3 \\
\hline
\end{tabular}

\subsubsection{Ertragsparameter}

\section{Tausendkornmasse}

Im Feldversuch Weende konnte über alle Varianten ein einheitliches TKM von etwa $43 \mathrm{~g}$ $+/$ - 0,1 g ermittelt werden. Der statistische Vergleich mittels Fisher LSD Test (alpha $=0,05$ ) unter Verteilungsanpassung zeigte keine signifikanten Unterschiede zwischen den Varianten.

\section{Anzahl Körner/ Ähre}

Aufgrund einer lückenhaften Datengrundlage ist bezüglich der Körner pro Ähre lediglich ein Vergleich unter Ausschluß der Sortenvarianten möglich (Abb. 21). Die Analyse signifikanter Effekte ergab, dass die Variante $(p=0,743)$ und die Aussaat $(p=0,852)$ keinen Effekt hatten, hingegen aber die Kombination aus Variante*Aussaat $(p=0,007)$. Die Anzahl Körner/Ähre lag zwischen minimal 36,6 (Frühsaat, inokuliert) und 43,5 (Frühsaat, Kontrolle). Dabei gab es innerhalb der Spätsaat keinen signifikanten Unterschied zwischen der inokulierten Variante mit 43,2 Körnern pro Ähre und der Kontrolle mit 37,8 Körnern pro Ähre. Dagegen war in der Frühsaatvariante die Kornzahl pro Ähre bei der inokulierten Variante mit 36,6 im Vergleich zur Kontrolle mit 43,5 signifikant verringert. 


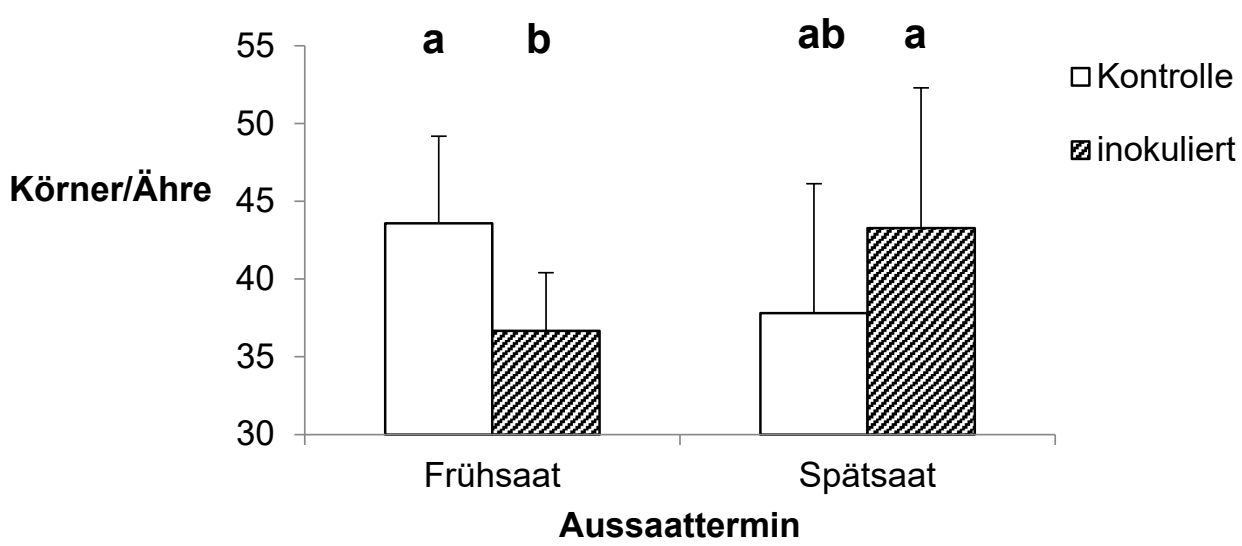

Abbildung 21: Körner/ Ähre $(n=8)$ im Feldversuch am Standort Weende in der Vegetationsperiode 2011/12 in der Früh- und Spätsaat, inokuliert (schraffierte Säule) mit Mischinokulum aus R. solani AG 5 und R. cerealis AG D im Mittel von vier Sorten (Winterweizen: Hermann, Inspiration, Mulan, Toras), Gesundkontrolle (weiße Säule). Statistische Analyse nach Fisher LSD (alpha = 0,05) mit Normalverteilung (gegeben oder angepasst), Signifikanzen über alle Varianten werden mit unterschiedlichen Buchstaben gekennzeichnet, vertikale Balken stellen positive Standardabweichungen dar.

\section{Ertragsdaten}

Die Ertragsdaten wurden am 08.08.2012 (Frühsaat) bzw. am 14.08.2012 (Spätsaat) erhoben. Der Ertrag wurde bei einer Kornfeuchte von 14,5\% in dt/ha angegeben. Bei der Betrachtung des Ertrags wurde zunächst unter Ausschluss der Variante Sorte die Frühgegen die Spätsaat verglichen (Abb. 22). Der statistische Vergleich mittels Fisher LSD Test (alpha $=0,05)$ und die Betrachtung der Effektgrößen zeigte, dass lediglich die Inokulationsvariante einen signifikanten Effekt hatte $(p=0,021)$, nicht hingegen die Aussaat $(p=0,056)$ oder die Interaktionskomponente aus Aussaat*Inokulation $(p=0,089)$. Die Frühsaat-Kontrolle mit 57,4 dt/ ha, die Spätsaat-Kontrolle mit 57,8 dt/ ha und die inokulierte Spätsaat mit 56,8 dt/ ha zeigten keine statistisch signifikanten Unterschiede. Die Differenzen zwischen den Varianten bewegen sich in einem nicht nennenswerten Bereich von unter $1 \mathrm{dt} /$ ha. Nur die inokulierte Frühsaatvariante hatte mit 51,0 dt/ ha statistisch betrachtet signifikant weniger Ertrag. Die gemittelte Differenz der Frühsaatvariante zu den drei erstgenannten Varianten belief sich auf etwa $6,3 \mathrm{dt} / \mathrm{ha}$. 


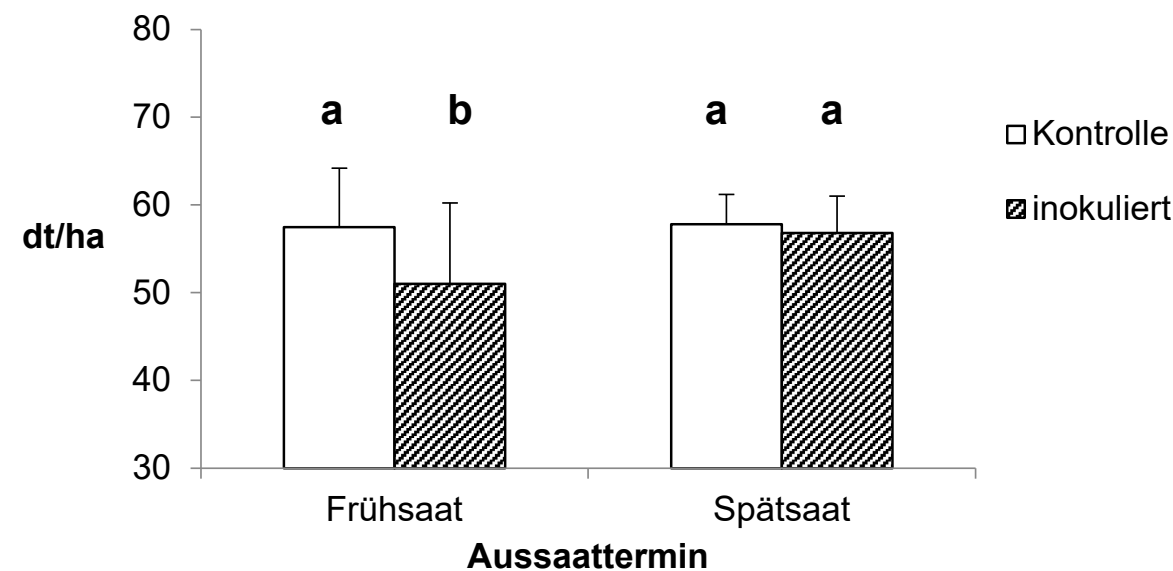

Abbildung 22: Erträge [dt/ ha] $(n=16)$ im Feldversuch am Standort Weende in der Vegetationsperiode 2011/12 in der Früh- und Spätsaat nach Inokulation mit einem Mischinokulum aus R. solani AG 5 und R. cerealis AG D im Mittel von vier Winterweizensorten (Hermann, Inspiration, Mulan, Toras), Gesundkontrolle (weiße Säule) und inokuliert (schraffierte Säule). Statistische Analyse nach Fisher LSD (alpha $=0,05$ ) mit Normalverteilung (gegeben oder angepasst), signifikante Unterschiede über alle Varianten werden mit unterschiedlichen Buchstaben gekennzeichnet, vertikale Balken geben die positive Standardabweichung an.

Bei der sortenspezifischen Ertragsbetrachtung der Spätsaat über alle Sorten hatten die Inokulation und die Sorte keinen signifikanten Effekt. Daher wurde eine gemeinsame Betrachtung von Früh- und Spätsaat gewählt. In dieser Betrachtung hatte die Inokulationsvariante insgesamt einen Effekt, was der p-Wert mit 0,006 anzeigt. Die Faktoren Sorte $(p=0,000)$, Aussaat $(p=0,000)$ und die Kombinationen aus Sorte*Aussaat $(p=0,000)$, sowie Inokulation*Aussaat $(p=0,025)$ stellten weitere signifikante Effekte dar. Die Kombination aus Sorte*Inokulation $(p=0,586)$ hingegen war nicht signifikant. Das nachfolgende Säulendiagramm stellt die Ertragsdaten von Früh- und Spätsaat graphisch dar (Abb. 23).

In der Frühsaat war der Ertrag in den Kontrollen und inokulierten Varianten der Sorten Hermann, Inspiration und Mulan signifikant gegenüber Toras reduziert. In allen drei Sorten war auch ein statistisch signifikanter Ertragsrückgang gegenüber der Kontrolle mit 50,9 dt/ ha messbar. Die Sorte Toras hingegen zeigte in der inokulierten Variante einen Ertrag von 65,8 dt/ ha und in Kontrolle einen Ertrag von 64,6 dt/ ha, was einer Differenz von 1,2 dt/ ha entspricht und keinen statistisch signifikanten Ertragsverlust ausmachte.

In der Spätsaat war bei keiner Sorte ein signifikanter Ertragsrückgang durch die Inokulation messbar. In der vergleichenden Betrachtung von Früh- und Spätsaat unter Einbeziehung der Sorten zeigte sich, dass nur im Falle der Sorte Toras ein frühgesäter Winterweizen 
Ergebnisse

einen höheren Ertrag erzielt als ein spät gesäter Winterweizen. So hatten die frühgesäten nicht-inokulierten Parzellen von Toras mit 65,8 dt/ ha einen signifikant höheren Ertrag als die spät gesäten mit 59,8 dt/ ha. Hingegen zeigten die inokulierten Parzellen diesen Trend nicht: der Ertrag der frühgesäten Parzellen mit 64,6 dt/ ha unterschied sich nicht signifikant von dem des spätgesäten mit $63 \mathrm{dt} /$ ha. Der Ertrag bei Toras blieb von der Inokulation und dem Aussaattermin unbeeinflusst. Hermann, Inspiration und Mulan war neben dem unerwarteten Ertragsrückgang in den frühgesäten Kontrollen (im Vergleich zur Spätsaat) ein weiterer Ertragsverlust in den frühgesäten inokulierten Parzellen gegenüber den Kontrollen zu beobachten. In der Spätsaat dieser 3 Sorten war dieser Trend nicht zu beobachten. Bei alleiniger Betrachtung der Spätsaat über alle Sorten war nur der Ertragsrückgang in den inokulierten Parzellen (53,2 dt/ ha) der Sorte Mulan im Vergleich zur Kontrolle ( $57,5 \mathrm{dt} / \mathrm{ha})$ signifikant. Allerdings war auch bei Mulan der Effekt der Inokulation nicht signifikant $(p=0,718)$.

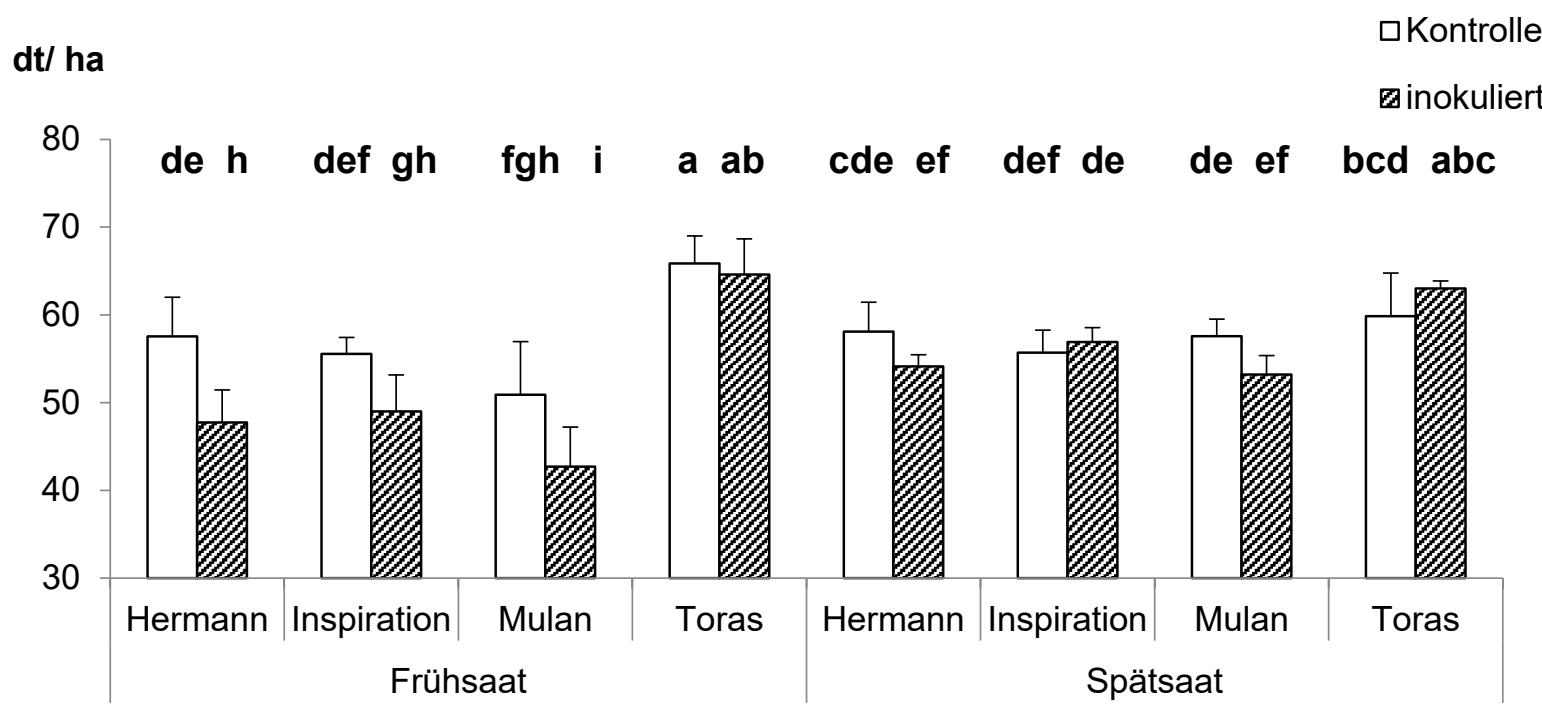

Winterweizensorte / Aussaattermin

Abbildung 23: Ertragsdaten von vier Winterweizensorten (Hermann, Inspiration, Mulan, Toras) im Feldversuch Weende 2011/12 in der Früh- und Spätsaat, nach Inokulation mit Mischinokulum zu gleichen Teilen aus $R$. solani AG 5 und $R$. cerealis AG D = schraffierte Säule; (Gesundkontrolle = weiße Säule). Die statistische Auswertung erfolgte mittels Fisher LSD Test (alpha 0,05) unter Normalverteilung (gegeben oder angespasst) über alle Varianten. Signifikanzen werden anhand von unterschiedlichen Buchstaben angezeigt, Vertikale Balken stellen die positive Standardabweichung dar. 
Ergebnisse

\subsection{Versuch in der Göttinger Bodenerwärmungsanlage}

\subsubsection{Meteorologische Daten}

Die Göttinger Bodenerwärmungsanlage wurde für den Versuch vom 04.10.2012 bis zum 25.07.2013 für insgesamt 294 Tage in Betrieb genommen. Dabei diente der Zeitraum vom 04.10. bis zum 09.10.2012 zur Stabilisation des Systems. Der eigentliche Versuch startete mit der Aussaat und Inokulation am 10.10.2012 und endete mit der Handernte am 23.07.2013. Während der Betriebszeit fanden im 5-minütigen Zeitabstand meteorologische Messungen statt (288 Messungen/ Tag). Nach Auswertung der Daten fielen die folgenden Tage mit unvollständigen Messungen aus: 13.04.2013 (88 Messungen), 15.04.2013 (147 Messungen), 17.06.2013 (93 Messungen), 19.06.2013 (120 Messungen) und am 25.07.13 (141 Messungen); am 14.04.13 und 18.06.13 wurden keine Messdaten erhoben. Zur Auswertung der Daten wurden Tagesmittelwerte berechnet und graphisch dargestellt. Im Folgenden sollen zunächst die Temperaturdaten in $5 \mathrm{~cm}$ und in $15 \mathrm{~cm}$ Bodentiefe (BT) aller drei Varianten sowie der Lufttemperatur betrachtet werden. Die Temperaturgrafiken der Bodentemperatur in 5 und in $15 \mathrm{~cm}$ Tiefe zeigen anschaulich den Verlauf der drei Kurven der Varianten „ohne Erwärmung“, „leicht erwärmt“ (graue Linie) und „stark erwärmt“ (gelbe Linie), wie diese im gleichmäßigen Abstand von $1,6^{\circ} \mathrm{C}$-Einheiten zueinander den Temperaturverlauf in der Vegetationsperiode abzeichnen (Abb. 24). Die blaue Linie in der Grafik stellt die Lufttemperatur dar. Diese verläuft meist unterhalb der Bodentemperaturen der leicht und stark erwärmten Varianten (grau, gelb). Insgesamt ist die Lufttemperatur sprunghafter und hat größere Amplituden nach unten, als die Bodentemperatur der Variante „ohne Erwärmung“. Im Zeitraum vom 13.04 .13 bis zum 22.05.13 liegen alle vier Temperaturkurven eng beieinander und verlaufen ähnlich der Lufttemperaturkurve, weil sich der Boden erwärmt hatte. 
Ergebnisse
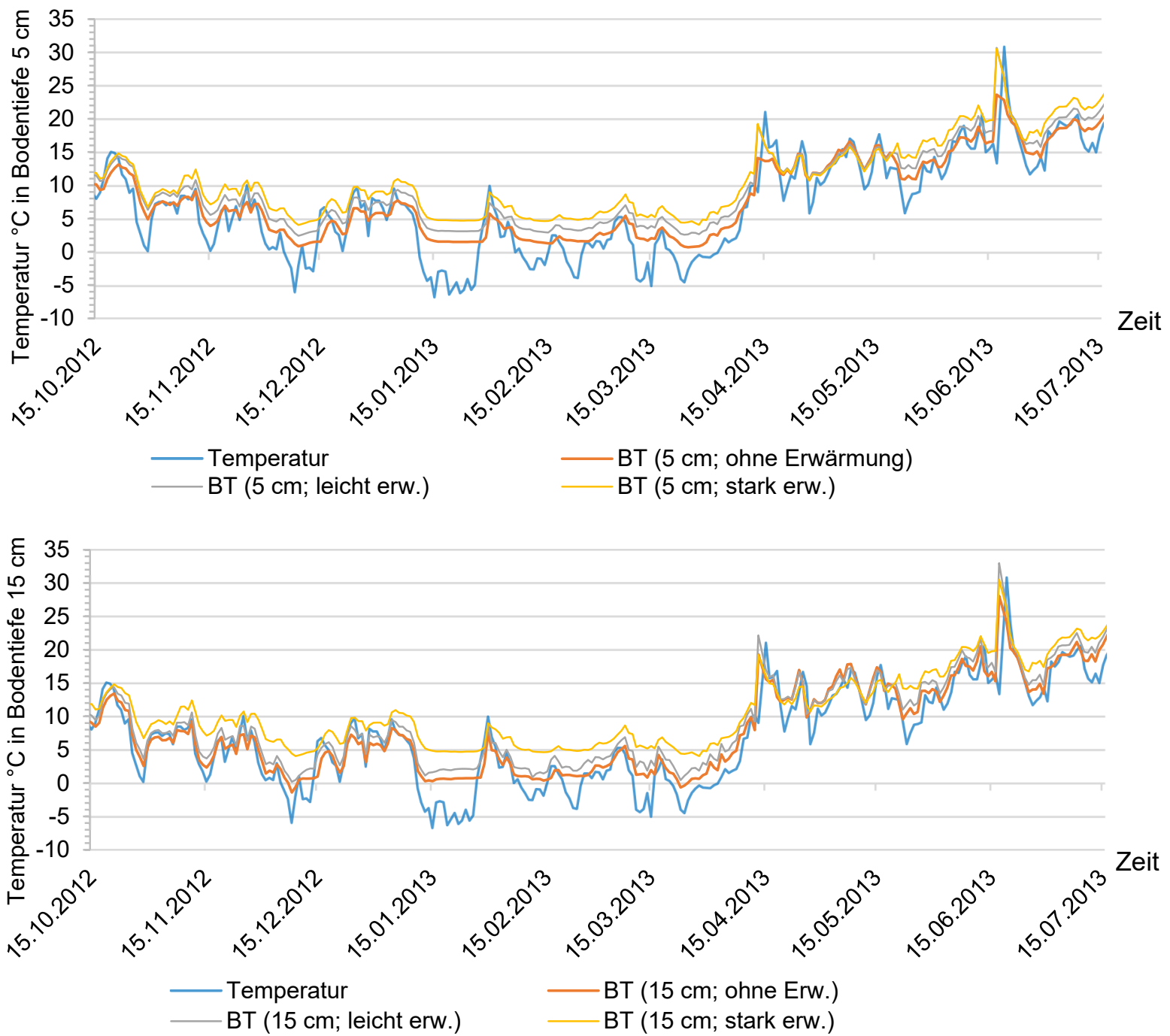

Abbildung 24: Temperaturdaten der Göttinger Bodenerwärmungsanlage gemessen in 5 (oben) und $15 \mathrm{~cm}$ (unten) Bodentiefe (BT). Zu sehen sind drei Temperaturvarianten des Versuchs mit Winterweizen (Sorte Toras) unter künstlicher Rhizoctonia-Inokulation (AG 5, AG 1-IB, AG D) sowie Gesundkontrolle. "Ohne Erwärmung“ als orangefarbene Linie, „leicht erwärmt“ als graue Linie und „stark erwärmt“ als gelbe Linie im Vergleich zur Luftemperatur „Temperatur“ als blaue Linie, gezeigt für die Vegetationsperiode von Mitte Oktober 2012 bis Mitte Juli 2013.

\subsubsection{Befallsverlauf und Erregernachweis}

Der Rhizoctonia-Befall auf der Göttinger Bodenerwärmungsanlage wurde als Befallshäufigkeit ( $\mathrm{BH}$ in \%) erfaßt und als Befallsstärke (DS) berechnet (Tab. 29). Insgesamt war der Befallsdruck in den künstlich inokulierten Testparzellen sehr gering. $R$. solani AG 1-IB führte in keiner Parzelle zu einem meßbaren Befall. Für R. solani AG 5 war lediglich auf einer Parzelle (Parzelle-Nr. 8, Variante: „ohne Erwärmung, AG 5“) eine BH 
Ergebnisse

von 16,66\% (DI = 0,025) feststellbar. Im Mittel hatte die Variante „ohne Erwärmung, AG 5“ somit eine $\mathrm{BH}$ von 4,16\% ( $\mathrm{DI}=0,0127)$. Die durch $R$. cerealis AG D erzeugte Befallshäufigkeit in den inokulierten Parzellen reichte von $6 \%$ bzw. DI = 0,012 bis zu 57,14\% bzw. $\mathrm{DI}=0,11$. In den nicht-inokulierten Kontrollparzellen war kein Befall feststellbar. Aufgrund des ausbleibenden Befalls durch $R$. solani AG 1-IB wurde die Auswertung auf die Inokulationsvariante mit $R$. cerealis AG D (alle 3 Temperaturstufen) und $R$. solani AG 5 (Temperaturvariante „ohne Erwärmung) im Vergleich zur nicht-inokulierten Gesundkontrolle beschränkt.

Die Analyse der Befallsdaten ergab, dass lediglich das Isolat einen signifikanten Effekt hatte $(p=0,000)$.

Innerhalb der mit $R$. cerealis AG D inokulierten Parzellen gab es signifikante Unterschiede zwischen den drei Temperaturstufen. Die beiden erwärmten Parzellen (leicht und stark erwärmt) hatten im Vergleich zur nicht erwärmten Kontrolle mit 26,6\% und 21,6\% signifikant höhere Befallshäufigkeiten. Alle übrigen Varianten, darunter erwartungsgemäß die Gesundkontrolle, hatten keinen Befall (0\%) oder eine BH unter 5\% (Inokulationsvariante $R$. solani AG 5 ohne Erwärmung) bzw. unter 10\% (Inokulationsvariante R. cerealis AG D ohne Erwärmung), was nicht signifikant war.

Tabelle 29: Einfluß der Bodentemperatur auf die Befallshäufigkeit (\%) an Winterweizen, Sorte Toras nach Inokulation mit Rhizoctonia im Versuch auf der Göttinger Bodenerwärmungsanlage 2012/13. Dargestellt sind die Temperaturvarianten „ohne Erwärmung ", „leicht erwärmt“ und „stark erwärmt" in den jeweiligen Inokulationsvarianten Gesundkontrolle (C), R. solani AG 5 (A), R. solani AG 1-IB (B) und R. cerealis AG D (D) mit der Standardabweichung (SD) und der statistischen Analyse $(n=4)$ nach Fisher LSD $($ alpha $=0,05)$ unter Normalverteilung (gegeben oder angepasst) über alle Varianten, wobei abweichende Buchstaben signifikante Unterschiede kennzeichnen.

\begin{tabular}{|c|c|c|c|}
\hline Inokulationsvariante & Temperaturvariante & Befallshäufigkeit \% & SD \\
\hline \multirow{3}{*}{$\mathrm{C}=$ Gesundkontrolle } & ohne Erwärmung & 0 & 0,0 \\
\hline & leicht erwärmt & $b$ & 0,0 \\
\hline & stark erwärmt & $\mathrm{b}$ & 0,0 \\
\hline \multirow{3}{*}{$A=R$. solani $A G 5$} & ohne Erwärmung & $4,1 \quad b$ & 8,3 \\
\hline & leicht erwärmt & 0 & 0,0 \\
\hline & stark erwärmt & $\mathrm{b}$ & 0,0 \\
\hline \multirow{3}{*}{$\mathrm{B}=$ R. solani $\mathrm{AG}$ 1-IB } & ohne Erwärmung & $\mathrm{b}$ & 0,0 \\
\hline & leicht erwärmt & $b$ & 0,0 \\
\hline & stark erwärmt & $\mathrm{b}$ & 0,0 \\
\hline \multirow{3}{*}{$\mathrm{D}=R$. cerealis $\mathrm{AG} \mathrm{D}$} & ohne Erwärmung & $8,8 \quad b$ & 4,8 \\
\hline & leicht erwärmt & 26,6 a & 22,1 \\
\hline & stark erwärmt & $21,6 a$ & 19,7 \\
\hline
\end{tabular}


Ergebnisse

Insgesamt war die Befallstärke sehr gering. Die statistische Analyse der Befallsstärke (DI) ergab keinerlei Signifikanzen.

Tabelle 30: Einfluß der Bodentemperatur auf die Befallsstärke (DS) an Winterweizen Sorte Toras nach Inokulation mit Rhizoctonia im Versuch auf der Göttinger Bodenerwärmungsanlage 2012/13. Dargestellt sind die Temperaturvarianten „ohne Erwärmung ", „leicht erwärmt“ und „stark erwärmt" in den jeweiligen Inokulationsvarianten Gesundkontrolle (C), R. solani AG 5 (A), R. solani AG 1-IB (B) und R. cerealis AG D (D) mit der Standardabweichung (SD) und der statistischen Analyse $(n=4)$ nach Fisher LSD $($ alpha $=0,05)$ unter Normalverteilung (gegeben oder angepasst) über alle Varianten, wobei abweichende Buchstaben signifikante Unterschiede kennzeichnen.

\begin{tabular}{|c|c|c|c|}
\hline Inokulationsvariante & Temperaturvariante & Befallsstärke (DS) & SD \\
\hline \multirow{3}{*}{$\mathrm{C}=$ Gesundkontrolle } & ohne Erwärmung & $0,000 \mathrm{a}$ & 0 \\
\cline { 2 - 4 } & leicht erwärmt & $0,000 \mathrm{a}$ & 0 \\
\cline { 2 - 4 } & stark erwärmt & $0,000 \mathrm{a}$ & 0 \\
\hline \multirow{3}{*}{$\mathrm{A}=$ R. solani AG 5 } & ohne Erwärmung & $0,012 \mathrm{a}$ & 0,0127 \\
\cline { 2 - 4 } & leicht erwärmt & $0,000 \mathrm{a}$ & 0 \\
\cline { 2 - 4 } & stark erwärmt & $0,000 \mathrm{a}$ & 0 \\
\hline \multirow{3}{*}{$\mathrm{B}=$ R. solani AG 1-IB } & ohne Erwärmung & $0,000 \mathrm{a}$ & 0 \\
\cline { 2 - 4 } & leicht erwärmt & $0,000 \mathrm{a}$ & 0 \\
\cline { 2 - 4 } & stark erwärmt & $0,000 \mathrm{a}$ & 0 \\
\hline \multirow{3}{*}{$\mathrm{D}=$ R. cerealis AG D } & ohne Erwärmung & $0,017 \mathrm{a}$ & 0,0096 \\
\cline { 2 - 4 } & stark erwärmt & $0,024 \mathrm{a}$ & 0,0240 \\
\cline { 2 - 4 } & leicht erwärmt & $0,045 \mathrm{a}$ & 0,0450 \\
\hline
\end{tabular}

Für den Erregernachweis mittels PCR wurde während der Bonituren symptomatisches Probenmaterial gewonnen. In den Parzellen Nr. 1 bis 9 sowie Parzelle Nr. 12 konnten erwartungsgemäß R. cerealis AG D mittels der RC-PCR nachgewiesen werden. Obgleich von Parzelle Nr. 11 symptomatisches Probenmaterial (insgesamt 4 Weizenhalme, Abb. 1) gesammelt wurde, gelang es nicht, Reinisolate erfolgreich aufzureinigen. $R$. solani konnte erfolgreich in symptomatischem Stängelmaterial von Parzelle Nr. 8 nachgewiesen werden. 
Tabelle 31: Nachweis von Rhizoctonia in Winterweizenproben (symptomatisches Stängelmaterial der Sorte Toras der Boniturnote 2 oder höher) aus dem Versuch auf der Göttinger Bodenerwärmungsanlage mittels der PCR. „RC-PCR“ für R. cerealis AG D und „RS AGx PCR“ stehen für PCR-Verfahren für $R$. solani AG 1 bis AG 14. Die Proben stammen aus den Temperaturvarianten „ohne Erwärmung“ (Parzelle Nr. 1, 6, 8), „leicht erwärmt“ (Parzelle Nr. 2, 5, 9, 12) und „stark erwärmt" (Parzelle Nr. 3, 4, 7, 11) mit den Inokulationsvarianten $R$. solani AG 5 (= A) und $R$. cerealis AG D (= D). Parzelle Nr. 11 zeigt ein Beispiel, bei dem die Isolatgewinnung aus dem Weizenhalm und die gDNA-Extraktion misslungen ist.

\begin{tabular}{|c|c|c|c|c|c|}
\hline $\begin{array}{l}\text { Inokulations- } \\
\text { variante }\end{array}$ & Temperaturvariante & Parzelle & $\begin{array}{l}\text { Anzahl symptomat. } \\
\text { Weizenhalme }\end{array}$ & $\begin{array}{c}\text { erhaltenes Reinisolat } \\
\text { (Anzahl) }\end{array}$ & Erregernachweis \\
\hline R. solani AG $5(=\mathrm{A})$ & \multirow[t]{4}{*}{ ohne Erwärmung } & 8 & 1 & 1 & R. solani AGx \\
\hline \multirow{11}{*}{$\begin{array}{l}\text { R. cerealis AG D } \\
(=\mathrm{D})\end{array}$} & & 1 & 2 & 1 & \multirow{10}{*}{ R. cerealis AG D } \\
\hline & & 6 & 8 & 4 & \\
\hline & & 8 & 5 & 2 & \\
\hline & \multirow[t]{4}{*}{ leicht erwärmt } & 2 & 2 & 1 & \\
\hline & & 5 & 3 & 2 & \\
\hline & & 9 & 6 & 2 & \\
\hline & & 12 & 3 & 1 & \\
\hline & \multirow[t]{4}{*}{ stark erwärmt } & 3 & 5 & 3 & \\
\hline & & 4 & 5 & 2 & \\
\hline & & 7 & 5 & 2 & \\
\hline & & 11 & 4 & 0 & Nachweis erfolglos \\
\hline
\end{tabular}




\subsubsection{Bestandesparameter}

\section{$\underline{\text { Auflauf }}$}

Die Daten des Auflaufs wurden vor Winter als Parameter [Pflanzen/ $\mathrm{m}^{2}$ ] am 07.11.2012 erfasst. In der statistischen Analyse zeigte sich, dass lediglich die Temperaturvariante einen Effekt hatte $(p=0,000)$, die Inokulationsvariante dagegen nicht (Tab. 32). Daher wurden die Daten des Auflaufs nur hinsichtlich der Temperaturvariante analysiert. So konnten bei den „leicht“ und bei den „stark erwärmten“ Parzellen im Mittel 176,5 bzw. 194,5 [Pflanzen/ $\mathrm{m}^{2}$ ] erfasst werden. Obgleich bei den „stark erwärmten“ Parzellen im Mittel 17,9 Pflanzen pro $\mathrm{m}^{2}$ mehr aufliefen, stellte dies jedoch keinen statistisch signifikanten Unterschied zur „leicht erwärmten“ Variante dar. Bei den unbeheizten Referenzparzellen (Temperaturvariante „ohne Erwärmung“) ergab sich ein Mittel von 157,6 [Pflanzen/ m²], was signifikant weniger Pflanzen repräsentierte als bei den den („leicht“ und „stark“) erwärmten Parzellen.

Tabelle 32: Auflauf des Winterweizens [Pflanzen pro $\mathrm{m}^{2}$ ] der Sorte Toras erfasst am 07.11.2012 auf der Göttinger Bodenerwärmungsanlage in drei Temperaturvarianten (stark/ leicht erwärmt u. ohne Erwärmung) im Mittel aller Inokulationsvarianten (R. solani AG 5, R. solani AG 1-IB und R. cerealis AG D) sowie der Gesundkontrolle $(n=16)$. Statistische Analyse nach Fisher LSD (alpha $=0,05)$ unter Normalverteilung (gegeben oder angepasst), wobei abweichende Buchstaben signifikante Unterschiede kennzeichnen; SD = Standardabweichung.

\begin{tabular}{|c|c|c|}
\hline Temperaturvariante & Pflanzen pro $\mathbf{~ m}^{\mathbf{2}}$ & SD \\
\hline stark erwärmt & 194,5 a & 45,9 \\
\hline leicht erwärmt & 176,5 a & 43,7 \\
\hline ohne Erwärmung & 157,6 b & 49,4 \\
\hline
\end{tabular}

\section{Frostschaden}

Die Frostschäden wurden am 09.04.2013 als grüne Triebe pro $\mathrm{m}^{2}$ erfasst. Die statistische Analyse zeigte, dass die Temperatur- und die Inokulationsvariante sowie deren Interaktion signifikante Effekte hatten $(p=0,000)$. Eingangs wurde zunächst nur die Temperaturvariante betrachtet. Es zeigte sich, dass die Variante „stark erwärmt“ mit durchschnittlich 333,6 signifikant mehr grüne Trieben pro $\mathrm{m}^{2}$ aufwies als die Variante „leicht erwärmt“ mit 281,2 und die Variante „ohne Erwärmung“ (Kontrolle oder Referenzparzelle) mit lediglich 232,0. Von den Inokulationsvarianten waren lediglich in den mit $R$. cerealis AGD (Inokulationsvariante D) inokulierten Parzellen mit 235 signifikant weniger grüne Triebe/ $\mathrm{m}^{2}$ als in den übrigen Inokulationsvarianten festzustellen. Alle Inokulationsvarianten mit $R$. solani hatten keinen signifikanten Effekt auf die Anzahl grüner Triebe (Abb. 25). 


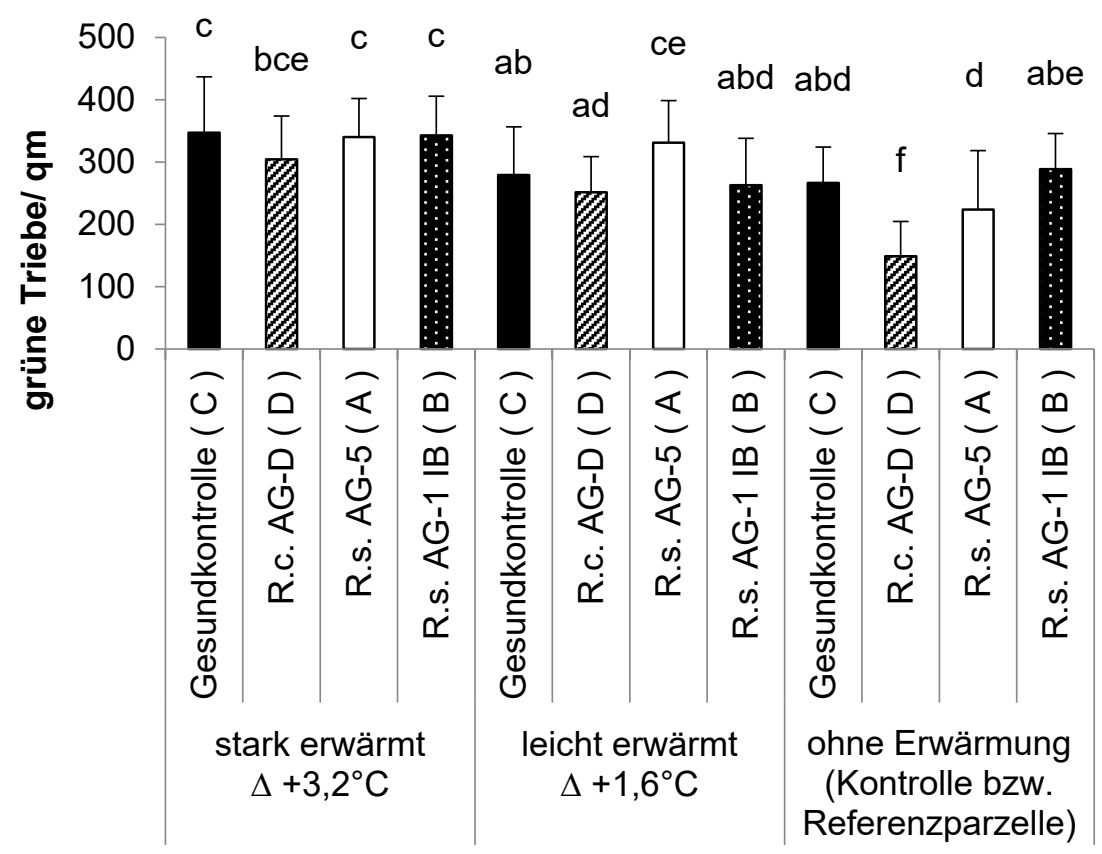

Inokulations- u. Temperaturvariante

Abbildung 25: Anzahl grüne Triebe/ $\mathrm{m}^{2}$ im Versuch mit Winterweizen Sorte Toras auf der Göttinger Bodenerwärmungsanlage in den Temperaturvarianten „stark erwärmt“ $\left(+3,2^{\circ} \mathrm{C}\right)$ und „leicht erwärmt “ (+ $\left.1,6^{\circ} \mathrm{C}\right)$ sowie der nicht künstlich erwärmten Variante „ohne Erwärmung" nach Inokulation mit $R$. solani AG 5 (A, weiße Säule), $R$. solani AG 1-IB (B, gepunktet) und $R$. cerealis AG D (D, schraffiert) im Vergleich zur Gesundkontrolle (C, schwarze Säule). Vertikale Balken geben die positiven Standardabweichungen wieder und unterschiedliche Buchstaben kennzeichnen signifikante Unterschiede nach statistischer Auswertung $(n=4)$ mit Fisher LSD (alpha $=0,05)$ unter Normalverteilung (gegeben oder angepasst) über alle Varianten. Vertikale Balken geben die positive Standardabweichung wieder.

Innerhalb der stark erwärmten Variante gab es keine signifikanten Unterschiede bei der Anzahl grüner Triebe pro $\mathrm{m}^{2}$. Der erhobene Parameter bewegte sich zwischen 304,4 und 346,9 Pflanzen pro $\mathrm{m}^{2}$. Innerhalb der Temperaturstufe leicht erwärmt war die Inokulationsvariante $R$. cerealis (D) und $R$. solani AG 1-IB (B) nicht signifikant verschieden von der Kontrolle (C). Verschieden war die R. solani AG 5 (A) inokulierte Variante mit signifikant mehr Pflanzen pro $\mathrm{m}^{2}(331,3)$ von der Kontrolle mit nur 279,2 sowie zu den übrigen Inokulationsvarianten $R$. solani AG 1-IB $(262,8)$ und $R$. cerealis AG D $(251,5)$. Innerhalb der Variante ohne Erwärmung waren die Varianten R. solani AG 5 (A) und $R$ solani AG 1-IB (B) nicht signifikant verschieden von der Kontrolle $(C)$. So bewegte sich der erhobene Parameter dieser Varianten von 223,9 (A), 288,8 (B) und 266,4 (C). Hingegen signifiikant weniger grüne Triebe pro $\mathrm{m}^{2}$ im Vergleich zur Kontrolle (C) mit 266,4 hatte die Inokulationsvariante $R$. cerealis AG D (D) mit 149,0 Pflanzen pro $\mathrm{m}^{2}$. Im Vergleich dazu war die Anzahl grüner Triebe pro $\mathrm{m}^{2}$ der mit $R$. cerealis AGD (D) inokulierten Variante der Temperatrstufe leicht erwärmt mit 251,5 und stark erwärmt mit 304,4 siginikant geringer. 


\section{Bestandesdichte}

Die Bestandesdichte wurde am 26.06.2013 als Ähren tragende Halme pro $\mathrm{m}^{2}$ erfasst (Tab. 33). Insgesamt hatte die Temperaturvariante einen signifikanten Effekt $(p=0,004)$, ebenso wie die Interaktion Temperatur* Inokulation mit einem $p$-Wert von 0,041. Dagegen hatte die Inokulationsvariante mit einem p-Wert von 0,553 keinen signifikanten Einfluß auf die Bestandesdichte.

Tabelle 33: Anzahl Ähren tragenden Halme/ $\mathrm{m}^{2}$ im Versuch mit Winterweizen Sorte Toras auf der Göttinger Bodenerwärmungsanlage in den Temperaturvarianten „stark erwärmt“ $\left(+3,2^{\circ} \mathrm{C}\right)$ und „leicht erwärmt “ $(+$ $1,6^{\circ} \mathrm{C}$ ) sowie der nicht künstlich erwärmten Variante „ohne Erwärmung“ nach Inokulation mit $R$. solani AG 5, R. solani AG 1-IB und R. cerealis AG D im Vergleich zur Gesundkontrolle. SD, Standardabweichung; unterschiedliche Buchstaben kennzeichnen signifikante Unterschiede nach statistischer Auswertung ( $\mathbf{n}=$ 4) mit Fisher LSD (alpha $=0,05$ ) unter Normalverteilung (gegeben oder angepasst) über alle Varianten.

\begin{tabular}{|c|c|c|c|}
\hline Inokulationsvariante & Temperaturvariante & [Ähren pro $\mathrm{m}^{2}$ ] & SD \\
\hline \multirow{3}{*}{$\begin{array}{c}\text { C = Gesundkontrolle } \\
\text { (Referenzparzelle für die } \\
\text { Beheizung und Kontrolle) }\end{array}$} & ohne Erwärmung & 479,5 abd & 94,0 \\
\hline & leicht erwärmt & $416,6 \mathrm{~cd}$ & 104,3 \\
\hline & stark erwärmt & 468,7 abd & 110,8 \\
\hline \multirow{3}{*}{$\mathrm{D}=R$. cerealis AG D } & ohne Erw. & 395,4 & 121,0 \\
\hline & leicht erw. & $425,8 \mathrm{bcd}$ & 87,0 \\
\hline & stark erw. & $491,9 \quad a b$ & 70,5 \\
\hline \multirow{3}{*}{$\mathrm{A}=R$. solani AG 5} & ohne Erw. & 395,8 & 126,3 \\
\hline & leicht erw. & 497,5 & 90,5 \\
\hline & stark erw. & 500,7 & 117,7 \\
\hline \multirow{3}{*}{$\mathrm{B}=R$. solani $\mathrm{AG} 1-\mathrm{IB}$} & ohne Erw. & $457,9 \mathrm{abcd}$ & 61,3 \\
\hline & leicht erw. & $435,4 \mathrm{abcd}$ & 117,5 \\
\hline & stark erw. & $496,3 \quad a b$ & 107,3 \\
\hline
\end{tabular}

Innerhalb der Inokulationsvariante C (Gesundkontrolle) lag der erhobene Parameter Ähren pro $\mathrm{m}^{2}$ zwischen 416,6 und 479,5. Es gab keine signifikanten Unterschiede. Unter Hinzunahme der Inokulation wird der Parameter Ähren pro $\mathrm{m}^{2}$ bei Ausbringung von R. solani AG 1-IB nicht beeinflusst. Der Parameter liegt im Bereich von 435,4 und 496,3 ohne signifikante Unterschiede. In der $R$. solani AG 5 inokulierten Variante zeigten die erwärmten Varianten signifikant mehr Ähren pro $\mathrm{m}^{2}$ im Vergleich zur nicht erwärmten Variante. In der mit $R$. cerealis AG D inokulierten Variante war die Anzahl Ähren pro $\mathrm{m}^{2}$ in der nicht erwärmten Variante mir nur 395,8 signifikant reduziert gegenüber den der erwärmten Varianten mit 425,8 und 491,9 Ähren pro m². Im Vergleich zur Gesundkontrolle waren die erwärmten Varianten hinsichtlich des erhobenen Parameters von dieser nicht signifikant verschieden. Die Variante ohne Erwärmung der Gesundkontrolle hatte mit 479,5 signifikant höhere Anzahlen Ähren pro $\mathrm{m}^{2}$ als die $R$. cerealis AG D (ohne Erwärmung) mit nur 395,4. 


\subsubsection{Ertragswirkungen}

Auf der Göttinger Bodenerwärmungsanlage war keine vollständige Erhebung von Ertragsdaten möglich. Aufgrund der geringen Parzellengröße sowie der installierten Messund Heiztechnik reduzieren sich die Maßnahmen auf eine Handernte der Stoppeln und die Erfassung der Tausendkornmasse (TKM).

Bei der Betrachtung des TKM zeigte sich, dass keine der Behandlungestufen einen signifikanten Einfluß auf die TKM hatte (Tab. 34). Das TKM lag im Bereich von 81,8 bis $88,95 \mathrm{~g}$.

Tabelle 34: Tausendkornmasse (g) im Versuch mit Winterweizen Sorte Toras auf der Göttinger Bodenerwärmungsanlage in den Temperaturvarianten „stark erwärmt" $\left(+3,2^{\circ} \mathrm{C}\right)$ und „leicht erwärmt" $(+$ $1,6^{\circ} \mathrm{C}$ ) sowie der nicht künstlich erwärmten Variante "ohne Erwärmung" nach Inokulation mit $R$. solani AG 5, $R$. solani AG 1-IB und $R$. cerealis AG D im Vergleich zur Gesundkontrolle. SD, Standardabweichung; unterschiedliche Buchstaben kennzeichnen signifikante Unterschiede nach statistischer Auswertung $(\mathbf{n}=$ 4) mit Fisher LSD (alpha $=0,05$ ) unter Normalverteilung (gegeben oder angepasst) über alle Varianten.

\begin{tabular}{|c|c|c|c|}
\hline \multicolumn{4}{|c|}{ Tausendkornmasse TKM } \\
\hline Temperaturvariante & Inokulationsvariante & TKM (g) & SD \\
\hline \multirow[t]{4}{*}{ ohne Erwärmung } & $\mathrm{C}=$ Gesundkontrolle & $81,8 \quad d$ & 7,9 \\
\hline & $A=R$. solani AG 5 & 84,4 bcd & 3,3 \\
\hline & $\mathrm{B}=$ R. solani $\mathrm{AG} 1-\mathrm{IB}$ & 85,4 abcd & 2,6 \\
\hline & $\mathrm{D}=R$. cerealis $\mathrm{AG} \mathrm{D}$ & 85,0 abcd & 0,8 \\
\hline \multirow[t]{4}{*}{ leicht erwärmt } & A & 85,0 abcd & 1,5 \\
\hline & $\mathrm{B}$ & 88,9 & 7,7 \\
\hline & C & 86,0 abcd & 1,4 \\
\hline & $\mathrm{D}$ & 90,6 & 3,3 \\
\hline \multirow[t]{4}{*}{ stark erwärmt } & $A$ & 83,8 bcd & 2,5 \\
\hline & B & 82,7 & 1,4 \\
\hline & C & 88,2 abc & 5,2 \\
\hline & D & 86,7 abcd & 3,1 \\
\hline
\end{tabular}

\section{Diskussion}

\subsection{Monitoring}

Zur Erfassung der Befallssituation mit dem Scharfen Augenfleck in Deutschland auf natürlichen Befallsflächen wurde in zwei aufeinanderfolgenden Jahren ein Monitoring auf Rhizoctonia in Weizen durchgeführt. Bei genauer Betrachtung konnten keine schlag- oder kulturspezifischen Parameter ausgemacht werden, die den Rhizoctonia-Befall begünstigt hätten. Der einzige Hinweis war die Bodenart. So fiel auf, dass bei sandigem Lehm häufig Befall vorlag - unabhängig von der Höhe der Befallshäufigkeit. Im molekularen Erregernachweis der einbehaltenen Proben des Monitorings konnte nur Rhizoctonia cerealis AGD nachgewiesen werden. Dieses Ergebnis unterstützt die Ablehnung der 
These, dass andere AG's als $R$. cerealis AG D wie bspw. $R$. solani AG 5 oder AG 8 an Weizen in Deutschland relevant sein könnten. Des Weiteren kann die Ablehnung der These mit Literaturquellen gestützt werden. So schreiben Boerema und Vanhoeven (1977), dass der Haupterreger des Scharfen Augenflecks am Weizen $R$. cerealis AGD ist. Untersuchungen in Polen von 2006 bis 2008 auf kommerziell bewirtschafteten Flächen zeigten im Weizen eine Befallshäufigkeit von im Mittel lediglich 1,9\%, was von Fläche zu Fläche schwankte (Lemańczyk, 2010a). Eine breite Schwankung der Befallshäufigkeit mit Rhizoctonia konnte in der vorliegenden Arbeit ebenfalls gezeigt werden. So lag die Befallshäufigkeit mit Rhizoctonia zwischen 0\% und 36,46\%. Dabei lag der Befall in 2012 (Standorte in Deutschland) von 0\% bis zu 13,19\%, während im Jahr 2013 der Befall von $0 \%$ bis zu $36,46 \%$ reichte. Der generell niedrige Befall mit Rhizoctonia auf Flächen mit natürlichem Befall lässt sich im Monitoring abbilden. Möglicherweise lassen lokal günstige Bedingungen hohe Befallshäufigkeiten zu, wie sie im Experiment beobachtet wurden, was die von Lemańczyk (2010a) angeführten Schwankungen andeuten. Zu den günstigen Bedingungen gehören bspw. Weizenmonokulturen. So wurde hier meist $R$. cerealis anstatt $R$. solani gefunden (Kurowski, 2002).

\subsection{Differenzierung von Rhizoctonia spp. in vitro}

\subsubsection{Erregernachweis}

In der vorliegenden Arbeit war die Polymerasekettenreaktion praktikabel für den Erregernachweis und überzeugte durch die Testsicherheit. Für $R$. cerealis AG D wurde die nach Guo et al. (2012) beschriebene spezifische PCR verwendet und für $R$. solani die von Lemańczyk (2010a) beschriebene spezifische PCR. Parallel zur PCR wurde der sogenannte PDA-Abgleichtest hinsichtlich seiner möglichen Eignung zum RhizoctoniaNachweis geprüft. In der vorliegenden Arbeit führte der PDA-Test in $88 \%$ der Fälle zu korrekten Aussagen im Vergleich mit der PCR. Daher kann festgestellt werden, dass der methodisch einfachere PDA-Test für einen schnellen Nachweis mit künstlicher Inokulation der aufwendigen PCR vorgezogen werden kann. In einem Artikel von Ko und Hora (1978) wird der Einsatz eines selektiven Mediums für R. solani zur Quantifizierung desselben im Boden beschrieben. Seitdem wird der erfolgreiche Einsatz des Ko \& Hora Mediums mehrfach in der Literatur erwähnt (Doornik, 1981; Samiram u. Grover, 1985; Paulitz u. Schroeder, 2005). Im Vergleich dazu bot der PDA-Test auch hier hinsichtlich des geringeren Präparationsaufwandes des Nährmediums Vorteile gegenüber dem Ko und Hora Medium. In der Literatur wird der erfolgreiche Einsatz von mit Antibiotika versetztem PDA-Medium zur Isolation von Rhizoctonia aus symptomatischen Pflanzenproben 
ebenfalls erfolgreich beschrieben (Hollins et al., 1983; Gangopadhyay u. Grover, 1985; Lemańczyk, 2010b; Yan et al., 2013).

\subsubsection{Morphologie}

Im Lichtmikroskop wurden verschiedene Anastomosegruppen von Rhizoctonia betrachtet, um etwaige Unterschiede im Myzelwachstum sowie in der Beschaffenheit herauszustellen. So zeichnete sich $R$. cerealis AG D durch sehr feine und wenig verzweigte Hyphen aus. $R$. solani AG 5 hatte ein im Vergleich dazu kräftiges Myzel mit vielen Verzweigungen in kurzen Abständen. Hamada et al. (2011a) stellt in morphologischen Untersuchungen fest, dass das Myzel von $R$. cerealis dünner ist als das von $R$. solani. Die in dieser Arbeit gewonnenen Eindrücke werden durch die Untersuchung bestätigt. R. solani AG 1-IB war vergleichbar mit AG 5 und fiel des Weiteren durch viele $90^{\circ}$ Winkel und Querverbindungen auf, die sich zwischen den Hyphen ausbildeten. Zheng und Wang (2011) beschreiben das Myzel des AG 1-IB als häufig $90^{\circ}$ verwinkelt und fusionsfreudig, was durch diese Ergebnisse erneut bestätigt wird. Bei R. solani AG 8 waren knäulartige Myzelpakete und endständige geweihartige Verästelungen zu sehen. Diese Daten wurden bislang nicht beschrieben. In in vitro-Pathogenitätstests mit Weizenkeimlingen konnte bei AG 8 die Ausbildung von orange bis gelben globulären Gebilden in Wurzelnähe beobachtet werden, die Pflanze schien davon unbeeinflusst zu sein. Möglicherweise sind globuläre Gebilde und die knäulartigen Myzelpakete frühe Stadien der Sklerotienbildung. Da sich Weizen für dieses spanische Isolat der AG 8 nicht als Wirtspflanze eignet, neigt der Pilz dazu, rasch ins Überdauerungsstadium überzutreten. Weitere Hinweise, dass dieses Isolat der AG 8 an Weizen nicht pathogen ist, leiten sich davon ab, dass im eigenen Monitoring kein AG 8 gefunden wurde und die Pathogenität aus der Ursprungsregion (Spanien) in der Literatur bisher nicht beschrieben wurde. In der Literatur als Wiezen schädigend beschrieben wurde AG 8 hingegen in der Türkei und in England (Ünal u. Dolar, 2012). Nach Goll et al. (2013) wurden große Unterschiede in der AG-Zusammensetzung in Bodenproben aus England und vom europäischen Festland gefunden. Möglicherweise kann von einer regionalen Spezialisierung der Anastomose-gruppen ausgegangen werden. Dies würde erklären, dass die australische AG 8 einschlägig als an Weizen pathogen beschrieben wird und dies in Europa nur vereinzelt in England der Fall ist. Zur Absicherung besteht in dieser Fragestellung weiterer Forschungsbedarf. Sinnvoll wären bspw. vergleichende Untersuchungen im Labor und im Feldversuch mit einem an Weizen nicht-pathogenen europäischen AG 8, einem pathogenen europäischen AG 8 (aus England und/ oder der Türkei) und einem pathogenen australischen AG 8. 


\subsubsection{Säurebildung}

Zur Ermittlung von Säureausscheidungen wurde Kartoffel-Dextrose-Festplattenmedium mit dem pH-Wert Indikator Bromphenolblau versetzt. Normalerweise dient derart präpariertes Medium dazu, virulente Stämme von Sclerotina zu identifizieren. Dieser pflanzenpathogene Pilz sezerniert Oxalsäure ins Milieu, um sich optimale Umgebungsbedingungen zu schaffen. Im Bezug auf Rhizoctonia wird 1963 durch Aoki et al. von möglicherweise phytotoxischen Metaboliten von R. solani berichtet. Bei den damaligen Untersuchungen gelang es nicht, klare Schlüsse hinsichtlich der chemischen Struktur bzw. der biologischen Funktion zu ziehen. Bartz et al. (2012) beschreiben eine spezifische Wirt-ParasitInteraktion, bei der $R$. solani AG 3 durch sezernierte Phenylessigsäure, sowie Derivate derselben, Nekrosen und Wachstumsdepressionen an Tomatenkeimlingen auslöst, jedoch nicht an Bohnenhypokotylen oder Takakblättern. Eine weitere wirtsspezifische Bildung von Toxinen beschreiben auch Vidhyasekaran et al. (1997) im Zusammenhang von R. solani an Reis. Zheng u. Wang (2011) beschreiben ebenfalls die Ausbildung von Tropfen auf dem gealterten, bereits braunen Myzel von R. solani AG 1-IB, die bei hoher Luftfeuchte entstehen können. Naiki und UI (1974) konnten feststellen, dass Sklerotien mancher Rhizoctonia-Isolate nach einer 8-monatigen Verweildauer in Erde einen starken mikrobiellen Befall zeigen und viele leere Zellhüllen aufweisen, während andere Sklerotien eine lange Zeitdauer weitgehend unbeschadet überstehen. Aliferis und Jabaji (2010) stellen fest, dass Sklerotien von $R$. solani AG 2-2 IIIB Exudate absondern, die bioaktiv sind und eine toxische Wirkung gegen Mikroorganismen haben. Es kann also festgehalten werden, dass Rhizoctonia biologisch aktive Substanzen absondern kann. Dieses kann von jungem Myzel - wie es gezeigt werden konnte - oder von altem Myzel (= Sklerotien) stammen. Verschiedene Literaturquellen legen die Vermutung nahe, dass es sich dabei um Substanzen aus der Stoffklasse der Säuren handelt. Dies bestätigt den im Versuch beobachteten Umschlag ins Gelbe bei AG 5 und AG 11. Siddiqui und Shaukat (2004) berichten von Phenylessigsäure (PAA) produzierenden $R$. solani Isolaten, führen aber keine $A G$ an. Somit ist zu sagen, dass es zwischen einzelnen AG's hinsichtlich der Säuresekretion Unterschiede geben kann. So scheinen eher die Vertreter der mehrzellkernigen Arten hinsichtlich dieser Eigenschaft aufzufallen, was die Gelbfärbung bei $R$. solani AG 5 und $R$. solani AG 11 und die Blaufärbung bei $R$. cerealis AG D bestätigen könnte. R. solani AG 4 HGll zeigte keine Gelbfärbung. Jedoch wird AG 4 hinsichtlich seiner Morphologie und der Reaktion auf verschiedenen Nährböden auch als deutlich differenziert beschrieben im Vergleich zu bspw. AG 5 (Furgał-Węgrzycka et al., 1997), was diese Abgrenzung zu mehrzellkernigen AG's erklären könnte. Es bedarf der Einzelfallprüfung, um 
festzustellen, ob die vom Pilz sezernierten Stoffe wirtsschädigende Eigenschaften haben oder als Schutz bspw. der Sklerotien vor Mikroorganismen im Boden dienen könnten. Des Weiteren bleibt die Frage nach der genauen chemischen Struktur ungeklärt. Die Untersuchungen in dieser Arbeit zeigen aber, dass Säure-sezernierende Anastomosegruppen der Gattung Rhizoctonia durch den Einsatz von Bromphenolblau auf einfache und schnelle Weise für mögliche weitere Untersuchungen identifiziert werden können.

\subsubsection{Temperaturansprüche}

In der vorliegenden Arbeit wurden in vitro-Tests durchgeführt, um die optimale Wachstumstemperatur von Rhizoctonia-Isolaten verschiedener Anastomosegruppen zu ermitteln. In einer Arbeit von Hollins et al. (1983) waren Isolate von R. solani und R. cerealis aus Pflanzenproben in einer vergleichbaren Untersuchung auf deren Temperaturpräferenzen untersucht worden. Die Experimente zeigten, dass $R$. cerealis eine bevorzugte Temperatur von 15 bis $24^{\circ} \mathrm{C}$ hatte. Die Wachstumsrate lag bei 4 bis $8 \mathrm{~mm}$ pro Tag. $R$. solani hingegen hatte generell einen stärkeren täglichen Zuwachs mit $15 \mathrm{~mm}$ pro Tag und präferierte eine Temperatur von 20 bis $25^{\circ} \mathrm{C}$. Damit bestätigen die Daten dieser Arbeit jene Untersuchungen von Hollins et al. (1983) in weiten Teilen, da hier ähnliche Temperaturbereiche und Wachstumsraten ermittelt wurden. Es scheint des Weiteren bei $R$. cerealis AG D einen Unterschied zu geben zwischen Isolaten aus Boden- und Pflanzenproben. So konnten die Daten von Hollins et al. (1983) lediglich die Ergebnisse der AG D Isolate aus Pflanzenproben erfolgreich abbilden. Bei den AG D Isolaten aus Bodenproben liegen die Temperaturoptima in einem viel engeren Bereich mit 12 bis $16^{\circ} \mathrm{C}$. Genauere Aussagen zu $R$. solani AG 3 können nicht gemacht werden, da dieser in der vorliegenden Arbeit nicht mit einbezogen wurde. Es kann aber festgehalten werden, dass auch Hollins et al. (1983) und auch bei Grosch et al. (2006) generell für R. solani AG's Temperaturvorlieben bei hohen Temperaturen ermittelt wurden, was mit den Ergebnissen dieser Arbeit konform ist. Eine Ausnahme hiervon stellt $R$. solani AG 8 dar, der in seiner Temperaturpräferenz $R$. cerealis AG D ähnelt und - anders als $R$. solani AG 3, AG 5 oder AG 1-IB - kühlere Temperaturen von 12 bis $20^{\circ} \mathrm{C}$ bevorzugt. In Untersuchungen von Paulitz und Schröder (2005) wird eine Methode zur quantitativen Bestimmung von R. solani AG 8 in Bodenproben beschrieben, deren zentrales Element eine Zahnstocher-basierte Fangmethode darstellt. Hierbei wurde zu Testzwecken AG 8 Inokulum bei Raumtemperatur künstlich hergestellt, was scheinbar gute Wachstumsbedingungen darstellt. Die Lagerung des Inokulums erfolgte bei $4^{\circ} \mathrm{C}$, was zu einem stark reduzierten Pilzwachstum führt und sich daher als Lagertemperatur anbieten würde. In sich anschließenden Isolations- und Folgeversuchen im Gewächshaus wird von einer Inkubations- bzw. Kultivierungstemperatur von $16^{\circ} \mathrm{C}$ berichtet, was dem Pilz und der 
Pflanze wiederum gute Wachstumsbedingungen offeriert. Damit bestätigen die Angaben von Paulitz und Schröder (2005) die in dieser Arbeit ermittelten Temperatureckdaten für $R$. solani AG 8, indem sie diese in gleicher Weise in einer erfolgreich etablierten Methode beschreiben. In einer Arbeit von Gill et al. (2000) wird - gleichsam wie bei Paulitz und Schröder (2005) - eine Zahnstocher-basierte Isolationsmethode für R. solani AG 8 aus Substrat beschrieben. Dabei verwendet der Autor eine Inkubation mit wechselnden Temperaturen, am $\operatorname{Tag} 20^{\circ} \mathrm{C}$ und in der Nacht $10^{\circ} \mathrm{C}$. Damit decken sich nahezu auch die Daten von Gill et al. (2000) mit den in dieser Arbeit ermittelten Temperaturdaten für $R$. solani AG 8 dahingehend, dass der Bereich von 10 bis $20^{\circ} \mathrm{C}$ gute Wachstumsbedingungen für den Pilz bietet.

Bei der Betrachtung der Ergebnisse dieser Arbeit und den Literaturquellen fällt es wiederholt auf, dass es einen Unterschied gibt zwischen den Temperaturansprüchen und Wachstumsraten zwischen Isolaten aus Boden- und Pflanzenproben bzw. zwischen Feldund Testerisolaten wie bei Grosch et al. (2006). Im ersten Temperaturexperiment in dieser Arbeit wurden Isolate verschiedener AG's aus Bodenproben geprüft, welche zum Zeitpunkt des Experiments bereits seit etwa 3 Jahren im Langzeitkonservierungsverfahren im Labor bei $4^{\circ} \mathrm{C}$ gehalten wurden. Im zweiten Temperaturexperiment wurde mit mehreren frischen AG D Isolaten aus Pflanzenproben gearbeitet, die kurze Zeit nach der Isolation im Test auf die optimale Wachstumstemperatur eingesetzt wurden. Im Falle von $R$. cerealis AG D konnte gezeigt werden, dass die Laborstämme aus Bodenproben ein Temperaturoptimum von 12 bis $16^{\circ} \mathrm{C}$ hatten, während die frischen Isolate aus Pflanzenproben im Bereich von 16 bis $24^{\circ} \mathrm{C}$ die höchste Wachstumsrate zeigten. Bei Hollins et al. (1983) zeigten R. cerealis Isolate von Pflanzenproben ein optimales Wachstum bei 15 bis $25^{\circ} \mathrm{C}$, was sich mit dem ermittelten Temperaturbereich der Pflanzenisolate in dieser Arbeit deckt. Bei den $R$. solani Isolaten haben Hollins et al. (1983) neben Pflanzenisolaten auch ein Isolat aus dem Boden getestet. Unabhängig vom Isolatursprung zeigt $R$. solani einen optimalen Temperaturbereich bei 20 bis $25^{\circ} \mathrm{C}$. Allerdings sind bei Hollins et al. (1983) keine Angaben zum Alter oder zur Lagerdauer der Isolate angegeben. Möglicherweise wurden für die Tests frische Isolate verwendet, was eine hier nicht auftretende Differenz in der Temperaturpräferenz der $R$. solani Isolate erklären könnte. In der Arbeit von Grosch et al. (2006) unterscheiden sich wiederum Isolate von der Pflanze und sogenannte als Testerisolate bezeichnete in ihrer Wachstumsrate, während die Temperaturpräferenzen gleich sind. Unter der Annahme, dass es sich bei Testerisolaten um Laborstämme handelt, ist hier also in Bezug zur Wachstumsrate bzw. Vitalität ein Unterschied zu sehen, der möglicherweise im Zusammenhang mit dem Isolatursprung steht. Eine Verschiebung des Temperaturbereichs ist nicht zu 
erkennen. Allerdings fehlen auch hier präzisere Angaben zu den Isolaten, gleichsam ist dies so auch bei Gill et al. (2000) und Paulitz und Schröder (2005).

Daher sollen im Folgenden nochmal die eigenen Daten betrachtet werden. In den Ergebnissen dieser Arbeit wurde bei AG D im Vergleich von Pflanzen- und Bodenisolaten ein optimaler Temperaturbereich von 16 bis $24^{\circ} \mathrm{C} \mathrm{bzw}$. von 12 bis $16^{\circ} \mathrm{C}$ beobachtet bei einer jeweiligen Wachstumsrate von etwa $1 \mathrm{~cm}$ pro Tag. Dies zeigt eine Verkleinerung des optimalen Temperaturbereichs sowie eine Verschiebung in einen kühleren Bereich bei den Bodenisolaten mit längerer Laborkonservierung bei $4^{\circ} \mathrm{C}$. Aufgrund der konstanten Wachstumsrate von $1 \mathrm{~cm}$ pro Tag kann bei beiden Gruppen ein Vitalitätsverlust ausgeschlossen werden. Betrachtet man dennoch die Pflanzenisolate als noch wenig beeinflusst durch Konservierungsverfahren, dann scheint es, als sei eine erzwungene Adaption an kühlere Temperaturen bei dem Bodenisolat erfolgt. Diese Adaption ist möglicherweise auf die Konservierungsdauer und -temperatur zurückzuführen. Berücksichtigt man die erfolgreich demonstrierte Pathogenität an Weizen bei dem Bodenisolat in verschiedenen Versuchen, kann der Aspekt Isolat aus Boden beim Vergleich mit dem Pflanzenisolat fortan vernachlässigt werden. Die einheitlichen Ergebnisse des zweiten Temperaturexperiments dieser Arbeit, bei dem auch die geographische Verteilung innerhalb Deutschlands Prüffaktor war, bestärken die Annahme, dass sich vom regionalen Ursprung keine Temperaturanpassung ableiten lässt. Die Verschiebung der Temperaturpräfenz des Bodenisolats in einen kühleren Bereich nach langer Lagerdauer zeigt aber, dass prinzipiell eine Temperaturanpassung möglich ist. Unklar ist, inwieweit diese Anpassung auch im Freiland erfolgt.

\subsubsection{Pathogenität und Infektionsprozess an Weizenkeimlingen}

In in vitro Untersuchungen zur Pathogenität am Weizenkeimling konnten für $R$. solani AG 5 und $A G$ 1-IB sowie für $R$. cerealis $A G D$ hohe Befallsindices in Form einer verbräunten Koleoptile ermittelt werden. In Folgeversuchen konnte lediglich bei $R$. cerealis AG D eine hohe Penetrationsaktivität in Form von Infektionskissen an der Weizenwurzel nachgewiesen werden.

Die im Experiment bei $R$. cerealis AG D beobachteten Myzelformen werden in der Literatur als charakteristische Phasen bzw. als die für den Erreger typische Infektionsstruktur bezeichnet (Keijer in Sneh et al., 1996; Zheng u. Wang, 2011). Dabei durchläuft der Pilz in einer kompatiblen Wirt-Pathogen-Interaktion zunächst die Phase der großflächigen Besiedelung der Pflanzenoberfläche, dann folgt die Ausbildung von T-förimgen Hyphen und schließlich die Initiation von Infektionsstrukturen, wobei es sich um sogenannte Infektionskissen handeln kann. Im durchgeführten Experiment konnten bei AG D alle diese Phasen 
beobachtet werden. Die zeitliche Spanne zwischen der Ausbildung von T-förmigen Hyphen und Infektionskissen wird bei $R$. solani AG 2-1 mit 18 Stunden angegeben (Keijer in Sneh et al., 1996). In dieser Arbeit wurde für $R$. cerealis $A G D$ eine etwa doppelt so lange Zeitspanne ermittelt. Möglicherweise ist dies auf eine im Vergleich zu R. solani AG's geringere Wachstumsrate zurückzuführen. In kompatiblen Pathosystemen wird eine hohe Anzahl an ausgebildeten Infektionskissen als Indikator für eine erfolgreiche Infektion der Pflanze beschrieben. Dies berichten Marshall und Rush (1980a) von Versuchen mit $R$. solani AG 1 an anfälligen und resistenten Reissorten. In nicht kompatiblen Systemen konnten wiederum nur wenige Infektionskissen beobachtet werden. Stattdessen wurden nur Appressorien beobachtet, die im Zusammenhang mit Rhizoctonia als weniger effektiv hinsichtlich ihrer Penetrationskraft beschrieben werden (Keijer in Sneh et al., 1996). Eine genaue Angabe zur Anzahl der Infektionskissen machen die genannten Autoren hingegen nicht. In der vorliegenden Arbeit konnte im Pathosystem R. solani AG 5 sowie $R$. solani AG 1-IB und Weizen eine im Vergleich zu AG D sehr geringe Anzahl von Infektionskissen an der Wurzel beobachtet werden. Die AG's haben damit lediglich die erste Infektionsphase, die großflächige Besiedlung der Pflanzenoberfläche, durchlaufen. Dies könnte erklären, weshalb im Agarplattentest zwar deutlich erkennbare Verbräunungen an der Weizenkoleoptile beobachtet werden konnten, aber an der Wurzel keine Penetration feststellbar war. In einem als nicht kompatibel beschriebenen Pathosystem, bestehend aus $R$. solani Isolat 21R6 und Tomate, konnte durchaus ein Überwachsen der Pflanze durch den Pilz beobachtet werden, obgleich aktive Penetrationsversuche ausblieben (Keijer in Sneh et al., 1996).

\subsection{Feldversuch}

Das Ziel war es, die Schadwirkung durch Rhizoctonia im Winterweizen unter Feldbedingungen in Deutschland zu ermitteln und die schadrelevante Erregerform zu identifizieren. Als Inokulumquelle dienten überwachsene Weizenkörner, welche in die obere Bodenkrume eingebracht wurden. Da der bodenbürtige Pilz ausgehend von Myzel auf abgestorbenen Pflanzenteilen oder keimenden Sklerotien in der oberen Bodenschicht die Weizenpflanze infiziert (Budge et al., 2009; Hamada et al., 2011a; Lemańczyk u. Kwasna, 2013), bot sich die verwendete Methode an. Lemańczyk und Kwasna (2013) berichten, dass spätes Säen im Herbst die Effekte durch Rhizoctonia reduziert. Gleichsam berichten Cromey et al. (2012) von Feldversuchen in Neuseeland, dass die Befallshäufigkeit bei im April gesätem Winterweizen höher war, als bei später im Mai gesätem Weizen. Dementsprechend bot es sich im Versuch an, Früh- und Spätsaat auf einem Standort in Deutschland miteinander zu vergleichen. 
Cromey et al. (2002) schreibt, dass in seinen Untersuchungen eine sehr geringe Infektionsrate mit Rhizoctonia in Sommerweizenschlägen beobachtet werden konnte, während auf Flächen mit Winterweizen Befall feststellbar war. Aus diesem Grund sowie aufgrund der größeren Anbaubedeutung in Europa wurde in diesem Versuch Winterweizen verwendet. Die eingesetzten Sorten waren Hermann, Inspiration, Mulan und Toras. Der Feldversuch lief unter Betrachtung der klimatischen Bedingungen. Der September 2011 war insgesamt wärmer und trockener als die Witterung im langjährigen Mittel. Cromey et al. (2012) beschreiben kühle und trockene Witterungsbedingungen als optimal für die erfolgreiche Rhizoctonia-Infektion der Sämlinge. In Versuchen dieser Arbeit konnte für R. cerealis-Isolate aus Pflanzenproben eine optimale Entwicklungstemperatur von 19 bis $24^{\circ} \mathrm{C}$ ermittelt werden. Möglicherweise haben die trockenen Bedingungen ausgereicht, um hohe Infektionen in der Frühsaat zu erzeugen. $R$. cerealis sucht sich bei trockenen Bedingungen eine Feuchtigkeitsquelle im Boden. Eine solche kann die Pflanze sein und die Infektion begünstigen (Schlüter, persönliche Kommunikation, 2011). Zu Beginn des Oktobers war ein leicht erhöhter Niederschlag zu verzeichnen, während die Temperatur im Normalbereich lag. Diese Bedingungen könnten wiederum erklären, dass die Befallshäufigkeit der Spätsaat signifikant schwächer ausfiel. Desweiteren hatte der Erreger bei der spät gesäten Variante eine vergleichsweise kürzere Zeitspanne vor Winter, um die Pflanze erfolgreich infizieren zu können (Hamada et al., 2011a). Ansonsten reiht sich das Ergebnis ein in weitere Berichte, die aussagen, dass eine Spätsaat weniger stark befallen wird im Vergleich zu einer Frühsaat (Cromey et al., 2012; Lemańczyk u. Kwasna, 2013). Im weiteren Verlauf der Vegetation zeigte die Spätsaat der Sorten Hermann, Inspiration und Mulan deutlich weniger Auswinterung als die Frühsaat. Dies spiegelte sich auch in einem tendenziell reduzierten Kornertrag der Frühsaat gegenüber der Spätsaat wider. Die Schadwirkung durch Rhizoctonia wurde durch den Kahlfrost in den inokulierten frostempfindlichen Varianten verstärkt. Auch andere Quellen führen neben niedrigen Temperaturen und frostinduzierter Austrocknung auch den Befall durch pathogene Pilze als mögliche Ursache für die Reduzierung der Winterhärte von Winterweizen an (Wisniewski et al., 1997), was eine Schädigung durch den Pilz verstärkt. Der Befallsrückgang nach Winter lässt darauf schließen, dass die von Rhizoctonia befallenen und geschwächten Triebe durch den Kahlfrost ausselektiert wurden und prozentual mehr unbefallene Triebe überlebt haben. Der Effekt, dass die Befallshäufigkeit im Feldversuch zwischen zwei Boniturterminen abnimmt, wird auch von Cromey et al. (2012) beschrieben mit der angeführten Vermutung, dass befallene Blätter absterben und die Infektion nicht weiter in jüngere Sprossteile vordringen kann. Durch den nicht mehr kompensierbaren Verlust an 
grünen Trieben und ganzen Pflanzen kam es letztlich zu dem Ertragsverlust bei den wenig winterharten Sorten.

Die Sorte Toras hingegen bewies in der Vegetationsperiode 2011/ 2012 deutschlandweit große Winterhärte (mündliche Mitteilung, Jan Hempel, 2012). Toras trotzte dem Kahlfrost und erlitt trotz des hohen Befalls mit Rhizoctonia keinen Verlust an grünen Trieben. So hatte auch die nicht inokulierte Kontrolle der Spätsaat nahezu das gleiche Ertragsniveau wie die nicht inokulierte Kontrolle der Frühsaat, was die Sorte Toras hinsichtlich der Winterhärte deutlich von den übrigen drei Sorten unterscheidet.

Dass Sortenunterschiede in der Winterhärte bestehen, wurde auch in der Literatur beschrieben (Chipilski u. Uhr, 2014). Die Winterhärte von Toras wurde auch nicht durch den Befall mit Rhizoctonia aufgehoben, was die inokulierten Varianten beweisen. Indem alle Pflanzentriebe, auch die befallenen, trotz Befall und Kahlfrost erhalten blieben, konnte sich der Erreger im weiteren Vegetationsverlauf gut enwickeln und bewirkte bei der Sorte Toras zur Milchreife zwar die höchste Befallshäufigkeit, aber auch einen hohen Ertrag. Im Umkehrschluss war der Pilzbefall ausschlaggebend für den Ertragsverlust bei den frostempfindlichen Sorten, der Winterausfall hatte einen noch verstärkenden Effekt, indem die Pflanzen abiotisch gestresst wurden. Bei der nicht ausgewinterten Spätsaatvariante fehlte der starke Befall der Pflanzen sowie der verstärkende abiotische Stress.

Der natürliche Befallsdruck auf den gesunden Kontrollparzellen des Feldversuchs lag bei $0 \%$ bzw. > 1\%. Anhand der Ergebnisse des Monitorings dieser Arbeit konnte gezeigt werden, dass es durchaus Weizenschläge gibt, die keinen bzw. einen äußerst geringen natürlichen Befall mit Rhizoctonia aufweisen. Bei der verwendeten Feldversuchsfläche in Weende/Göttingen schien es sich um eine solche derart schwach befallene bzw. befallsfreie Fläche zu handeln.

Es wurden bereits Sortenunterschiede hinsichtlich der Winterhärte beschrieben (Chipilski u. Uhr, 2014) und auch das Bundessortenamt teilt Winterweizen in 9 Härteklassen ein. Dies würde erklären, dass die Inokulationsvariante statistisch betrachtet stets einen Ertragseffekt hatte, dass jedoch ein Sorteneffekt lediglich bei der dritten Bonitur zu BBCH 55 statistisch feststellbar war und möglicherweise nur auf die Winterhärte zurückzuführen ist.

Die Tausendkornmasse von etwa $43 \mathrm{~g}$ in allen Varianten konnte den Ertragsverlust nicht erklären. Als ursächlich für den Ertragsverlust im Versuch war die reduzierte Anzahl der Körner pro Ähre. Diese Beobachtung stimmt mit den Daten von Clarkson und Cook (1983) überein, die die Reduktion der Körner pro Ähre wird infolge moderater und starker Infektionen mit Rhizoctonia im Winterweizen beschrieben (Clarkson u. Cook, 1983). Da die Befallshäufigkeit in der vierten Bonitur deutlich über 10\% lag waren diese Bedingungen erfüllt. 
In der Spätsaat waren die Kontrollen befallsfrei bzw. die Befallshäufigkeit lag bei $<1 \%$. Bei den inokulierten Varianten war ein durchweg eher geringes Befallsniveau zu beobachten. So lag die Befallshäufigkeit meist um die $10 \%$ oder war noch geringer. Es wurden nur in Einzelfällen Werte von um die $20 \%$ oder $30 \%$ erreicht. So gab es bei der Spätsaat keine Ertragsverluste. Der Sorteneffekt war in der zweiten und in der vierten Bonitur feststellbar, wo es auch signifikante Unterschiede zwischen den Sorten gab. So wird in der Literatur die unterschiedliche Anfälligkeit der Sorten berichtet (Cromey et al., 2012; Plonka u. Roj, 2012). Im Falle der Spätsaat war nur bei Hermann und bei Mulan ein Winterausfall feststellbar, was jedoch keinen Ertragseinfluss hatte. Der vergleichsweise sehr hohe Befallswert der Sorte Mulan in der ersten Bonitur von 30\% muss aufgrund der sehr hohen Standardabweichung relativiert werden. Möglicherweise war hier die Probenahme nicht ausreichend gleichmäßig über die Parzelle verteilt. Obgleich der Winterausfall bei Hermann in der Spätsaat mit etwa 27\% noch höher war als bei Hermann in der Frühsaat mit etwa 23\%, kam es dennoch nicht zu einem Ertragsausfall. Möglicherweise konnte sich der Bestand aufgrund der nur sehr geringen Infektionsrate mit Rhizoctonia im Verlauf der Vegetationsperiode ausreichend gut erholen. Cromey et al. (2002) halten fest, dass eine Befallshäufigkeit mit dem Scharfen Augenfleck von unter 10\% keine Ertragseffekte hat. Möglicherweise kann dieser Wert - bei gegebener Winterhärte der Sorte - noch höher angesetzt werden, bspw. bei $15 \%$. So hatte die sehr winterharte Sorte Toras in den Bonituren B1 bis B4 Befallshäufigkeiten von minimal 13,2\% (B3) und maximal 23,43\% (B4) und erlitt keinen Ertragsverlust. Es kann festgestellt werden, dass es in der Spätsaat nur zu einem geringen Pflanzenstress durch Winterschaden kam. Daher konnte in der Spätsaat die typische Erregerbiologie in einem Winterweizenbestand beobachtet werden: ein geringes Befallsniveau nach Winter und ein Befallsanstieg durch Rhizoctonia mit zunehmendem Alter der Weizenpflanze (Matusinsky, 2008). In der Frühsaat hingegen waren durchweg erregergünstige Bedingungen gegeben durch die hohe Infektionsrate infolge der frühen Aussaat unter günstigen klimatischen Bedingungen und durch den durch Kalhlfrost verursachten Pflanzenstress.

Bei der Analyse von symptomatischen Halmen in Früh- und Spätsaat konnte ausschließlich $R$. cerealis AG D nachgewiesen werden. Dies bestätigt die Aussage, dass $R$. cerealis AG D die vorherrschende und relevante Rhizoctonia-Art an Winterweizen ist (Boerema $u$. Verhoeven, 1977).

\subsection{Versuch in der Bodenerwärmungsanlage}

In der Literatur sind derzeit keine Angaben zu finden, die Rhizoctonia an Winterweizen mit Winterhärte und Ertragsausfall unter extremen Kahlfrostbedingungen und Sortensensibilität 
in Zusammenhang bringen. Daher wurde zur Verifizierung der aufgrund des Feldversuchs gemachten Aussagen ein Versuch auf der Göttinger Bodenerwärmungsanlage durchgeführt. Es sollte geprüft werden, ob sich das Schadpotenzial durch Rhizoctonia erhöht, wenn abiotischer Pflanzenstress hinzukommt. Durch die Variante mit künstlicher Erwärmung wurde die Wahrscheinlichkeit erhöht, dass es bodenfrostfreie Testparzellen gab. Zudem sollte im Versuch nochmals geprüft werden, welche AG an Winterweizen Symptome erzeugt. Die künstliche Erwärmung erfolgte in zwei Stufen $\left(+1,6^{\circ} \mathrm{Cu} .+3,2^{\circ} \mathrm{C}\right)$. Die Inokulation der Parzellen erfolgte einzeln mit $R$. cerealis AG D, R. solani AG 1-IB und $R$. solani AG 5 im Vergleich zur Gesundkontrolle. Die Pathogenität aller eingesetzten Isolate gegenüber Winterweizen konnte vorab im Agarplattentest nachgewiesen werden. Die verwendete Winterweizensorte war Toras. Aufgrund des reduzierten Versuchsmaßstabs wurde lediglich zur Milchreife bonitiert und nur die Tausendkornmasse bestimmt. Die klimatischen Bedingungen der Vegetationsperiode 2012/13 bedingten einen Winterausfall auf der Versuchsfläche mit Kleinparzellen. Die Schadwirkung durch Rhizoctonia trat zutage durch eine reduzierte Anzahl Pflanzen pro qm, wie es auf der mit AG D inokulierten und nicht-erwärmten Variante zu sehen war. Auf der stark erwärmten Parzelle hingegen entwickelten sich die Pflanzen ohne Frosteinfluss und eine Schadwirkung durch den Pilz blieb aus. Hinsichtlich der Ertragswirkungen (TKM) konnte in diesem Versuch wiederum kein negativer Effekt festgestellt werden, was möglicherweise letztlich auf die durchschlagende große Winterhärte und Kompensationsfähigkeit der Sorte Toras zurückzuführen ist.

Es konnte ein leichter Befall (nicht erwärmte Variante) von 8,9\% und ein moderater Befall (erwärmte Varianten) von ca. $23 \%$ mit $R$. cerealis AG D festgestellt werden. Im Falle von $R$. solani AG 5 war nur auf einer Parzelle ein geringer Befall festgestellt worden; im Mittel lag die Befallshäufigkeit bei $4 \%$. Bei $R$. solani AG 1-IB lag die Befallshäufigkeit bei $0 \%$. Damit konnte auch hinsichtlich der Frage des dominanten Erregers wiederum gezeigt werden, dass in Deutschland $R$. cerealis AG D den Hauptschaderreger im Winterweizen darstellt. Es kann auch die Aussage von Cromey et al. (2002) bestätigt werden, dass Ertragseffekte durch Rhizoctonia bei einer Befallhäufigkeit von unter $10 \%$ ausbleiben. In diesem Experiment festigt sich die schon zuvor gemachte Aussage, dass bei möglicherweise sehr winterharten Sorten Ertragseffekte auch noch bei Befallshäufigkeiten von $>10 \%$ ausbleiben. Es sollte weiterhin geprüft werden, ob Winterhärte als Zuchtziel im Winterweizen indirekt auch für Toleranz gegenüber Rhizoctonia verwendet werden kann. In den gemachten Untersuchungen erwies sich $R$. cerealis AGD an Winterweizen in Deutschland als Schwächeparasit, der bei zusätzlichem abiotischen Pflanzenstress ertragsrelevant wird. Die reduzierte Anzahl Körner pro Ähre bei gleichbleibendem TKM 
signalisierte diesen biotischen Stress der Pflanzen und stützt die gemachte Aussage. Rhizoctonia kann unter besonderen klimatischen Bedingungen wie bspw. Kahlfrost bei frostsensiblen Winterweizensorten den Winterausfall fördern und somit einen Ertragsausfall begünstigen. Bei sehr winterharten Sorten scheint die tolerierbare Befallshäufigkeit mit Rhizoctonia höher als $10 \%$ liegen zu können, ohne dass Schad- oder Ertragseffekte auftreten.

Bislang stehen keine eindeutig resistenten Sorten zur Verfügung, um Rhizoctonia im Weizen zu bekämpfen (Hamada et al., 2011a). Daher sollten Zuchtziele darauf fokussiert werden, die Pflanze gegenüber prädispositionierenden Faktoren toleranter zu machen (Oros et al., 2013). Somit kann im Umkehrschluss das Zuchtziel der Winterhärte auch stellvertretend für verbesserte Rhizoctonia-Toleranz verwendet werden. Um Winterweizen hinsichtlich seiner Frosttoleranz testen zu können, steht der Züchtung ein breites Methodenspektrum zur Simulation eines harschen Winters zur Verfügung (Sãulescu u. Braun, 2001). Prinzpiell wird hierfür Weizen in Gebinde gepflanzt, unter Feldbedingungen abgehärtet und anschließend einer Kältereizprozedur ausgesetzt (Fowler et al., 1981). 


\section{Zusammenfassung}

Der Scharfe Augenfleck an Weizen, ausgelöst durch Rhizoctonia, spielt im deutschen Winterweizenanbau eine eher untergeordnete Rolle und wird allgemein als wenig ertragswirksam eingeschätzt. Dennoch konnte im Rahmen dieser Arbeit gezeigt werden, dass besondere Konstellationen eine Infektion durch den bodenbürtigen pilzlichen Erreger begünstigen und deutliche ertragsmindernde Effekte auslösen können.

Rhizoctonia nimmt dabei die Rolle eines Schwächeparasiten ein, welcher die Pflanze zusätzlich zu abiotischen Einflüssen und infolge einer ungünstigen Prädisposition schädigen kann. Im Monitoring in zwei aufeinanderfolgenden Vegetationsperioden (2012 u. 2013) konnte $R$. cerealis AG D in Weizen als vorherschende AG verifiziert werden. Dabei wurden Anbauflächen mit Winterweizen beprobt und auf natürlichen Befall mit Rhizoctonia hin analysiert. Im Feldversuch wurden teilrandomisiert die Prüffaktoren Winterweizensorte (Hermann, Inspiration, Mulan, Toras), künstliche Inokulation und Gesundkontrolle sowie Aussaattermin (früher Termin Ende August und später Termin mit + 4 Wochen) gewählt. Es konnte erfolgreich gezeigt werden, dass früh im Herbst gesäte frostempfindliche Winterweizensorten (Hermann, Inspiration, Mulan) unter Kahlfrostbedingungen durch Rhizoctonia-Befall signifikant geschädigt werden. Infolge der befallenen und ausgewinterten Triebe trat zur Ernte ein mittlerer Ertragsverlust von 15\% auf. Die Befallshäufigkeiten in BBCH 75 beliefen sich auf 47,4\% (Hermann), 38,5\% (Inspiration) und $28,0 \%$ (Mulan). Die sehr winterharte Weizensorte (Toras), die unter Kahlfrost und trotz hoher Befallshäufigkeit $(60,0 \%$ in $\mathrm{BBCH} 75)$ keine befallenen Triebe verlor, zeigte diesen Effekt nicht.

Des Weiteren konnte im genannten Versuch gezeigt werden, dass sich in einem Mischinokulum aus $R$. solani AG 5 und $R$. cerealis AGD lediglich die letztgenannte Erregerform an den Pflanzen erfolgreich etablierte und zum Boniturtermin der späten Milchreife in allen erfolgreich aufgereinigten Proben nachweisbar war.

Als weiterführende Untersuchung wurden die isolierten Pilze auf ihre optimale Wachstumstemperatur im sterilen Laborassay untersucht. Es konnte jedoch keine mögliche Adaption an verschiedene Klimate und/ oder Temperaturbedingungen festgestellt werden. Zur Verifizierung der These, dass ein früh gesäter Winterweizen unter Rhizoctonia-Infektion kombiniert mit Kahlfrostbedingungen, Frostschäden aufweist und ertragsmindernde Effekte zeigen kann, wurde ein Versuch auf der Göttinger Bodenerwärmungsanlage durchgeführt. In der Anlage kann durch im Boden verlegte Heizkabel der Froststress durch die Erwärmung des Bodens vermindert werden. Im Versuch zeigte sich, dass die nicht erwärmten und mit $R$. cerealis AG D inokulierten Parzellen einen Winterausfall zeigten, 
während die erwärmten inokulierten Parzellen keine Reduktion des Bestands aufwiesen. Bei der Gesundkontrolle erlitt keine der Temperaturvarianten (erwärmt/ nicht erwärmt) einen Winterschaden. Weiterhin konnte im Versuch nochmals verifiziert werden, dass $R$. cerealis AG D die vorherrschende und Symptom auslösende Anastomosegruppe am Winterweizen ist; $R$. solani AG 5 löste nur artifiziell Symptome an wenigen Pflanzen aus und $R$. solani AG 1-IB war nicht pathogen. Zur weiterführenden Untersuchung dieses Resultats wurde im sterilen Infektionsassay im Labor durch Färbemethoden die Aktivität der genannten AG's an der Weizenwurzel untersucht. Es zeigte sich, dass $R$. solani AG 5 und $R$. solani AG 1-IB zwar die Weizenwurzel großflächig besiedeln und starke Verbräunungen bevorzugt an der Koleoptile verursachen, aber keine aktive Penetration in das Wurzelgewebe erfolgt.

Neben diesen konnten in Laboruntersuchungen weitere Unterschiede von $R$. solani und $R$. cerealis $A G D$ sowie $R$. solani AG 8 gefunden werden. So haben $A G D$ und $A G 8$ ein Temperaturoptimum von etwa $20^{\circ} \mathrm{C}$, während die übrigen $R$. solani AG's (AG 5, AG 11, AG 1-IB, AG 4 HGII) bei etwa $24^{\circ} \mathrm{C}$ optimal wachsen. Des Weiteren können die Pilzarten anhand morphologischer Eigenheiten differenziert werden. So haben R. solani AG's ein im Vergleich eher kräftiges und fusionsfreudiges Myzel, während bei R. cerealis feine und wenig verzweigte Hyphen beobachtet werden konnten. Davon differenziert war wiederum $R$. solani AG 8 mit einer frühen Sklerotienbildung und geweihartigen Fortsätzen an frisch verzweigten Hyphen. Durch den Einsatz von Bromphenolblau im Agarplattenmedium konnte bei $R$. solani AG 5, AG 11, AG 1-IB, AG 4 HGII und AG 8 eine sezernierte Säure identifiziert werden, bei $R$. cerealis AG $D$ hingegen nicht. Bei diesem Isolat konnte zu 6 dpi im Mittel 7 Infektionseinheiten pro cm befallener Wurzel ausgezählt werden, bei AG 5 waren es nur 2 Einheiten pro cm und bei AG 1-IB war es im Mittel nur 1 Einheit pro cm.

Es wird vorgeschlagen, dass Winterhärte als stellvertretendes Merkmal für RhizoctoniaToleranz bei neuen Sorten geprüft werden kann, weil Rhizoctonia lediglich unter Frosteinwirkung bei wenig frosttoleranten Sorten ertragsmindernde Effekte gezeigt hat. 


\section{Summary}

The sharp eye spot on wheat (WSED), caused by Rhizoctonia spp., plays a minor role in German winter wheat cultivation and is therefore considered less important. However, the present work has shown that specific conditions may favour infection by this soil-borne fungal pathogen and ultimately lead to yield reduction. Thus, Rhizoctonia is a weakness parasite, which may damage the plant in association with abiotic stress, by which susceptibility and thus infection are enhanced. In a monitoring conducted in two successive growing seasons (2012 and 2013), data on the occurrence of Rhizoctonia in German winter wheat fields were collected. The areas of winter wheat were sampled and analysed for natural infestation with Rhizoctonia. As a result, surprisingly, only $R$. cerealis AG (Anastomosis group) D could be detected.

In a field trial, the variety (Hermann, Inspiration, Mulan, Toras), artificial inoculation and sowing date (end of August vs. 4 weeks later) were chosen as experimental factors. The early autumn-sown frost-sensitive winter wheat varieties (Hermann, Inspiration, Mulan) suffered irreversibly from shoot losses due to Rhizoctonia under black frost conditions. As a result of the infection and the loss of shoots, the average yield was reduced by $15 \%$ compared to the more frost resistant variety 'Toras'. The infection rates with Rhizoctonia at growth stage (GS) 75 were $47.4 \%$ (Hermann), 38.5\% (Inspiration) and $28.0 \%$ (Mulan). The highly frost resistant variety (Toras), which did not lose infested shoots due to black frost and despite a high infection rate of $60.0 \%$ at GS 75 , did not show any yield reduction. Furthermore, the experiment demonstrated that after a mixed inoculation with Rhizoctonia solani AG 5 and Rhizoctonia cerealis AG D only the latter was successfully establishing on the plants and detectable in all samples at the late milk stage of grains. In a further experiment, the optimal growth temperature of the isolated fungi was assessed under sterile laboratory conditions. However, there was no adaptation to different climates and/or temperature conditions detectable.

To verify the assumption that early sowing of winter wheat under Rhizoctonia infection combined with black frost conditions shows frost damage and yield-reducing effects, a trial was carried out at the Göttingen soil heating facility. The system can prevent winter losses by warming the top soil with heating cables in the ground. The experiment showed that the non-warmed and $R$. cerealis AG D inoculated plots showed losses due to infection and winter stress, while the warmed and inoculated plots did not show any reduction of plants. In the non-inoculated checks, neither of the two temperature variants (warmed/ unwarmed) suffered from winter damage. Furthermore, the experiment showed that $R$. cerealis AG D is the predominant anastomosis group in winter wheat that causes WSED symptoms while 
$R$. solani AG 5 caused symptoms only in a few plants and $R$. solani AG 1-IB did not cause any symptoms at all. For further verification of this result, the activity of the mentioned AG's on the wheat root was examined using staining methods in an artificial infection test under sterile conditions. The results indicate that $R$. solani AG 5 and $R$. solani AG 1-IB colonize the wheat root extensively and tend to cause strong browning at the coleoptile, but are not able to actively penetrate the root cells. In addition to these results, further differences between $R$. solani and $R$. cerealis AGD and R. solani AG 8 were found in laboratory experiments. Thus, AG D and AG 8 have a temperature optimum of about $20^{\circ} \mathrm{C}$, while the AG's of $R$. solani (AG 5, AG 11, AG 1-IB, AG 4 HGII) have a higher growth optimum at about $24^{\circ} \mathrm{C}$.

Further, the fungal species were differentiated on the basis of morphological differences. The mycelium of $R$. solani AG's, for example, is relatively strong and fusible, while $R$. cerealis has fine and less branched hyphae. $R$. solani AG 8 was distinguishable by early sclerotia formation and antler-like extensions on freshly branched hyphae. By using a bromophenol blue stained agar plate medium, an acid secretion was identified in $R$. solani AG 5, AG 11, AG 1-IB, AG 4 HGII and AG 8, but not in R. cerealis AG D. As concerns the ability to penetrate the wheat root, only $R$. cerealis AGD showed activity and formed an average of 7 infection units per $\mathrm{cm}$ of infected root at $6 \mathrm{dpi}$, while $R$. solani AG 5 only formed 2 units per $\mathrm{cm}$ and $A G 1-\mathrm{IB}$ formed an average of 1 unit per $\mathrm{cm}$.

It is suggested that winter hardiness could be tested as an indirect indicator of Rhizoctonia susceptibility in new varieties, because Rhizoctonia has shown yield reduction only under frost conditions in a frost-sensitive cultivar. This may be a useful screening approach as susceptibility tests with a soil-borne pathogen are rather difficult and complex, while there are already well-established methods for screening cultivars for winter hardiness. 


\section{Literaturverzeichnis}

Abdel-Shife, M. A. u. Jones, J. P. (1981). Differentiation of 2 Rhizcotonia isolates from wheat sharp eyespot. Phytopathology, 71: 856-856.

Ahlemeyer, J. u. Friedt, W. (2010). Progress in winter wheat yield in Germany - What's the share of the genetic gain? 61. Tagung der Vereinigung der Pflanzenzüchter und Saatgutkaufleute Österreichs, 2010: 19-23.

Aliferis, K. A. u. Jabaji, S. (2010). Metabolite composition and bioactivity of Rhizoctonia solani sclerotial exudates. Journal of Agricultural and Food Chemistry, 58: 76047615.

Anderson, N. A. (1982). The genetic and pathology of Rhizoctonia solani. Annual Review Phytopathology, 20: 329-347.

Anees, M., Edel-Hermann, V. u. Steinberg, C. (2010). Build up patches caused by Rhizoctonia solani. Soil biology \& Biochemistry, 42: 1661-1672.

Aoki, M., Sassa, T. u. Tamura, T. (1963). Phytotoxic metabolites of Rhizoctonia solani. Nature, 200: 575. DOI: 10.1038/20057a0.

Bartz, F. E., Glassbrook, N. J., Danehower, D. A. u. Cubeta, M. A. (2012). Elucidating the role of the phenylacetic acid metabolic complex in the pathogenic activity of Rhizoctonia solani anastomosis group 3. Mycologia, 104 (4): 793-803.

Bateman, G. L., Edwards, S. G., Marshall, J., Morgan, L. W., Nicholson, P. u. Nuttall, M. (2000). Effects of cultivar and fungicides on stem-base pathogens, determined by PCR, and on diseases and yield of wheat. Annual Applied Biology, 137: 213-221.

Bockus, W. W., Bowden, R. L., Hunger, R. M., Morrill, W. L., Murray, T. D. u. Smiley, R. W. (eds.). Compendium of Wheat Diseases and Pests. APS Press - The American Phytpathology Society St. Paul, MN U.S.A., 3. Auflage, 151, 2010 (978-0-89059385-6).

Boerema G. H. u. Verhoeven, A. A. (1977). Checklist for scientific names of common parasitic fungi. Netherlands Journal of Plant Pathology, 13 (3): 165-204.

Boswell, G. P., Jacobs, H., Davidson, F. A, Gadd, G. M. u. Ritz, K. (2002). Functional consequences for nutrient translocation in mycelial fungi. Journal of Theoretical Biology, 217 (4): 459-477.

Brisson, N., Gate, P., Gouache, D., Charmet, G., Oury, F. X. u. Huard, F. (2010). Why are wheat yields stagnating in Europe? A comprehensive data analysis for France. field crops research, 119 (1): 201-212.

Budge, G. E., Shaw, M. W., Colyer, A., Pietravalle, S. u. Boonham, N. (2009). Molecular tools to investigate Rhizoctonia solani distribution in soil. Plant Pathology, 58: 1071-1080.

Candolle, De, A. (1815). Uredo rouille des cereals in Forafran caise, famille des champignons. Mémoires du Muséum national d'histoire naturelle, 2: 209-216. 
Carling, D. E. (1996) Grouping in Rhizoctonia solani by hyphal anastomosis reaction. In: Sneh, B., Jabaji-Hare, S., Neate, S. u. Dijst, G. (eds.): Rhizoctonia Species: Taxonomy, Molecular Biology, Ecology, Pathlogy and Disease Control, Dordrecht, Niederlande (1996), 37-47.

Carling, D. E., Baird, R. E., Gitaitis, R. D., Brainard, K. A. u. Kuninaga, S. (2002). Characterization of AG-13, a newly reported anstomosis group of Rhizoctonia solani. Phytopathology, 92 (8): 893-899.

Carling, D. E., Pope, E. J., Brainard, K. A. u. Carter, D. A. (1999). Characterization of mycorhizal isolates of Rhizoctonia solani from an orchid, including AG-12, a new anastomosis group. Phytopathology, 89 (10): 942-946.

Cecchini, G. (2003). Function and structure of complex II of the respiratory chain. Annual Review of Biochemistry, 72: 77-109.

Chen, L., Zhang, Z. Y., Liang, H. X., Liu, H. X., Du, L. P., Xu, H. U. Xin, Z. (2008). Overexpression of TiERF1 enhances resistance to sharp eyespot in transgenic wheat. Journal of Experimental Botany, 59 (15): 4195-4204.

Chipilski, R. u. Uhr, Z. (2014). Study of frost resistant of common winter wheat varieties. Trakia Journal of Sciences, 2: 169-176.

Clarkson, J. D. S. u. Cook, R. J. (1983). Effect of sharp eyespot on yield loss in winter wheat. Plant Pathology, 32 (4): 421-428.

Colbach, H., Lukas, P. u. Cavelier, A. (1997). Influence of cropping system on sharp eyespot in winter wheat. Crop Protection, 16 (5): 415-422.

Cromey, M. G., Butler, R. C., Boddington, H. J., Moorhead, A. R. (2002). Effects of sharp eyespot on yield of wheat (Triticum aestivum). New Zealand Journal of Crop and Horticulture Science, 30 (1): 9-17.

Cromey, M. G., Hide, C. C. L. u. Meenken, E. D. (2012). Resistance to sharp eyespot in wheat. New Zealand Plant Protection, 65: 204-212.

Cromey, M. G., Parkes, R. A. u. Fraser, P. M. (2006). Factors associated with stem base and root diseases of New Zealand wheat and barley crops. Australasian Plant Pathology, 35: 391-400.

Diao, C. Y., Miao, R. R. u. Lu, Y. M. (1998). Analysis on cause of regional distribution of wheat sharp eyespot (Rhizoctonia solani) outbreak in Jiangsu Province (in Chinese). Jiangsu Agricultural Science, 2: 38-40.

Doornik, A. W. (1981). Comparison of methods for detection of Rhizoctonia solani in soil. Netherlands Journal of Plant Pathology, 87: 173-176.

Doyle, J. (1991). Total DNA isolation. Molecular Techniques in Taxonomy, 57: 283-284.

FAO. URL: http://www.fao.org/worldfoodsituation/csbd/en/. Weltweite Weizenproduktion im Jahr 2020. (Zugriff am 11.07.2020).

Fowler, D. B., Gusta, L. V. u. Tyler, N. J. (1981). Selection for winterhardiness in wheat. III Screening methods. Crop Science, 21: 896-901. 
Furgal-Wegrzycka, H., Adamiak, J. u. Adamiak, E. (1997). Rhizoctonia cerealis anastomosis group GAG-1, the common pathogen of wheat and sugar beet. Acta Mycologica, 32 (1): 101-117.

Gangopadhyay, S. u. Grover, R. K. (1985). A selective medium for isolating Rhizoctonia solani from soil. Annuals of Applied Biology, 106 (3): 405-412.

Gill, J. S., Sivasithamparam, K. u. Smettem, K. R. L. (2000). Effect of soil moisture at different temperatures on Rhizoctonia root rot of wheat seedlings. Plant Soil, 231 (1): 91-96.

Goll, M. B., Schade-Schütze, A., Swart, G., Oostendorp, M., Schott, J. J., Jaser, B. u. Felsenstein, F. G. (2014). Survey on the prevalence of Rhizoctonia spp. in European soils and determination of the baseline sensitivity towards sedaxane. Plant Pathology, 63 (1): 148-154.

Grosch, R., Schneider, J., H., M. u. Kofoet, A. (2006). Nachweis des Erregers der Salatfäule Rhizoctonia solani. Nachrichtenblatt Deutscher Pflanzenschutzdienst, 58 (9): 235-240.

Guo, Y., Li, W., Sun, H., Wang, N., Yu, H. u. Chen, H. (2012). Detection and quanification of Rhizoctonia cerealis in soil using real-time PCR. Fungal Disease, 78: 247-254.

Gupta, V. V. S. R., McKay, A., Diallo, S., Smith, D., Cook, A., Kirkegaard, J., Ophel-Keller, K. u. Roget, D. K. (2010). Temporal dynamics of Rhizoctonia solani AG-8 inoculum in Australien soils. Australasien Soilborne Disease Symposium, 6: 51.

Hamada, M. S., Yin, Y., Chen, H. u. Ma, Z. (2011a). The escalating threat of Rhizotonia cerealis, the causual agent of sharp eyespot disease. Pest Management Science, 67: $1411-1419$.

Hollins, T. W., Jellis, G. J. u. Scott, P. R. (1983). Infection of potato and wheat by isolates of Rhizoctonia solani and R. cerealis. Plant Pathology, 32 (3): 303-310.

Hyakumachi, M., Priyatmojo, A., Kubota, M. u. Fukui, H. (2005). New anastomosis groups, AG-T and AG-U, of binucleate Rhizoctonia spp. causing root and stem rot of cutflower and miniature roses. Phytopathology, 95 (7): 784-792.

Johanson, A., Turner, H. C., McKay, G. J. u. Brown, A. E. (1998). A PCR-based method to distinguish fungi of the rice sheat-blight complex, Rhizoctonia solani, R. oryzae and $R$. oryzae-sativae. FEMS Microbiology Letters, 162 (2): 289-294.

Keijer, J., (1996). The initial steps of the infection process in Rhizoctonia solani. In: Sneh, B., Jabaji-Hare, S., Neate, S. u. Dijst, G. (eds.): Rhizoctonia Species: Taxonomy, Molecular Biology, Ecology, Pathlogy and Disease Control, Dordrecht, Niederlande (1996), 149-162.

King, P. M. (1984). Crop and pasture rotations at Coonalpyn, South Australia: effects on soil-borne diseases, soil nitrogen and cereal production. Australian Journal of Experimental Agriculture and Animal Husbandry, 24 (127): 555-564.

Ko, W. u. Hora, F. K. (1974). A selective medium for the quantitative determination of Rhizoctonia solani in soil. Phytopathology, 61: 707-710. 
Kurowski, T. P. (2002). Studia nad chorobami podsuszkowymi zbóż uprawianych w wieloletnich monokulturach. Rozprawy i Monografie. Uniwersytet WarminskoMazurski w Olsztynie, 56: 1-86.

Kurowski, T. P. u. Adamiak, E. (2007). Occurrence of stem base diseases of four cereal species grown in long-term monocultures. Polnish Journal of National Science, 22 (4): $574-583$.

Lemańczyk, G. (2010a). Occurrence of sharp eyespot in spring cereals grown in some regions of Poland. Journal of Plant Protection Research, 50 (4): 505-512.

Lemańczyk, G. (2010b). Occurrence of sharp eyespot (Rhizoctonia cerealis) in winter triticale grown in some provinces of Poland. Phytopathologia, 56: 27-38.

Lemańczyk, G. (2012). The role of the preceding crop and weed control in the transmission of Rhizoctonia cerealis and $R$. solani to winter cereals. Journal of Plant Protection Research, 52 (1): 93-105.

Lemańczyk, G. und Kwasna, H. (2013). Effects of sharp eyespot (Rhizoctonia cerealis) on yield and grain quality of winter wheat. European Journal of Plant Pathology. 135 (1): 187-200.

Li, Z., Zhou, Z., Ren, L., Du, L., Zhang, B., Xu, H. u. Xin, Z. (2011). Expression of a radish defensin in transgenic wheat confers increased resistance to Fusarium graminearum and Rhizoctonia cerealis. Functional Integrative Genomics, 11: 6370.

Lovell, D. J., Baldwin, S. R. u. Fraaije, B. A. (2003). Peduncle rot of dwarf wheat caused by Rhizoctonia cerealis. Plant Health Network, DOI: 10.1094/PHP-2003-0717-01$\mathrm{HN}$.

MacNish, G. C. (1985). Methods of reducing Rhizoctonia patch of cereals in Western Australia. Plant Pathology, 34 (2): 175-181.

Marshall, D. S. u. Rush, M.C. (1980a). Infection cushion formation on rice sheats by Rhizoctonia solani. Phytopathology, 70 (10): 947-950.

Matusinsky, P., Mikolasova, R., Klem, K., Spitzer, T. u. Urban, T. (2008). The role of organic vs. conventional farming practice, soil management and preceding crop on the incidence of stem-base pathogens on wheat. Journal of Plant Disease Protection, 115 (1): 17-22.

Matusinsky, P., Mikolasova, T., Spitzer, T. u. Klem, K. (2008). Colonization of winter wheat stem bases by communities of pahtogenic fungi. 36 (1): 77-88.

Murray, G. M. u. Brennan, J. P. (2009). Estimating disease losses to the Australian wheat industry. Australasian Plant Pathology, 38: 558-570.

Naiki, T. u. UI, T. (1974). Ultrastructure of sclerotia of Rhizoctonia solani Kühn invaded and decayed by soil microorganism. Soil Biology and Biochemistry, 7 (4-5): $301-$ 304.

Nyvall, R. F. (1989). Field Crop Disease Handbook, US Springer New York, 2.Auflage, 91$169,1989$. 
Okubara, P. A., Leston, N., Micknass, U., Kogel, K.-H. u. Imani, J. (2016). Rapid quantitative assessment of Rhizcotonia resistance in roots of selected wheat and barley genotypes. Plant Disease, 100 (3): 640-644.

Oros, G., Naá, Z. u. Magyar, D. (2013). Susceptibility of wheat varieties to soil-borne Rhizoctonia infection. American Journal of Plant Sciences, 4 (11): 2240-2258.

Parmeter, J. R. Jr. u. Whitney, H. S. (1970). Taxonomy and nomenclature of the imperfect state. In: Parmeter, J. R. Jr. (ed.): Biology and Pathology of Rhizoctonia solani, University of California Press, Berkeley (1970), 7-19.

Paulitz, T. C. u. Schroeder, K. L. (2005). A new method for the quantification of Rhizoctonia solani and R. oryzae from soil. Plant Disease, 89 (7): 767-772.

Paulitz, T. C., Zhang, H. u. Cook, R. J. (2003). Spatial distribution of Rhizoctonia oryzae and Rhizoctonia root rot in direct-seeded cereals. Canadian Journal Plant Pathology, 25 (3): 295-303.

Pfennig, N. u. Wagener, S. (1986). An improved method of preparing wet mounts for photomicrographs of microorganism. Journal of Microbiological Methods, 4 (5-6): 303-306.

Petersen, J., Haastrup, M., Knudsen, L. u. Olesen, J. E. (eds.) (2010). Causes of yield stagnation in winter wheat in Denmark, Tjele, Denmark: Aarhus University, DJF Report on Plant Science No. 147, 139-150, 2010, 87-91949-46-7.

Plonka, K. J. u. Roj, J. (2012). Susceptibility of five winter wheat cultivars to Rhizoctonia cerealis and $R$. solani. Progress in Plant Protection, 52 (3): 657-662.

Rovira, A. D. (1986). Influence of crop rotation and tillage on Rhizoctonia bare patch of wheat. Phytopathology, 76: 669-673.

Samuel, G. u. Garrett, S. D. (1932). Rhizoctonia solani on cereals in Shout Australia. Phytopathology, 22: 827-836.

Sãulescu, N. N. u. Braun, H.-J. (2001). Cold Tolerance. In: Reynolds, M. P., Ortiz-Monasterio, J. I. u. McNab, A.: Application of Physiology in Wheat Breeding, Mexiko, Mexiko (2001), 111-124.

Schillinger, W. F. u. Paulitz, T. C. (2006). Reduction of Rhizoctonia bare patch in wheat with barley rotations. Plant Disease, 90 (3): 302-306.

Siddiqui, I. A. u. Shaukat, S. S. (2005). Phenylacetic acid-producing Rhizoctonia solani represses the biosynthesis of nematicidal compounds in vitro and influences biocontrol of Meloidogyne inognita in tomato by Pseudomonas fluorescens strain $\mathrm{CHAO}$ and its GM derivatives. Journal of Applied Microbiological 98 (1): 43-55.

Siebold, M. u. Tiedemann, von, A. (2012). Application of a robust experimental method to study soil warming effects on oilseed rape. Agricultural and Forest Meteorology, 164: $20-28$.

Sneh, B., Jabaji-Hare, S., Neate, S. u. Dijst, G. (1996). Rhizoctonia species: Taxonomy, Molecular Biology, Ecology, Pathology and Disease Control, Kluwer Academic Dordrecht Niederlande, 1.Auflage, 578, 1996 (978-0-7923-3644-0). 
Ünal, F. u. Dolar, F. S. (2012). First Report of Rhizoctonia solani AG-8 on Wheat in Turkey. Journal of Phytopathology, 160 (1): 52-54.

Vidhyasekaran, P., Ruby Ponmalar, T., Samiyappan, R., Velazhahan, R., Vimala, R., Ramanathan, A., Paranidharan, V. u. Muthukrishnan, S. (1997). Host-specific toxin production by Rhizoctonia solani, the rice sheat bligth pathogen. Biochemistry and Cell Biology, 87 (12): 1258-1263.

White, T. J., Bruns, T. D., Lee, S. B. u. Taylor J. W. (1990). Amplification and direct sequencing of fungal ribosomal RNA Genes for Phylogenetics. In: Innis, M. A., Gelfand, D. H., Sninsky, J. J. u. White, T. J. (eds.): PCR Protocols: A Guide to Methods and Applications. New York, U.S.A. (1990), 315-322.

Wisniewski, K., Zagdanski, B. u. Pronczuk, M. (1997). Interrelationship between frost tolerance, drought and resistance to snow mould (Microdochium nivale). Acta Agronomica Hungarica 45, 3: 311-316.

Woodhall, J. W., Laurenson, L. u. Peters, J. C. (2012). First report of Rhizoctonia solani anastomosis group 5 (AG 5) in wheat in the UK. New Disease Reports, 26 (1): 9.

Yan, H. H., Zhang, R. Q. u. Du, H. F. (2013). Rhizoctonia solani identified as the disease causing agent of peanut leaf rot in China. Plant Disease, 97 (1): 140.

Zheng, A. u. Wang, Y. (2011). The research of infection process and biological characteristic of Rhizoctonia solani AG-1 IB on soybean. Journal of Yeast and Fungal Research, 2 (6): 93-98. 
Anhang

$\underline{\text { Schlagdateien der verwendeteten Feldversuchsflächen }}$

\begin{tabular}{|c|c|c|}
\hline $\begin{array}{l}\text { Versuch, } \\
\text { Standort, } \\
\text { Kultur und } \\
\text { Vegetationsperiode }\end{array}$ & $\begin{array}{l}\text { Feldversuch } \\
\text { Göttingen- Weende } \\
\text { Winterweizen } \\
2011 / 12\end{array}$ & $\begin{array}{l}\text { Feldversuch } \\
\text { Bodenerwärmungsanlage } \\
\text { Winterweizen } \\
2012 / 13\end{array}$ \\
\hline \multicolumn{3}{|c|}{ Standort \& Koordinaten (markiert Mittelpunkt der Anlage) } \\
\hline Standort Name & Göttingen-Weende & Göttingen, Nordcampus \\
\hline Längengrad & $51.565947^{\circ}$ & $51.557888^{\circ}$ \\
\hline Breitengrad & $09.918740^{\circ}$ & $09.951937^{\circ}$ \\
\hline \multicolumn{3}{|l|}{ Aussaatvorbereitung } \\
\hline Vorfrucht & $\begin{array}{l}\text { Winterweizen (= WW), Ernte } \\
\text { 12.08.11 }\end{array}$ & Winterraps, Ernte 01.07.12 \\
\hline 1Stoppelbearbeitung & 14.08.11 Carrier & \\
\hline 2 Stoppelbearbeitung & --- & \\
\hline Totalherbizid & --- & \\
\hline Bodenbearbeitung & $\begin{array}{l}\text { 24.09. + 17.10.11 Pflug mit } \\
\text { Packer }\end{array}$ & \\
\hline Saatbettbereitung & $\begin{array}{l}26.09 .+19.10 .11 \\
\text { Kreiselegge }+ \text { Walze 2x }\end{array}$ & \\
\hline \multicolumn{3}{|l|}{ Aussaat } \\
\hline \multirow[t]{2}{*}{ Datum } & 1.Termin 28.09.2011 & 10.10.2012 \\
\hline & 2.Termin 21.10.2011 & \\
\hline Technik & $\begin{array}{l}\text { Hege } \\
\text { (Parzellendrillmaschine) }\end{array}$ & Handaussaat \\
\hline $\begin{array}{l}\text { Saatgut (Menge u. } \\
\text { Sorte) }\end{array}$ & $\begin{array}{l}\text { WW „Hermann“, „Inspiration“, } \\
\text { "Mulan“, „Toras“; } \\
\text { je } 300 \text { keimfähige Körner/ m² }\end{array}$ & $\begin{array}{l}\text { WW „Toras“ je } 300 \text { keimfähige } \\
\text { Körner/ m² }\end{array}$ \\
\hline Beizung & Arena C & Arena C \\
\hline Aufgangszählung & -- & \\
\hline Wege spritzen & 03.04 .2012 & \\
\hline Vorscheiteln & -- & \\
\hline scheiteln & -- & \\
\hline \multicolumn{3}{|l|}{ Düngung } \\
\hline Grunddüngung & --- & \\
\hline $\mathrm{P}$ & --- & \\
\hline $\mathrm{K}$ & --- & \\
\hline $\mathrm{N}_{\min }$ Probenahme & 07.03 .2012 & 21.02 .2013 \\
\hline $\mathrm{N}_{\min }$ & $46,9 \mathrm{~kg} \mathrm{~N} / \mathrm{ha}$ & $\begin{array}{l}1=97,6 ; 2=119,3 ; 3=122,8 \\
\mathrm{~kg} \mathrm{~N} / \mathrm{ha}\end{array}$ \\
\hline 1.N-Düngung & $\begin{array}{l}\text { 12.03.12 EC 12/13: } 70 \mathrm{~kg} \\
\text { N/ha als AHL }\end{array}$ & $\begin{array}{l}\text { 04.03.13 EC } 2160 \mathrm{~kg} \mathrm{~N} / \mathrm{ha} \text { als } \\
\mathrm{KAS}(1,67 \mathrm{dt} / \mathrm{ha})\end{array}$ \\
\hline 2.N-Düngung & $\begin{array}{l}23.04 .12 \text { EC } 25 \text { spät; EC } 27 \\
\text { früh } 60 \mathrm{~kg} \mathrm{~N} / \mathrm{ha} \text { als AHL }\end{array}$ & \\
\hline 3.N-Düngung & --- & \\
\hline 4.N-Düngung & --- & \\
\hline $\mathrm{N}_{\text {gesamt }}$ (incl. $\left.\mathrm{N}_{\min }\right)$ & $236,9 \mathrm{~kg} \mathrm{~N} / \mathrm{ha}$ incl. $\mathrm{N}_{\min }$ & $\begin{array}{l}\text { Var. } 1 \text { (ohne Enwärmung) }=157,6 ; \\
\left.\text { Var. } 2 \text { (leichte Em. }+1,6^{\circ} \mathrm{C}\right)=179,3 ; \\
\left.\text { Var. } 3 \text { (starke Emw. }+3,2^{\circ} \mathrm{C}\right)=182,8 \mathrm{~kg} \mathrm{~N} / \mathrm{ha}\end{array}$ \\
\hline
\end{tabular}




\begin{tabular}{|c|c|c|}
\hline \multicolumn{3}{|l|}{ Pflanzenschutz } \\
\hline 1.Herbizid (1.Termin) & $\begin{array}{l}26.10 .11 \text { EC 11/12 0,6 I/ha } \\
\text { Herold SC }\end{array}$ & $\begin{array}{l}06.11 .12 \text { EC } 120,9 \text { I/ha Axial } \\
50+2 \text { I/ha Fenikan }\end{array}$ \\
\hline 1.Herbizid (2.Termin) & $\begin{array}{l}09.11 .11 \text { EC } 10 \text { 0,6 I/ha } \\
\text { Herold SC }\end{array}$ & \\
\hline 2. Herbizid & $\begin{array}{l}\text { 10.05.12 EC 31/32 0,7 I/ha } \\
\text { Tomigan }\end{array}$ & \\
\hline 3.Herbizid & $\begin{array}{l}25.07 .12 \text { EC } 852,5 \mathrm{~kg} / \mathrm{ha} \\
\text { Round Up Turbo }\end{array}$ & \\
\hline 1.Wachstumsregler & $\begin{array}{l}20.04 .12 \text { EC } 25 \text { spät; EC } 27 \\
\text { früh } 1 \mathrm{I} / \mathrm{ha} \text { CCC } 720\end{array}$ & $\begin{array}{l}30.04 .13 \text { EC 30/31 0,7 I/ha } \\
\text { CCC } 720+0,3 \text { I/ha Moddus }\end{array}$ \\
\hline 2.Wachstumsregler & $\begin{array}{lr}\text { 10.05.12 EC 31/32 } & 0,5 \\
\text { l/ha CCC } 720+ & 0,2 \mathrm{l} / \mathrm{ha} \\
\text { Moddus } & \end{array}$ & \\
\hline 1.Fungizid & $\begin{array}{l}\text { 21.05.12 EC 37/39 } 1 \mathrm{l} / \mathrm{ha} \\
\text { Capalo + } 1 \mathrm{I} / \mathrm{ha} \text { Bravo }\end{array}$ & 06.06.13 EC 49 0,3 I/ha Vegas \\
\hline 2.Fungizid & $\begin{array}{l}\text { 11.06.12 EC } 61 / 631 \mathrm{l} / \mathrm{ha} \\
\text { Prosaro + } 1,1 \mathrm{~kg} / \mathrm{ha} \text { Don-Q }\end{array}$ & \\
\hline \multicolumn{3}{|l|}{ 3.Fungizid } \\
\hline 1.Insektizid & $\begin{array}{l}22.06 .12 \text { EC69 0,3 I/ha } \\
\text { Biscaya }\end{array}$ & $\begin{array}{l}\text { 05.06.13 EC } 49 \text { 0,2 I/ha } \\
\text { Sumicidin Alpha EC }\end{array}$ \\
\hline 2.Insektizid & $\begin{array}{ll}-- \\
\end{array}$ & \\
\hline Schneckenkorn & --- & $\begin{array}{l}29.10 .12+16.11 .12 \text { Patrol } \\
\text { Metapads ca. } 4 \mathrm{~kg} / \mathrm{ha}\end{array}$ \\
\hline Mäusegift & --- & \\
\hline \multicolumn{3}{|l|}{ Ernte } \\
\hline Datum & $\begin{array}{l}\text { 08.08.12 (früh); } 14.08 .12 \\
\text { (spät) }\end{array}$ & $\begin{array}{l}\text { 23.07.13 Handernte (incl. } \\
\text { Stoppel) }\end{array}$ \\
\hline Ertrag & s. Erntelisten & $\begin{array}{l}\text { Keine Ertragserfassung, nur } \\
\text { TKM }\end{array}$ \\
\hline
\end{tabular}




\section{Danksagung}

Ich möchte mich ganz besonders bei Herrn Prof. Dr. Andreas von Tiedemann für die Bereitstellung des Themas, die Diskussions- und Hilfsbereitschaft bedanken. Durch seine Loyalität und Geduld während der Bearbeitung des Projektes habe ich nie das Ziel aus den Augen verloren.

Dem Zweitprüfer und dem Drittpüfer, Herrn Prof. Dr. Klaus Schlüter (FH Kiel), danke ich sehr für die Übernahme des Korreferats.

Mein besonderer Dank gilt allen Mitarbeitern und ehemaligen Kollegen in der Abteilung Allgemeine Pflanzenpathologie und Pflanzenschutz für die stets konstruktive Arbeitsatmophäre und übergroße Hilfbereitschaft. Insbesondere danken möchte Herrn Dr. Birger Koopmann, Herrn Hubertus Reintke, Frau Evelin Vorbeck, Frau Martina Bode und Frau Dagmar Tacke, ohne die diese Arbeit nicht schaffbar gewesen wäre. Ein herzliches Dankeschön für die Hilfe möchte ich den Auszubildenen Frau Martina Grohe und Frau Magdalena Bömecke hiermit aussprechen, die mir bei allen anfallenden Arbeiten stets eine große Unterstützung waren.

Ich danke recht herzlich dem Kooperationspartner Syngenta Deutschland für die finanzielle und inhaltliche Unterstützung, insbesondere Herrn Dr. Michael Käsbohrer, Herrn Ronald Zeun, Herrn Eckhard Krukelmann, Frau Gina Swart und besonders Herrn Michael Oostendorp sowie Frau Anja Schade-Schütze. Ganz besonders danke ich Herrn Jan Hempel, der mir bei Fragen aller Art immer sehr geholfen hat.

Ich möchte mich bei meinem ehemaligen Büronachbarn herzlich danken, Herrn Dr. Mark Winter, für die vielen hilfreichen Tipps und Hinweise während der gesamten Zeit und darüber hinaus. Ein ganz besonderer Dank für viele sehr hilfreiche und offene Gespräche möchte ich Frau Susanne Weigand und Frau Xia Ha aussprechen.

Weiterhin gilt mein Dank meinen studentischen Hilfskräften Herrn David Frische und Herrn Andreas Rahlves für die Unterstützung. Des Weiteren möchte ich meinen B.Sc. und M.Sc.-Studenten:innen Frau Meike Lüdecke, Herrn Andreas Rahlves und Herrn Daniel Husmann recht herzlich für die großartige Unterstützung danken, sowie den beiden Auszubildenen Martina Grohe und Magdalena Bömeke.

Schlussendlich danke ich besonders meiner Familie für die stete und uneingeschränkte Unterstützung während meiner Ausbildung. 


\section{Eidesstattliche Erklärung}

Hiermit erkläre ich, dass diese Arbeit weder in gleicher noch in ähnlicher Form bereits anderen Prüfungsbehörden vorgelegen hat.

Hiermit erkläre ich eidesstattlich, dass diese Dissertation selbständig und ohne unerlaubte Hilfe angefertigt wurde.

Weiter erkläre ich, dass ich mich an keiner anderen Hochschule um einen Doktorgrad beworben habe.

Lippstadt, den

$$
\text { Ines Döring }
$$

